C13.44 156

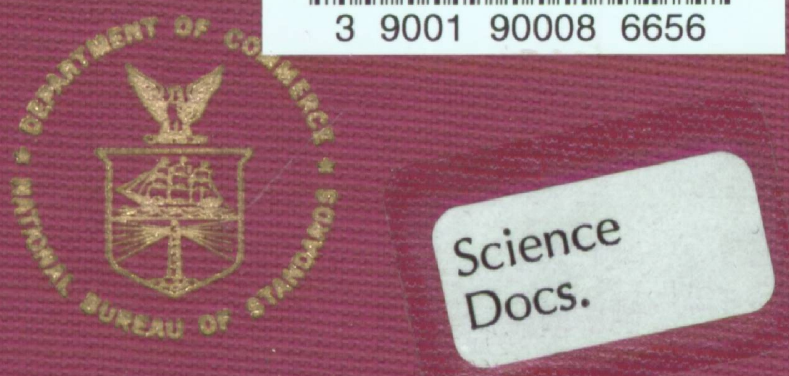




$$
\begin{gathered}
C 13.44 \\
156
\end{gathered}
$$

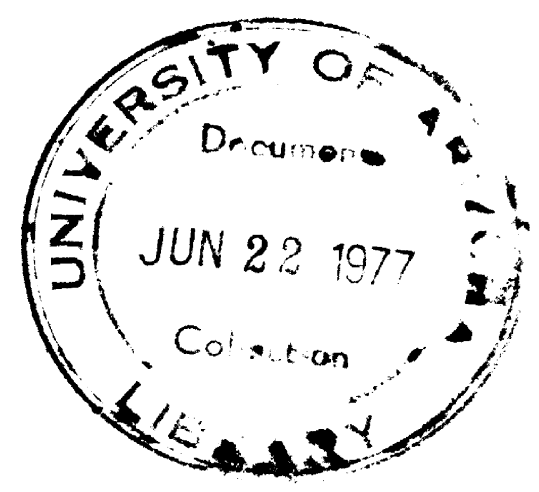




\title{
Stress Corrosion Cracking Control Measures
}

\author{
B. F. Brown
}

Chemistry Department

The American University

Washington, D.C. 20016

Sponsored by the

Advanced Research Projects Agency

under ARPA Order No. 2616, through contract No. N00014-68-A-0245-0007

of the Office of Naval Research.

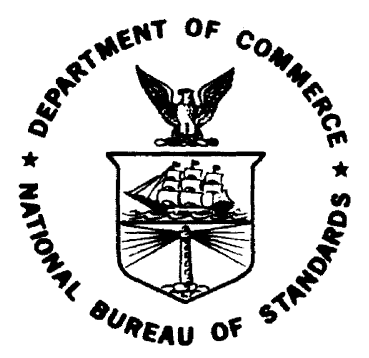

U.S. DEPARTMENT OF COMMERCE, Juanita M. Kreps, Secretary Dr. Sidney Harman, Under Secretary

NATIONAL BUREAU OF STANDARDS, Ernest Ambler, Acting Director

Issued June 1977 
Library of Congress Cataloging in Publication Data

Brown, Benjamin Floyd, 1920-

Stress corrosion cracking control measures.

(NBS monograph ; 156)

Bibliography: $p$.

Includes index.

Supt. of Docs. no.: C 13.44:156

1. Stress corrosion. I. Title. II. Series:

United States. National Bureau of Standards. Monograph ; 156.

QC100.U556 no. 156 [TA462] 602'.1s [620.1'6'23]

76-608306

\section{National Bureau of Standards Monograph 156}

Nat. Bur. Stand. (U.S.), Mono. 156, 81 pages (June 1977)

CODEN: NBSMA6 
Truth will sooner come out from error than from confusion.

Francis Bacon, 16th century

Were I to await perfection, my book would never be finished.

Tai K'ung, 13th century 


\section{SI Conversion Units}

In view of present accepted practice in this technological area, U. S. customary units of measurement have been used throughout this report. It should be noted that the U. S. is a signatory to the General Conference on Weights and Measures which gave official status to the metric SI system of SI units in 1960. Readers interested in making use of the coherent system Guide, ASTM Designation E 380-76 (available from American Society for Testing and Materials, 1916 Race Street, Philadelphia, Pennsylvania 19103). Conversion factors for units used in this paper are:

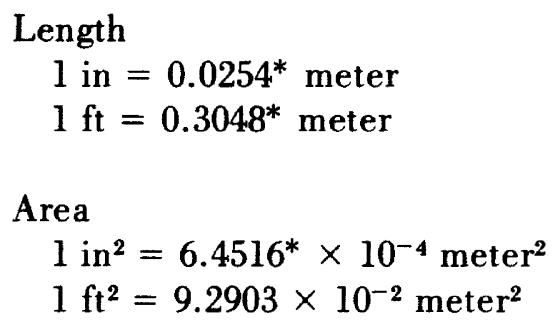

Force

$1 \mathrm{lb}(\mathrm{lbf})=4.448$ newton

$1 \mathrm{kip}=4448$ newton

Pressure, Stress

$1 \mathrm{psi}=6895$ pascal

$1 \mathrm{psf}=47.88$ pascal

Energy

$1 \mathrm{ft}-\mathrm{lbf}=1.3558$ joule

Moment

$1 \mathrm{lbf}-\mathrm{ft}=1.3558$ newton meter

Temperature

$\mathrm{t}_{{ }^{\circ} \mathrm{C}}=5 / 9\left(\mathrm{t}_{{ }_{\mathrm{F}}}-32\right)$

*Exact Value 


\section{FOREWORD}

An important responsibility of the National Bureau of Standards is the dissemination of information to the engineering public. Such information becomes especially significant when it helps prevent the failure of materials and thereby saves both lives and money. It is thus especially gratifying that NBS has been given the opportunity to contribute towards diminishing the incidence of stress corrosion cracking, an increasingly serious mode by which metals fail, by publishing this monograph. Dr. B. Floyd Brown, its author and a former guest worker at NBS, has provided an invaluable tool to the design engineer to help him in the proper selection of materials in order to minimize the danger of fracture by stress corrosion. Dr. Brown calls this a "missionary volume" because its aim is to inculcate the fear of stress corrosion into those who in the past have not always been aware of its possibility.

This long needed work would not have been possible without the support provided by the Advanced Research Projects Agency through the Office of Naval Research.

We are also grateful to American University for providing Dr. Brown with the opportunity to write this monograph.

Jerome Kruger

Chief, Corrosion and Electrodisposition Section

National Bureau of Standards 


\section{PREFACE}

This present volume is the first of a two part series on stress corrosion cracking planned by the Advanced Research Projects Agency for the designer. This first part is introductory in nature, is largely non quantitative, covers only the major alloy families, and treats only stress corrosion cracking. The second part, currently being written under the direction of Professor R. W. Staehle of the Ohio State University and Dr. M. O. Speidel of Brown Boveri Co., will be an advanced treatment, will be quantitative, will cover all alloy families, and will treat both stress corrosion cracking and corrosion fatigue.

Stress corrosion cracking is a failure mode which has occurred with increasing frequency in both the military and the civilian sectors as our technological way of life has increased in complexity. Research on the problem has brought much new understanding in recent years, but the theory has not been brought to the point of enabling us to avoid or control the problem, and there is no basis for confidence that it will do so in the near future.

Meanwhile, if we are to reverse the trend and diminish the incidence of stress corrosion failures, we need to assemble the available practical measures to avoid or minimize the problem and present these measures in a form comprehensible to those persons responsible for the design, fabrication and maintenance of new structures. The assembly of these measures and that sort of presentation are the aims of the present volume. Needless to say, in any dynamic technology such as stress corrosion cracking, any such assembly will require supplementation and modification as our knowledge and understanding of that subject increase.

It should be emphasized that neither the theory nor the technology of stress corrosion cracking is either complete or probably without flaw, and we are without the capability of predicting accurately the cracking hazards or lack thereof for fundamentally new combinations of alloys and environments. If one is concerned with components or structures the failure of which cannot be accepted, then one must obtain test data on the specific alloy in the specific environment of concern. In this connection the reader should absorb the warning implicit in the account (in chapter 5) of the catastrophes which occurred to titanium alloy pressure vessels when the nitrogen tetroxide they contained was furnished in slightly higher purity then previously.

References to key literature are included in the text for the benefit of the reader who wishes to dig deeper on a given topic, but these references are kept to a minimum, and names of investigators and other "trappings of scholarship" so customary in research literature are omitted entirely, in the interest of ease of reading by the nonresearch oriented person.

The modus operandi of this project was to prepare drafts of generalizations in various specialty areas and submit these drafts to persons knowledgeable in these specialty areas for review and comment. Many of these reviewers kindly provided invaluable contributions in such forms as unpublished data, obscure references, unwritten or unpublished practices, and various aids, often provided at the expense of personal time despite the press of busy schedules. Without implying any responsibility on their part for any or all shortcomings of this volume, the author would like to record here his indebtedness and appreciation to these reviewers:

I. M. Bernstein, W. K. Boyd, H. S. Campbell, M. A. Cordovi, J. B. Cotton, R. L. Cowan, II, H. L. Craig, Jr., G. Danek, C. P. Dillion, N. C. Feige, S. Glorioso, S. Goldberg, J. J. Heger, E. C. Hoxie, R. W. Huber, H. H. Johnson, S. J. Ketcham, J. A. Kies, L. J. Korb, J. Kruger, B. F. Langer, R. Maersch, M. McNeil, D. A. Meyn, F. Ogburn, H. W. Paxton, E. H. Phelps, J. M. Popplewell, E. N. Pugh, P. P. Puzak, S. D. Reynolds, J. H. Smith, D. van Rooyen, F. N. Rhines, L. Schapiro, L. R. Scharfstein, R. Schmidt, J. Sedricks, M. O. Speidel, D. O. Sprowls, R. W. Staehle, M. Streicher, T. J. Summerson, D. H. Thompson, R. S. Treseder, J. H. Westbrook, and H. W. Zoeller. Prof. R. T. Foley of The American University not only reviewed the sections but, additionally, made numerous helpful constructive suggestions and merits special appreciation, which is here recorded. 
The author also wishes to express his appreciation to Dr. Jerome Kruger.of the National Bureau of Standards, and to the other NBS personnel, for their kind assistance in the publication of this volume.

Finally, the author would like to express his appreciation to Dr. E. van Reuth of the Advanced Research Projects Agency for financial support of this writing, and to Dr. P. A. Clarkin of the Office of Naval Research for the very considerate manner in which the supporting contract was administered.

B. F. Brown Washington, D. C. October 31, 1975 


\section{Stress Corrosion Cracking Control Measures}

\section{B. F. Brown}

Stress corrosion cracking is a failure mode which has occurred with increasing frequency in all sectors of technology. This publication attempts to diminish the incidence of stress corrosion failures by assembling the available practical measures to avoid or minimize the problem and present these measures in a form comprehensible to those persons responsible for the design, fabrication and maintenance of new structures. The alloys covered are copper, aluminum, titanium and nickel alloys and high strength and stainless steels.

Key words: Aluminum alloys; copper alloys; high strength steels; nickel alloys; stainless steels; stress corrosion cracking; titanium alloys. 


\section{Contents}

Foreword

Preface

Abstract

Chapter 1. Placing the Problem in Perspective

I. Sustained load environmental cracking $\ldots \ldots \ldots \ldots \ldots \ldots \ldots \ldots \ldots \ldots \ldots \ldots \ldots \ldots \ldots \ldots \ldots$

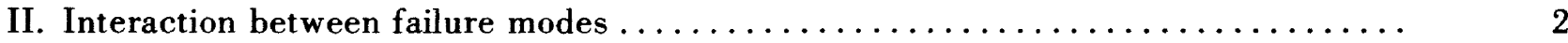

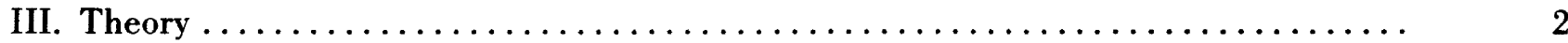

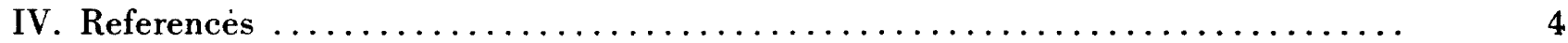

Chapter 2. Test methods and Interpretation of Test Data $\ldots \ldots \ldots \ldots \ldots \ldots \ldots \ldots \ldots \ldots$.

I. Smooth specimen tests under static loads ........................ 5

II. Precracked (fracture mechanics) specimens under static loads . . . . . . . . . 7

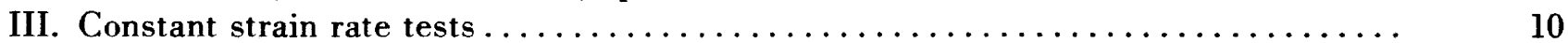

IV. Metallurgical considerations in tests $\ldots \ldots \ldots \ldots \ldots \ldots \ldots \ldots \ldots \ldots \ldots \ldots \ldots \ldots$

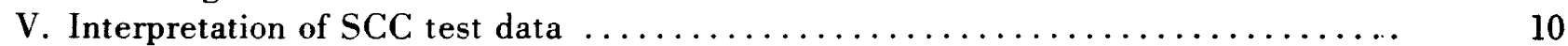

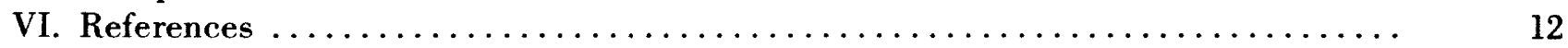

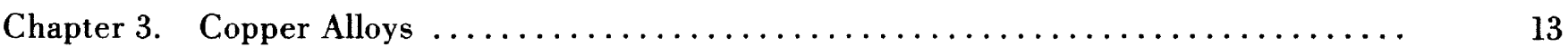

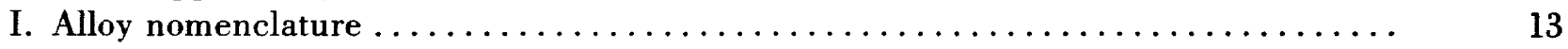

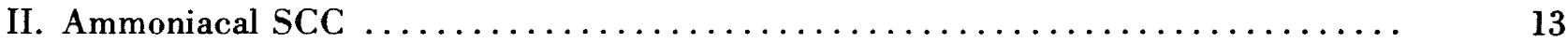

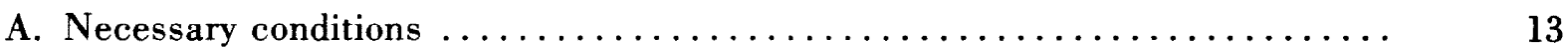

B. Case Histories and other illustrations of principles $\ldots \ldots \ldots \ldots \ldots \ldots \ldots \ldots$

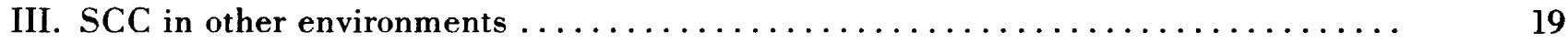

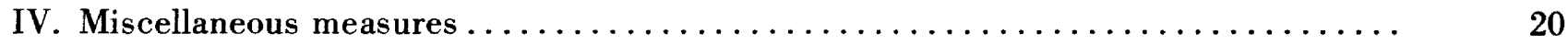

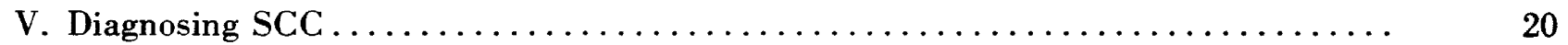

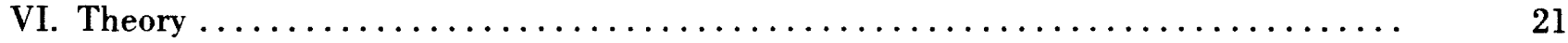

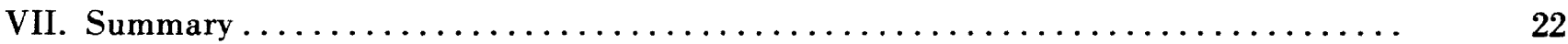

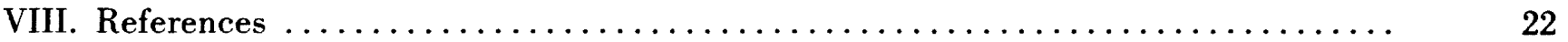

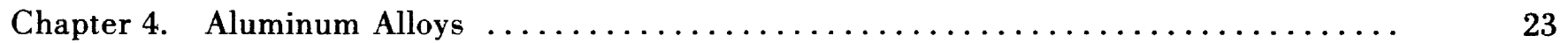

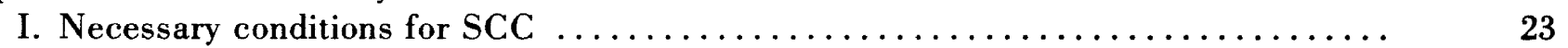

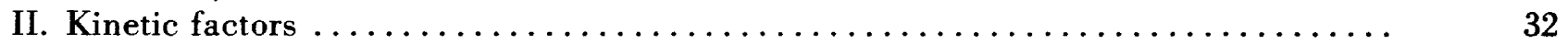

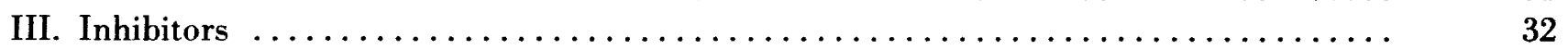

IV. An example of applying the principles to avoid the problem $\ldots \ldots \ldots \ldots \ldots \ldots \ldots . \ldots$

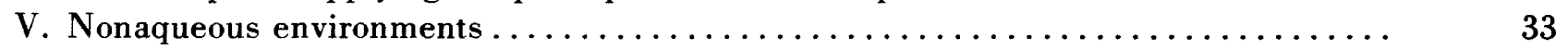

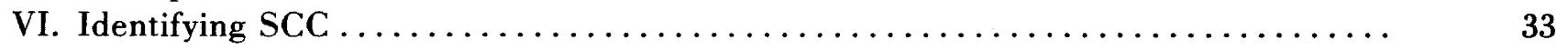

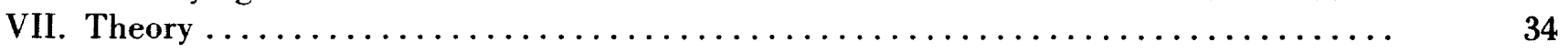

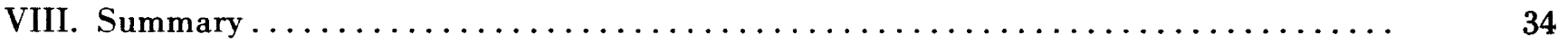

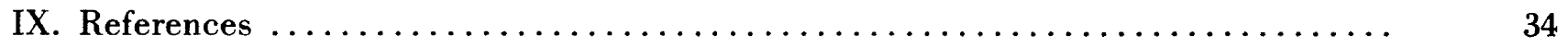

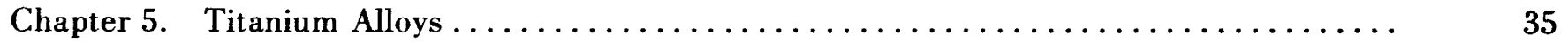

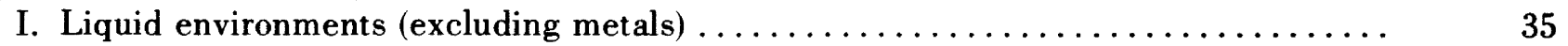

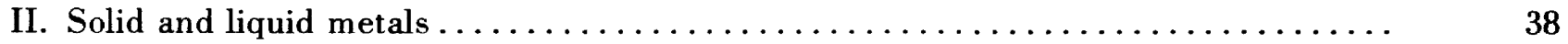

III. Sustained load cracking in inert environments $\ldots \ldots \ldots \ldots \ldots \ldots \ldots \ldots \ldots \ldots \ldots . \ldots \ldots$

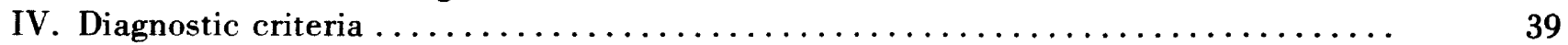

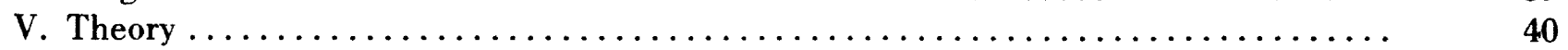

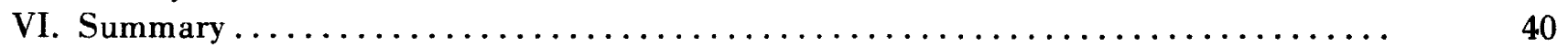

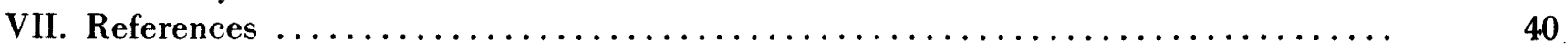

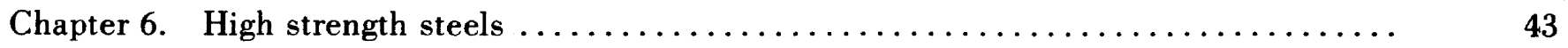

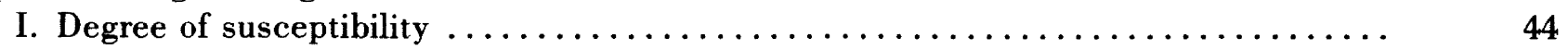

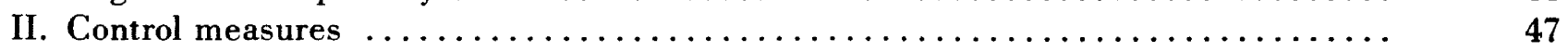

III. Examples of practices and failures illustrating principles $\ldots \ldots \ldots \ldots \ldots \ldots \ldots \ldots \ldots . \ldots$

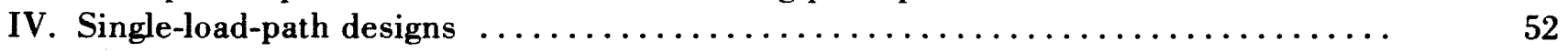

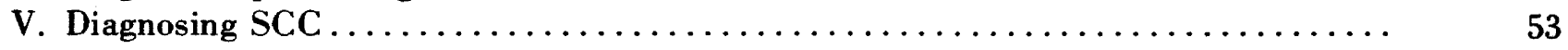




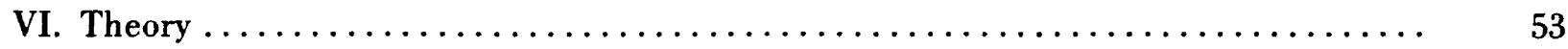

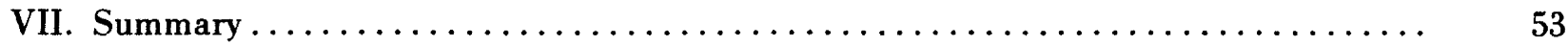

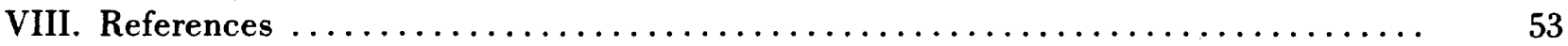

Chapter 7. Stainless Steels (Austenitic and Ferritic) $\ldots \ldots \ldots \ldots \ldots \ldots \ldots \ldots \ldots \ldots \ldots \ldots$

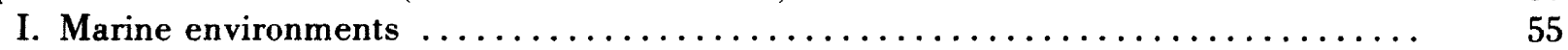

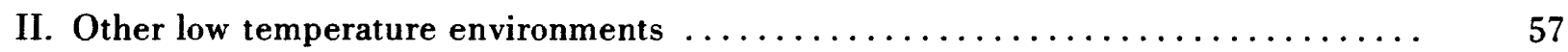

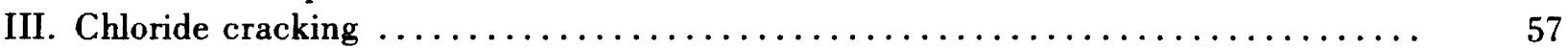

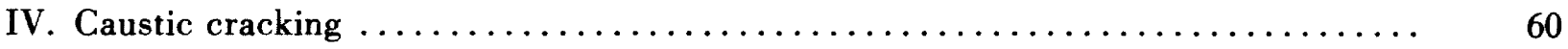

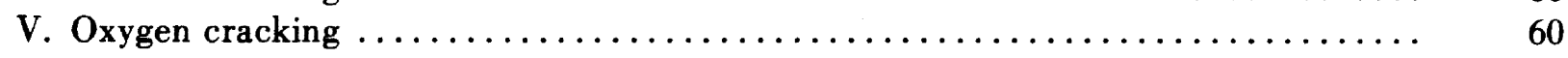

VI. Protective measures illustrating principles $\ldots \ldots \ldots \ldots \ldots \ldots \ldots \ldots \ldots \ldots \ldots \ldots \ldots \ldots$

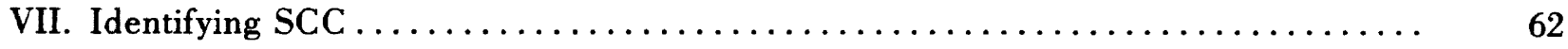

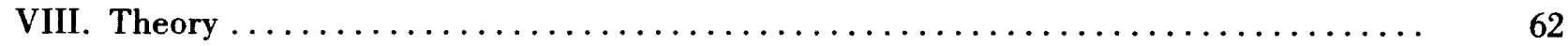

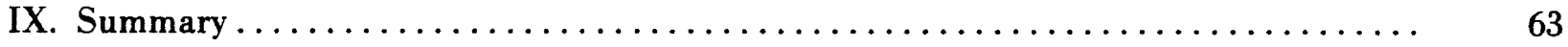

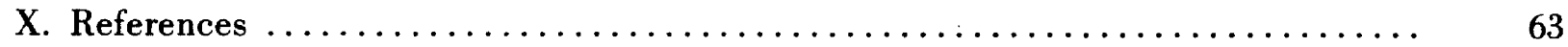

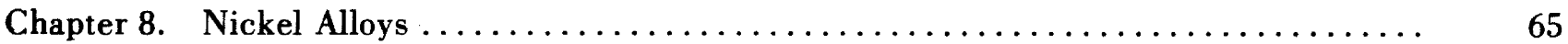

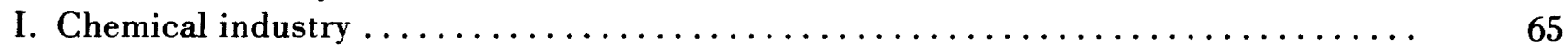

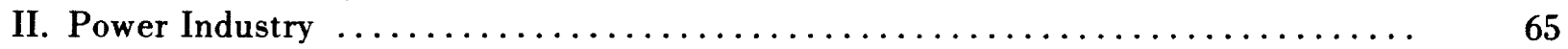

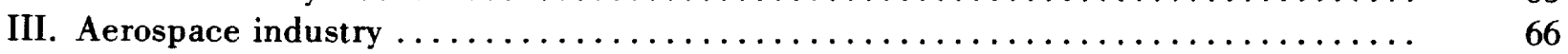

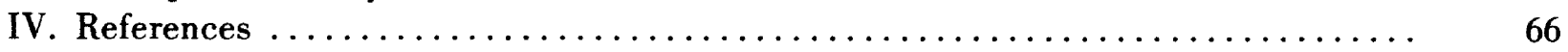

Appendix-Glossary of Terms $\ldots \ldots \ldots \ldots \ldots \ldots \ldots \ldots \ldots \ldots \ldots \ldots \ldots \ldots \ldots \ldots \ldots$

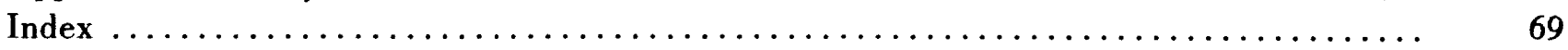




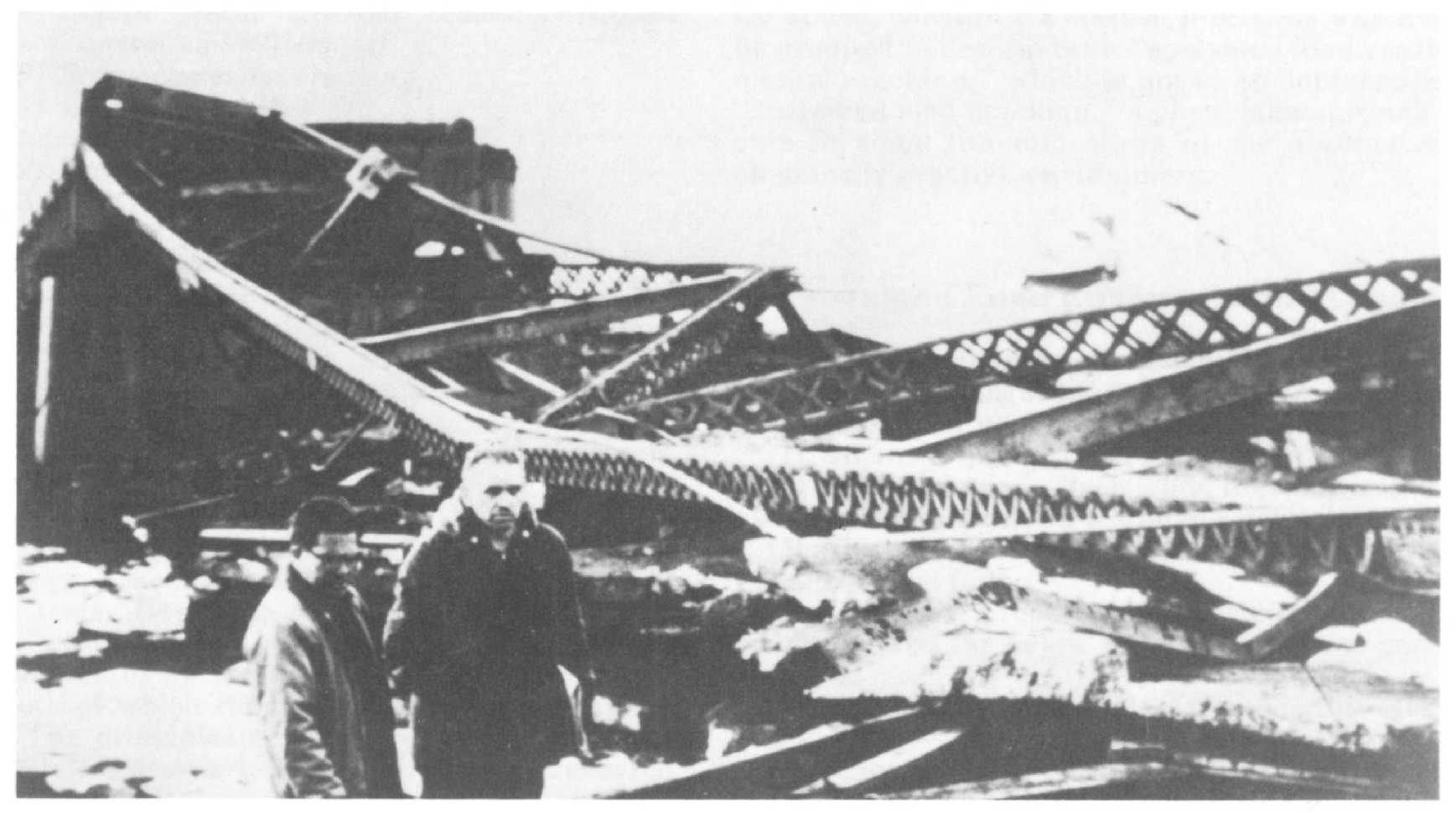

Consequence of stress corrosion cracking in a nonredundant load path structure: collapse of the "Silver Bridge" over the Ohio River, which occurred on December 15, 1967, carrying 46 persons to their death. Photo courtesy of Mr. H. C. Burnett, National Bureau of Standards. 



\section{CHAPTER 1}

\section{PLACING THE PROBLEM IN PERSPECTIVE}

Stress corrosion cracking (SCC) is one of 19 processes which can affect the structural integrity or limit the life of metallic structures. These processes are the following:
Mechanical
(1) Yielding
(2) Brittle fracture
(3) Overload or ductile fracture
(4) High temperature creep, with or without rupture
(5) Fatigue
(6) Wear
Mechanical plus Chemical
(7) Corrosion fatigue
(8) Hydrogen cracking (hydrogen embittlement)
(9) Liquid metal assisted cracking (liquid metal embrittlement)
(10) Stress corrosion cracking
(11) Erosion corrosion
Chemical
(12) Uniform corrosion
(13) Crevice corrosion
(14) Pitting
(15) Dissimilar metal corrosion
(16) Intergranular corrosion
(17) Selective dissolution (as in the selective corrosion of zinc in brass)
(18) Filiform corrosion (as in surface grooving of steel under a lacquer coating)
(19) High temperature oxidation (including sub- scaling)

Designing against yielding is of course an old technology, based on well standardized macroscopic tensile tests. Designing against brittle fracture is based either on the transition temperature phenomenon or on fracture mechanics characteristics, both of which require macroscopic test specimens. The principles of designing against overload or ductile fracture are in a state of rapid research development. Designing against high temperature creep is a well developed technology, based on data from macroscopic specimens. For designing against fatigue, there are fatigue limit data and fatigue crack growth behavioral rules which are of general applicability. The principles of the transition temperature and the fracture mechanics approaches to the brittle fracture problem, and the principles of fatigue cracking, are treated in reference [1]. For maximum utility in a given technology, the special rules applicable to that technology may be profitably collected and presented, as in reference [2], which summarizes the rules of thumb which have been found useful in controlling fatigue in Naval aircraft.

The technology for controlling wear is summarized in handbooks. The principles of designing against the processes necessarily involving corrosion (processes 7 through 19 in the list above) are treated in the standard texts (see for example refs. [3-5]). The technology for designing against many of these forms of corrosion is presented in numerous monographs. The theory of stress corrosion cracking has been treated in the proceedings of a number of recent conferences (refs. [6-8]), but no comprehensive conference on the technology of SCC and its avoidance has been held since the conference of 1944 (ref. [9]). The aim of the present work is to fill this technological need. Rather than restricting the coverage of SCC alone, portions of the subjects of hydrogen cracking and liquid metal assisted cracking are included for reasons which are noted below. These three cracking processes, which are italicized in the list above, constitute a class of processes which may be grouped under the term "sustained load environmental cracking," which is not to be confused with "sustained load cracking," a phenomenon which occurs in some titanium alloys in the absence of a chemically reactive environment.

\section{Sustained Load Environmental Cracking}

Hydrogen cracking, liquid metal assisted cracking, and stress corrosion cracking have a strikingly large number of common features:

(1) All three processes can produce macroscopically brittle fractures, even when they occur in metals which are ductile in a simple tensile test.

(2) All three processes are believed to involve localized plastic flow.

(3) All three processes can occur at stresses which may be far below those required for general yielding.

(4) Only a tensile stress will produce this class of cracking.

(5) Fracture occurs on a plane nominally perpendicular to the tensile axis, that is, it is an "opening mode" fracture (as in opening a book). No analog to the shear lip has been noted to be generated by sustained load environmental fracturing, although in some instances what appears to be a purely mechanical shear lip may form as a border after the passage of a stress corrosion crack.

(6) There is a wide range of susceptibility among various combinations of alloys and environments. This feature is related to the following one.

(7) There is an approximation of specificity about those combinations of alloy and environment which lead to the most severe cracking problems. In SCC, in other words, generally only a few chemical species cause serious cracking problems in a given alloy. 
(8) The chemical species in the environment essential for the cracking process may not be needed in either high concentrations or large quantities.

(9) The combinations of alloy and environment which lead to the most severe cracking problems are usually those in which the alloy is almost, but not quite, inert to the environment.

(10) The cracks may be either simple or branched.

(11) Although the cracks are macroscopically brittle, on a microscopic level the sustained load environmental cracking processes involve localized plasticity and may follow paths which are different from that of purely mechanical brittle fracture; and environmental cracking may select either intergranular or transgranular paths depending on seemingly minor changes in environment, composition of alloy, stress level, or processing variables.

(12) In addition to these eleven generalizations, which apply to all three failure modes, stress corrosion cracking appears to occur only when certain electrochemical conditions are met, as will be discussed in detail in subsequent chapters.

A thirteenth generalization is often found in the older literature, namely that only alloys experience SCC, and pure metals do not. From a practical standpoint this rule has merit, but a few laboratory cases of SCC have been observed in copper of extremely high purity, so that the rule may have to be stricken when considering theory.

Liquid metal assisted cracking can be regarded as sufficiently akin to SCC to be treated in the present writing, and it is so included in the metal systems where major problems have occurred. Some processes which are labelled SCC may be, mechanistically, manifestations of hydrogen cracking; and in such cases certain corrosion control measures such as zinc electroplating of and cathodic protection of high strength steel can cause problems of hydrogen cracking as serious as or more so than the SCC they may be intended to prevent. Therefore, although the primary focus of this volume is on SCC, liquid metal assisted cracking (and related solid metal cracking) will be included in important systems because the general approach to controlling the problem is similar to the approaches for controlling SCC, and treatment of a small portion of the vast subject of hydrogen effects is included where it is intimately related to SCC and its control.

\section{Interaction between Failure Modes}

There is extensive interaction between various of the 19 failure modes, especially the modes involving fracturing. It is common for SCC to be initiated by corrosion pitting. It is also common for SCC to initiate fatigue cracking, and in fact premature initiation of fatigue cracks by SCC in airframe components is an important reason for concern about SCC in that technology. Brittle fracture may initiate from fatigue cracks, stress corrosion cracks, hydrogen cracks, and in brittle steels from even corrosion pits.
The "Silver Bridge" (frontispice) represents an unusually complex chain of interactions between different failure modes: (1) A corrosion pit initiated (2) SCC, which caused, (3) brittle fracture of one half of the ring forming the eye of an eye bar. This brittle fracture transferred such a high load to the other half of the ring as to cause it to fail by (4) overload fracture, setting in motion the progressive collapse of the entire bridge.

The design of the "Silver Bridge" represents a generic design type which may be termed nonredundant load path, non-redundant in the sense that if one load path (such as one half of the ring which forms the eye of the eye bar) fails, the entire structure is doomed. The implications of such designs to requirements for knowledge of stress corrosion cracking and brittle fracture are discussed in chapter 6.

\section{Theory}

SCC involves the disciplines of metallurgy, mechanics, and chemistry, and it should be not surprise that the theory has proven to be difficult to formulate even qualitatively. One might suspect that if all SCC has 12 features in common (as listed above), then there must be a strong element common to all cases of SCC. And indeed throughout the older literature on the subject there was an implied conviction that a unified theory of all SCC awaited the diligent investigator. With the passage of years and no single theory forthcoming to account for SCC in all systems (combinations of alloys and environments), attempts to find a single theory have gradually given way to attempts to find any theory which will account for all the observations on any one system.

It has long been recognized that SCC characteristics are controlled by microfeatures and microprocesses. In microfeatures we include grains, grain boundaries, precipitate particles, etc. By microprocesses we include motion of dislocations, passing of metallic atoms into the ionized (corroded) state, reduction and diffusion of hydrogen, etc. These features and processes are on a scale of roughly a micron to an angstrom. Most of the microfeatures and microprocesses thought possibly involved in SCC are summarized schematically in figure 1.

A full discussion of figure 1 would require a large book in itself, for research is continuously adding to our knowledge of these microfeatures and microprosses. From an analysis of such knowledge a variety of theories of SCC have emerged, which can be classified in six groups as follows:

(1) Film rupture, with consequent crack propagation by dissolution at the crack tip. (See upper left area of fig. 1.)

(2) Stress accelerated dissolution.

(3) Hydrogen embrittlement (which itself is understood very imperfectly).

(4) Adsorption and interaction of environment species with strained bonds. (See black "atoms" 
Placing the Problem in Perspective

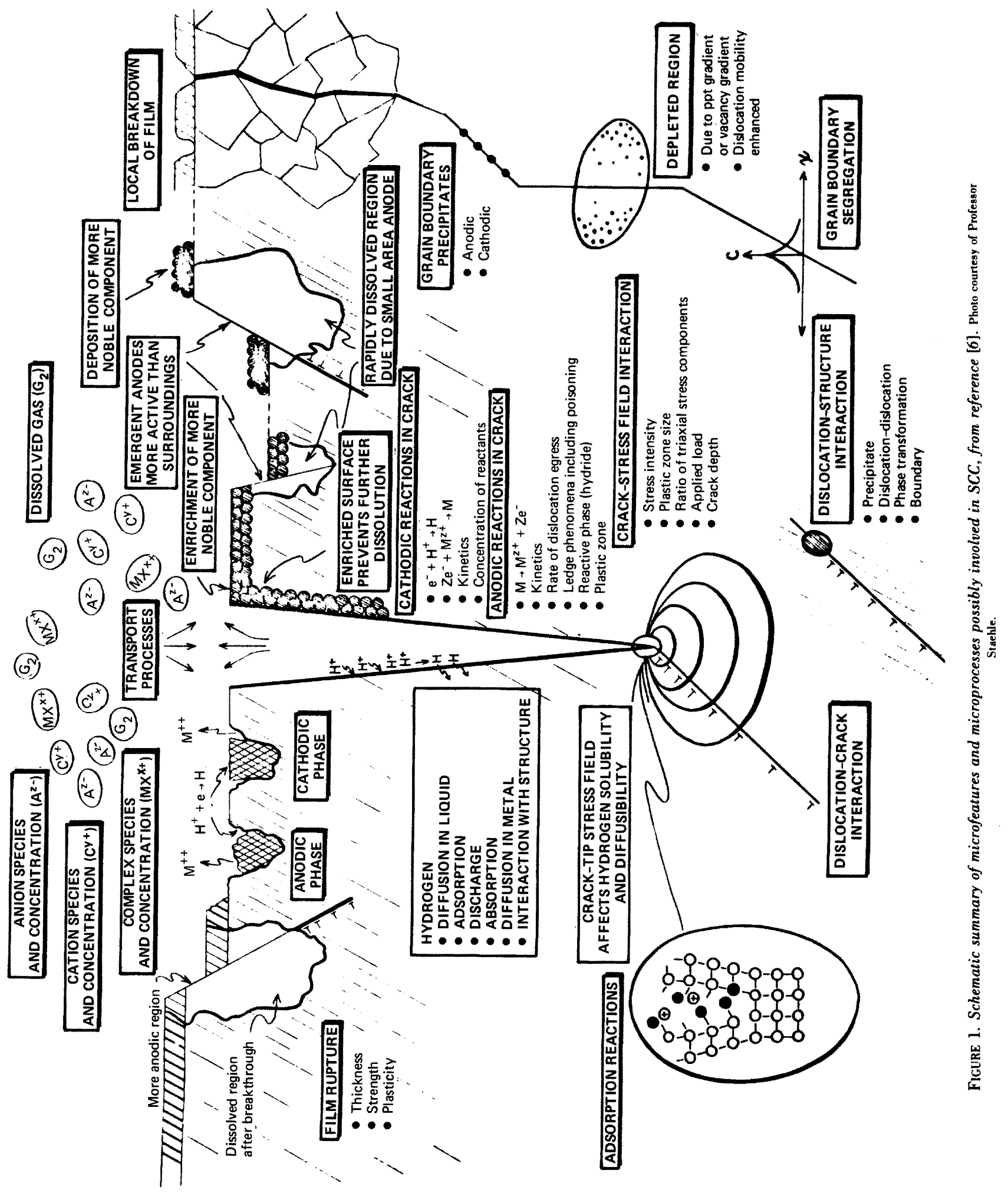


adsorbed or sorbed at strained and broken bonds, lower left area of fig. 1.)

(5) Brittle film formation and rupture, repeated cyclically. This model is discussed in detail in chapter 3.

(6) Formation of rows of corrosion pits which lengthen into an array of parallel corrosion tunnels, with uncorroded walls between the tunnels ultimately repturing mechanically to produce crack advance.

Some evidence has been found for all these models, yet none has been established and universally accepted for even one system. Furthermore none of the information which has been derived from these fine-scale studies has eliminated the SCC problem, and we have no basis for confidence that it will do so in the near future. Such studies are essential to provide the guidance for orderly development of alloys, but even if any one of the above theories were to be firmly established, we do not at this stage know how to use such knowledge for practical avoidance of SCC. Theoretical studies are required for understanding for the alloy development, but information on another scale is required for practical control measures. That is the subject of the next chapter.

The reader interested in more detailed discussion of theory should consult references [6-8].

\section{References}

[1] Tetelman, A. S. and McEvily, Jr., A. J., Fracture of Structural Materials, (John Wiley \& Sons, New York, 1967).
[2] Grover, Horace J., Fatigue of Aircraft Structures (NAVAIR 01-1A-13), Government Printing Office, Washington (1966).

[3] Fontana, Mars G. and Greene, Norbert D., Corrosion Engineering, (McGraw-Hill, New York, 1967).

[4] Uhlig, Herbert H., Corrosion and Corrosion control, (WileyInterscience, New York, 1971).

[5] Evans, Ulick R., The Corrosion and Oxidation of Metals, (Arnold, London, 1960).

[6] Staehle, R. W., Fundamental aspects of stress corrosion cracking, (R. W. Staehle, A. J. Forty and D. van Rooyen, Eds.) National Association of Corrosion Engineers, Houston, Texas (1969), p. 4.

[7] Scully, J. C., Ed., The theory of stress corrosion cracking in alloys, NATO Scientific Affairs Division, Brussels (1972).

[8] Hochmann, J. and Staehle, R. W., Eds., Stress corrosion cracking and hydrogen embrittlement of iron base alloys, National Association of Corrosion Engineers, Houston, Texas, in press.

The following are additionally recommended for further reading on many topics treated in this book.

[9] Anon., Symposium on stress corrosion cracking of metals, American Society for Testing Materials, Philadelphia, PA (1945).

[10] Robertson, W. D., Ed., Stress Corrosion Cracking and Embrittlement (John Wiley \& Sons, New York, 1956).

[11] Rhodin, Thor, Ed., Physical Metallurgy of Stress Corrosion Fracture, (Interscience, New York, 1959).

[12] Logan, Hugh L., The Stress Corrosion of Metals (John Wiley \& Sons, New York, 1966).

[13] Anon., Stress corrosion cracking of titanium, STP 397, American Society for Testing Materials, Philadelphia, PA (1966).

[14] Anon., Stress corrosion testing, STP 425, American Society for Testing Materials, Philadelphia, PA (1967).

[15] Craig, H. Lee, Ed., Stress corrosion cracking of metals - A state of the art, STP 518, American Society for Testing Materials, Philadelphia, PA (1972). 


\section{CHAPTER 2}

\section{TEST METHODS AND INTERPRETATION OF TEST DATA}

Since the theory of SCC based on microfeatures and microprocesses (ch. 1, fig. 1) has not been developed to the point of providing predictive capability with respect to SCC behavior in engineering components and structures, another approach is required until that capability can be developed. The other approach is the use of macroscopic specimens, and it is the one upon which we presently rely for guidance in making materials selection decisions. One might say that the macroscopic specimen under test acts as an analog computer to sum up experimentally (and quantitatively) the effects of all the microfeatures and microprocesses operative in a given system (combination of alloy and environment). The reader should have a clear view of the roles of the two types of experimentation: The study of microfeatures and microprocesses, often termed "basic research", is required for understanding the nature of SCC and to provide guidance for orderly development of alloys. The testing of macroscopic specimens is necessary for determination of SCC characteristics, the knowledge of which is necessary for materials selection. The two approaches are complementary. Neither will do the work of the other, and both are essential. Except for ASTM standards, reference [1] contains the most recent compilation of macroscopic SCC test procedures.

There are three fundamentally different types of macroscopic specimens and tests. One employs an essentially smooth specimen under static load, the second uses a precracked specimen (also called a fracture mechanics specimen) also under static load, and the third employs a smooth specimen under a rising load with a constant strain rate.

\section{Smooth Specimen Tests under Static Loads}

There are engineering situations in which the full component is the logical choice for a specimen. If, for example, one wishes to determine whether a given annealing treatment is adequate to remove the forming stress from a rolled brass plug-fuse shell sufficiently to avoid SCC in an ammoniacal atmosphere, the obvious choice of specimen is one of the shells. Particularly when theory is incomplete, or poorly established, we would prefer to conduct tests resembling in every way possible the practical situation, and the shell thus makes an ideal specimen. Such ideality of specimen as the fuse shell is of limited availability in the engineering world. We cannot afford to run SCC tests on a whole submarine hull or even very many landing gears, so it is necessary to select smaller specimens which will afford the needed predictive capability with respect to the larger structures or components.

One such group of specimens in common use has a spectrum of stresses in each specimen, usually varying from beyond the yield strength to zero. A widely used specimen in this category is the U-bend specimen (see fig. 1), made by bending a strip of metal into a $U$-shape and restraining the legs by a tie rod or other means. If desired, the U-bend specimen can be so dimensioned as to avoid plastic deformation and produce only a spectrum of elastic stresses. Other specimens in this category are sheet or plate specimens which may be stressed by being indented by a Brinell hardness indenter or by an Erichsen cup test plunger. These self-stressed specimens are

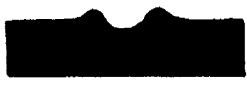

BRINELL IMPRESSION

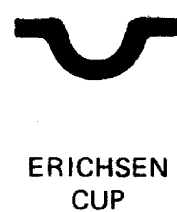

CUP

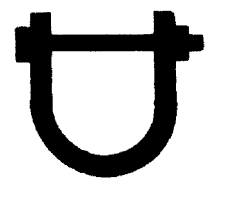

U-BEND

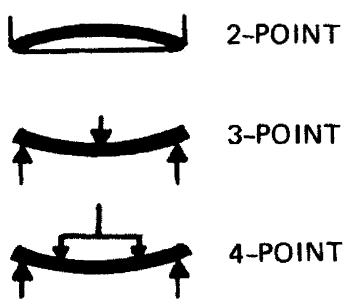

BEAMS

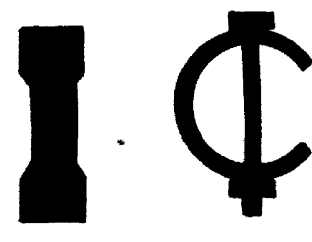

TENSILE C-RING

FIGURE 1. Smooth SCC specimens. 
suitable for insertion into chemical process streams, but they do not give a very quantitative picture of the stress dependency of cracking.

In order to determine this stress dependence, it is common practice to use a bent beam specimen, a C-ring specimen, or an uniaxial tensile specimen which may be stressed in a stout test frame. These specimens are shown schematically in figure 1 .

The U-bend specimen and test procedure have been standardized as ASTM recommended practice G30-72. The preparation and use of two-, three-, and four-point loaded bent beam specimens have been developed to ASTM Standard Method G39-73, which includes procedures for calculating stress. C-ring specimens may be cut from tubing or machined from plate or bar stock. The making and using of C-ring specimens have been developed to ASTM Standard Recommended Practice G38-73.

If the environment of interest is known, as, for example, uncontaminated sea water, or a chemical process stream of known composition, the test environment of choice will be the service environment. But if the service environment is incompletely defined, for example that of an airplane, the selection of a test environment poses problems which have not been completely answered to everyone's satisfaction. Should one test in a "worst-case" environment including worst temperature and worst electrochemical potential? There are two problems here, first that we don't know the worst-case environment for all alloys, and second, testing of some materials in worst-case environments (or reasonable approximation thereto) would probably lead to excessive rejection of alloys. Regardless of the possible merits of using worst-case test environments, they are not in widespread use even for those alloy families for which we think we have identified something approaching the worst-case environment.

Instead of the worst-case approach for general characterization of SCC properties the approach most commonly used is to select either natural environments (e.g., atmosphere, sea coast, sea water), or alternatively to use standardized laboratory solutions or atmospheres. Among the standardized solutions there are several ASTM standardized environments: G36-73 for cracking of stainless steels in boiling magnesium chloride solution; G35-73 for cracking of stainless steels in polythionic acids; G37-73 for cracking of copper-zinc alloys (brasses) in Mattsson's solution; and G44-75 for alternate immersion testing in sodium chloride solution at room temperature.

It is tacitly presumed that testing various stainless steels in the standardized boiling magnesium chloride solution will permit assigning an order of merit rating valid for the most part for the cracking of the same steels in dilute hot chloride solution representative of slightly contaminated boiler water. Likewise tests in Mattsson's solution presumably afford an order of merit rating of copper-zinc alloys which would more or less predict the relative performance of the same family of alloys in other ammoniacal environments, particularly the more dilute ones. And so forth with the other standardized environments.

In the most general case, the sequence of events in a stress corrosion cracking test on an initially smooth specimen is as shown left to right in figure 2 .

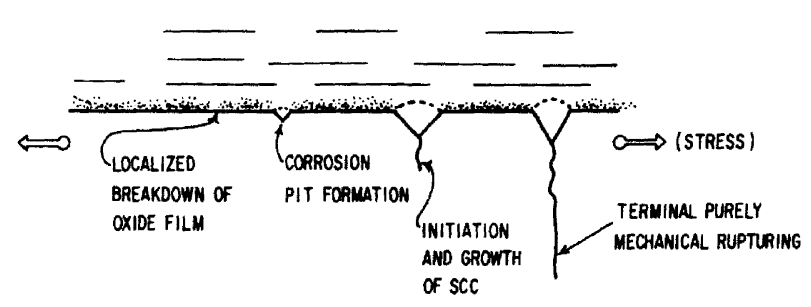

FIGURE 2. Generalized sequence of events in SCC, left to right, assuming nonrelaxation of stress. Some systems may exhibit SCC without a visible pit. Some systems (notably titanium/water) do not exhibit pitting, but SCC readily initiates from a fatigue crack.

Most metals are covered with thin films, often oxides, which may be protective against corrosion as long as they remain intact. The first step in the SCC process in the breakdown of this film, which may occur because of mechanical damage or because of electrical currents, but the most common cause of film breakdown in the action of certain chemical species in the environment, particularly the chloride ion. After the film is broken down, a corrosion pit may form. In some combinations of environments and alloys cracking may initiate without visible pitting, but in a large proportion of service failures a corrosion pit precedes the SCC. The pit acts as a stress intensifier, but it serves a second and perhaps even more important function in some systems: the corrodent within the pit tends to be different in nature from the bulk environment because of a class of reactions known in chemistry as hydrolysis. One such reaction involving one of the corrosion products of stainless steel is as follows:

$$
\mathrm{Cr}^{+++}+3 \mathrm{H}_{2} \mathrm{O}=\mathrm{Cr}(\mathrm{OH})_{3}+3 \mathrm{H}^{+}
$$

The hydrogen ions thus produced cause local acidity within a corrosion pit, and this acidity may be at least as important as the stress intensification of the pit in causing SCC initiation.

Returning to the sequence in figure 2 , if the load is not relaxed as the stress corrosion crack grows, eventually the stress on the uncracked ligament increases to the point that the ligament tears apart mechanically. This final rupture can be either ductile overload fracture or brittle fracture, depending on factors such as the nature of the alloy, the geometry of the specimen, and the temperature.

In a test on a smooth specimen, the parameter commonly measured is the time from commencement of test to failure. Failure is sometimes defined as the appearance of a recognizable crack. In that case the total time to failure represents (for the general case) the sum of the times for film breakdown, 
pit initiation and growth, and SCC initiation and growth to an arbitrary size crack.

If failure is defined as separation of the specimen, a convenience in that the separation event can be used to actuate a timer, then the nature of the terminal fracture can make important contributions in determining the total time to failure. Let us consider the case of a high strength steel in which the terminal fracture is a brittle fracture. If one heat treats the steel specimens to several levels of toughness and puts them into a stress corrosion cracking test, the tougher specimens will require a longer stress corrosion crack before they undergo terminal fracture than the more brittle specimens. The tough specimens would then show a longer time to failure than the brittle ones even if their stress corrosion characteristics were identical.

For emphasis of the deficiencies of the total time to failure as a SCC parameter, note that the magnitude of this time depends not only in SCC kinetics but also on such non-SCC factors as specimen size, specimen geometry, toughness of the metal, initial stress level, and initiation behavior.

Despite such deficiencies in the total-time-tofailure parameter for initially smooth specimens, this parameter, perhaps tempered in interpretation by investigators who take into account non-SCC factors which influence the parameter, has been the principal basis on which our SCC control technology rests.

This time-to-failure parameter, when plotted as a function of initial stress, typically shows what appears (fig. 3) to be a horizontal asymptote which is usually denoted the threshold stress $\sigma_{t h}$. This apparent threshold stress is important in determining order of merit ratings of alloys or environments, as will be seen in the chapters on copper alloys, aluminum alloys and stainless steels.

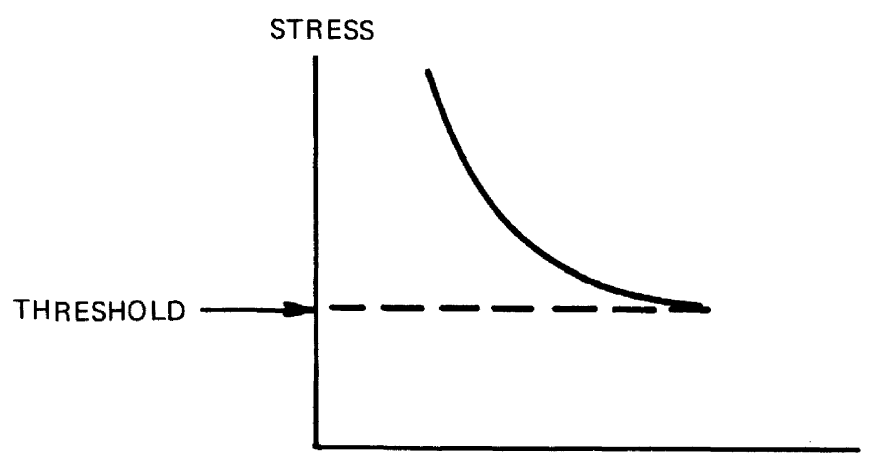

TIME TO FAILURE

FIGURE 3. Schematic SCC data from smooth specimens. Existence of a true horizontal asymptote threshold stress is not always readily provable.

\section{Precracked (Fracture Mechanics) Specimens under Static Loads}

The existence of a crack-like surface defect completely alters the analysis of the SCC behavior of an alloy, for whether the defect extends as a stress corrosion crack depends not only on the nature of the alloy and the environment and the magnitude of stress but also on the depth of the initial crack-like defect. In the presence of a crack-like defect or of a stress corrosion crack, nominal stress is a fiction which can be misleading, and at the present time the response of a cracked body to loading can only be treated quantitatively by fracture mechanics. Stress corrosion cracks are brittle, that is, for the most part they occur before the onset of general yielding, while the bulk of the metal is still in the elastic state. Therefore it is appropriate to use the Irwin-Kies linear elastic fracture mechanics for SCC even in metals too ductile for the practical measurement of purely mechanical fracture toughness by fracture mechanics methods.

When a piece of metal containing a crack is stressed in such a fashion as to tend to open and extend the crack, the nominal stress is intensified near the crack tip. Elasticians have given us the means to quantify this stress intensity, ${ }^{1}$ which is designated $K$ and which has the units $\mathrm{ksi} \sqrt{\mathrm{in}}$ or $\mathrm{MNm}^{-3 / 2}$.

Some of the various types of fracture mechanics specimens which have been used in SCC studies are shown in figure 4 . The equations for calculating $K$ values for various types of specimens are collected in reference [2].

If one measures SCC growth rate as a function of $K$, general appearance is as shown in figure 5. Here it will be seen that in the area marked Region II the crack growth rate is high and is insensitive to $K$. This plateau is discussed further in chapter 4. At lower levels of $K$, in region $\mathrm{I}$, the crack growth rate becomes very sensitive to $K$ (note the log scale). At a sufficiently low value of $K$ there appears to be a threshold which has been designated $K_{I 8 c c}$. That such a genuine threshold $K$ exists has been clearly proven for titanium alloys in salt water, and it appears probable in steels; but its existence is in question in some aluminum alloys. The value of such a parameter of $K_{I s c c}$, where such a genuine threshold exists, lies in one's ability to predict the combination of remote (nominal) stress and size of crack-like surface flaw through the use of the Irwin equation:

\footnotetext{
${ }^{1}$ Note that "stress intensity" as used throughout this volume is the fracture mechanics parameter. It is unrelated to "stress intensity" as used in the ASME code to designate the stress difference or two times the shear stress.
} 

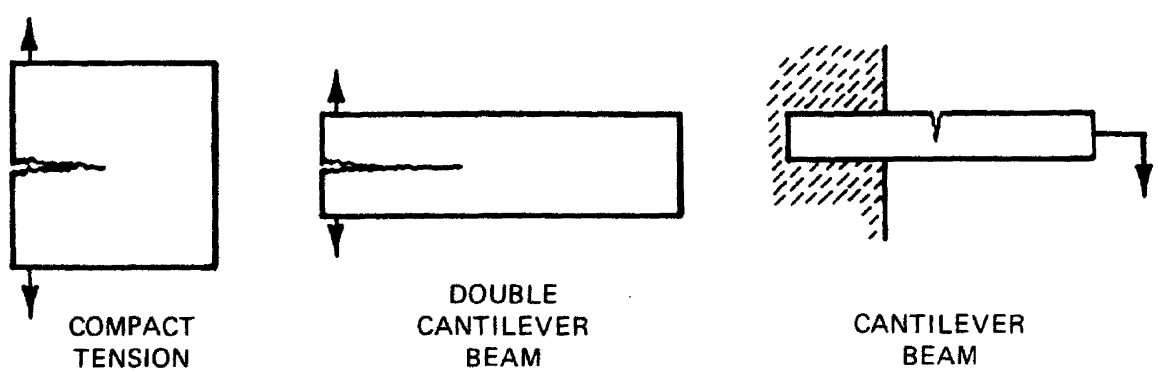

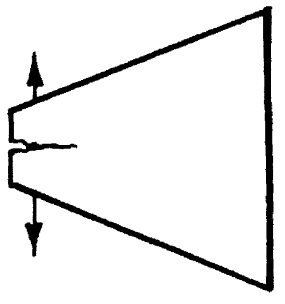

CONSTANT K

FIGURE 4. Principal fracture mechanics type specimens which have been used in SCC studies.

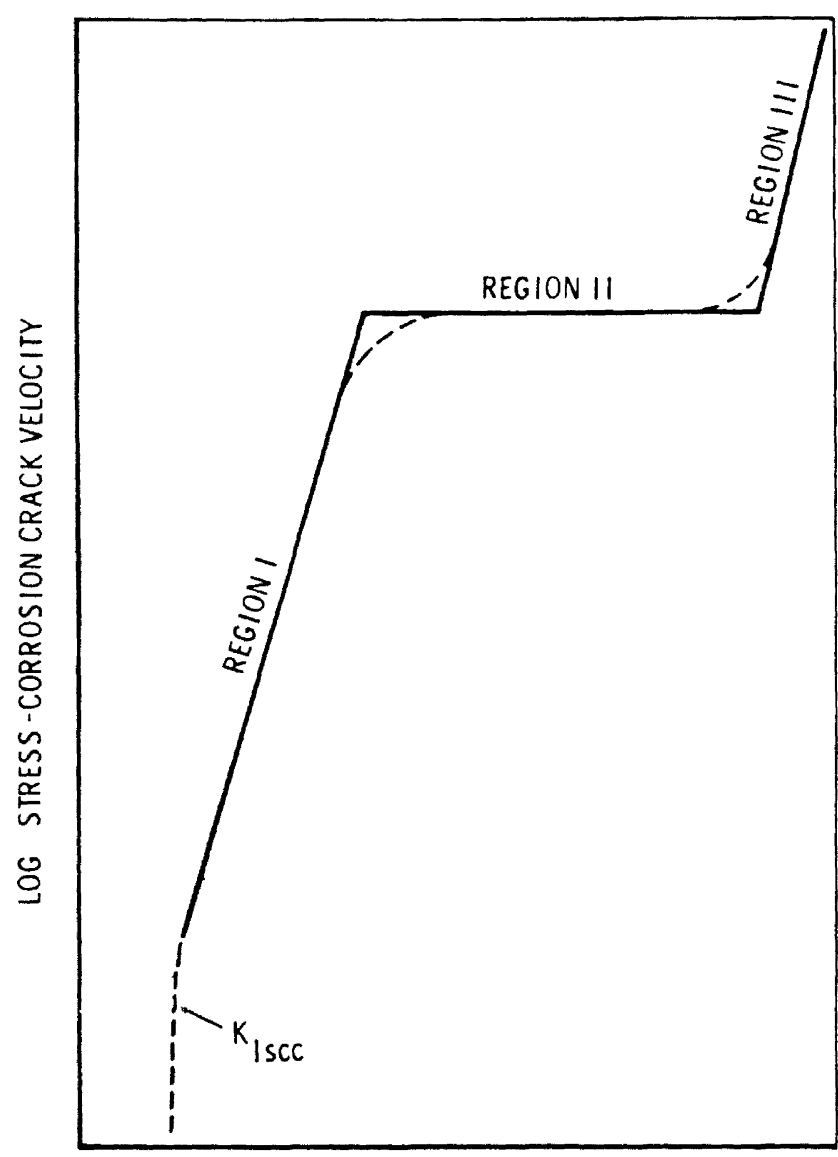

CRACK-TIP STRESS INTENSITY

FIGURE 5. Effect of stress intensity on SCC Kinetics. Region III is of little interest and is often missing. Region I is missing in some systems. Regions I and II are not always straight lines in such a plot but may be strongly curved.

$$
K^{2}=\frac{1.2 \pi \sigma^{2} a}{\varphi^{2}-0.212\left(\frac{\sigma}{\sigma_{y}}\right)^{2}}
$$

where $a$ is the depth of the crack, $\sigma$ is the stress, $\sigma_{y}$ is the yield strength, and $\varphi$ is a factor for the shape of the crack. If the length of the crack is $2 b$, then $\varphi^{2}$ has the values for various crack shapes listed in table 1 . If one assumes a long, thin flaw and the existence of yield-point stress, then from eq (1) stress corrosion would be expected to propagate if the flaw depth exceeded $a_{c r}$, given by

$$
a_{c r}=0.2\left(\frac{K_{I s c c}}{\sigma_{Y}}\right)^{2}
$$

The value of $a_{c r}$ may thus be regarded as a figure of merit which incorporates both the SCC resistance $K_{I s c c}$ and the contribution which yield strength stress levels can make to SCC hazard by virtue of residual or fit-up stresses.

TABLE 1. Values of $\varphi^{2}$

\begin{tabular}{ll}
\hline$\frac{a}{b}$ & $\varphi^{2}$ \\
\hline $0 \quad$ (very long, thin crack) & 1.00 \\
.25 (semicircular) & 1.14 \\
.75 . & 1.46 \\
1.0 (5) & 1.89 \\
\hline
\end{tabular}


One can plot eq (2) for various values of $a_{c r}$ as shown in figure 6. This plot is a convenient framework for displaying the SCC characteristics of materials. If a given material was found to have a $K_{I s c c}$ as indicated by point $x$, a surface crack 0.1 in $(2.5 \mathrm{~mm})$ deep would be deeper than required to propagate a stress corrosion crack in the same environment used to determine the $K_{I s c c}$. But a crack 0.01 in $(0.25 \mathrm{~mm})$ deep would not propagate a stress corrosion crack in the same material in the same environment.

A plot of $K_{\text {Iscc }}$ data such as figure 6 can be used in a slightly different way: If one knows that he cannot detect and remove crack-like flaws less than, say 0.01 in $(0.25 \mathrm{~mm})$ deep, then if he has yield-point stresses he must select a material having a $K_{\text {Iscc }}$ above the 0.01 in line in figure 6.

The $K_{\text {Isce }}$ values for a number of commercial and experimental titanium alloys are shown in figure 7 as a function of yield strength. Lines corresponding to various critical crack depths (following eq (2)) are included in this plot as an aid to interpretation of the degree of susceptibility of various alloys. Another way to regard $K_{I s c c}$ is to view it as linearly proportional to the load-carrying capability of a specimen or component containing a standard size flaw.

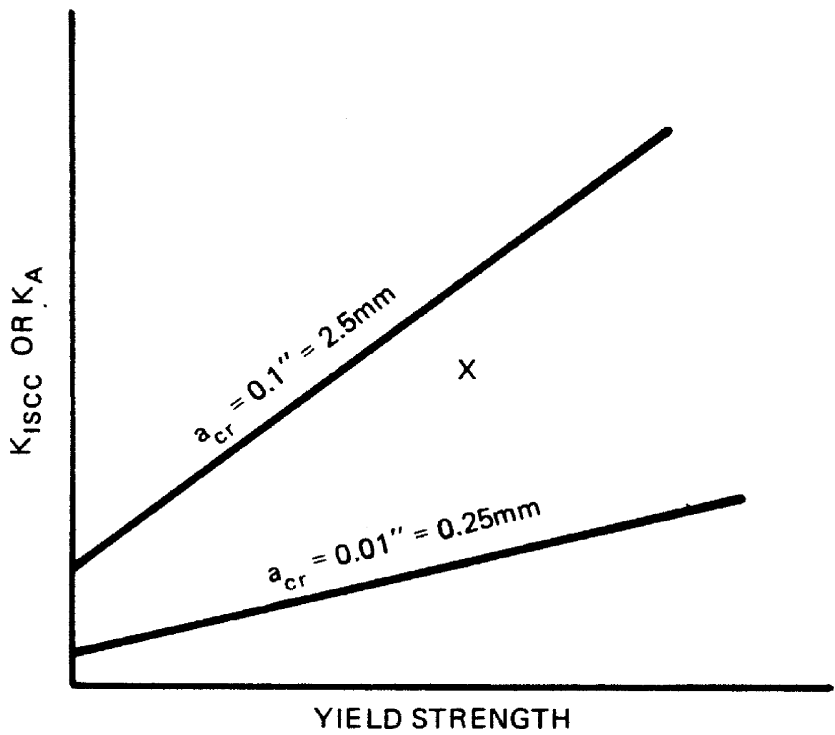

FiguRE 6. Plot of eq (2) for two assumed values of $a_{c r}$, assuming long surface flaws and yield strength stresses operating. A material having a $K_{\text {tarr }}$ value as indicated by X would be safe from SCC in the pertinent environment if one can be sure surface flaws will be no deeper than 0.01 in $(0.25 \mathrm{~mm}$ ): SCC will occur if they are as deep as 0.1 in $(2.5 \mathrm{~mm})$.

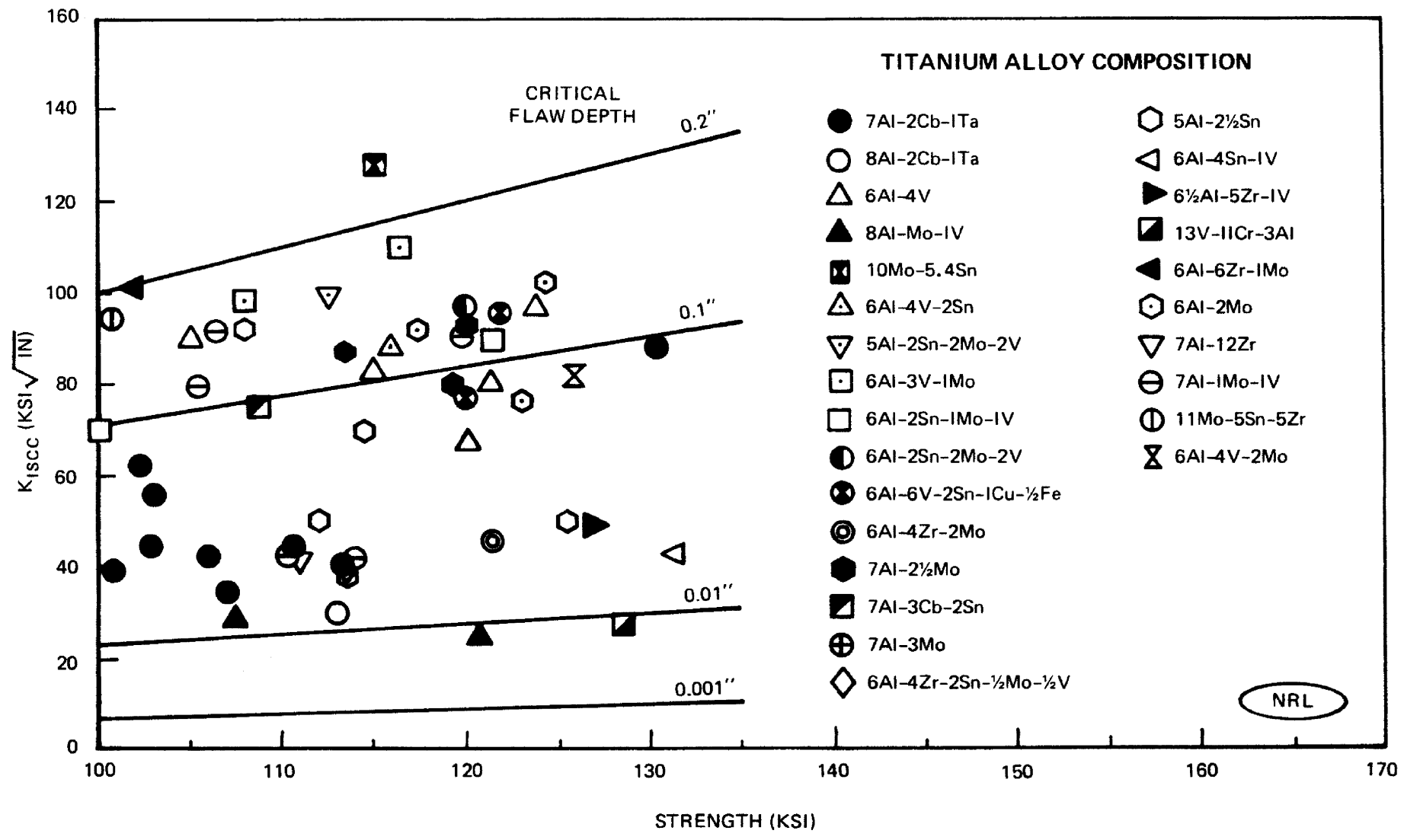

FIGURE 7. $\mathrm{K}_{\mathrm{Iscc}}$ data on titanium alloys in sea water. Data of B. F. Brown, R. J. Goode, R. W. Judy, R. L. Newbegin, and L. J. Waldron. Figure kindly supplied by R. W. Judy. 


\section{Constant Strain Rate Tests}

A fundamentally different way to assess SCC characteristics is to pull to fracture a series of small smooth tensile specimens, each one at a different but constant rate, and measure the reduction in area as in a conventional tensile test. (Other parameters may be used as indices of SCC effects, such as elongation or fracture stress.) This series is done in an inert environment and again in the corrodent of interest. If one or more stress corrosion cracks nucleate and grow during the test, that event decreases the ductility to an extent related to the number and size of the stress corrosion cracks. A schematic plot of data representative of such tests appears in figure 8 and shows the behavior of an alloy in an environment which causes SCC compared with behavior in an inert environment. The extent of the maximum separation between the two curves of figure 8 is an indicator of the degree of susceptibility of the alloy in the environment causing cracking (ref. [3]).

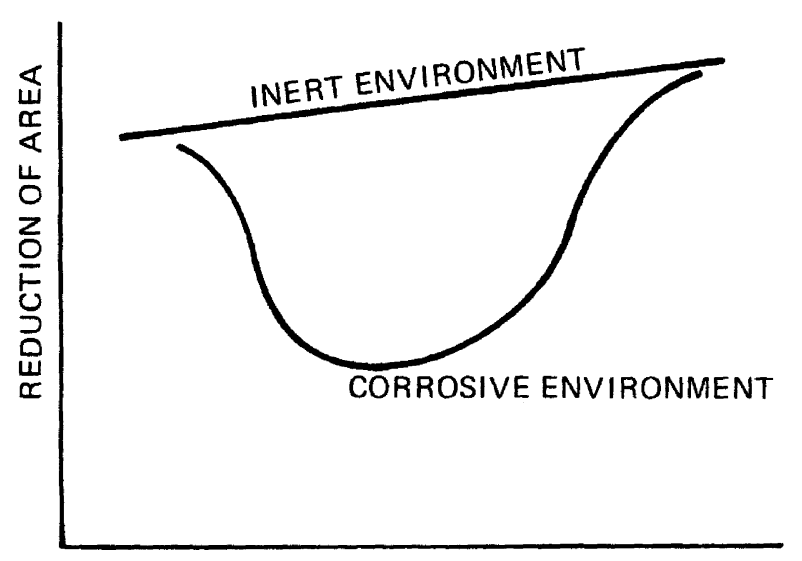

LOG STRAIN RATE

Figure 8. Plot of typical results in the Parkins constant strain rate tests on one material in two environments, one inert and one causing SCC. After reference [3].

Constant strain rate test data might be used in the following way. Let us suppose that unprotected steel in (moist) soil would behave according to the sagging curve of figure 8. But if zinc anodes are connected to the steel the electrochemical potential of the steel can be altered with consequent altering of the corrosion behavior of the steel. Let us accept that the electrochemical potential of this particular steel can be so altered that the steel would behave as if it were inert (top curve of fig. 8). Such behavior, if it were observed, might form the basis for specifying this electrochemical treatment (cathodic protection).

It might be pointed out that such a procedure would be precisely analogous to the standard method for avoiding brittle fracture in ship plate. The absolute toughness of the ship plate steel is not measured, but rather the temperature of transition between brittle behavior and tough behavior is determined, and the transition temperature is required to be safely below any possible operating temperature.

\section{Metallurgical Considerations in Tests}

Those unfamiliar with the internal structure of metals and alloys might not know that their chemical reactivity - their corrosion behavior-can be greatly influenced not only by their nominal composition but also by the way in which they are produced. The chemical behavior of reagent grade sodium hydroxide is identical whether it comes out of a large bottle or a small one, but the stress corrosion cracking behavior of a large forging may differ greatly from that of the same metal rolled down to a thin strip. Also, because of grain testure (analogous to the texture of wood) in certain alloys, notably aluminum and some high alloy steels, the SCC characteristics are directional. The stress required to drive a stress corrosion crack across the grain texture can be vastly greater than that required to drive it parallel to the grain texture (in the "weak" direction). This "anisotropy" (as it is called) is also true for other fracturing modes.

For these reasons, for critical components care must be exercised in interpreting SCC data. One should not think of the SCC characteristics of an alloy as having general applicability for all mill product forms. The careful worker would tend to report SCC characteristics somewhat in the following pattern: $K_{I s c c}$ for 18 percent nickel maraging steel, vacuum induction melted and vacuum arc remelted, rolled to 1 in plate, heat treated to a yield strength of $190 \mathrm{ksi}\left(1300 \mathrm{MNm}^{-2}\right)$ and tested in the weakest direction in natural sea water, was found to be 90 ksi $\sqrt{\text { in }}\left(99 \mathrm{MNm}^{-3 / 2}\right)$, based on tests of $1,000 \mathrm{~h}$ duration.

\section{Interpretation of SCC Test Data}

For the benefit of the person with little background in the subject, it should be admitted that a great deal of the published data on SCC are difficult to interpret in terms of practical materials engineering. Most of the extant data on the SCC of austenitic stainless steels were taken in hot concentrated magnesium chloride solutions, solutions which are never encountered anywhere except in SCC testing chambers. We think that the order of merit of various stainless steels determined in those solutions will largely pertain also to the practical case of boiler water containing only traces of chloride, just as we think that the data taken on aluminum alloys in alternate immersion tests in 3.5 percent sodium chloride solution at room temperature are meaningful in predicting the performance of the same alloys in aircraft. When such test data are interpreted by someone with extensive field experience, the data are meaningful, but the contribution of experience not now expressable in quantitative terms is the key here. 
It is certain folly to design for a sustained working stress equal to a measured SCC threshold stress, however carefully that determination may have been made, but rather a sizeable margin must be left. The reason for this margin is that unknown stresses from heat treatment, fit-up, welding, and thermal expansion are the causes of a majority of service failures, and one does not want to run the risk that unknown stresses from such causes may elevate his design stress above the SCC threshold stress.

An attempt has been made to harmonize the fracture mechanics term $K_{I s c c}$ and its implications to behavior of smooth specimens of the same alloy, which was 7079-T651. $K_{\text {Iscc }}$ was estimated to be $4 \mathrm{ksi}$ $\sqrt{\text { in }}\left(4.4 \mathrm{MNm}^{-3 / 2}\right)$. For the same material, the threshold stress was fond to be $8 \mathrm{ksi}\left(55 \mathrm{MNm}^{-2}\right)$. The yield strength of the material was $67 \mathrm{ksi}(460$ $\mathrm{MNm}^{-2}$ ). It is instructive to compare the implications of these data graphically, as shown in figure 9. Inserting the data above in the Irwin equation (eq (1) above) and rearranging and taking logarithms of both sides, one finds that the log of the stress in linearly proportional to the $\log$ of the flaw $\operatorname{depth} a$, as shown by the sloping line in figure 9. One would suppose that this line should intersect the threshold stress line at some value of flaw depth approximating either the initial surface roughness of the specimen of else some value of the flaw size commensurate with any corrosion pits which may have formed. In fact, however, as may be seen in figure 9 , the intersection is at about 0.06 in $(1.5 \mathrm{~mm})$. Either the estimate of $K_{I s c c}$ is too high, if the concept of $K_{I s c c}$ is valid for this alloy, or some extraneous phenomenon is entering. In any event as matters now stand, one would have to be governed by both the smooth specimen threshold data and the fracture mechanics data. The threshold data from smooth specimens is incapable of taking account of the effects of flaws, and clearly from the sloping line one cannot be safe at the threshold stress level with flaws present deeper than about 0.06 in $(1.5 \mathrm{~mm})$, assuming the customary surface flaw shape, 10 times as long as deep; likewise one is not safe using the fracture mechanics guidance below that flaw size.

It seems to be the present status of SCC technology that one must act upon the most pessimistic SCC characterization data, whether they be

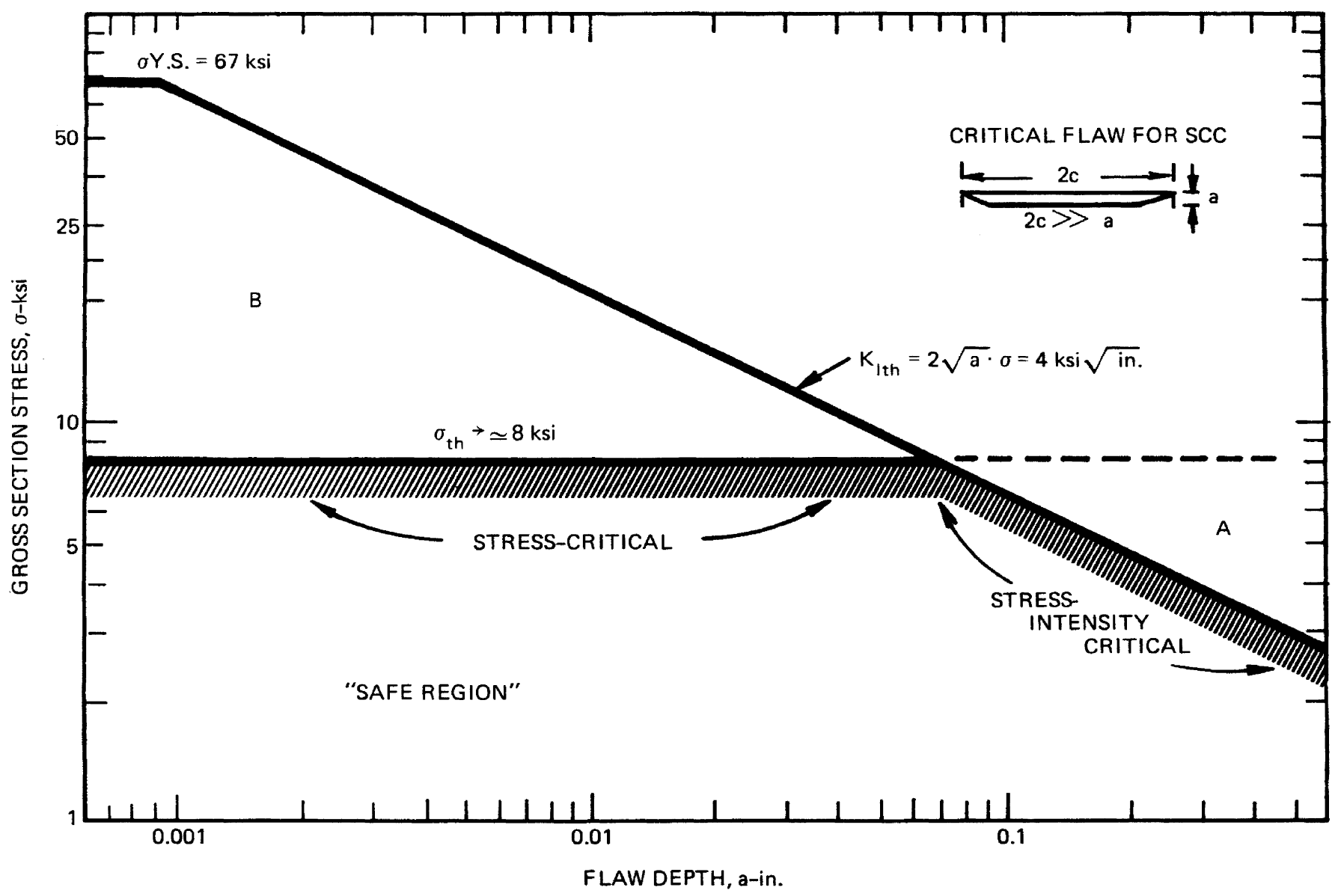

FIGURE 9. Flaw depth a versus section stress, showing threshold stress for aluminum alloy 7079-T651 rolled plate. (S-L cracks; see chapter 4 for meaning.) Sloping line is a plot of eq 1 on a log scale for this material. In triangutar area to right marked "A", smooth specimen data would erroneously imply safety against SCC. In triangular area " $B$ " fracture mechanics data would erroneously fail to predict SCC. After reference [4]. 
threshold data from smooth specimens, fracture mechanics data, or data from constant strain rate tests, and in the absence of positive information to the contrary, it is a prudent rule to assume that somewhere in the structure there will probably be stresses equal to the yield strength.

The reader should appreciate that few laboratory SCC characterization tests are of durations comparable with the desired service life of most structures, and added conservatism taking this state of affairs into account is warranted in interpreting laboratory SCC data to engineering practice.

\section{References}

[1] Craig, Jr., H. L., Sprowls, D. O., and Piper, D. E., Handbook on Corrosion Testing and Evaluation, William $\mathrm{H}$. Ailor, Ed. (John Wiley \& Sons, New York, 1971) p. 231.

[2] Smith, H. R. and Piper, D. E., Stress corrosion cracking in high strength steels and in titanium and aluminum alloys, B. F. Brown, Ed., Naval Research Laboratory, Washingtion, D.C., 18 (1972) p. 17.

[3] Parkins, R., Corrosion, Vol. 32, No. 5, p. 205 (1976).

[4] Sprowls, D. O., Shumaker, M. B., and Walsh, J. D., Evaluation of stress corrosion cracking susceptibility using fracture mechanics techniques, Final Report on Contract No. NAS 8-21487, May 31, 1973. 


\section{CHAPTER 3}

\section{COPPER ALLOYS}

\section{Alloy Nomenclature}

The atomic arrangement in crystals of pure copper is face-centered cubic, and as long as this arrangement is retained in copper alloys, they are designated alpha alloys, such as alpha brass. If a brass contains more than about 35 percent zinc, grains of a second phase termed beta appear among the alpha grains. The beta phase has the atoms arranged in a body-centered cubic lattice. Brasses containing both phases are termed alpha-beta brasses. Above about 40 percent zinc the alloys consist of all beta grains and are termed beta brasses. Beta brass alloys are rare in commerce, but a few are produced in Europe.

Copper alloys are not strengthened by heat treatment, with few exceptions, notably beryllium copper. But they are commonly strengthened by cold working. Ordering reactions occur during annealing of some alloys, as will be noted, but these reactions are not used for strengthening purposes.

The term bronze was once reserved for copper alloys in which the principal alloy addition was tin, but the term has been debased to the point that its use serves little more than to exclude the nearly all-copper alloys and the nearly pure binary copperzinc alloys (brasses).

\section{Ammoniacal SCC}

Ammoniacal compounds are generally believed to be the principal service environments causing SCC in copper alloys, although these are known not to be the only ones. SCC in the copper/ammoniacal system has often been termed "season cracking" by leading authorities, but there is a lack of unanimity in defining this term by various authors and nomenclature committees. Therefore, to avoid any possible confusion, the term "ammoniacal SCC" will be used here instead, though even so it should be understood that the word "ammoniacal" is a convenience intended to include amines and all other species which can react with copper to produce the cupricammonium complex ion or perhaps structurally similar complexes.

If one learns how to avoid ammoniacal SCC, a large proportion of the practical SCC threat to copper alloys can be prevented. Not only is ammoniacal SCC a major hazard to copper alloys, but it is also the SCC system for which we have by far the most intercomparable laboratory data and field experience. We will therefore treat ammoniacal SCC as the principal topic of this chapter, thereafter treating the other alloy/environment systems which do not fit into the major group. These other systems, though they have been responsible historically for fewer SCC failures than ammoniacal SCC, can neverthe- less be extremely troublesome, as will be seen. It should be especially noted that recent studies with copper sulfate and copper nitrate solutions suggest that some of the service failures surmised to have been caused by ammonia may have been caused rather by sulfate or nitrate ions under conditions permitting the generation of concentrated copper solutions. Also some of the SCC failures occurring in the atmosphere and attributed to ammonia may have been caused instead by sulfur dioxide, oxides of nitrogen, or other contaminants, as discussed under "SCC in Other Environments" below.

\section{A. Necessary Conditions}

There are five conditions which must be met before ammoniacal SCC occurs:

(1) Water

(2) Oxygen

(3) Tensile stress

(4) Alloy of susceptible composition and structure

(5) Ammonia

Considering these in turn:

(1) Water must be present, probably in the condensed liquid state; a film of moisture on the metal surface suffices to cause cracking if other conditions are met. It appears possible that there are hygroscopic corrosion products which can produce the aqueous film believed necessary in an atmosphere well above the dew point. An example of cracking attributed to the action of deliquescent contaminants and another example attributed to a film of condensate caused by dew-point conditions will be described.

(2) Oxygen or an oxidizing agent must be present, unless there is an independent source of copper ions in solution. An example will be given illustrating how preventing access of oxygen is a practical strategy to avoid ammoniacal SCC in some situations. The higher the oxygen content of the environment the higher is the incidence of SCC (other necessary factors being supplied and kept constant), but quantitative data are lacking.

As a corollary of (1) and (2), anhydrous ammonia having neither water nor oxygen is quite compatible with copper alloys, even those which are highly susceptible to ammoniacal SCC. Under circumstances where control measures may be so lax that one cannot be certain to exclude water contamination, it is of course unwise to employ brasses which are susceptible to ammoniacal SCC. This is true of tankage fittings in highway tankers used to transport agricultural ammonia in the summer and which upon 
discharge may be purged with water in a manner creating an SCC hazard possibly causing leaks. Not only could the leaking ammonia be troublesome, but in winter these tankers are used to transport low pressure gas to utility plants, and if a cracked fitting in such a tanker should leak gas and the gas ignite, a major catastrophe could ensue. Therefore, the Department of Transportation regulations prohibit the use of copper or any of its alloys in such tankers if these metals come into contact with the lading. Note the conservatism here: As will be seen, pure copper and several of its alloys are highly resistant to ammoniacal SCC. But in the transportation industry maintenance personnel cannot be expected to know this, so one simply excludes all yellow or red structural alloys.

(3) Tensile stress must be present, and the hazardous level may be only a small fraction of the yield strength or higher depending upon the alloy and the environment. This stress may be supplied by working stress (design stress), assembly stress, cold work remaining from forming operations, or any combination of these stresses as long as their vector sum on the surface is a tensile stress of sufficient magnitude. In structures or components likely to be made of copper alloys it is seldom the design stresses which are important to cracking, but rather the stresses residual from cold forming (as by spinning, drawing, sinking, roll-forming, stamping) or fit up or assembly stresses, including especially straightening or bending of pipe or tubing. As a corollary of this generalization, thickening the structural elements is seldom effective in avoiding the cracking problem in the applications for which these alloys are commonly used. As another corollary, since castings are usually much freer from residual stresses than unannealed wrought products, they are not as frequently beset by the cracking problem as wrought products.
Two apparently similar forming methods to produce the same product may generate vastly different residual stresses. For example forming tubing by pulling it through a die without internal support (sinking) leaves vastly higher residual stresses than pulling over an internal support or mandrel (drawing).

One way to remove the hazard of SCC caused by cold work is to anneal the product, but the reader is warned that removing the cold work by annealing is no guarantee that stresses of hazardous magnitude may not be re-introduced by even minor subsequent deformation, even dropping the annealed article from the bench to the floor!

If one decides the tactic to be used to avoid SCC in a given product includes removal of cold-work stresses, he may elect to specify either a full (recrystallization) anneal or alternatively a stress-relief anneal. Achievement of full annealing can be verified by hardness measurements or (if feasible) by metallographic examination, or if the product is one whose recrystallization characteristics are well known, as for example brass condenser tubes, one may rely upon a conservative specification based on experience. If, however, one does not wish to sacrifice strength and chooses to anneal only enough for stress relief, experimentation may be needed. Table 1 gives some guidance for such stress relief treatments and illustrates the wide range of annealing temperatures which may be required. The temperatures in table 1 are typical values only. If for a given cold-worked product avoiding SCC depends critically on relief of cold-work stresses, the exact minimum annealing temperature must be found by trial, as it varies with such factors as composition, degree of cold work, and microstructure. The procedure then is to try some annealing temperature near the typical ones shown, and afterward to expose the heat treated article to see whether it will crack in the

TABLE 1. Typical stress relief annealing temperature ${ }^{\text {a }}$

\begin{tabular}{|c|c|c|c|}
\hline Alloy name & Alloy number ${ }^{\mathrm{b}}$ & Tempe & ature ${ }^{c}$ \\
\hline Commercial Bronze & $\mathrm{C} 22000$ & $400^{\circ} \mathrm{F}$ & $200^{\circ} \mathrm{C}$ \\
\hline Cartridge brass & C 26000 & 500 & 260 \\
\hline Muntz metal & C28000 & 375 & 190 \\
\hline Admiralty brass & $\mathrm{C} 44300$ & 575 & 300 \\
\hline Cupronickel (30\%) & C.71500 & 800 & 425 \\
\hline Phosphor bronze (5\%) & C51000 & 375 & 190 \\
\hline Phosphor bronze (10\%) & C52400 & 375 & 190 \\
\hline Silicon bronze $(3 \%)$ & C65500 & 700 & 370 \\
\hline Aluminum bronze $\mathrm{D}$ & C61400 & 1112 & 600 \\
\hline
\end{tabular}

a After Metals Handbook, 8th ed., Vol. 1, p. 1001, ASM, Metals Park OH, 1961

b ASTM-SAE Unified Numbering System for Metals and Alloys. The first three digits are the Copper Development Association designations for the same alloys.

"Unified Numbering System for Metals and Alloys," published by the Society of Automotive Engineers (1975) shows the metals and alloy numbers assigned through July 1975 together with common designations for the same materials.

c Suggested annealing time for Muntz metal is $1 / 2 \mathrm{~h}$; for all other alloys listed, $1 \mathrm{~h}$. 
most hazardous environment (from the point of view of SCC) to be encountered in service. Only infrequently is this most hazardous environment known; if it is not known then an arbitrary severe standard test environment must be used.

A quick test used to detect high and even moderate stresses in many copper alloys employs acidified mercurous nitrate as the environment. This test has been standardized as ASTM B154-71. In this test the article is acid-pickled to remove oxides, rinsed in running water, immersed for $30 \mathrm{~min}$ in an aqueous solution of $10 \mathrm{~g} \mathrm{Hg}_{2}\left(\mathrm{NO}_{3}\right)_{2}$ (11.4 $\mathrm{g}$ if tetrahydrate) plus $10 \mathrm{ml}$ concentrated $\mathrm{HNO}_{3}$ per liter, and examined for cracks. Note that this is not necessarily a test for susceptibility to SCC but rather a qualitative and potentially destructive test for residual stresses in copper alloys. The mercurous nitrate environment acts more rapidly than ammoniacal environments; but at low stresses the mercurous nitrate may not crack an article which cracks (albeit slowly) in a concentrated ammonia environment. Thus passing the mercurous nitrate test is no guarantee against subsequent failure in an ammoniacal environment, and this fact has caused expensive failures. In this respect the German standafd DIN-1785 is slightly more conservative than customary U. S. standards, for DIN-1785 calls for testing for residual stresses in condenser tubing by use of an ammonia atmosphere when so agreed by the manufacturer and the customer.

But note that some alloys (aluminum bronzes C61900 and C63800, and aluminum brass C68800) may, when annealed in certain temperature ranges, undergo an ordering reaction which may increase the degree of susceptibility to ammoniacal SCC even though partial stress-relief has occurred. Hence the mercurous nitrate test, which checks only for residual stress, not susceptibility, is not as conservative a test for these alloys as an ammoniacal test.

Note also that an article such as a condenser tube may be adequately annealed or stress relieved only to have stresses of dangerous level re-introduced by straightening, denting, cutting and deburring, or improper installation. For these reasons conservative practice does not rely solely on annealing to avoid SCC.

Unfortunately to verify adequate annealing for stress relief there is no practical alternative to potentially destructive tests, though one may elect to over-anneal and thereby soften the alloy enough that hardness or microstructure can be used as evidence of the stress relief. Conservative practice limits straightening brass tubing after final annealing to 2-plane straightening and disallows rotary straightening.

(4) An alloy of susceptible composition and structure is a fourth (and obvious) condition which must be met before ammoniacal SCC is a problem; the degree of susceptibility differs enormously among copper alloys. One measure of degree of susceptibility is the highest stress which the alloy will sustain in a specified environment without cracking. Data of this sort from a "season cracker" environment are shown in table 2 for various alloys in assorted degrees of cold work. The experiments from which this table was constructed extended to about $1,000 \mathrm{~h}$, which appears adequate to characterize a threshold stress for this system. It would be very unwise to use the stresses in table 2 as design working stresses for critical parts, but when considered together with other data and experience these stress levels provide the basis for the very useful general classification of the relative resistance of various classes of copper alloys to season cracking shown in table 3 . The purist might wish for a more quantitative presentation than is shown in table 3 , but the data are simply not available for it, nor is it certain that the quantification would be interpretable in practice since in many applications we do not know either the stress in the completed and operating structure or the environment very well. Minor impurities in a highly susceptible alloy such as cartridge brass $(30 \% \mathrm{Zn})$ have not been found to affect susceptibility. But note in table 3 that the small amount of $P$ in phosphorized copper causes this alloy to be in a distinctly more susceptible category than the phosphorus-free tough pitch copper.

Other alloys have been reported susceptible to ammoniacal SCC, but the data are not easily compared with those from which table 3 was made. These miscellaneous alloys are $\mathrm{Cu}-\mathrm{Si}-\mathrm{Mn} ; \mathrm{Cu}-\mathrm{Au}$; $\mathrm{Cu}-\mathrm{Si}$; $\mathrm{Cu}-\mathrm{Ni}-\mathrm{Si}$; $\mathrm{Cu}-\mathrm{Be}$; and $\mathrm{Cu}-\mathrm{Al}-\mathrm{Fe}$.

(5) Ammonia in some form is the fifth (and also obvious) condition necessary to cause ammoniacal SCC. There are almost unbelievably diverse and obliging sources of ammonia, including the decay of all sorts of by-products of many living organisms and the decay of the organisms themselves, electrical storms, spark discharges, some soldering fluxes $\left(\mathrm{NH}_{4} \mathrm{Cl}\right)$, and agricultural and industrial chemicals. Three examples which have caused SCC in phosphorized copper tubing used in heating systems will illustrate the diversity of ammonia sources: (a) amines used as foaming agents in foamed concrete used to insulate underground pipes, (b) latex adhesives used to lay vinyl tile on floors pierced by copper tubing, and (c) ammonia-containing agents used to clean those floors. Not only can ammonia be produced by a wide variety of reactions, but additionally there is some evidence that the ammonia so produced in dilute solution can be concentrated in corrosion pits by an unexplained process. It is not uncommon for evidence of ammonia surmised to have caused SCC to be missing at the time for analyzing a failure, which may be done long after the cracked item has been removed from the environment causing cracking and has been dried. More on this below. (ref. [4])

Organic amines and hydrazine cause copper alloys to crack (if oxygen is present), and it is sometimes implied that they do so by first decomposing to ammonia. As an alternative and more reasonable possibility, perhaps they simply perform a complexing role directly without the intermediate decomposition (ref. [5]). In any event the presence around copper alloys of any nitrogenous compound which has the 
TABLE 2. Approximate sustained tensile stress for several copper alloys in an atomsphere of $16 \% \mathrm{NH}_{3,} 4 \% \mathrm{H}_{2} \mathrm{O}$, balance air, at $35{ }^{\circ} \mathrm{C}$ a

\begin{tabular}{|c|c|c|c|c|}
\hline \multirow[b]{2}{*}{ Alloy name } & \multirow[b]{2}{*}{ Alloy number } & \multirow[b]{2}{*}{ Temper } & \multicolumn{2}{|c|}{ Stress c } \\
\hline & & & ksi & $\mathrm{MNm}^{-2}$ \\
\hline $\mathrm{Cu}-30 \% \mathrm{Ni}$ & C71500 & $70 \%$ reduction & 85 & 585 \\
\hline Silnic bronze & C64700 & $75 \%$ reduction, aged & 80 & 550 \\
\hline $\mathrm{Cu}-30 \% \mathrm{Ni}$ & C71500 & Annealed & 60 & 410 \\
\hline High silicon bronze & C65500 & ${ }^{b} 6$ hard & 50 & 345 \\
\hline Commercial bronze $(10 \% \mathrm{Zn})$ & $\mathrm{C} 22000$ & 4 hard & 40 & 275 \\
\hline Electrolytic tough pitch copper & $\mathrm{C} 11000$ & Annealed & 35 & 240 \\
\hline Low brass $(20 \% \mathrm{Zn})$ & $\mathrm{C} 24000$ & 4 hard & 35 & 240 \\
\hline Silnic bronze & C64700 & Solution treated, aged & 20 & 140 \\
\hline High silicon bronze & C65500 & Annealed & 20 & 140 \\
\hline Admirality brass & - & Annealed & 10 & 70 \\
\hline Commercial bronze $(10 \% \mathrm{Zn})$ & $\mathrm{C} 22000$ & Annealed & 10 & 70 \\
\hline Low brass $(20 \% \mathrm{Zn})$ & $\mathrm{C} 24000$ & Annealed & 10 & 70 \\
\hline Antimonial Admiralty brass & $\mathrm{C} 44400$ & 2 hard or annealed & 5 & 35 \\
\hline Low silicon bronze & C65100 & Annealed & 5 & 35 \\
\hline Cartridge brass & C26000 & Annealed or cold worked & $<5$ & $<35$ \\
\hline Muntz metal & $\mathrm{C} 28000$ & Annealed or cold worked & $<5$ & $<35$ \\
\hline Admiralty brass & - & 6 hard & $<5$ & $<35$ \\
\hline
\end{tabular}

After Whittaker (1), quoting data of Thompson and Tracy (2).

b "6 hard" etc.: An arbitrary copper industry scale of hardness due to cold work ranging from 1 hard (approx. Rockwell B68) to 8 hard (about B97).

c These stresses are not to be used in design. See text.

TABLE 3. Relative susceptibility of copper alloys to ammoniacal $S C C^{\text {a }}$

\begin{tabular}{|c|c|}
\hline Very low susceptibility: & $\begin{array}{l}\text { Cupronickels, }{ }^{b} \text { tough pitch cop- } \\
\text { per, silicon bronze }{ }^{c}\end{array}$ \\
\hline Low susceptibility: & Phosphorized copper \\
\hline Intermediate susceptibility: & $\begin{array}{l}\text { Brasses containing less than } 20 \% \\
\mathrm{Zn} \text {, such as red brass, commer- } \\
\text { cial bronze, aluminum bronze, } \\
\text { nickel silver, phosphor bronze, } \\
\text { and gilding metal. }\end{array}$ \\
\hline High susceptibility: & $\begin{array}{l}\text { Brass containing over } 20 \% \mathrm{Zn} \text {, } \\
\text { with or without small amounts of } \\
\mathrm{Pb}, \mathrm{Sn}, \mathrm{Mn} \text {, or Al (such as } \\
\text { leaded brass, Naval brass, Ad- } \\
\text { miralty brass, manganese } \\
\text { bronze, or aluminum brass). } \\
\text { The higher the } \mathrm{Zn} \text {, the higher } \\
\text { the susceptibility. }\end{array}$ \\
\hline
\end{tabular}

a After Thompson (3).

b For lowest susceptibility, the iron in 90-10 cupronickel should be solutionized.

c But note that this alloy is highly susceptible to SCC in high temperature steam. capability of forming complexes resembling the cupric-ammonium complex should be considered as potentially causative of SCC as ammonia, unless proven otherwise.

The effect of ammonia concentrations on cracking kinetics in various alloys is not known quantitatively. There is a recent adopted ASTM Standard Recommended Practice for ammoniacal SCC tests at one constant ammonia concentration, designated ASTM $\mathrm{G} 37-73$, but this test is valid for binary $\mathrm{Cu}-\mathrm{Zn}$ alloys only. It is being modified to include $\mathrm{Cu}-\mathrm{Ni}-\mathrm{Zn}$ alloys (nickel silvers).

Even if all five of the above conditions are met, and if among these, stress, susceptibility, and ammonia concentration are at or near maximum hazardous levels, ammoniacal SCC doesn't necessarily occur immediately. There is a finite period available to take preventive measures, although there are no quantitative rules available to fix the length of the grace period. An example will be cited, 
however, which will permit deducing something about the length of this period for one set of conditions.

The presence of $\mathrm{CO}_{2}$ is not a necessary condition for cracking, but it is observed to speed up the process markedly. Corrosion pits or other stress intensifiers also do not seem to be necessary conditions for initiating ammoniacal SCC, but some service experience suggests that plug type dezincification may speed up the initiation. Corosion pits may also act as ammonia concentrators and/or concentrators of other chemical species.

\section{B. Case histories and other illustrations of principles}

(1) A case of liquid attributed to deliquescence. Springs used in central office telephone equipment w.ere made of highly cold worked nickel silver (nickel brass) (C75700) and installed in a nominally dry space with provision for air cooling from the outside atmosphere. (ref. [6]) Some of the springs ultimately failed by SCC. Let us check out our five necessary conditions: Water was not expected to be present, at least in the condensed phase, but atmospheric oxygen, high stress, and at least intermediate susceptibility were present, and one might assume the possibility of ammonia unless conditions were such as to afford confidence of its exclusion. The problem was to explain how, in air of low humidity, the moisture requirement was met. Careful examination revealed the presence of particles of airborne solids, including nitrates, which could deliquesce in air having a relative humidity as low as 55 percent. As a result of laboratory tests with these solids, the condensate so produced on the brass surface from air of low humidity was concluded to account for the cracking observed in service. Incidentally the airborne nitrate turned out to be ammonium nitrate which is used as a fertilizer.

The tactic chosen to control the problem was to switch to a less susceptible alloy, cupronickel. High stress and the same environment including presumably the same ammonia source were still present, but substituting an alloy two categories lower in susceptibility was found to afford the necessary security. One might postulate alternative measures such as filtering out the airborne particles, or zinc coating, about which more below.

This case illustrates an important concept: that with water and oxygen requirements met, the probability of cracking is a function of the joint action of the stress, susceptibility, and ammonia concentration. This extremely important practical relationship is not quantifiable by existing data, and one is reduced to using qualitative terms. In the nickel silver instance the stress was certainly high, the susceptibility intermediate, and the ammonia concentration perhaps low (but perhaps high locally due to the reduction of nitrate to form ammonia). Lowering the susceptibility factor rather drastically by the substitution of cupronickel sufficed to avoid SCC even though the other factors remained unchanged.
(2) Annealing usually avoids the problem but in one case was not done soon enough. High-zinc brass is rolled to form the screw shells used as bases for incandescent light bulbs and plug fuses. The stresses after forming are high, the susceptibility of the material is in the highest category, and one could confidently predict that in service or in storage many of the shells would eventually encounter enough water, ammonia and oxygen to satisfy all remaining conditions for cracking. But ammoniacal SCC does not occur instantaneously, and there is usually ample time to get the cold-formed shells into an annealing furnace to remove the forming stresses. After proper annealing the stress is sufficiently low to avoid trouble.

But there was trouble in one case described by Thompson (ref. [3]): During a cold New England winter one lot of shells cold-formed in one building of a plant was trucked to another building to be annealed. If the shells had gone into the annealing furnace at once all would have been well, but this particular lot arrived in the annealing building too late on a Friday afternoon to be annealed that week, and on the following Monday morning the shells were found to be cracked by the thousands. Let us analyze this case by inventorying the necessary conditions for cracking. The stress and susceptibility were high, there was presumably at least a trace of ammonia present in the annealing building perhaps from chemical processes, and of course, atmospheric oxygen was present. But what about the requirement for moisture? The annealing building was warm, with air particularly humid from nearby pickling and cleaning operations. The cold shells at lower than room temperature undoubtedly picked up a thin film of moisture which along with even a trace of ammonia would be sufficient to complete the necessary conditions for cracking. If the lot had been warmed and dried with hot air, or even more simply if it had been left outside in the cold, dry air, the cracking would probably have been avoided. Of course, the safer procedure would have been to modify the schedule to ensure annealing immediately after forming. The incident shows us that for these conditions the time allowed to get the annealing started before cracking starts was something less than about $2 \frac{1 / 2}{2}$ days.

(3) Sometimes materials of low susceptibility crack. Phosphorized copper (C12200) is used for water pipe in great quantities. The alloy has a low susceptibility to ammoniacal SCC and in straight lengths is commonly supplied in the fully hard condition. But the stresses from cold forming might be expected to relax at least partially because of room temperature creep, and in any event the experience is that ammoniacal SCC of this material is extremely rare. The susceptibility is low, but the stresses as formed are high. There is usually adequate oxygen and moisture, and enough ammonia is produced somewhere to cause the rare failures. In one instance the cracking initiated from the outside and was attributed to ammonia produced by the decomposition of damp animal hair in felt insulation surrounding the pipe. In 
two other cases the ammonia was concluded to have been formed by microbial decomposition in cooling water. In another pair of cases involving residential piping, the stresses were attributed to straightening of coiled pipe, and the ammonia was surmised to have come from lawn fertilizer. To emphasize the rarity of the occurrence of SCC in this material, it is instructive to note that the two cases cited last were the only two failures reported out of 50,000 installations in the same area. Annealing is an obvious way to reduce the hazard if a component is sufficiently critical to justify the special treatment.

(4) Many highly susceptible alloys are used successfully. Many tube-and-shell heat exchangers are used both for main condensers and for auxiliaries in various kinds of steam power plants. These may be tubed with cupronickel, particularly in naval power plants, but for economy reasons central station power plants are largely tubed with aluminum brass or with Admiralty brass, both highly susceptible to ammoniacal SCC. Although the brass tubing is customarily supplied in the fully annealed condition and the cupronickel tubing (less susceptible) in the stress-relieved condition, when tubing is expanded to form the seal at the tube sheet dangerous stresses may be introduced in the tube if the rolling tool is allowed to extend beyond the inner edge of the tube sheet. In such circumstances the tube is expanded, and stresses are produced in the outer surface of the tube. As if this were not enough of a hazard, on the steam (shell) side ammonia may be present due to decomposition of amines sometimes used to control corrosion, or perhaps the amines may play the essential complexing role directly without need to be converted to ammonia, as indicated above. Additionally, on the water side (tube interior) there is always the possibility of ammonia being produced from decaying organic matter in the riverine, estuarine, or sea water widely used to cool the condensers. Let us see how, with stressed susceptible alloys very probably in the presence of ammonia (or adequate substitute), it is possible to control the cracking problem well enough for these alloys to be viable candidates as materials of construction.

In a well designed and well operated plant, the oxygen level on the steam side outside the airremoval section is low, low enough to effectively remove that one necessary condition for cracking in all but exceptional cases. (In the air-removal section where oxygen can be high and ammoniacal compounds are likely, alloys susceptible to SCC are avoided). On the tube side the sluicing through of the cooling water is almost always adequate to prevent the build-up of dangerous levels of ammonia, and failures originating on the water side are very rare.

Note that the practical solution is to use two partial measures, (1) the tubing is stress relieved if cupronickel or fully annealed if brass, and care is taken not to introduce too much assembly stress (difficult to avoid), and (2) the oxygen is kept low on the steam side, and the ammonia is kept low on the water side.

When the system is shut down, new hazards must be considered. On the shell side, oxygen can leak ir and, if amines or residual ammonia and water are also present, the conditions for cracking are fulfilled. On the tube side any ammonia produced by the decomposition of organic matter is no longer being diluted by incoming water, and dangerous levels of ammonia may build up. If either side is drained, there is a hazard that water and ammonia sources may remain in pocketed zones and in sagging tubes. Two strategies are available to avoid the cracking problem on each side of the condenser. If design permits, the shell side can be filled with clean deaerated water, which should minimize in-leakage of oxygen and also minimize the concentration of residual ammonia; or it can be drained, thoroughly dried, and blanketed with nitrogen for extra insurance. The tube side can likewise be filled with water and left so; or it can be drained, dried, and possibly additionally filled with nitrogen. The most hazardous lay-up situation is to allow either side to remain partially covered with water. Thorough drying is the preferred stabilizing procedure during a long lay-up.

It is a common occurrence for a completely fabricated condenser or other heat exchanger tubed with aluminum brass or Admiralty brass to be delivered to the site where a large fossil-fuel or nuclear power plant is scheduled to be build three years or even more before the plant is finally completed. The condenser already has the highly susceptible alloy condition met, frequently with stresses from tube straightening and rolling. If on the construction site rain or condensate furnishes water and the atmosphere provides the oxygen, only ammonia remains to be supplied to complete the conditions for cracking. The addition of this last remaining condition has obviously happened in a number of recent plants, for units intact at the time of shipment have been found cracked at installation a few years later. Proper packaging to exclude water and also ammonia is an obvious step to avoid this problem.

Incredible as it may seem there have been a few cases in which completed condensers were leaktested on the plant site using ammonia as the pressurizing fluid! The other four conditions were already met for cracking, and the ammonia factor was now high. Needless to say the condensers were ruined. One tube sheet was cracked completely through its 2-in thickness. (ref. [7])

Admiralty brass heat exchanger tubing is used successfully in the oil refining industry in process streams containing ammonia. It has been generally assumed that the prescence of hydrogen sulfide in these streams contributes an inhibiting effect on SCC. This effect may be due to the ability of hydrogen sulfide to reduce oxygen.

The conservative approach to designing a heat exchanger is to select a tubing material immune to SCC in all the environments which the component will encounter. If this approach is not feasible, one selects the best material which it is feasible to use, but does not rely entirely upon stress relieving or annealing of the unassembled tubing: The tubes are welded to the tube sheet, then rolled to fill the 
crevice between tube and tube sheet (to prevent concentration of corrodents in the crevice); then the entire exchanger is stress-relieved. (ref. [8])

(5) Household articles such as coffee urns and metal goblets sometimes illustrate the SCC phenomenon. Cold-formed articles in this category are often made of brass, plated (often one side only) with chromium or silver. They may serve intact for a long time and then exhibit rapid cracking. In some instances the onset of cracking has been definitely associated with exposures to enhance levels of ammonia, such as the unfortunate use of a cleaning compound high in ammonia, formulated for use on copper but not suited for brass. Since there is no nondestructive way to ascertain the degree of stress relief (if any) in these low-technology items, the only prudent policy is to minimize access of ammonia.

\section{SCC in Other Environments}

Industrial and marine environments. Moist air containing as little as $5 \mathrm{ppm}$ of sulfur dioxide can cause SCC (ref. [9]). It is thus not surprising that a recent extended systematic test program (ref. [10]) showed that an industrial atmosphere (New Haven, Connecticut), badly contaminated with sulfur dioxide but essentially free from ammonia, caused cracking of many alloys. By contrast only a few alloys cracked in the marine atmosphere. The findings of the program, greatly condensed, are shown in table 4. It is typical of the complexities of SCC that at high concentrations of sulfur dioxide $(>0.1 \%$ by volume in air) copper alloys do not crack, but they corrode (ref. [10]). Ammoniacal stress corrosion cracks are tarnished, whereas sulfur dioxide cracks are bright.

TABLE 4. SCC behavior of wrought alloys in industrial and marine atmospheres. ${ }^{\mathrm{a}}$

INDUSTRIAL Alloys which cracked: C26000 b, 353, 443, $672,687,688,762,766,770,782$

Alloys which did not crack, 2.2 years or longer: $110,194,195,230,405,411,422$, $425,510,521,619,638,706,725,752$

MARINE Alloys which cracked: 672, 766, 770, 782

Alloys which did not crack, 2.2 years or longer: All the alloys shown under INDUSTRIAL except these four above.

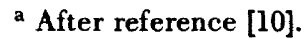

" Omitting thenceforward the prefix " $\mathrm{C}$ " and the suffix " 00 ".
}

High tensile alpha-beta brass has been used for fasteners in sea water, but because of cracking it is being replaced by either aluminum bronze or silicon bronze (ref. [9]). Manganese propeller bronze (C86100) has been observed to undergo SCC in sea water, attributed by some to biologically produced ammonia, but by some simply to water; this bronze contains both alpha and beta phases, and heat treatment plus care to keep the composition within specified limits to reduce the amount of beta has been reported effective in lowering the incidence of SCC. Cracking of bronze propellers has also been reported in some cases where cathodic protection has been applied to the hull and therefore probably to the propellers as well; perhaps this is a form of hydrogen embrittlement.

Ship propellers are usually bronze castings for which the following are the most representative alloys: manganese bronze, nickel manganese bronze, manganese nickel aluminum bronze, and nickel aluminum bronze. The nickel aluminum bronze and the manganese nickel aluminum bronze are practically immune to SCC in sea water. The other two alloys are very susceptible to SCC, and if the castings are not cooled slowly in the mold, or if they are straightened or weld-repaired, they must be stress relieved to reduce residual stresses to safe levels before the propellers are placed in service.

Stress relief temperatures, including those recommended to follow straightening, are as follows for the four alloys mentioned above (ref. [11]):

\begin{tabular}{|c|c|}
\hline Manganese bronze & $320-430^{\circ} \mathrm{C}\left(600-800^{\circ} \mathrm{F}\right)$ \\
\hline $\begin{array}{l}\text { Nickel Manganese } \\
\text { bronze }\end{array}$ & $370-430^{\circ} \mathrm{C}\left(700-800^{\circ}\right.$ \\
\hline $\begin{array}{l}\text { Nickel aluminum } \\
\text { bronze }\end{array}$ & none \\
\hline $\begin{array}{l}\text { Manganese nickel } \\
\text { aluminum bronze } \\
\text { (after major } \\
\text { straightening only) }\end{array}$ & $450-510^{\circ} \mathrm{C}(850-9$ \\
\hline
\end{tabular}

Miscellaneous environments. SCC has been observed in the field (and confirmed in the laboratory) when nitric acid fumes react with stressed brass; whether or not the ammonium ion, as a decomposition product of nitric acid, is involved does not seem to have been established. SCC has been observed in the laboratory when brasses are stressed statically in the presence of aqueous solutions of sulfate, nitrate, acetate, tartrate, or citrate which also contain copper ions. There is some evidence that oxides of nitrogen (generating ammoniacal species?), carbonates, and phosphates can cause SCC of some copper alloys.

Common aluminum bronze D (C61400) is susceptible to SCC in plain live steam. Minor additions of alloying elements, (especially about $0.2 \% \mathrm{Sn}$ ) as in a proprietary grade of the same basic bronze has been reported helpful in avoiding the problem (ref. [12]). Silicon bronze is also susceptible to cracking in steam to the extent that one authority arbitrarily places a temperature limit of $120^{\circ} \mathrm{C}\left(230{ }^{\circ} \mathrm{F}\right)$ on the steam if silicon bronze is to be used with it (ref. [9]). Sulfamic acid in the concentrations used for cleaning is capable of causing SCC in brass condenser and heat exchanger tubes (ref. [13]).

None of these miscellaneous corrodents has received anything approaching the amount of systematic study that ammonia has received. The lesson here is that if one is concerned about a fundamentally new combination of copper alloy and chemical 
If the crack path is found to be transgranular, SCC can still be the cause (fig. 3). Whether the crack path is intergranular or transgranular is a complex function of alloy composition and electrochemical factors, and few reliable simple rules are available to specify crack path choice. One such rule, however, is that in alpha-beta alloys the SCC path is intergranular between alpha grains and transgranular across beta grains; in all-beta alloys SCC is predominantly transgranular.

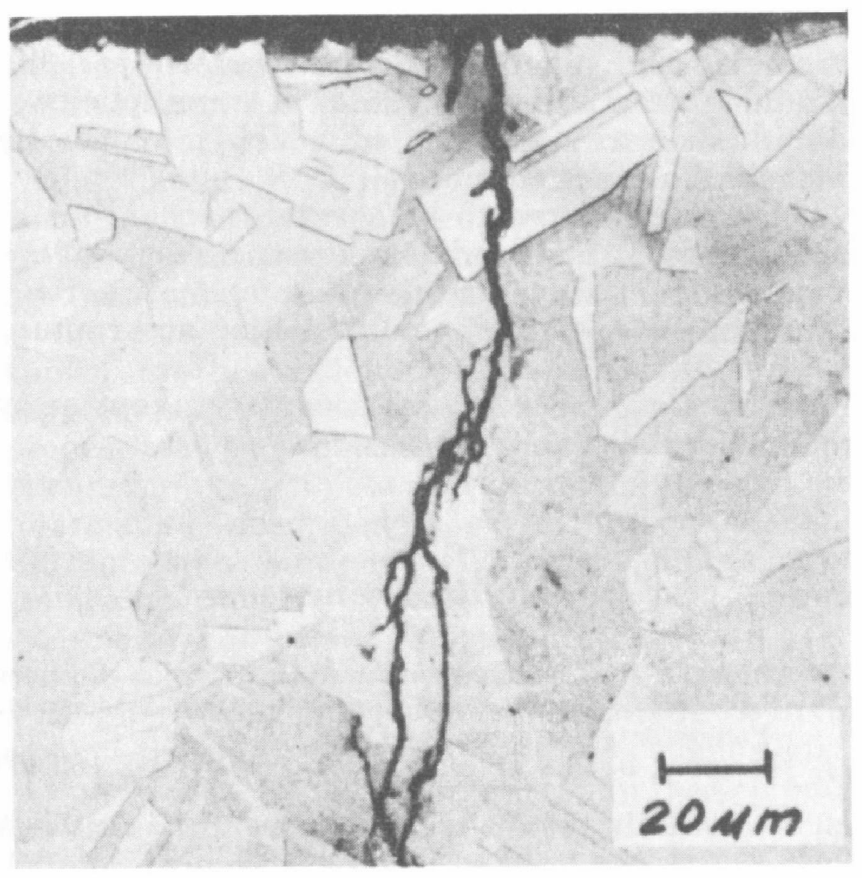

Figure 3. Transgranular stress corrosion cracking of Admiralty brass condenser tubing. Courtesy of S. D. Reynolds, Jr., and F. W. Pement, Westinghouse.

Fatigue cracks are also transgranular, whether across alpha or beta grains. Transgranular SCC usually is branched, and there is usually some change in direction when a crack crosses a grain boundary. Except for aluminum brass, transgranular SCC is usually associated with some intergranular cracking with some change in direction as a transgranular crack crosses a grain boundary. One practical rule for commencing the distinction between fatigue and SCC from optical microscopy on a polished section is as follows: If the crack is transgranular and blunt ended, it is probably not SCC but fatigue. If it is transgranular but sharp ended, look further into the failure conditions, such as the possibility of vibrations or other cause of reciprocating stress, before ruling out fatigue. Although most transgranular SCC is associated with some intergranular cracking (except for aluminum brass), fatigue cracks almost never propagate even partially along a grain boundary, and they tend not to deviate when passing from one grain to another. A definitive distinction of fatigue from SCC is available with electron fractography by which fatigue can be positively identified by its characteristic striations. Striations from plastic cross slip are sometimes seen on SCC fracture surfaces, but they lack the special features which are conclusively diagnostic of fatigue striations. In summary, in a normally ductile copper alloy a brittle crack lacking genuine fatigue striations may be diagnosed as SCC unless $\mathrm{Hg}$ (or other metal liquid at some point in the history of the part) is present indicating liquid metal cracking.

\section{Theory}

As in all other systems, SCC in copper alloys is caused by the strain induced activation of the metal in the vicinity of the crack tip and the consequent reaction of the active metal locally with the corrodent within the crack. There is considerable (though not universal) agreement about how the strain activates the corrosion process and how the consequent reaction occurs for the case of alpha brasses in the ammoniacal environments which tarnish them. The model is basically as follows: Copper in the alloy reacts first with ammonia to produce a complex ion, then the copper in the complex ion reacts with hydroxyl ions to produce cuprous oxide. The cuprous oxide grows into the metal from which the copper is derived and would stifle further reaction unless a separate process occurred. At this stage two views have been advanced to account for crack growth. One view is that the cuprous oxide film, which tends to intrude along grain boundaries, is brittle and eventually cracks to expose bare (reactive) metal at the end of the crack. A new layer of oxide forms at this point and eventually cracks also. This sequence is shown in figure 4. Another view is that the dislocation arrays in the stressed metal are blocked at barriers and that the growth of the cuprous oxide at the expense of underlying metal destroys some of the blocking action, permitting highly localized plastic flow of the metal to rupture the oxide layer and expose bare metal for the beginning of another cycle. Thus the one view is that the metal is exposed by the cracking of a brittle oxide, the other is that dislocation unlocking by corrosion permits plastic flow of the metal to punch through a (ductile) oxide film.

The chemical reactions may be written as follows (ref. [14]):

\begin{tabular}{|c|c|}
\hline $\begin{array}{l}\text { Dissolution } \\
\text { reaction: }\end{array}$ & $\begin{array}{l}\mathrm{Cu}+\mathrm{nNH}_{3}+\frac{1}{2} \mathrm{O}_{2}+\mathrm{H}_{2} \mathrm{O} \rightarrow \\
\quad \mathrm{Cu}\left(\mathrm{NH}_{3}\right)_{\mathrm{n}}^{2+}+2 \mathrm{OH}^{-}\end{array}$ \\
\hline $\begin{array}{l}\text { Cathodic } \\
\text { reaction: }\end{array}$ & $\begin{array}{l}\mathrm{Cu}\left(\mathrm{NH}_{3}\right)_{5}^{2+}+\mathrm{e} \rightarrow \mathrm{Cu}\left(\mathrm{NH}_{3}\right)_{2}^{+} \\
\quad+3 \mathrm{NH}_{3}\end{array}$ \\
\hline $\begin{array}{l}\text { Precipitation } \\
\text { reaction: }\end{array}$ & $\begin{array}{l}2 \mathrm{Cu}\left(\mathrm{NH}_{3}\right)_{2}^{+}+20 \mathrm{H}^{-} \rightarrow \mathrm{Cu}_{2} \mathrm{O}+ \\
\quad 2 \mathrm{NH}_{3}+\mathrm{H}_{2} \mathrm{O}\end{array}$ \\
\hline
\end{tabular}


environment compared with any studied in the laboratory or experienced in service, there is no adequate substitute for conducting a realistic test for compatibility.

Liquid metal cracking. Certain liquid metals cause stressed copper alloys to crack. Mechanistically this process is certainly different from SCC in aqueous solutions in at least some aspects and it is usually called liquid metal embrittlement, not SCC. But from a practical standpoint it will be treated here together with the other forms of sustained load cracking which the design and maintenance engineer must control.

Mercury $(\mathrm{Hg})$ is particularly troublesome to copper alloys, and neither metallic $\mathrm{Hg}$ nor its compounds should be permitted to contact copper alloys. Thompson illustrates the seriousness of the trouble that can be caused when this stricture is violated:

A small brass heat exchanger had been manufactured. It was vacuum tested using a $\mathrm{Hg}$ manometer to check the vacuum. A slug of $\mathrm{Hg}$ was accidentally allowed to enter the heat exchanger. This was known and the heat exchanger was opened and the $\mathrm{Hg}$ was cleaned out, presumably perfectly. The heat exchanger was one of four that were used as chillers in the air contitioning of a submarine. It was installed outboard of the keel on the lowest deck. After the vessel was completed and launched, the system was pressure tested and it was found that the chiller leaked. The only way to remove the chiller was to cut holes through every deck from the top of the submarine to the bottom, remove and replace the chiller, and repair weld all the decks. The chiller was, of course, the victim of liquid metal embrittlement from $\mathrm{Hg}$. The dire warning is never trust $\mathrm{Hg}$ in contact with any copper metal. (ref. [3])

Figure 1 shows a brass heat exchanger tube cracked by $\mathrm{Hg}$.

The difference between $\mathrm{Hg}$ cracking and ammoniacal SCC is emphasized by the experience that cupronickel, highly resistant to ammoniacal SCC, is highly susceptible to cracking by $\mathrm{Hg}$.

Molten solder, molten tin, and molten sodium have also been observed to cause cracking of stressed copper alloys.

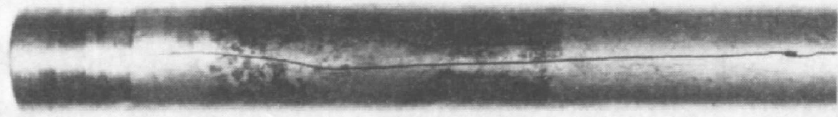

FigURE 1. Admiralty brass condenser tube failure induced by accidental exposure to mercury in a marine condenser. Courtesy of S. D. Reynolds, Jr., and F. W. Pement, Westinghouse.

\section{Miscellaneous Measures}

Coatings, of course, are not an attractive way to control the SCC problem on heat exchanger surfaces, but organic coatings have been reported useful in preventing or delaying SCC in other situations, such as phenolformaldehyde films on cartridge brass. Systematic data in the open literature are lacking. Chromium plating and nickel plating have not been found effective in the situations in which it is practical to apply them.

Metallic zinc coating has been reported to be highly effective, on the other hand. The zinc may act partly as a barrier, but there is evidence that, additionally, cathodic protection from the zinc can prevent cracking at openings in the coating. If zinc coating and cathodic protection can be proven dependable control measures, they may be found useful in many more situations than now employ them.

Benzotriazole either as a surface treatment or as an inhibitor in the environment may be useful in preventing SCC in marginal situations.

\section{Diagnosing SCC}

Even in alloys highly ductile in a tensile fracture, all stress corrosion fractures (and those produced by liquid metal cracking) are macroscopically brittle. Particularly when they are caused by complex residual stress fields from forming operations the cracks may be branched, but not necessarily so. Multiplicity of cracks, whether more or less parallel to each other or diverging, is highly indicative of SCC, but absence of multiplicity or of branching is by no means a basis for excluding SCC.

If a crack path is examined by standard optical methods and found to be intergranular (fig. 2), either SCC (including ammoniacal SCC) or liquid metal cracking can be assigned as the cause. If the cracking is caused by $\mathrm{Hg}$, it is inevitably intergranular, and there may be enough $\mathrm{Hg}$ amalgamated with the metal of the crack walls to be readily detected by standard chemical analysis. Cracking by $\mathrm{Hg}$ in metals at high temperatures, however, may leave so little $\mathrm{Hg}$ that special spectrographic trace analysis methods may be required to detect it.

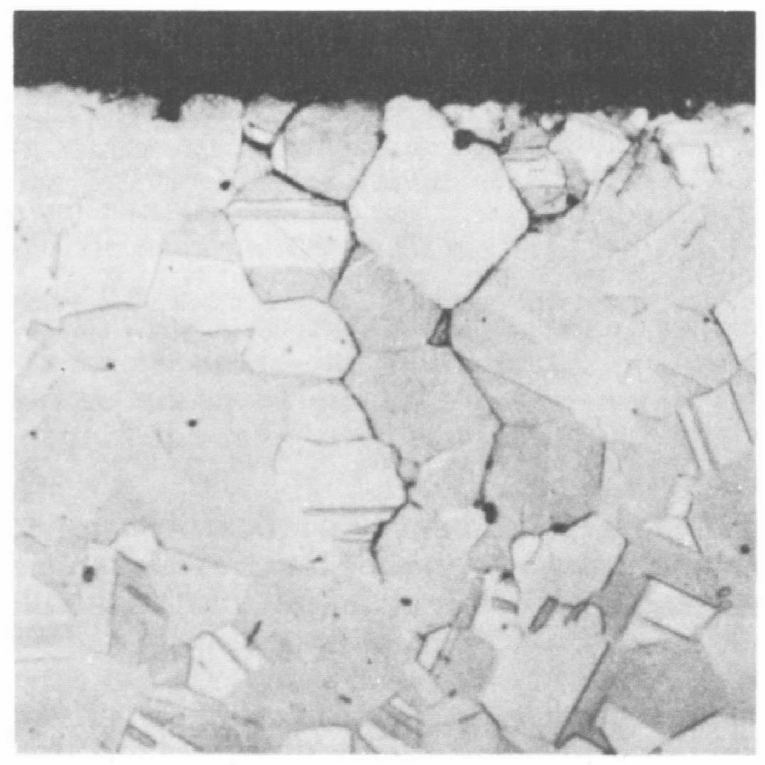

FiguRE 2. Intergranular stress corrosion cracking of Admiralty brass condenser tubing (500x). Courtesy of S. D. Reynolds, Jr., and F. W. Pement, Westinghouse. 


\section{Summary}

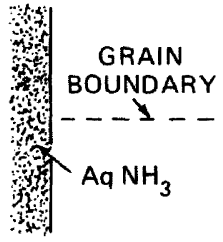

(a)

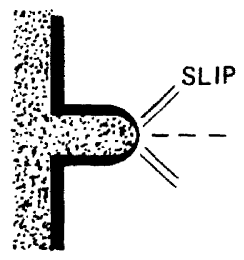

(d)

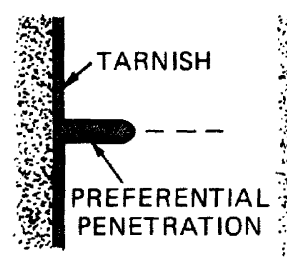

(b)

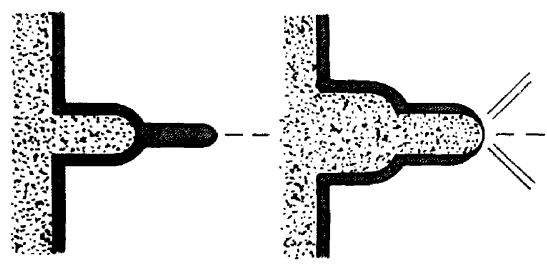

(e)
BRITTLE CRACK $--$

(f)

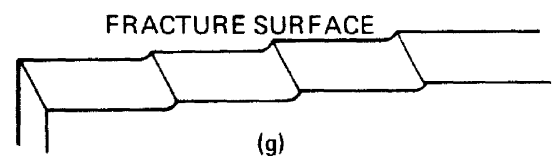

FIGURE 4. Schematic illustration of the tarnish-rupture mechanism for SCC of alpha-brass in tarnishing solutions. The tarnish is considered to grow preferentially along a grain boundary (b), until it undergoes brittle fracture (c). The crack is arrested by slip in the substrate, exposing the metal to the environment (d). Further intergranular penetration then occurs (e), leading to further limited fracture (f). Crack propagation thus proceeds by repeated cycles, the resulting fracture surface showing evidence of discontinuous fracture (g). (Pugh, ref. [14].)

We can now account for the four factors (other than inherent susceptibility) which combine to cause ammoniacal SCC: The ammonia is required to take up the copper as a solution complex; the oxygen generates the hydroxyl ions which precipitate the cuprous oxide, and additionally oxygen is observed to be required to dissolve copper initially; the water serves both as a solvent for the copper ammonium complex and is recycled between the dissolution reaction and the precipitation reaction; and the stress serves to bare metal by either cracking the oxide film or by causing the metal to flow through the film plastically, reinitiating the cycle of film growth and rupture. Recent observations have suggested that this theory may require modification.

The theory of SCC by other mechanisms has not been worked out to the point of general acceptance and will not be included here. Readers interested in this aspect will find reference [14] a useful starting point.
Most service failures by SCC in copper alloys are caused by the conjoint action of five factors, (1) water, (2) oxygen, (3) tensile stress, (4) alloy composition and structure, and (5) ammonia or perhaps alternatively ammonia-like complexing agents. Sulfur dioxide can also be responsible for SCC in industrial atmospheres.

Alloys have been classified in four categories of susceptibility. Examples have been given illustrating the roles of each of the five factors.

Although in principle one might think to avoid SCC in a given case by decisively controlling one of these five factors, uncertainties about the precise nature of the environment and about the stress in assembled and functioning components in real life situations often lead to a strategy of a multiplicity of control measures any one of which may not be amenable to exact control.

There are believed to be several mechanisms of SCC depending upon environment and alloy, but the model widely believed responsible for most service failures involves the periodic formation and rupture of a film of $\mathrm{Cu}_{2} \mathrm{O}$.

Mercury and its compounds must be kept away from copper alloys at all costs.

\section{References}

[1] Whittaker, J. A., A survey on the stress corrosion of copper based alloys, International Copper Research Association, Potters Bar, Herts., England (1966).

[2] Thompson, D. H. and Tracy, A. W., Trans. AIME 185100 (1949).

[3] Thompson, D. H., Stress corrosion cracking of metals-A state of the art, (H. Lee Craig, Jr., Ed.), STP 518, Am. Soc.-Testing Mat., Philadelphia (1972), p. 39.

[4] Popplewell, J. M., private communication, 1974

[5] Foley, R. T., private communication, 1974.

[6] Schick, G., Manual of Industrial Corrosion Standards and Control, STP 534 (F. A. Cocks, ed.) Am. Soc. Testing Mat., Philadelphia (1973), p. 107.

[7] Thompson, D. H., personal communication, 1974.

[8] Dillon, C. P., private communication, 1975.

[9] Cotton, J. B., private communication, 1974.

[10] Popplewell, J.M. and Gearing, T. V., Corrosion, 31, No. 8, p. 279 (1975).

[11] Anon., Guidance Manual for Making Bronze Propeller Repairs, American Bureau of Shipping, New York, (1972).

[12] Dillion, C. P., Mater. Performance, 13, No. 2,49 (1974).

[13] Presley, Maurice, Proc. of the 18th Annual Water Conference, p. 79 (1957).

[14] Pugh, E. N., The theory of stress corrosion cracking in alloys (J. D. Scully, ed.) NATO, Brussels, 418 (1971), (Available from the editor at The University, Leeds LS 2 9JT). 


\section{CHAPTER 4}

\section{ALUMINUM ALLOYS}

There are many commercial aluminum alloys having a wide variety of composition, but all of them are predominantly face-centered cubic in structure. There may be particles of other phases present, including impurity phases, but the matrix of all alloys is face-centered cubic.

Aluminum alloys may be strengthened by cold work (strain hardening). However, the highest strength alloys are strengthened by heat treatment. This consists of first heating to dissovle one or more elements, rapidly cooling the alloy to retain these solute elements in solution (solution heat treatment), then producing controlled precipitation either by "aging" naturally at room temperature or by artificial aging at slightly elevated temperature (precipitation heat treatment). This heat treatment is termed age hardening or precipitation hardening, and it is the only process for strengthening metals not known to the ancients. Age hardening may be supplemented by cold work. The artificial aging process may be deliberately carried past the point of maximum strength to ensure stability, and the treatment is described as overaging or stabilizing. Certain strain hardened alloys may also be given stabilizing anneals. These straining and thermal treatments are termed "tempers."

The Aluminum Association system for alloy designation is the one in common use in the U. S. In this system the basic composition of a wrought alloy is indicated by a four-digit number, and the temper is designated by an appended letter, usually plus one or more numbers according to an arbitrary code. Thus the letter $\mathrm{O}$ in the alloy designation 2024-O indicated that that particular alloy is in the annealed condition, 5456-H32 indicated another specific alloy in a specified strain-hardened temper, and 7075-T6 indicates still another alloy which has been age hardened in a specific manner. The key to these compositions and tempers may be found in reference [1]. Cast alloys have their own special system for composition designation but have the same temper designation system as wrought alloys. The number of commercial alloys and tempers in increasing at an appreciable rate, and the reader may find it necessary to consult one of the major aluminum producers for alloy information not found in the standard handbooks. In the Unified Numbering System for Metals and Alloys, the Aluminum Association system has been retained. For the wrought alloys the AA number is preceded by A9, so that AA7075 becomes UNS A97075. For cast alloys the letter if any is replaced by a number representing its alphabetical position, and the decimal point is dropped. Thus AA 705.1 becomes UNS A07051, AA B358.2 becomes UNS A23582, etc. The Unified Numbering System for aluminum alloys is too new to have gotten into the literature.

\section{Necessary Conditions for SCC}

Most of the SCC service failures in aluminum alloys occur because of water, water vapor, or aqueous solutions. Except for the cracking described in the sections on liquid metals and other nonaqueous environments, then, SCC in this chapter is to be understood to be aqueous SCC. Other constituents of the environment such as salts and acid fumes may profoundly affect the kinetics, as will be discussed below, but in most instances water is the essential cracking ingredient in service failures. The necessary conditions for SCC in aluminum alloys are as follows:

1. Water, aqueous solutions, or atmospheric moisture

2. Alloy of susceptible composition and structure

3 . Sustained tensile stress

In a subsequent section we will consider those factors affecting kinetics which are important to the strategy of controlling SCC in various engineering situations, but let us first consider these three necessary conditions in detail.

(1) Water. Cracking is observed not only in liquid water and aqueous solutions, but also in air and inert gases at relative humidity levels as low as 1 percent. At such low humidities corrosion products are unlikely to produce liquid solutions by deliquescence, therefore water in the liquid state is not considered a necessary condition for cracking. Oxygen is likewise not needed. Water in the liquid state causes more rapid cracking than does water vapor, and therefore one of the strategies used to mitigate SCC in aluminum structures for atmospheric service such as aircraft is to design so that water will not accumulate and stand in pockets and crevices. Not only is liquid water more aggressive than the usual atmospheric humidity, but also undrained pockets may collect salts which concentrate during evaporation and further accelerate SCC. Therefore, although unnecessary machining of heat treated aluminum parts is discouraged (see section on Stress below), in some unfortunately designed structures some engineers would prefer to drill holes to provide drainage rather than to allow water to accumulate. One model of aircraft was so entensively drilled for this reason that it was dubbed the "flying sieve," but the tactic paid off.

The annular space between the end of an aircraft hydraulic tube and an aluminum connector fitting is an example of an area from which water must be excluded. Not only can water collect in that crevice and accelerate SCC of the high strength fitting if other necessary conditions are met, but also the 
water tends to generate bulky corrosion products in the confined space, stressing the fitting in tension and causing SCC; hence, the military specification requires sealing such space by soldering, brazing, or filling with an organic sealant.

The essential function which most paints perform in mitigating SCC of aluminum alloys is one of restricting access of water to the metal surface. Good quality paint systems are helpful in this respect even though none of them totally excludes moisture; they should always be considered one of the possible supplemental measures in an SCC control plan even though such a measure operates only on a kinetic factor and even though they may lose their effectiveness where damaged. Anodized films, which may be specified for resistance to abrasion or wear or for improved paint adhesion, are of little or no direct benefit in mitigating SCC, and may even slightly promote it.

Further remarks on coatings are included in the sections on "Kinetic Factors," "Inhibitors" and "An Example of Applying the Principles to Avoid the Problem."

(2) Alloy susceptibility. The relative susceptibilities of the various alloys and of individual alloys having various tempers (heat treatments and/or mechanical treatments) may vary widely. Members of the wrought 2000 -series and 7000 -series are particularly vulnerable in some tempers, as are some of the more highly alloyed 5000 -series in some strainhardened tempers. When these alloys are extruded, rolled, forged or drawn, the grains are elongated in the direction of maximum flow to produce a grain structure or texture which is of major importance to the SCC behavior of these alloys, as the crack path is invariably intergranular. The longest grain axis is designated the longitudinal direction, and fracture properties (including SCC) determined by stressing parallel to this longest dimension are designated "longitudinal" properties, even though the fracture propagates at least nominally in a transverse direction. Correspondingly the direction in which the grain dimension is shortest is designated the short transverse, and the direction of intermediate grain dimension is designated the long transverse direction.

The directionality (anisotropy) of wrought aluminum alloy products is so important to SCC that the ASTM code for describing both the orientation of the fracture plane with respect to texture and the direction of propagation on that plane should be learned. These designations are both precise and brief, and they are expected to be in increasing usage in the literature in the years ahead. This code employs two letters, the first of which indicates the stress axis and the second letter the direction of propagation. For long plates the letters are $\mathrm{L}$ for longitudinal, $\mathrm{S}$ for short transverse, and $\mathrm{T}$ for transverse (fig. 1). ${ }^{1}$ If one has not a plate but an extruded

\footnotetext{
${ }^{1}$ An earlier ASTM code used the letters $R$ (for rolling direction), W (for width) and T (for thickness) rather than the currect $\mathrm{L}, \mathrm{T}$ and $\mathrm{S}$. The crack orientation now given as S-L (note the hyphen) was given in older biterature as TR (without the hyphen). A T-L orientation was formerly written as WR.
}

or drawn cylinder, modified designations are required, C for circumferential and $\mathrm{R}$ for radial (fig. 2).

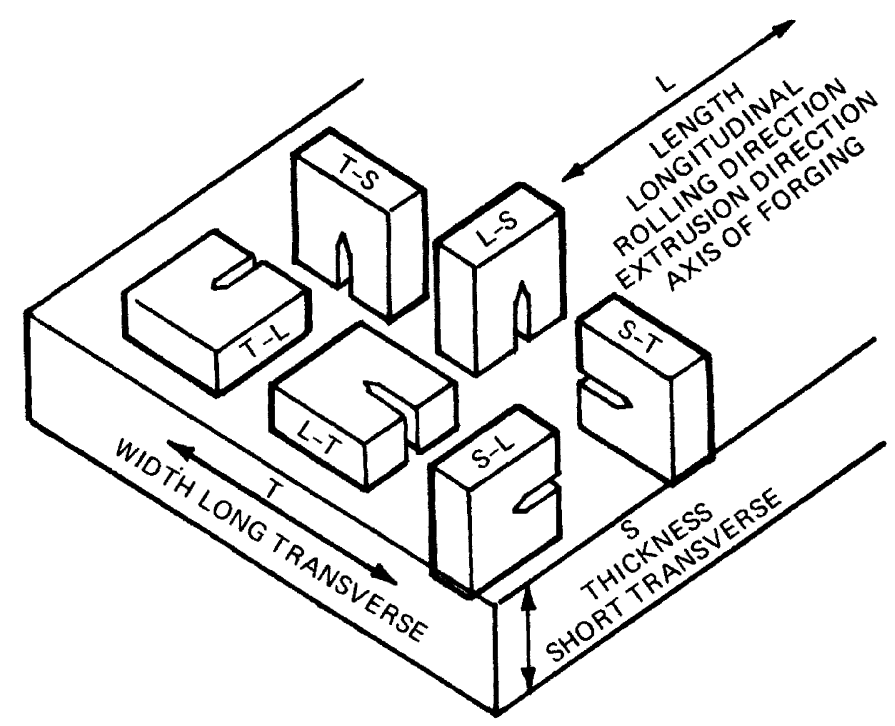

FIGURE 1. Crack plane orientation identification code for rolled plate (ref. [2].)

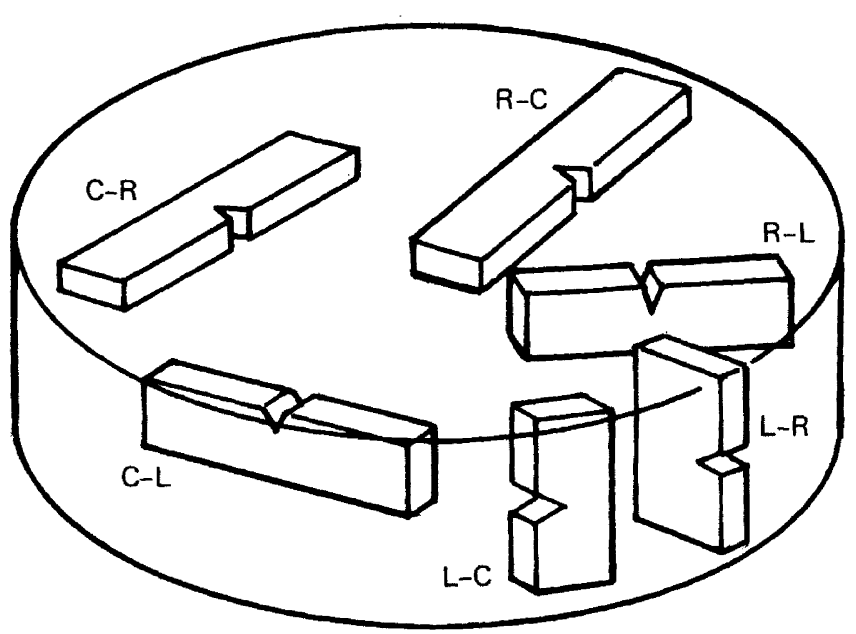

FIGURE 2. Crack plane orientation identification code for drawn bars (ref. [2].)

It is of course the grain geometry rather than the product geometry (the external geometry of the piece) which is important to the relative susceptibility to SCC in various directions with respect to grain texture, and L, T and S may be thought of in terms of grain shape rather than product shape. This concept becomes important in complicated forgings in which external shape may give no clue to internal texture, which may have to be determined by etching a section if it cannot be inferred from knowledge of forging practice. 
Practically all service SCC failures in aluminum alloy components involve the short transverse properties, and the fractures would be designated S-L or S-T. A few service failures are T-L or T-S fractures. Longitudinal (L-T or L-S) SCC cracks are essentially unknown in practice. Figure 3 shows a cylindrical landing gear forging which failed by SCC. Examination of an etched section of the forging would disclose that the failure is in the forging parting plane or "flash line." The grain texture on this plane is roughly equivalent to that of the short transverse direction of a rolled plate, that is, having the poorest resistance of SCC of any planes in the piece.

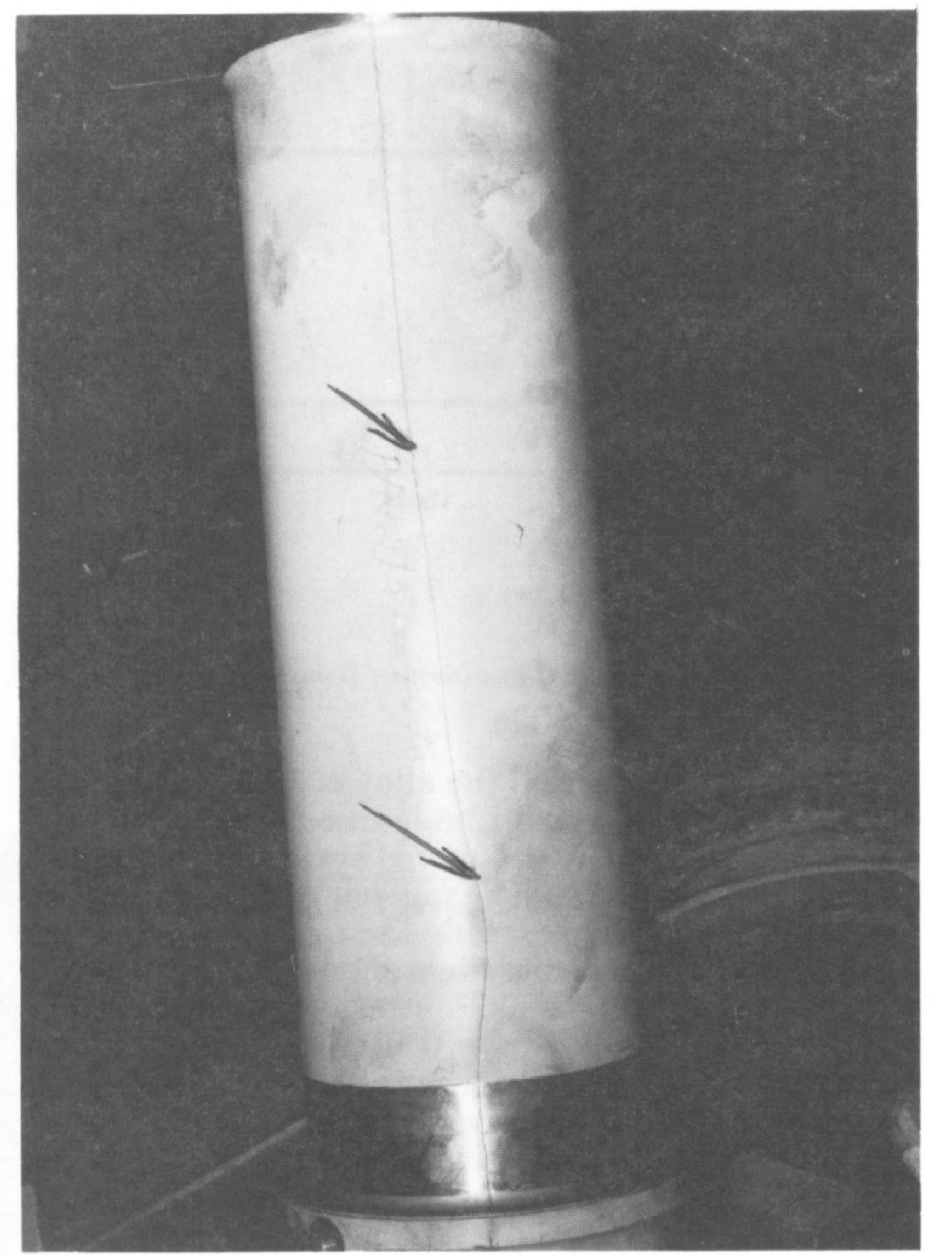

FIGURE 3. Stress corrosion crack in a nose landing gear assembly. Cylinder is made of 7075-T6. After the stress corrosion crack had propagated about $33 / 4$ in the remainder of the cylinder split by brittle fracture. Heat treatment to the $-\mathrm{T} 73$ temper would greatly reduce the probability of failures such as this. Photo courtesy of S. J. Ketcham.

The relative susceptibility of different alloys and of the same alloy in various tempers is currently being assessed in two basically different ways. One method employs smooth specimens which may be of various shapes. These are placed under sustained stresses of various levels, exposed to selected environments, and the total time for a specimen to crack is observed. Maximum exposure times in laboratory tests for specimens which do not crack are typically a few months. Data from experiments with one alloy in three orientations with respect to the texture are shown in figure 4. Two important features are apparent in this figure: First that there appears to be a threshold stress, designated $\sigma_{t h}$, below which SCC appears not to initiate; and second, that the $\sigma_{t h}$ for the longitudinal direction is much higher than for the short transverse direction. Because it is the short transverse cracking which constitutes the bulk of service SCC problems, the $\sigma_{t h}$ values for this orientation form the principal basis for ranking alloys and tempers according to susceptibility.

The only formally standardized environment for conducting susceptibility tests for aluminum alloys is the 3.5 percent solution of sodium chloride in water specified in FED-STD ASTM G44-75. This method calls for repeated cycles of immersion for 10 $\mathrm{min}$ in the salt water followed by drying $50 \mathrm{~min}$ in air (described as "alternate immersion"). This environment and test procedure have been adopted in MIL-STD 1568 which calls for an exposure of 2000 cycles. Such laboratory tests are backed up with correlative tests in natural environments such as seacoast and industrial atmospheres.

Some typical $\sigma_{t h}$ data from alternate immersion tests are shown in table 1 , together with yield strengths.

A second and fundamentally different method to rate the relative susceptibility of alloys and tempers is to pre-crack fracture mechanics type specimens and measure the plateau crack growth rate (Region II, fig. 5, ch. 2); the apparent $K_{I s c c}$ can also be used to rank alloys, but at the present time there is some uncertainty whether there is an absolute threshold $K$ below which SCC will not occur on some aluminum alloys, many plots of $K$ versus crack growth rate show no clear sign of such a threshold. As with smooth specimens there is no formally standardized environment for ranking the relative susceptibilities of aluminum alloys using fracture mechanics specimens, but aqueous 3.5 percent sodium chloride has been used extensively. A more complex corrodent the composition of which is shown in figure 5 is also in current use. Some typical plateau and apparent $K_{I s c c}$ values for several alloys may be observed in figure 5 .

$\sigma_{t h}$ values such as those in table 1, plateau velocities and apparent $K_{I s c c}$ data, together with service experience, form the basis for arranging alloys and tempers in four arbitrary categories of relative susceptibility, as follows (after refs. [5, 6]):

(a) Very low susceptibility: No known instance of SCC in service or in standard laboratory tests.

(b) Low susceptibility: No known instance of SCC in service; cracking in standard tests only at high stress (intensity) levels.

(c) Moderate susceptibility: No known SCC in service. SCC not anticipated in service due to short transverse tensile stress caused by heat treating and quenching, or from design or assembly stress providing these are kept below 40-50 percent of the guaranteed minimum yield strength. Higher sustained tensile stress from any source must be avoided. 


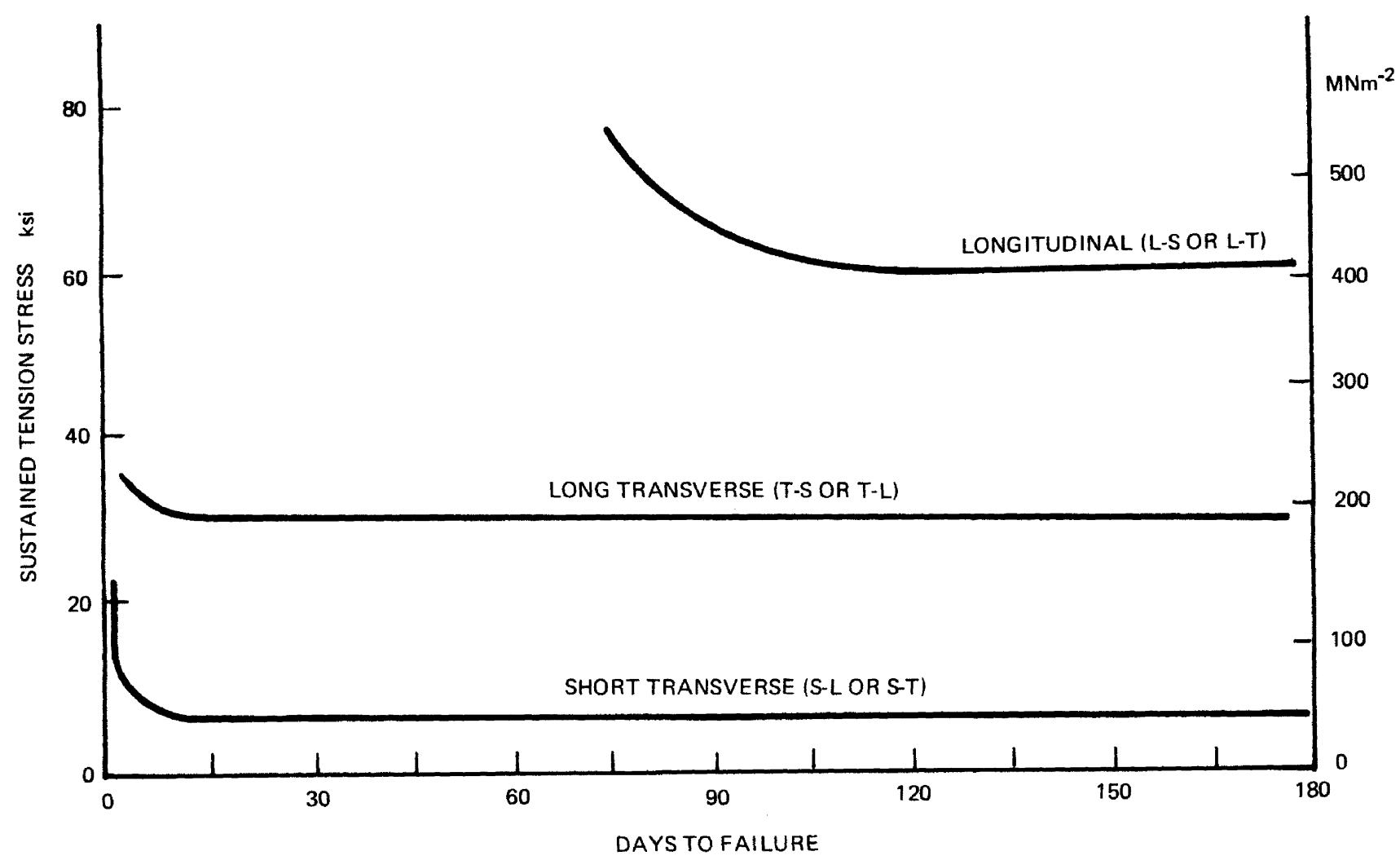

FIGURE 4. Effect of orientation of 7075-T6 extruded section of a given thickness on resistance to SCC by alternate immersion in 3.5\% NaCl solution (lower bound data, after ref. [3]).

(d) Appreciable susceptibility: Appreciable SCC in service; avoidance of SCC requires sophisticated use of several control measures, such as protection of the end-grain texture from aqueous environments, peening, and cathodic protection. SCC not likely if tensile stress is only longitudinal to the grain direction.

It is possible to characterize the categories chosen above somewhat quantitatively, as shown in table 2 . It is not now clear whether plateau velocities will afford a positive measure of SCC characteristics, but they are included here for possible usefulness in comparing with plateau values (rapidly obtainable) for future alloys and tempers.

Using these categories, the relative susceptibilities of various wrought alloys are shown in table 3 , and those of cast alloys are shown in table 4 .

(3) The tensile stress which causes SCC in aluminum alloys may be provided by working stress (design stress), but a large majority of service failures are caused by assembly stresses, or heat treating stresses, or both.

Considering first the assembly stresses, the sketch of figure 6 shows how a component, machined in such a way as to expose the vulnerable short transverse texture (or end grain), is assembled by bolting to a rigid member with a slight angular mismatch, so that there is sustained high tensile stress across the short transverse texture, a sure-fire recipe for SCC failure if the alloy is susceptible. The lesson of figure 6 should be learned thoroughly, for the principles apply to many seemingly different situations. For example hexagonal coupling nuts are often machined from extruded or rolled bar stock. In service such a nut, when tightened, experiences circumferential (hoop) tensile stresses, and these are across the vulnerable short transverse texture of the extruded material. When made of alloy 2024-T4, which is appreciably susceptible to SCC, these nuts fail by SCC from atmospheric moisture. When the material specification is shifted to 6061-T6, which has very low susceptibility to SCC, the problem is eliminated, even though qualitatively both alloys have the same fabrication texture. (As a precautionary measure, however, Naval aircraft practice prohibits use of $n$ ats machined from extruded rod regardless of alloy.) Figure 7 shows an SCC failure in an extruded tube of 7075-T651, with the failure originating at a hole which in service contained a tapered pin fastener. Note that once again this design causes sustained stresses (from the tapered pin) across the vulnerable short transverse texture of the extrusion. The use of forced-fit inserts such as the tapered pin or bearings in aluminum alloys susceptible to SCC is unwise, and when such designs must be used, conservative practice dictates that the alloy and temper be in the "low" or "very low" category as these terms are used in table 3. 
TABLE 1. Comparison of the resistance to stress corrosion of various aluminum alloys and products (ref. [4], change no. 2)

Estimate of highest sustained tension stress $(\mathrm{ksi})^{\mathrm{e}}$ at which test specimens of different orientations to the the $3.5 \% \mathrm{NaCl}$ alternate immersion test in 84 days ${ }^{f}$ (not for specimens of different orientations to the grain structure would not fail in

\begin{tabular}{|c|c|c|c|c|c|c|}
\hline $\begin{array}{l}\text { Alloy and } \\
\text { Type of } \\
\text { Temper }\end{array}$ & $\begin{array}{c}\text { Test } \\
\text { Direction }\end{array}$ & Plate & $\begin{array}{c}\text { Rolled Rod } \\
\text { and Bar }\end{array}$ & $\begin{array}{c}\text { Extruded Shapes } \\
\text { Section Thickness, } \\
0.25-1 \\
\end{array}$ & $\begin{array}{l}\text { Inch } \\
>1-2 \\
\end{array}$ & $\begin{array}{c}\text { Hand } \\
\text { Forgings }\end{array}$ \\
\hline 2014-T6 & $\begin{array}{l}\text { L } \\
\text { LT } \\
\text { ST }\end{array}$ & $\begin{array}{l}45 \\
30 \\
\text { a } 8\end{array}$ & $\begin{array}{r}45 \\
\ddot{15}\end{array}$ & $\begin{array}{l}50 \\
27 \\
\cdots\end{array}$ & $\begin{array}{l}45 \\
22 \\
8\end{array}$ & $\begin{array}{l}30 \\
25 \\
{ }^{9} 8\end{array}$ \\
\hline 2219-Т8 & $\begin{array}{l}\text { L } \\
\text { LT }\end{array}$ & $\begin{array}{l}\text { c } 40 \\
{ }^{c} 38 \\
{ }^{c} 38\end{array}$ & $\begin{array}{l}\ldots \\
\ldots \\
\ldots\end{array}$ & $\begin{array}{l}\text { c } 35 \\
\text { c } 35 \\
\quad .\end{array}$ & $\begin{array}{l}\text { ' } 35 \\
\text { c } 35 \\
\text { ' } 35\end{array}$ & $\begin{array}{l}38 \\
338 \\
\text { c } 38\end{array}$ \\
\hline 2024-T3, T4 & $\begin{array}{l}\text { L } \\
\text { LT } \\
\text { ST }\end{array}$ & $\begin{array}{l}35 \\
20 \\
\text { a } 8\end{array}$ & $\begin{array}{r}30 \\
\mathrm{~b} 10\end{array}$ & $\begin{array}{r}{ }^{c} 50 \\
37 \\
\cdots\end{array}$ & $\begin{array}{r}c 50 \\
18 \\
{ }^{c} 8\end{array}$ & $\begin{array}{l}\cdots \\
\cdots \\
\cdots\end{array}$ \\
\hline 2024-T8 & $\begin{array}{l}\text { L } \\
\text { LT } \\
\text { ST }\end{array}$ & $\begin{array}{l}\text { c } 50 \\
\text { c } 50 \\
30\end{array}$ & $\begin{array}{r}\text { c } 47 \\
\text { b } 43\end{array}$ & $\begin{array}{r}{ }^{c} 60 \\
50 \\
\cdots\end{array}$ & $\begin{array}{r}c 60 \\
50 \\
\text { c } 45\end{array}$ & $\begin{array}{r}\text { c } 43 \\
43 \\
15\end{array}$ \\
\hline 7075-T6 & $\begin{array}{l}\text { L } \\
\text { LT } \\
\text { ST }\end{array}$ & $\begin{array}{l}50 \\
45 \\
\mathrm{a} 8\end{array}$ & $\begin{array}{r}50 \\
\text { b } 15\end{array}$ & $\begin{array}{l}60 \\
50 \\
\ldots\end{array}$ & $\begin{array}{l}60 \\
32 \\
\mathbf{a} 8\end{array}$ & $\begin{array}{l}35 \\
25 \\
\text { a } 8\end{array}$ \\
\hline 7075-T76 & $\begin{array}{l}\text { L } \\
\text { LT }\end{array}$ & $\begin{array}{r}\text { c } 49 \\
\text { c } 49 \\
25\end{array}$ & $\begin{array}{l}\ldots \\
\cdots \\
\cdots\end{array}$ & $\begin{array}{r}{ }^{c} 52 \\
\text { c } 49 \\
25\end{array}$ & $\begin{array}{l}\ldots \\
\cdots \\
\ldots\end{array}$ & $\begin{array}{l}\cdots \\
\cdots \\
\cdots\end{array}$ \\
\hline 7075-T73 & $\begin{array}{l}\text { L } \\
\text { LT } \\
\text { ST }\end{array}$ & $\begin{array}{r}\text { c } 50 \\
\text { c } 48 \\
c, d 43\end{array}$ & $\begin{array}{r}50 \\
48 \\
\mathrm{c,d} \\
43\end{array}$ & $\begin{array}{r}54 \\
48 \\
\text { c } 46\end{array}$ & $\begin{array}{r}c 53 \\
c 48 \\
c, d 46\end{array}$ & $\begin{array}{r}{ }^{c} 50 \\
c 48 \\
c, d 43\end{array}$ \\
\hline 7079-T6 & $\begin{array}{l}\text { L } \\
\text { LT } \\
\text { ST }\end{array}$ & $\begin{array}{r}\text { c } 55 \\
40 \\
\text { a } 8\end{array}$ & $\begin{array}{l}. . \\
. \\
.\end{array}$ & $\begin{array}{l}60 \\
50 \\
.\end{array}$ & $\begin{array}{r}c 60 \\
35 \\
{ }^{\mathrm{a}} 8\end{array}$ & $\begin{array}{r}c 50 \\
30 \\
{ }^{\mathrm{a}} 8\end{array}$ \\
\hline $7178-\mathrm{T} 6$ & $\begin{array}{l}\text { L } \\
\text { LT } \\
\text { ST }\end{array}$ & $\begin{array}{l}55 \\
38 \\
\text { a } 8\end{array}$ & $\begin{array}{l}\ldots \\
\ldots \\
\ldots\end{array}$ & $\begin{array}{l}65 \\
45 \\
\cdots\end{array}$ & $\begin{array}{l}65 \\
25 \\
\text { a } 8\end{array}$ & $\begin{array}{l}\ldots \\
\cdots \\
\cdots\end{array}$ \\
\hline 7178-T76 & $\begin{array}{l}\text { L } \\
\text { LT } \\
\text { ST }\end{array}$ & $\begin{array}{r}{ }^{\mathrm{C}} 52 \\
{ }^{\mathrm{C}} 52 \\
25\end{array}$ & $\begin{array}{l}\ldots \\
\ldots \\
\ldots\end{array}$ & $\begin{array}{r}\text { c } 55 \\
\text { c } 52 \\
25\end{array}$ & $\begin{array}{l}\ldots \\
\ldots \\
\ldots\end{array}$ & $\begin{array}{l}\ldots \\
\ldots \\
\ldots\end{array}$ \\
\hline
\end{tabular}

a Lowest stress at which tests were conducted; failures were obtained.

b Ratings are for transverse specimens machined from round or square bar stock.

c Highest stress at which tests were conducted; no failure observed.

d These values will be lower for sections greater than 3 in thick, but will be at least $75 \%$ of the guaranteed yield strength.

e See section 9.5 .2 for test method used to determine values.

f Tests performed at Alcoa Research Laboratories.

Tensile axis during test, $\mathrm{L}=$ Longitudinal, $\mathrm{LT}=$ Long-transverse and $\mathrm{ST}=$ Short-transverse.

TABLE 2. Approximate quantitative characteristics of SCC susceptibility categories used if this chapter (after ref. [5])

\begin{tabular}{lccc}
\hline \multicolumn{1}{c}{$\begin{array}{c}\text { Category of } \\
\text { susceptibility }\end{array}$} & $($ Cracking in short transverse orientation $)$ & plateau velocity \\
\hline A. Very low & $>90 \%$ & $\left(\sigma_{\text {th }} /\right.$ yield strength $) \times 100$ & $>95 \%$ \\
B. Low & $75-90 \%$ & $80-95 \%$ & $<7 \times 10^{-11} \mathrm{~m} / \mathrm{s}$ \\
C. Moderate & $40-75 \%$ & $50-80 \%$ & $7 \times 10^{-11}-3 \times 10^{-10}$ \\
D. Appreciable & $<40 \%$ & $<50 \%$ & $3 \times\left(10^{-10}-10^{-9}\right)$ \\
\hline
\end{tabular}




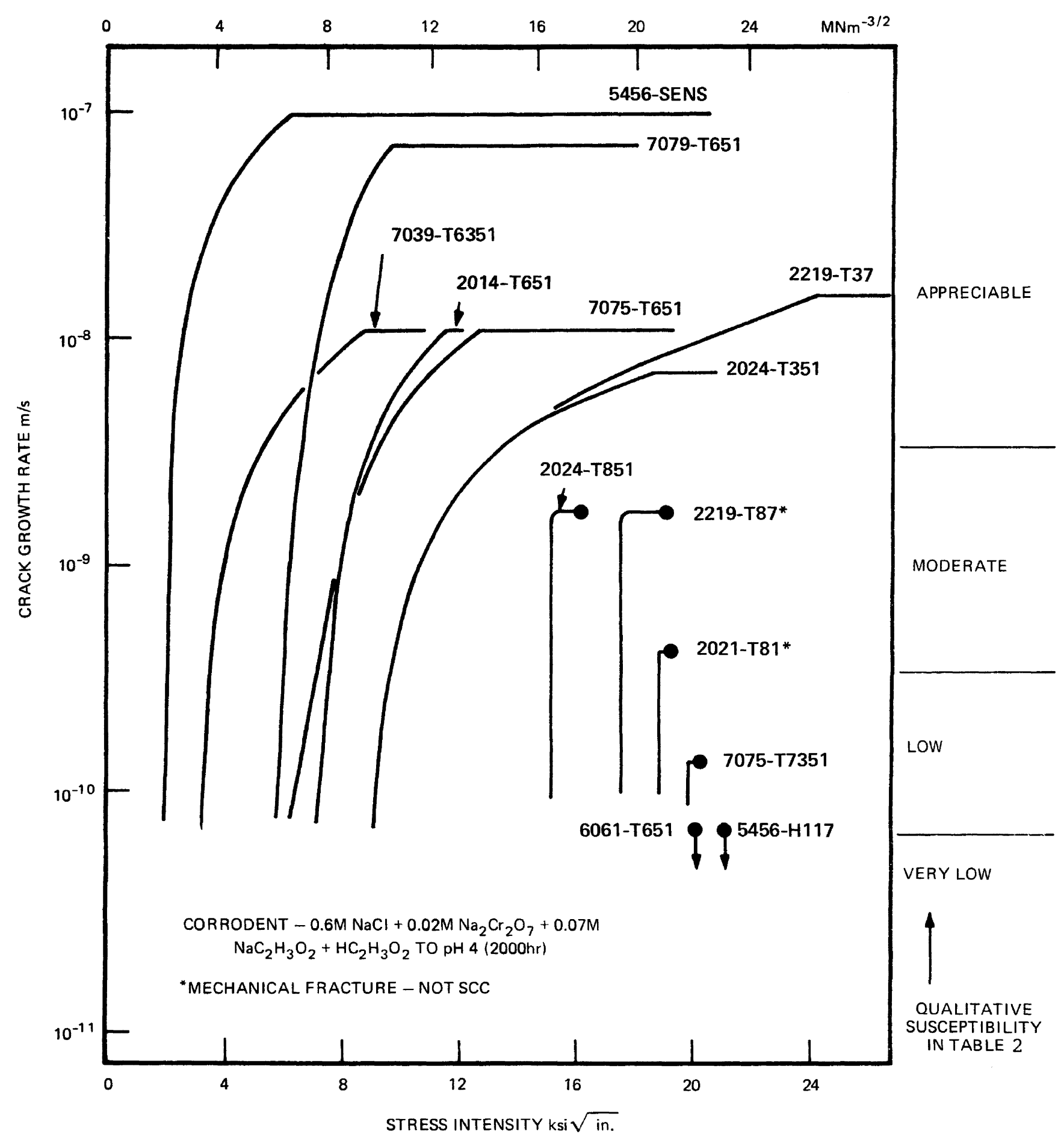

FIGURE 5. K-SCC rate curves for several alloys showing various plateau levels and various apparent $\mathrm{K}_{\mathrm{Iscc}}$ levels (after ref. [5]).

Let us now consider heat treating stresses. Aluminum alloys which are strengthened by age hardening are first given a solution treatment at elevated temperature, quenched, and then are either allowed to age at room temperature or are aged at an elevated temperature. To establish the right conditions for age hardening it is necessary to then cool a given alloy from the solution temperature faster than some minimum rate, and for many alloys this re- quires quenching in cold water. Quenching usually places the surface in compression, as shown in figure 8. SCC does not initiate or propagate when the alloy is in compression, therefore machining off the compressive layer after quenching is undesirable from the SCC viewpoint. Note in figure 8 that if machining should extend to the centerline, stresses there if unaltered by the machining operation would exceed the threshold stress for SCC for several al- 
TABLE 3. Categories of aqueous susceptibility of commercial wrought alloys in plate form-short transverse orientation (after ref. [6])

\begin{tabular}{|c|c|c|}
\hline $\begin{array}{l}\text { Susceptibility } \\
\text { category }\end{array}$ & Alloy & Temper \\
\hline A. Very low & $\begin{array}{l}1100 \\
3003,3004,3005 \\
5000,5050,5052,5154, \\
\quad 5454,6063 \\
\text { a } 5086 \\
6061,6262 \\
\text { Alclad: } 2014,2219,6061, \\
\quad 7075\end{array}$ & $\begin{array}{l}\text { all } \\
\text { all } \\
\text { all } \\
\text { O, H32, H34 } \\
\text { O, T6 } \\
\text { all }\end{array}$ \\
\hline B. Low & $\begin{array}{l}2219 \\
5086 \\
5083,5456 \\
6061 \\
6161,5351 \\
6066,6070,6071 \\
2021 \\
7049,7050,7075\end{array}$ & $\begin{array}{l}\text { T6, T8 } \\
\text { H36 } \\
\text { controlled } \\
\text { T4 } \\
\text { all } \\
\text { T6 } \\
\text { T8 } \\
\text { T73 }\end{array}$ \\
\hline C. Moderate & $\begin{array}{l}2024,2124 \\
7050,7175 \\
7049,7075,7178\end{array}$ & $\begin{array}{l}\text { T8 } \\
\text { T736 } \\
\text { T6 }\end{array}$ \\
\hline D. Appreciable & $\begin{array}{l}2024,2219 \\
2014,7075,7079,7178 \\
5083,5086,5456 \\
7005,7039\end{array}$ & $\begin{array}{l}\text { T3, T4 } \\
\text { T6 } \\
\text { sensitized } \\
\text { T5, T6 }\end{array}$ \\
\hline
\end{tabular}

a See precautionary notes about some members of the 5000 series alloys given in text.

TABLE 4. Categories of aqueous SCC susceptibility of commercial cast alloys a (after ref. [6])

\begin{tabular}{|c|c|c|}
\hline Category & Alloy & Temper \\
\hline A. Very low & $\begin{array}{l}514.0,518.0,535.0, \text { A } 712.0 \\
356.0, \text { A357.0, 359.0, B358.0 }\end{array}$ & $\begin{array}{l}\text { as cast } \\
\text { all }\end{array}$ \\
\hline B. Low & $\begin{array}{l}319.0,333.0,380.0 \\
355.0, \mathrm{C} 355.0,354.0\end{array}$ & $\begin{array}{l}\text { as cast } \\
\text { T6, T61 }\end{array}$ \\
\hline C. Moderate & $\begin{array}{l}520.0 \\
295.0, \mathrm{~B} 295.0,707.0 \\
\text { D712.0 }\end{array}$ & $\begin{array}{l}\text { T4 } \\
\text { T6 } \\
\text { as cast }\end{array}$ \\
\hline
\end{tabular}

a This table is based on far less experimental data than table 3.

loys, as shown in table 1 . If the quenched piece is stretched mechanically, the quenching stresses are largely removed (fig. 8). This mechanical relief is a standard mill procedure available for most product forms and converts the - T6 temper to the - T651 temper.

Blind holes in pieces being quenched cause residual tensile stresses in the poorly quenched regions of the hole unless special fixturing or sprays are used. Quenching stresses may be reduced by quenching in air or hot water providing the alloy, part thickness, and mill product form are favorable. But quenching some alloys in boiling water rather than in cold water, such as 2024-T4, can render the product highly susceptible to intergranular corrosion without being stressed, perhaps because of precipitation during the quench. Therefore one follows faithfully the heat treating procedure which has been proven for each commercial alloy.

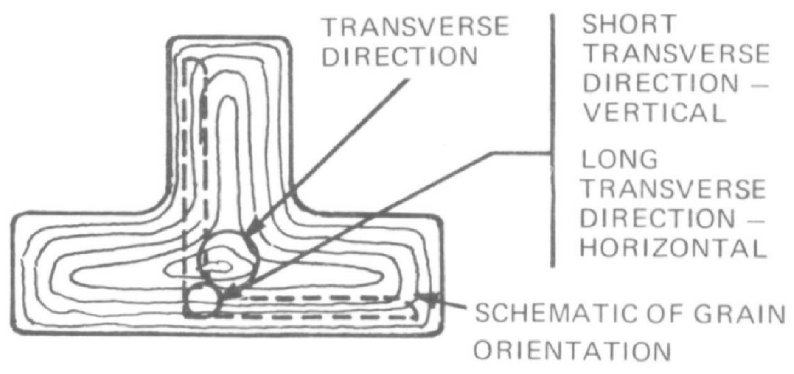

\section{LOCATION OF MACHINED ANGLE WITH RESPECT TO TRANSVERSE GRAIN FLOW IN THICK TEE}

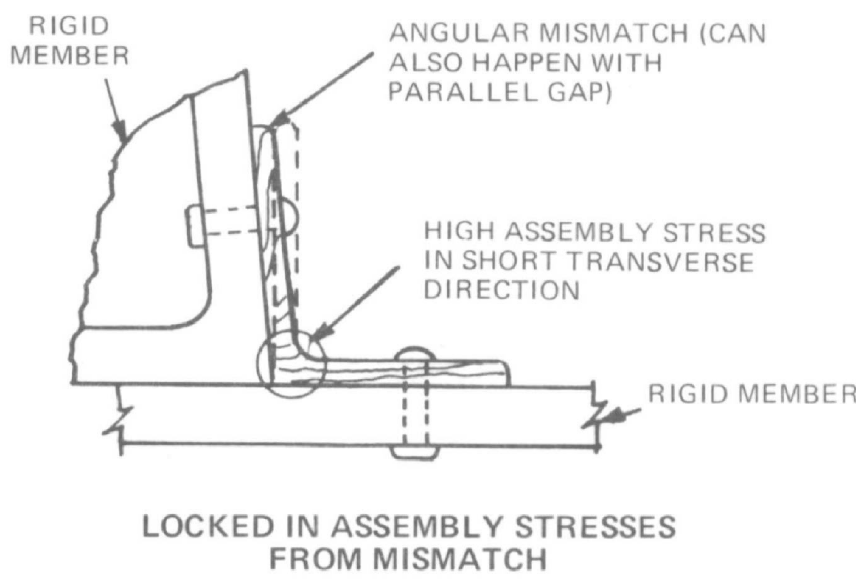

FIGURE 6. One method of generating high sustained stress across the short transverse direction-an open invitation to SCC if alloy is susceptible. Upper figure shows grain flow pattern in mill product. Lower figure shown how sustained stress can be generated by mismatched assembly. (ref. [6]).

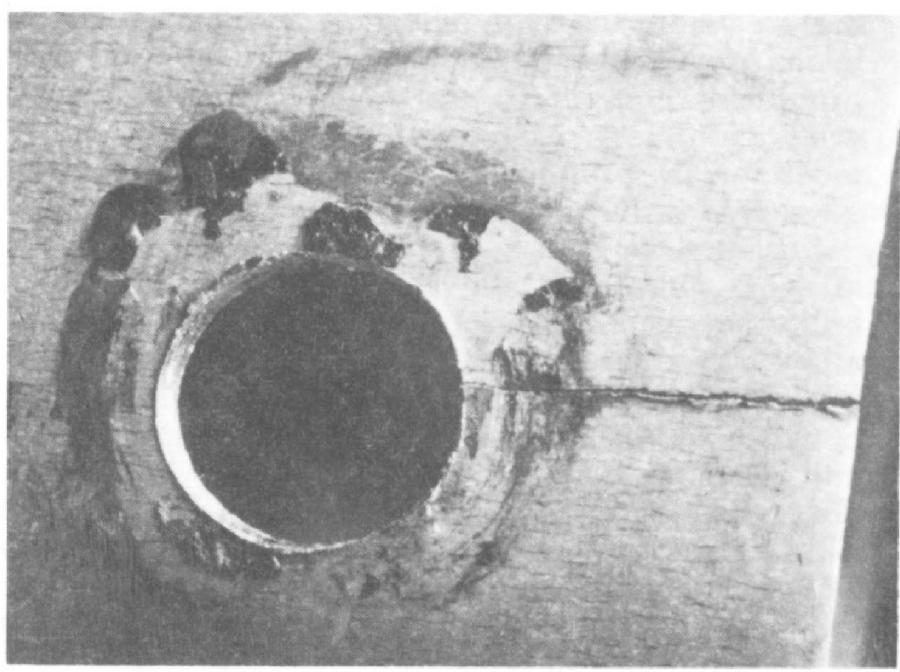

Figure 7. SCC in end of extruded tube of 7075-T651, C-L crack plane. Terrestrial failure of Apollo Program Lunar Excursion Module component. stressed by taper pin which was driven into the hole shown. Cautious practice does no permit such pins stressing the vulnerable texture unless the -T73 temper is used. Magnified 3X. Courtesy of Mr. C. D. Beachem. 

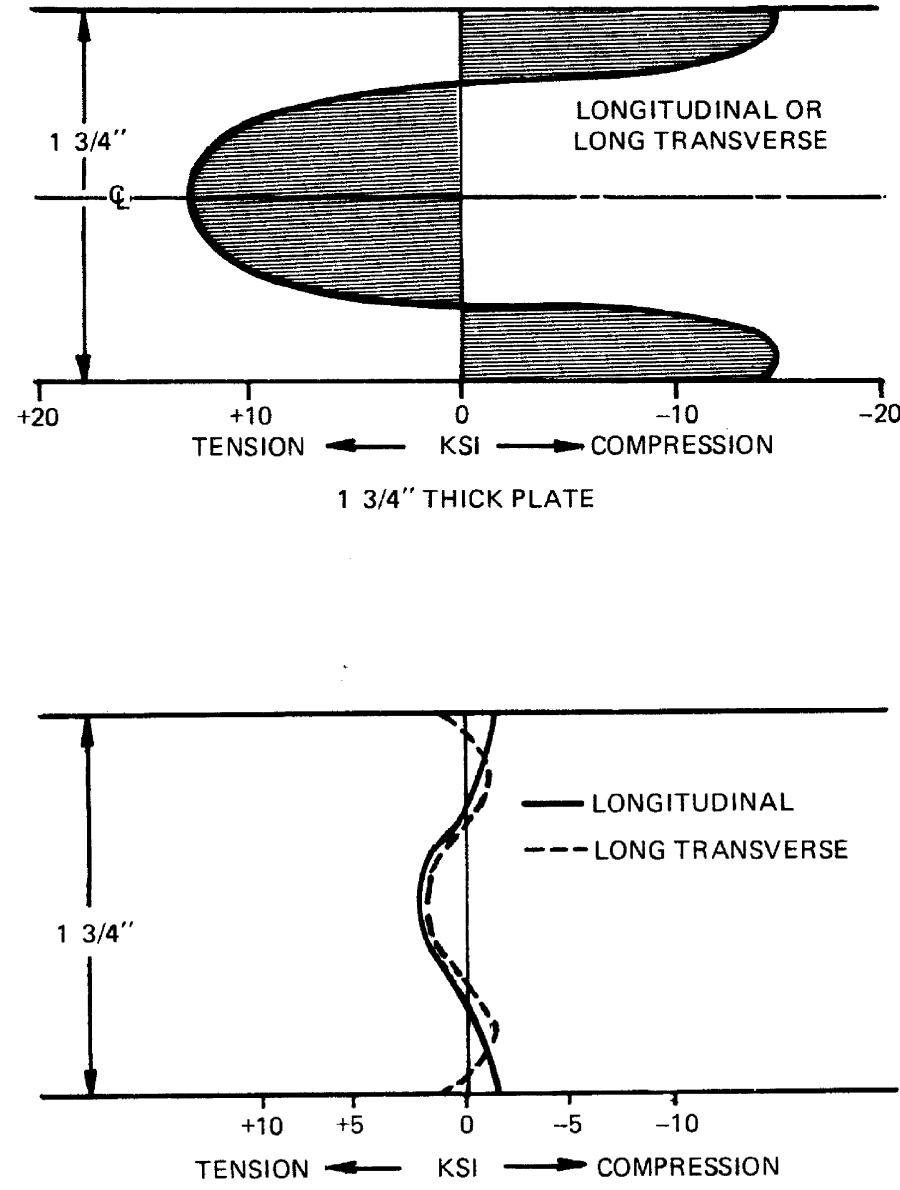

FIGURE 8. (Above) Stresses in 7075-T6 plate given cold water quench and not stress relieved. (Below) Stresses in 7075-T651 plate stretched $2 \%$ aftercold water quench. (ref. [6])

Another tactic to minimize quenching stresses is to quench in water-glycol solutions of controlled composition and temperature. These quenching baths can be used for sheet material which it has been proved that there is no loss in mechanical properties compared with sheet quenched in cold water, and for forgings where there is no loss in mechanical properties compared with forgings quenched in hot water.

Still another source of stress important in the SCC of some aluminum alloys is the wedging action of bulky corrosion products within the crack; in such alloys a stress corrosion crack initiated at one end of a long bar may propagate the entire length of the bar because of this corrosion product wedging. Alloys and tempers in which this action has been either observed or surmised include 2014-T351, 2024T351, 2219-T37, 5456 sensitized by heating, 7039 T6351, 7075-T651 and 7079-T651. It may be noted that most of these alloys are in the highest category of susceptibility in table 3 .

It is good practice to use stress relieved parts where possible, and to avoid residual tensile stress being introduced by plastic deformation of fully hardened alloys. Severe forming operations should be performed with annealed metal and the part sub- sequently solution heat treated. Less severe forming can be done in the freshly quenched condition, preferably followed by mechanical stress relief.

Cold shearing or stamping of susceptible alloys, particularly those subject to corrosion product wedging noted above and particularly sections thicker than about $1 \mathrm{~mm}(1 / 32$ in), can introduce enough residual stress to initiate severe SCC problems in the sheared edges. Cutting by other methods, such as milling, is preferred.

It is possible to introduce compressive stresses on the surface of a part by shot peening. If this treatment is one of thorough saturation everywhere, it is effective providing the surface compressive layers are not subsequently removed by corrosion, abrasion or machining. But at sharp re-entrant angles as where a bolt head meets a flat surface, the peening action may not extend far enough into the sharp corner to prevent initiation of SCC there. Shot peening may thus be a practical measure for certain situations, but where 100 percent coverage cannot be conferred and maintained, this technique is of marginal value. It is however considered sufficiently worthwhile as a supplementary measure to be frequently specified for military aerospace structures, particularly when the structure is given a subsequent coating system.

Following are some precautionary notes for aluminum alloys exerpted from reference [4].

Alloys 5083, 5086, and 5456 should not be used under high sustained stress at temperatures exceeding $65^{\circ} \mathrm{C}\left(150^{\circ} \mathrm{F}\right)$ because of the hazard of developing susceptibility to SCC (sensitization). In general the H34 through $\mathrm{H} 38$ tempers of 5086, and the H32 through $\mathrm{H} 38$ tempers of 5083 and 5456 are not recommended, because these tempers can become susceptible to SCC.

In the recommended tempers, $\mathrm{H} 113$ and $\mathrm{H} 321$ for sheet and plate, cold forming of 5083 and 5456 should be held to a minimum radius of five times the thickness. Hot forming of the $\mathrm{O}$ temper of alloys 5083 and 5456 is recommended, and is preferred for the $\mathrm{H} 113$ and $\mathrm{H} 321$ tempers in order to avoid excessive cold work and high residual stress. If the H113, $\mathrm{H} 321, \mathrm{H} 323$, and H343 tempers are heated for hot forming, a slight decrease in mechanical properties, particularly yield strength, may result.

Where short times at elevated temperatures of $65-260{ }^{\circ} \mathrm{C}\left(150-500{ }^{\circ} \mathrm{F}\right)$ may be encountered, the precipitation heat treated tempers of 2024 and 2219 are recommended over the naturally aged tempers.

Certain alloy-temper combinations, notably 2024 and 2219 in the T6 or T8-type tempers and 7049, 7075 and 7175 in the T73-type tempers are decidedly more resistant and sustained tensile stresses of 50 to 75 percent of the minimum yield strength may be permitted without concern about SCC. The T76 temper of 7075 and 7178 provides an intermediate degree of resistance to SCC, i.e., superior to that of the T6 temper, but not as good as that of the T73 temper of 7075 . 
The following guidelines are given in MIL-STD1568 "Material and Processes for Corrosion Prevention and Control in Aerospace Weapons Systems."

"Whenever the design requires the selection of aluminum for structural components, maximum use shall be made of alloys, heat treatments, and claddings which minimize susceptibility to pitting, intergranular and stress corrosion. The following are alloy/temper recommendations for resistance to . . . stress corrosion: 2024, 2124, and 2219 all artificially aged; 7049, 7050, 7075, 7175, and 7475 all in the T73XXX temper.

"In the event these alloys and tempers or other approved alloys are not used, the susceptibility to stress corrosion cracking of the selected alloy will be established for each application in accordance with ... (a detailed alternate immersion test in salt water).

"All aluminum sheets used in external environments and interior corrosive environments shall be clad on both sides except where the design requires surface metal removal by machining or chemical milling or where the design requires adhesive bonding or where the design uses alloys of the 5000 or 6000 series type... All mill product forms of aluminum alloys 2020,7079, and 7178 in all temper conditions shall not be used for structural applications. The use of 7075-T6 shall be limited to thicknesses not to exceed 0.125 in $(3 \mathrm{~mm})$... Maximum metal removal from the surfaces of nonstress relieved structural parts after final heat treatment shall not exceed 0.150 in $(3.8 \mathrm{~mm})$ unless the final temper or condition has been demonstrated to have a stress-corrosion resistance of $25 \mathrm{ksi}$ (172 $\mathrm{MN} / \mathrm{m}^{2}$ ) in the short transverse grain direction as determined by a 20-day alternate immersion test given in FED-STD-151, Method 823 . . . Maximum metal removal requirements are not intended to apply to mechanically stress relieved products because of the low level of internal stresses resulting from mechanical stress-relieving . . .

"All surfaces of all structural forgings, where accessible, after final machining and heat treatment, must be completely shot peened using a minimum of two coverage passes or placed in compression by other suitable means, except for forgings having a demonstrated stress corrosion resistance of $25 \mathrm{ksi}$ $\left(172 \mathrm{MN} / \mathrm{m}^{2}\right)$ or higher in the short transverse direction and web areas under 0.080 inches $(2 \mathrm{~mm})$ thick where no short transverse grain is exposed by machining ...."

NASA Marshall Space Flight Center (MSFC) has published further guidance for controlling SCC in aluminum alloys for space vehicles and associated equipment in a document (ref [10]) based on laboratory tests in salt water at room temperature, on marine and industrial atmosphere tests, and on service experience summarized (for aluminum alloys) as follows:
The alloys shown in table 5 have been found to have high resistance to SCC. They are preferred materials and may be selected without prior MSFC approval. No other aluminum alloys may be selected (for MSFC hardware) without a materials usage agreement.

TABLE 5. Aluminum alloys with high resistance to stress corrosion cracking (from ref. [10])

\begin{tabular}{|c|c|c|c|}
\hline \multicolumn{4}{|c|}{ Aluminum alloys } \\
\hline \multicolumn{2}{|c|}{ Wrought ${ }^{\text {a.b }}$} & \multicolumn{2}{|c|}{ Cast } \\
\hline Alloy & Condition & Alloy ${ }^{f}$ & Condition \\
\hline $\begin{array}{l}1000 \text { Series } \\
2011 \\
2024 \\
2219 \\
3000 \text { Series } \\
4032 \\
5000 \text { Series } \\
6000 \text { Series } \\
7075 \\
7475\end{array}$ & $\begin{array}{l}\text { All } \\
\text { T8 } \\
\text { T6 } 6^{c} \mathrm{~T}^{d} \\
\mathrm{~T}^{c}, \mathrm{~T} 8 \\
\text { All } \\
\text { T6 } \\
\text { Alr } \\
\text { All } \\
\text { T73 } \\
\text { T73 }\end{array}$ & $\begin{array}{l}319.0, \text { A319.0 } \\
333.0, \text { A333.0 } \\
355.0, \text { C355.0 } \\
356.0, \text { A356.0 } \\
357.0 \text {. } \\
\text { B358.0 (Tens-50) } \\
359.0 \\
380.0, \text { A380.0 } \\
\text { A612.0, C612.0 } \\
514.0 \text { (214) } \\
518.0 \text { (218) } \\
535.0 \text { (Almag 35) }\end{array}$ & $\begin{array}{l}\text { As Cast } \\
\text { As Cast } \\
\text { T6 } \\
\text { All } \\
\text { All } \\
\text { All } \\
\text { All } \\
\text { As Cast } \\
\text { As Cast } \\
\text { As Cast } \\
\text { As Cast } \\
\text { As Cast }\end{array}$ \\
\hline
\end{tabular}

a Mechanically stress relieved (TX5X or TX5XX) where possible.

b Including weldments of the weldable alloys.

c Except plate and forgings which have low resistance.

d Except forgings which have low resistance and plate which has moderate resistance.

e High magnesium content alloys 5456, 5083, \& 5086 should be used only in controlled tempers for resistance to SCC and exfoliation; these alloys are not recommended for high temperature application $\left(65^{\circ} \mathrm{C}, 150^{\circ} \mathrm{F}\right.$, and above).

$f$ The former designation is shown in parenthesis when significantly different.

The alloys shown in table 6 are considered moderately resistant to SCC. MSFC approval must be secured before any alloy or weldment in table 6 can be used. The materials in table 6 will not be approved for applications involving high sustained installation stresses, such as springs or fasteners.

TABLE 6. Aluminum alloys with moderate resistance to $S C C^{\mathrm{a}, \mathrm{b}}$ (from ref. [10])

\begin{tabular}{ll}
\hline \multicolumn{1}{c}{ Alloy } & \multicolumn{1}{c}{ Condition } \\
\hline 2024 Plate & T8 \\
2124 Plate & T8 \\
7001 & T75, T76 \\
7049 & T73 \\
7050 & T736, T76 \\
7075 & T76 \\
7175 & T766 \\
7475 & T76 \\
\hline
\end{tabular}

\footnotetext{
a Mechanically stress relieved products (TX5X or TX5XX) should be specified where possible.

b Sheet, unmachined extrusions, and unmachined plate are the least susceptible forms.
} 
The alloys shown in table 7 are classed as highly susceptible to SCC. They should be considered for use only where it can be demonstrated that SCC is not possible for environmental reasons, and even then prior MSFC approval is required.

TABLE 7. Aluminum alloys with low resistance to $S C C^{\mathrm{a}, \mathrm{b}}$ (from ref. [10])

\begin{tabular}{lllll}
\hline \hline \multicolumn{2}{c}{ Wrought Alloys } & \multicolumn{2}{c}{ Casting } \\
\hline \multicolumn{2}{c}{ Alloy } & Condition & \multicolumn{1}{c}{ Alloy } & Condition \\
\hline & & & & \\
2011 & & T3 & $295.0(195)$ & T6 \\
2014 & & All & B295.0 (B195) & T6 \\
2017 & All & $520.0(220)$ & T4 \\
2024 & & T3, T4 & 707.0 (Ternalloy 7) & T6 \\
2024 Plate \& & T6 & D712.0 (40E, D612) & As cast \\
& forgings & & & \\
2024 & Forgings & T8 & & \\
7001 & & T6 & & \\
7039 & All & & \\
7075 & T6 & & \\
7079 & T6 & & \\
7178 & T6 & & \\
7475 & & T6 & & \\
\end{tabular}

a Mechanically stress relieved products (TX5X or TX5XX) should be specified where possible.

b Sheet, unmachined extrusions, and unmachined plate are the least susceptible forms.

\section{Kinetic Factors}

In addition to stress intensity and alloy composition and heat treatment, the following factors affect SCC kinetics to degrees which are of practical importance:

(a) Water concentration (in nonaqueous solutions) and relative humidity (in the atmosphere)

(b) Chloride concentration

(c) Temperature

(d) Electrochemical potential

Increasing water concentration, whether in nonaqueous solutions or as relative humidity in the atmosphere, increases SCC kinetics appreciably. So does increasing chloride concentration and increasing temperature-the plateau velocity in one alloy was observed to increase about a factor of 10 between the ice point and the boiling point of water. The effect of electrochemical potential is such that cathodic protection methods are important measures where feasible. Coupling a susceptible alloy to zinc in salt water, for example, greatly delays initiation of stress corrosion cracks and decreases the crack velocity above $K_{I s c c}$. Cathodic protection also greatly reduces the tendency to form corrosion pits which can stimulate the initiation of cracking. As a corollary to this cathodic effect, cladding a susceptible alloy with a sacrificial coating (which can confer cathodic protection to an area of the underlying alloy laid bare by a deep scratch) can shift the alloy from the "appreciable susceptibility" category to "very low susceptibility." (See for example alloy 2014 in table 3).

\section{Inhibitors}

Although paint coatings reduce the susceptibility of an aluminum structure to SCC by restricting the passage of moisture, such coatings are not completely impermeable to moisture, and SCC can nucleate and grow under a paint film, particularly under a film which has become cracked by aging. For such structures as aircraft it is possible to provide some additional defense against SCC by incorporating an inhibitor such as a chromate in the primer coat. One such formulation is a polymer system containing from 2 to 10 percent magnesium chromate, which is sufficiently soluble in water permeating the overlying paint coating to inhibit corrosion reactions on the aluminum surface (7). Chromate inhibited primer coats are called out in military specifications for all aluminum aerospace weapons systems, structures and parts, even though this measure does not guarantee freedom from SCC. The primer widely used by the military (MIL-P-23377) employs 12 percent strontium chromate as the inhibitor, applied to a surface which has been either anodized or given a chromate conversion coating for paint adhesion purposes.

\section{An Example of Applying the Principles to Avoid the Problem}

The world's most capacious research submersible is the Aluminaut (fig. 9). To meet the strength requirements for preventing collapse, the alloy 7079T6 $w$ as selected. This alloy is highly susceptible to $\mathrm{SCC}$, in the short transverse direction, but the vehicle saw lengthy satisfactory service in a hostile environment. Let us see how this was done.

First, the problem of possible SCC was not avoided by ignoring it until the structure was designed and fabricated: The control measures started in the conceptual design state. The design called for a cylindrical hull with two hemispherical end closures. The cylinder was formed by bolting together rings which had been ring-forged in such a manner that the most vulnerable end-grain area was folded into the interior of the vehicle where it would experience only atmospheric moisture rather than salt water (reducing both the water and chloride kinetic factors). After being fabricated, the vehicle was painted with six coats of polyurethane based paint; each coat was of a different color from the preceding in order to ensure full coverage by each coat, and also in order to enable one to determine, in case of scratch damage, how deep the scratch entended into the paint system. Rather than attempt to clad the ring forgings, the electrochemical equivalent was provided by attaching galvanic (sacrificial) anodes of a special aluminum alloy to the hull exterior, which would minimize corrosion while the hull was in the 


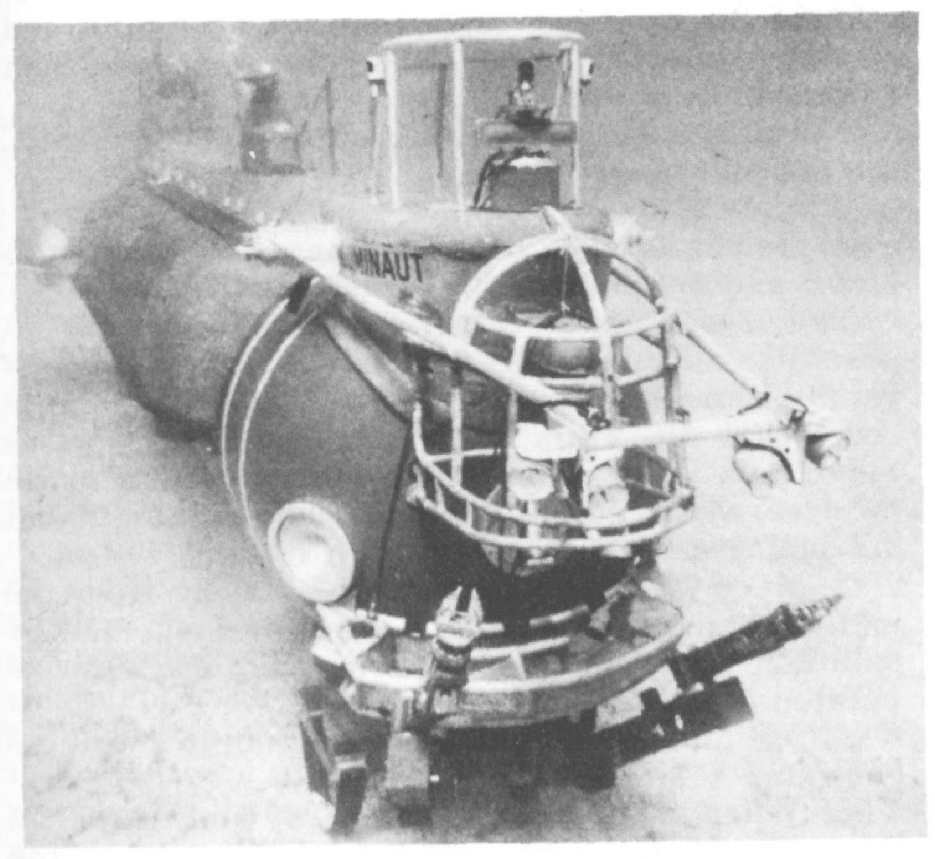

FIGURE 9. The deep submersible ALUMINAUT resting on the ocean floor near Bimini. This vehicle, though made of a highly susceptible alloy, performed successfully because of meticulous attention to redundant measures to avoid SCC. Photo courtesy of Reynolds International, Inc.

sea. Finally, when the submersible was hauled out after each cruise, it was washed down with fresh water, minimizing chloride concentration on the hull exterior between cruises.

One might be tempted to conclude that since the working stresses in a submerged submersible are compressive, and since SCC cannot occur in compression, all these SCC control measures for Aluminaut were superfluous. But most SCC is caused by fabrication stresses, not design stresses in aluminum structures, and the fabrication stresses could be high enough to cause the resolved surface stresses to be tensile even during a dive. The actual fact is that an entire class of foreign (steel) submarines had to be redesigned because of the appearance of SCC in the hulls because of fabrication stresses, as noted in the chapter on high strength steels.

In summary, design constraints for a submarine hull forced the selection of a highly susceptible alloy, and the stresses as fabricated could not be predicted with high confidence. But by controlling kinetic factors (keeping the end-grain out of the sea water, cathodically protecting the hull exterior when in the sea, removal of chloride by washing down after each cruise), the susceptible alloy performed satisfactorily.

\section{Nonaqueous Environments}

Liquid metal cracking (liquid metal embrittlement). Mercury, gallium, indium, sodium, tin and zinc in the molten state cause cracking of aluminum alloys. Mercury is the most common cause of liquid metal cracking of aluminum alloys in service, and it causes cracking at exceedingly low stresses. In addition to mercury, its compounds can also cause cracking. Mercury-bearing antifouling paints are still used occasionally on boat hulls, and although a vinyl barrier coat six mils $(0.15 \mathrm{~mm})$ thick is sometimes specified between the aluminum and the antifouling paint to isolate (hopefully) the mercury compounds from the metal, in point of fact this barrier is not reliable. No waivers should be permitted from the rule that mercury and its compounds should not be allowed in proximity to aluminum alloys.

Other nonaqueous environments. Some alloys have been found to crack in nitric acid, inhibited red fuming nitric acid, nitrogen tetroxide, methanol, and carbon tetrachloride. (ref. [8])

\section{Identifying SCC}

Essentially all SCC service failures are in aluminum alloys intergranular, sometimes with patches of plasticity interspersed on a microscopic scale, but sometimes devoid of apparent plasticity. By searching on a metalographic plane normal to the principal fracture plane one can usually find crack branching, which may vary in degrees from incipient to extended (fig. 10). A "mud crack" pattern (fig. 11) can usually be seen on fracture surfaces caused by SCC in salt water, but electron fractography is required to see the pattern in most cases. The pattern is often missing in SCC due to atmospheric moisture, so that its absence does not rule out SCC. The pattern may also be seen at the bottom of corrosion pits, and hence its presence is not absolute proof of SCC. The material in which this pattern forms appears to be a noncrystalline oxide or hydroxide which may be removed by repeated replication of the surface (often practiced to clean a fracture for study of the final replica in the electron microscope); therefore an early replica should be examined for this diagnostic evidence. Liquid metal cracking is also usually intergranular, but can be distinguished from aqueous SCC by identifying the residual liquid metal, supplemented by noting the

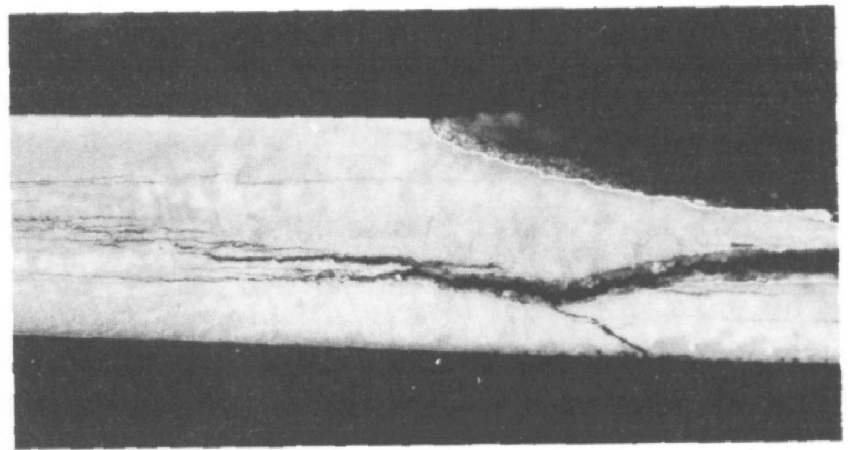

FIGURE 10. Intergranular stress corrosion cracks in alloy 5456, showing extensive branching. Optical micrograph of polished section, magnified 7X. Photo courtesy of Dr, C. T, Fujii. 


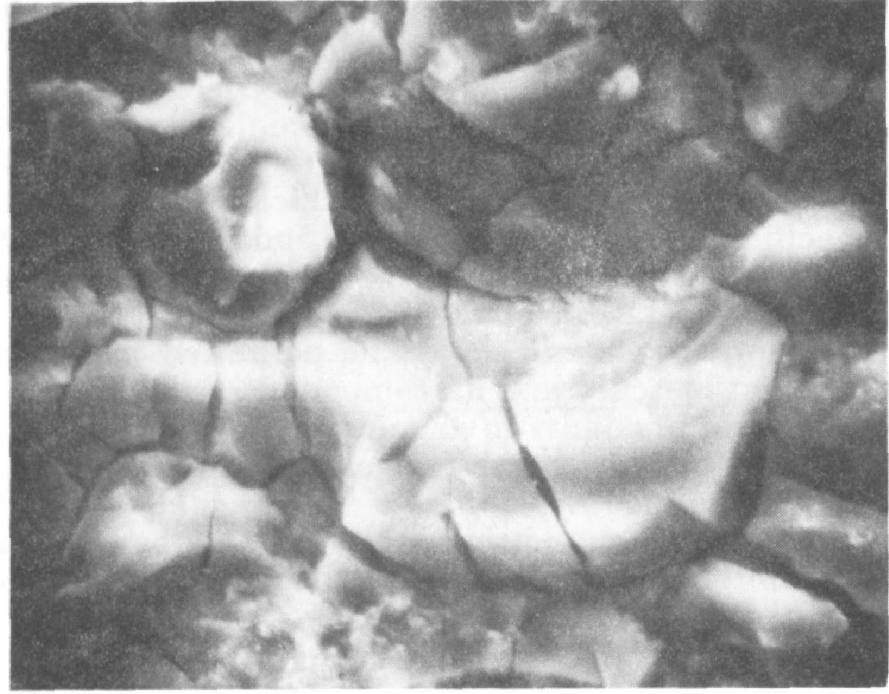

FIGURE 11. "Mud Crack" pattern on surface of stress corrosion crack in alloy $5456-H 321$, possibly sensitized in service. The features of the mud crack pattern are unrelated to features of the underlying metal. Scanning electron micrograph, magnification 1500X. Photo courtesy of Dr. C. T. Fujii. (From ref.

absence of the mud-crack pattern. Purely mechanical fractures in aluminum alloys, particularly of the $\mathrm{S}-\mathrm{L}$ orientation may also be largely intergranular in the alloys of high strength, usually lacking both crack branching and mud-crack pattern.

Although all service failures due to SCC are reported to be intergranular, laboratory failures of 7000 -series alloys in the T73 temper have been reported to be transgranular. These latter require long times at high stress levels compared to the T6 temper.

\section{Theory}

The mechanism of aqueous SCC in aluminum alloys is considered by some authorities to be one of highly localized removal of metal by corrosion at the crack tip. The remainder of the crack walls may be passive, but the crack tip is kept chemically reactive by localized straining, abetted if the environment is aqueous chloride solution by acidity in the solution immediately adjacent to the crack tip. Alternatively the cracking has been postualted as due to a lowering of the surface energy by an adsorbed layer of hydrogen ions, which is more plausible for cracking in air of only moderate humidity.

\section{Summary}

The most prevalent form of SCC service failures in aluminum alloys is caused by a combination of water, aqueous solutions or atmospheric moisture, alloy of susceptible composition and structure, and sustained tensile stresses, most often caused by heat treatment or assembly.

The principal practical measures to control SCC are the following:

(1) Select an alloy of minimum susceptibility (tables 3 and 4) permitted by other constraints.

(2) For wrought alloy, take precautions not to impose high sustained stresses across the short transverse grain direction unless the alloy and temper confer low susceptibility. Remember that stresses other than design stresses are those which cause most service failures by SCC in aluminum. Avoid machining after heat treatment if feasible.

(3) Keep water and water vapor away from the metal surface by providing natural drainage and by painting, with an inhibitor such as chromate incorporated in at least the primer coat.

(4) Minimize opportunities for chlorides to concentrate.

(5) When using a susceptible alloy and temper, if geometry is favorable, compressively stress the metal surface by peening or rolling followed by painting.

(6) Use cathodic protection if feasible.

(7) Do not permit mercury or its compounds in close proximity to any aluminum structure, regardless of alloy or temper, and regardless of protective coatings.

\section{References}

[1] Metals Handbook, 8th ed., Am. Soc. for Metals, Metals Park, OH (1961). See also latest annual Aluminum Standards and Data, Aluminum Association, New York.

[2] 1973 Annual Book of ASTM Standards, Am. Soc. Testing \& Materials, Philadelphia, PA, (1973) 975-6. part 31.

[3] Sprowls, D. O. and Brown, R. H., Metal. Prog. 81 No. 4, 79 (1962); 81, No. 5, 77 (1962).

[4] MIL-HANDBOOK-5.

[5] Sprowls, D. O., Shumaker, M. B. and Walsh, J. D., Evaluation of stress-corrosion cracking susceptibility using fracture mechanics techniques, Marshall Space Flight Center Contract No. NAS 8-21487, Final Report, Part I, May 31, 1973.

[6] Spuhler, E. H. and Burton, C. L., Avoiding stress corrosion cracking in high strength aluminum alloy structures, ALCOA Green Letter, Aluminum Co. of America, New Kensington, PA, April 1970.

[7] U. S. Patent 3,730.937, May 1, 1973 (Wilburn A. Boggs and Robert N. Miller).

[8] Hyatt, M. V. and Speidel, M. O., Stress-corrosion cracking in high strength steels and in titanium and aluminum alloys, (Ed. by B. F. Brown), p. 147, Naval Research Laboratory, Washington, D. C., 1972 p. 147.

[9] Fujii, C. T., Beachem, C. D., Meyn, D. A. and Brown, B. F., NRL Memorandum Report 2422, Naval Research Lab., Washington, D. C., April 1972.

[10] Franklin, D. B., Design criteria for controlling stress corrosion cracking, Marshall Space Flight Center Document 10M33107(B), August 20, 1975. 


\section{CHAPTER 5}

\section{TITANIUM ALLOYS}

Unalloyed titanium at room temperature has a close-packed hexagonal crystal structure designated alpha. The incidental presence of small amounts of iron, manganese and silicon or the addition of certain alloying elements, particularly vanadium, molybdenum, nickel or chromium, causes the appearance of grains of body-centered crystal structure designated beta. Alpha alloys have been developed for sheet material that could be heli-arc welded and retain sufficient ductility in the weld zone to allow some forming without complicated heat treatments. The other alloys which have become technologically important have been those containing both alpha and beta phases. Alloys of pure beta phase have been produced but have not yet found appreciable technological application. The physical metallurgy of titanium is discussed in detail in reference [1].

Titanium and its alloys have a good record of freedom from the SCC problem in service, but not a perfect one. The reasons for a good record include (1) the low stresses which were characteristic of many of the early applications, (2) the predominance of unalloyed titanium, resistant to SCC in many environments, in the early history of titanium technology, (3) the fact that many applications were in technologically advanced areas involving personnel aware of published accounts of earlier failures, and (4) the fact that some of the combinations of environment and alloy which might have produced widespread SCC in service were identified in the laboratory before they could occur in the field. Consequently there have not been enough service failures nor enough different alloys used to establish a failure pattern, except that design stresses rather than stresses caused by heat treatment or assembly have been responsible for some of the better known service failures. The SCC characteristics of titanium alloys will be presented according to the more important environments which have caused cracking, whether the cracking has been observed in service or only in the laboratory. Note that some of the environments which have been found capable of causing SCC in laboratory tests have not been reported incompatible with titanium alloys in service. (fig. 1)

One of the striking features about the environments which can cause SCC in titanium alloys is the great fundamental diversity of their chemical nature. Not all investigators are agreed that each of many seemingly different environments is fundamentally different as far as the cracking mechanism is concerned. For example, some investigators postulate that the fundamental cracking agent in hydrogen gas, water, methanol, hot salt, and carbon tetrachloride is hydrogen, provided in the last two

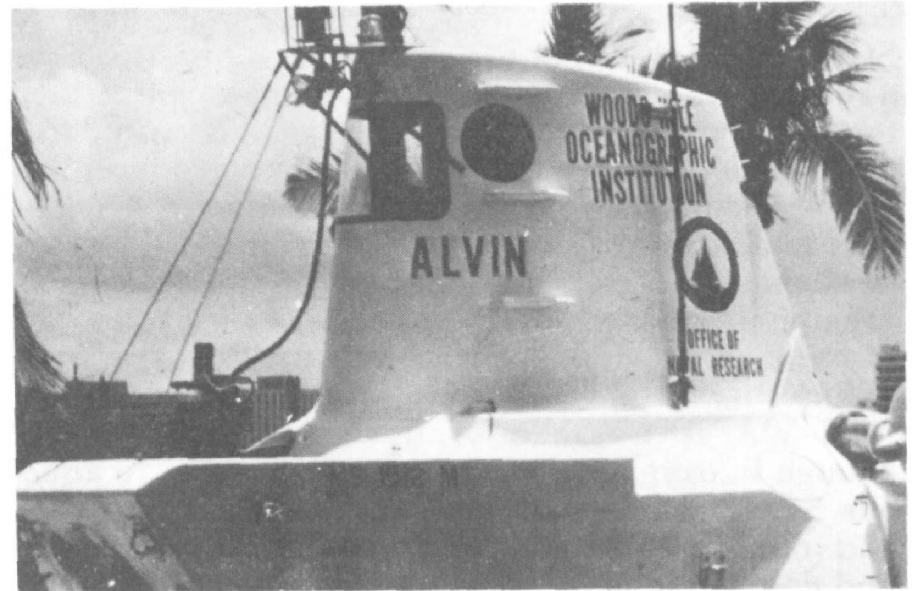

Figure 1. The research submersible ALVIN, which is equipped with a pressure hull made of Ti-6\% $\mathrm{Al}-2 \% \mathrm{Cb}-1 \% \mathrm{Ta}-0.8 \% \mathrm{Mo}$ and with 15 buoyancy spheres made of low oxygen Ti-6\%Al-4\%V. It is possible to crack both these alloys in the laboratory at high $K$ levels, but the design and fabrication of the full and buoyancy spheres were such that the vehicle has performed satisfactorily in the sea.

named substances by traces of moisture, so it is supposed. Such investigators might then tend to think of a number of seemingly different environments under a single heading "hydrogen-bearing environments." Perhaps this approach will eventually prove to be valid, and other groupings such as "chloride containing environments" may also prove to be valid and useful. But at the present it seems wiser to discuss SCC behavior largely according to individual nominal environments until we are surer about possible roles of trace impurities in both environment and metal.

\section{Liquid Environments (Excluding Metals)}

Water (sea water, tap water, distilled water, and nearly neutral aqueous solutions, but apparently not atmospheric water vapor.) All these environments cause SCC in many titanium alloys in the presence of pre-existing crack-like flaws, but susceptibility of these alloys is not detected by smooth specimens because these alloys do not undergo pitting attack, the precursor to SCC in the absence of a pre-crack in many systems. Therefore the significant characterization data are of the fracture mechanics type, and a genuine threshold $K_{I s c c}$ appears to exist. The resistance of alloys to SCC in 3.5 percent sodium chloride solution, which may be indicative of their resistance to SCC in many neutral or near-neutral aqueous environments, has been found to vary enormously from alloy to alloy even at a given strength level, as may be seen in figure 7 of chapter 2 . 
Systematic study of data of the sort presented in that figure has shown that high aluminum, high oxygen, and high tin contents in aluminum-bearing titanium alloys are undesirable from the standpoint of SCC because each of these elements promotes the formation of ordered domains of $\mathrm{Ti}_{3} \mathrm{Al}$ or $\mathrm{Ti}_{3}(\mathrm{Al}+$ $\mathrm{Sn}$ ) in the alpha phase, and the appearance of this compound correlates with decreased resistance to SCC. The upper limit for aluminum in order to have a reasonable resistant alloy is about 6 percent, which fortunately permits (albeit barely) the workhorse alloy $\mathrm{Ti}-6 \% \mathrm{Al}-4 \% \mathrm{~V}$ to lie in what is considered acceptable compositional territory. Even so, it is desirable to restrict oxygen to $1300 \mathrm{ppm}$, and even less is desirable. Iron causes a phase designated omega to precipitate in any beta phase grains which may be present in the microstructure, making the beta grains susceptible to SCC.

Ti-50A is a grade of unalloyed titanium low enough in oxygen to be essentially immune to aqueous SCC. Ti-75A and Ti-100A have higher oxygen and iron content, so that some beta phase is present, and depending on processing history they may have enough omega phase precipitation in beta regions to make the alloys moderately susceptible to aqueous SCC.

$\mathrm{Ti}-50 \mathrm{~A}$ and low oxygen $\mathrm{Ti}-6 \% \mathrm{Al}-4 \% \mathrm{~V}$ have sufficiently high resistance to aqueous SCC that these alloys offer the engineering solution to avoiding the problem. Note however that the $\mathrm{Ti}-6 \% \mathrm{Al}-4 \% \mathrm{~V}$ alloy may have widely varying properties depending upon actual composition and processing, as may be seen in figure 2, and until stricter specifications are developed and put into effect, it may be necessary to test the alloy lot by lot for critical applications such as fracture-critical aircraft components. As other alloys are developed, they can be readily characterized using one of the fracture mechanics type tests.

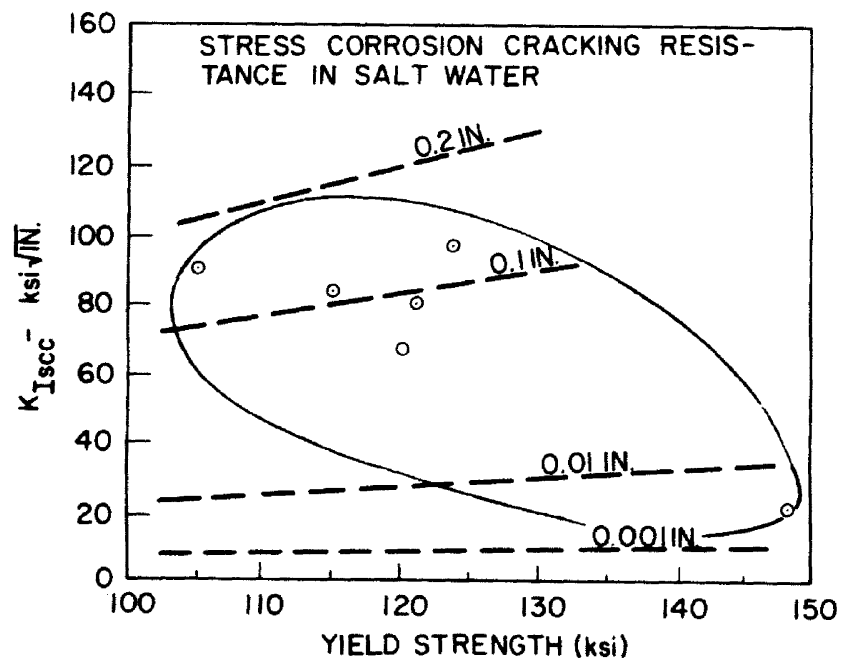

FIGURE 2. $\mathrm{K}_{\mathrm{Iscc}}$ characteristics of various lots of Ti-6\% Al-4\%V at various strengths levels, in salt water. Oval encloses all known $K_{\text {lscr }}$ data for this alloy in salt water.
Methanol. This liquid was first found to cause SCC in titanium alloys when it was used as a supposedly inert pressurizing fluid to leak-test a fuel tankage and associated system made of $\mathrm{Ti}-6 \% \mathrm{Al}-$ $4 \%$ V. Extensive SCC of the tankage occurred during the pressure hold. (fig. 3) Laboratory experiments then confirmed that many titanium alloys, including the most important commercial ones, are susceptible to cracking in both commercial and high purity methanol, and without the need of a pre-existing crack-like flaw. Unalloyed 50-A titanium cracks intergranularly even without stress. Laboratory tests also demonstrated that 1-5 percent of water added to the methanol inhibits the initiation of a crack from a smooth surface, but not if the solution is contaminated with about $10 \mathrm{ppm}$ of chloride. Even in the absence of chloride, water does not inhibit SCC growth from a preexisting crack. Also, methanol attacks the grain boundaries of even unstressed titanium alloys. The practical conclusion from these laboratory observations is simply that one does not expose titanium structures to methanol.

It is to be noted that methanol is a constituent of many industrial substances such as marking fluids, de-icing fluids, and paint removers. One would be ill advised to allow any of these substances to contact stressed critical components made of titanium without direct experimental evidence of compatibility, using precracked specimens. See figure 4 for an example of a failure which may have been due to such fluids. Ethanol and ethylene glycol have also been observed to crack titanium alloys.

Hot Salt. On one occasion when some weldments were heated for stress relief, they were found to experience SCC during the annealing operation in a largely inert gas atmosphere. The cause of the phenomenon, which is rarely encountered in practice, was traced to sodium chloride, and it was found to occur only if the temperature exceeds about 275 ${ }^{\circ} \mathrm{C}\left(525^{\circ} \mathrm{F}\right)$ and only if water vapor and apparently oxygen are present. The sodium chloride responsible for some instances of hot salt cracking has been traced to fingerprints. Practical control measures during annealing include chloride removal from and white glove handling of parts before annealing, perhaps supplemented by the use of furnace atmospheres which are dry and nonoxidizing, such as dry argon.

For parts which may experience both chloride contamination and elevated service temperatures, a barrier in the form of commercial nickel paint reported to be adherent at $540{ }^{\circ} \mathrm{C}\left(1000^{\circ} \mathrm{F}\right)$ has been suggested (ref. [2]).

All commercial titanium alloys are susceptible to hot salt cracking in laboratory tests, alpha alloys being more susceptible than alpha-beta alloys. Unalloyed titanium appears not to be susceptible.

Somewhat surprisingly, titanium alloys have been used for compressor blades in aircraft gas turbines operating at temperatures which exceed the minimum for hot salt cracking without a reported instance of service failure, possible due to low operating stress. MIL-STD 1568 notes that "All ap- 


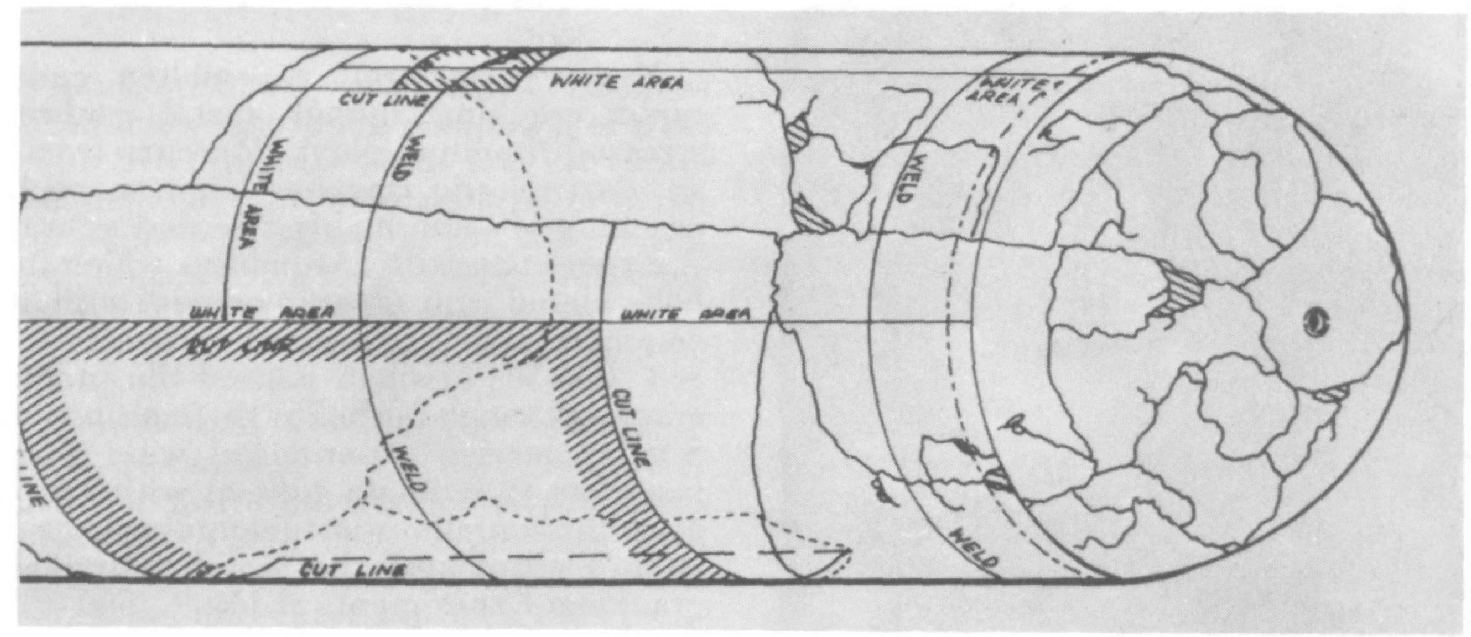

FIGURE 3. Sketch showing jagged fracturing of Ti-6\% $\mathrm{Al}-4 \% \mathrm{~V}$ Apollo pressure vessel as a consequence of SCC by methanol used as a pressuring fluid. Courtesy of Dr. L. J. Korb. Rockwell International Space Division.

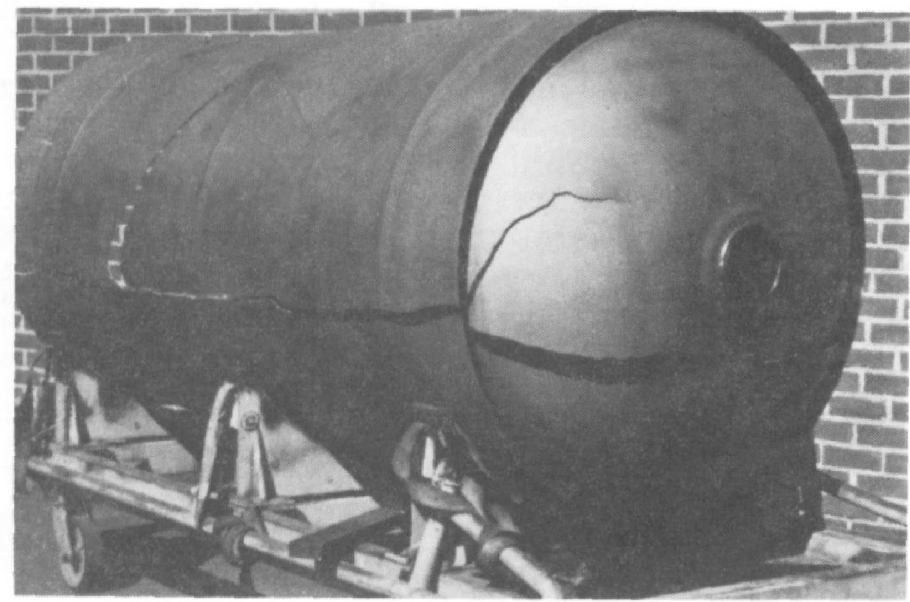

FIGURE 4. Rocket motor case made of $\mathrm{Ti}-6 \% \mathrm{Al}-4 \% \mathrm{~V}$ which failed during hydrostatic testing, possibly due to marking fluid. Photo courtesy of Mr. Carl Hartbower.

plications of titanium above $600{ }^{\circ} \mathrm{F}\left(315^{\circ} \mathrm{C}\right)$ should include considerations of the hot salt cracking phenomenon."

Organic fluids. In addition to methanol, the following organic compounds have been reported to cause SCC in one or more titanium alloys: Carbon tetrachloride, chlorinated diphenyl (at 315 ${ }^{\circ} \mathrm{C}, 600{ }^{\circ} \mathrm{F}$ ), ethanol, monomethyl hydrazine, trichlorofluoromethane, trichlorotrifluoroethane, and trichloroethane. None of these fluids poses as serious a threat as does methanol. Although laboratory tests indicate that $\mathrm{Ti}-6 \% \mathrm{Al}-4 \% \mathrm{~V}$ is susceptible to cracking in monomethyl hydrazine, the susceptibility is sufficiently minor (according to NASA's Johnson Space Center) that there has been a perfect service performance record with this combination of alloy and environment.
Some specifications for aircraft prohibit the use of chlorinated hydrocarbons to degrease titanium components for fear of residues, particularly chlorides and acids, which might give problems in service. MIL-STD 1568 cautions that care be taken to ensure that cleaning fluids and other chemicals used on titanium alloys are not detrimental to them. Substances known to be capable of producing SCC include "hydrochloric acid, trichloroethylene, carbon tetrachloride, chlorinated cutting oils, freons, methyl alcohol, and all chlorides." British practice reportedly permits the use of chlorinated hydrocarbons, including trichloroethylene, providing they are inhibited by the addition of deactivating agents such as butylene and acid absorbers such as triethylamine.

In the chemical industry some cracking has been observed in titanium processing equipment attributed to reducing organic acids at elevated temperatures. Iron contamination of the surface such as by wire brushing or by using steel forming tools plays a causative role, with high iron content of the alloy perhaps playing a contributive role. Preventive measures include avoiding contamination of the surface by iron, or, failing this, removing the iron before heat treatment or welding operations, which cause the iron to diffuse into the titanium. A preventive measure routinely practiced by one large chemical industry consists of anodizing equipment after final assembly. The anodizing removes any iron from the surface and also generates a thick oxide which better insulates the metal from the chemical environment than does the naturally formed oxide. (ref. [3])

Nitrogen tetroxide $\left(\mathrm{N}_{2} \mathrm{O}_{4}\right)$. This liquid is an oxidizer widely used in aerospace propulsion units, and it had been contained successfully in pressure vessels made of $\mathrm{Ti}-6 \% \mathrm{Al}-4 \% \mathrm{~V}$ until one such pressure vessel shattered (fig. 5). Investigation ultimately disclosed that the $\mathrm{N}_{2} \mathrm{O}_{4}$ which caused cracking was purer than had been previously supplied, in 


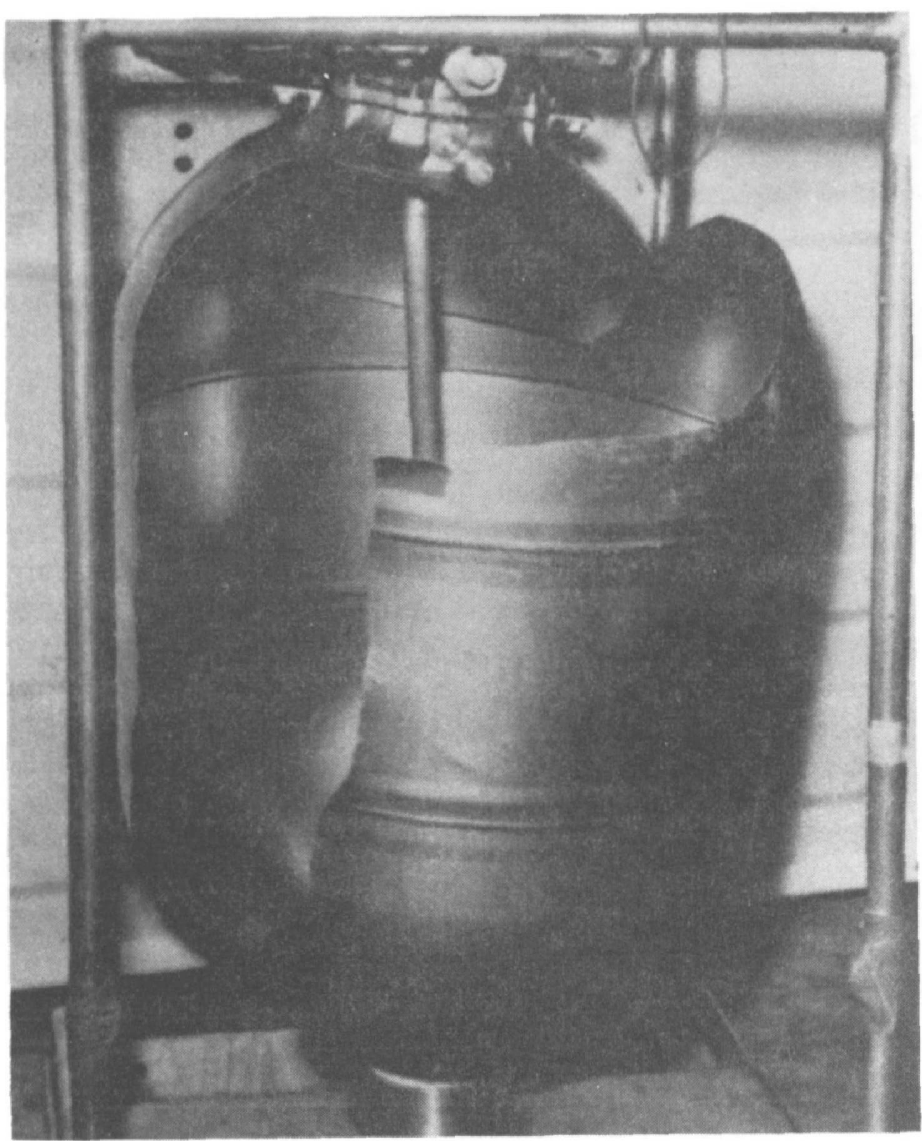

FIGURE 5. Pressure vessel made of Ti-6\%Al-4\%V which cracked because of $\mathrm{N}_{2} \mathrm{O}_{4}$. Photo courtesy of Dr. L. J. Korb, Rockwell International Space Division.

particular being low in nitric oxide (NO) (a "no-NO" situation, as it were.) The problem was brought under control when the SCC inhibitive property of the NO was identified and a specification was put into effect (NASA PPD-2B) which calls for $0.60-1$ percent NO. The reason for the inhibitive action of $\mathrm{NO}$ is unknown.

Red fuming nitric acid. This liquid has also been widely used as an oxidizer in aerospace propulsion units. It was found to cause SCC in, and pyrophoric reaction with, titanium until the addition of water was found to inhibit the attack. A military specification was then written calling for up to 14 percent $\mathrm{NO}_{2}$ and 2.5 percent $\mathrm{H}_{2} \mathrm{O}$, balance $\mathrm{HNO}_{3}$.

Gases. Moist chlorine gas at temperatures of 290 ${ }^{\circ} \mathrm{C}\left(550{ }^{\circ} \mathrm{F}\right)$ and higher has been reported to crack various titanium alloys. Hydrogen chloride has caused cracking of the alloy $\mathrm{Ti}-8 \% \mathrm{Al}-1 \% \mathrm{Mo}-1 \% \mathrm{~V}$. Hydrogen gas causes slow crack growth of preexisting cracks in stressed titanium alloys but is of little hazard to relatively unstressed titanium at room temperature providing the protective oxide film is in good condition and gross flaws are absent. Water vapor does not appear to cause slow crack growth even in $\mathrm{Ti}-8 \% \mathrm{Al}-1 \% \mathrm{Mo}-1 \% \mathrm{~V}$, which is very sensitive to aqueous SCC.

\section{Solid and Liquid Metals}

Mercury, gallium and molten cadmium cause rapid cracking (liquid metal embrittlement) of stressed titanium alloys. Mercury from a biocide in an elastromeric ring has been suspected to cause cracking of some highly stressed aircraft parts.

Experience with assemblies which included steel bolts plated with silver in contact with any of several commercial titanium alloys demonstrated that above $343{ }^{\circ} \mathrm{C}\left(650^{\circ} \mathrm{F}\right)$ silver caused the titanium alloys to crack, although far below the melting point of sliver. Similar service experienced with cadmium plated fasteners in intimate contact with various commercial titanium alloys at temperatures as low as $38^{\circ} \mathrm{C}$ $\left(100{ }^{\circ} \mathrm{F}\right)$ indicates that solid cadmium can cause cracking. Experiments at $150^{\circ} \mathrm{C}\left(300^{\circ} \mathrm{F}\right)$ showed that cracks so formed are self-limiting in depth at about 1 $\mathrm{mm}(0.05 \mathrm{in})$. Cracks of such depth might not be of much concern unless conditions should be such that they might initiate fatigue or fast (brittle) fracture. It should be noted that this solid cadmium cracking of titanium is not related to the cracking problem caused by electroplating cadmium on high strength steels.

As a consequence of the experience cited above and other evidence, MIL-STD 1568 prohibits cadmium plating of titanium parts and their use in direct contact with other cadmium plated parts or tools. This Standard also calls for avoiding silver brazing of titanium parts and avoiding silver plated fasteners for elevated temperature service. MIL-S-5002C prohibits silver plating on titanium or in contact with titanium.

\section{Sustained Load Cracking in Inert Environments}

Sustained load cracking (SLC) in inert environments (including air) is a type of slow crack growth of practical importance to highly stressed critical components for contemporary military aircraft and possibly to other applications of advanced titanium technology. It is similar to SCC except that it is much slower and occurs in the total absence of a reactive environment. SLC is caused by, or is enormously exacerbated by, hydrogen dissolved in the titanium during processing, and the present military specification of $125 \mathrm{ppm}$ maximum hydrogen for most titanium alloys is far too generous to prevent this mode of cracking under high sustained stresses. Weldments are particularly vulnerable to SLC partly due to the additional hydrogen which tends to be added during the welding process and partly due to the residual stresses left in a weldment unless it can be stress relieved. Vacuum annealing can reduce the hydrogen level to less than $10 \mathrm{ppm}$, at which concentrations the threat of SLC is largely removed (ref. [4]). Even as high as $125 \mathrm{ppm}$ hydrogen appears not to have caused SLC in the alloys and designs (including stress levels) common in the chemical industry. 


\section{Diagnostic Criteria}

The purely mechanical overload fracture surfaces of commercial titanium alloys are composed of dimples (fig. 6). The SCC fracture paths may be cleavage (fig. 7) in alpha alloys, or in beta alloys, or in the alpha phase of alpha-beta alloys; in the latter case, the beta phase may part by a microvoid coalescence process. Cleavage SCC fractures may or may not exhibit branching. SCC in these alloys may also be intergranular.

Whether the crack path is cleavage or intergranular, or whether it is branched or not, does not appear to be diagnostic of just what sort of environment caused the cracking. These choices of crack path appear rather to be related to the region in the stress intensity $(K)$-cracking rate curve in which the cracking was produced, in a manner as shown in figure 8 .

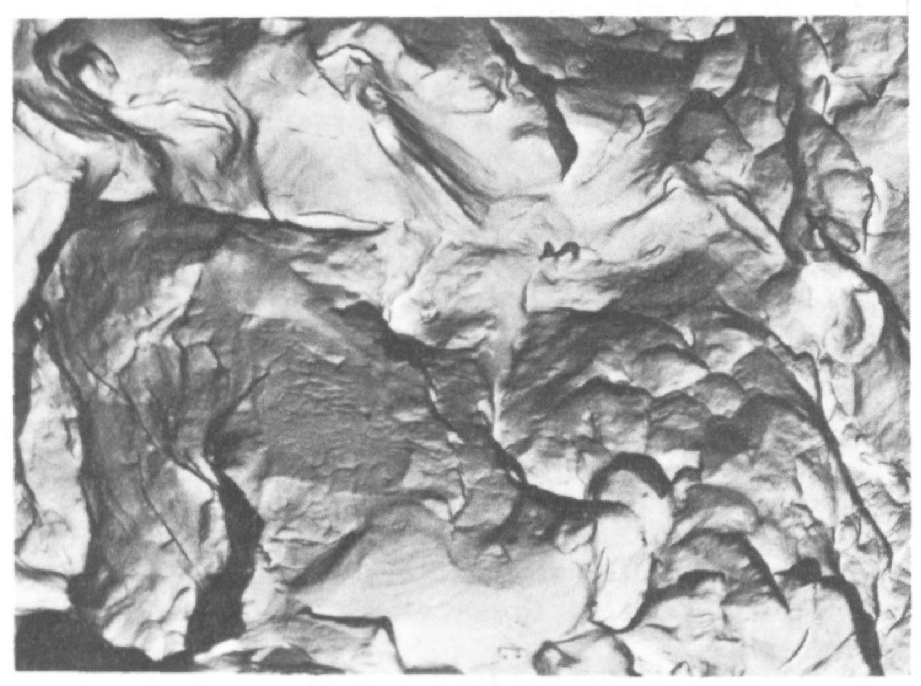

FIGURE 6. Dimples of variegated size produced by purely mechanical "plane strain" fracturing of Ti-8\%Al-1\%Mo-1\%V. Electron fractograph, magnification 6000X. Courtesy of Mr. D. A. Meyn.

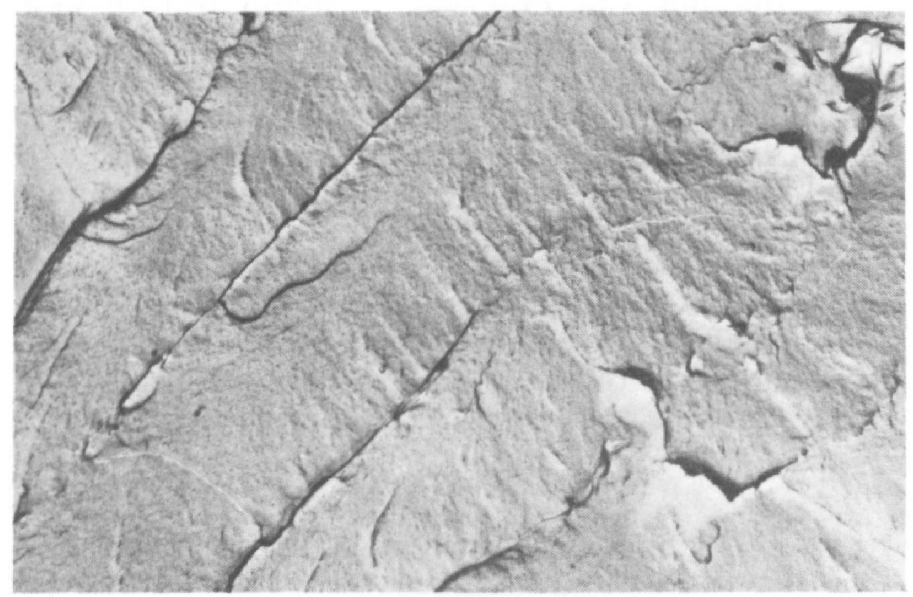

FIGURE 7. Intergranular cleavage-like SCC fracture of Ti-8\%Al$1 \% \mathrm{Mo}-1 \% \mathrm{~V}$ in salt water. Note local plasticity toward right side. Electron fractograph, magnification $6000 \mathrm{X}$. Courtesy of Mr. D. A. Meyn.

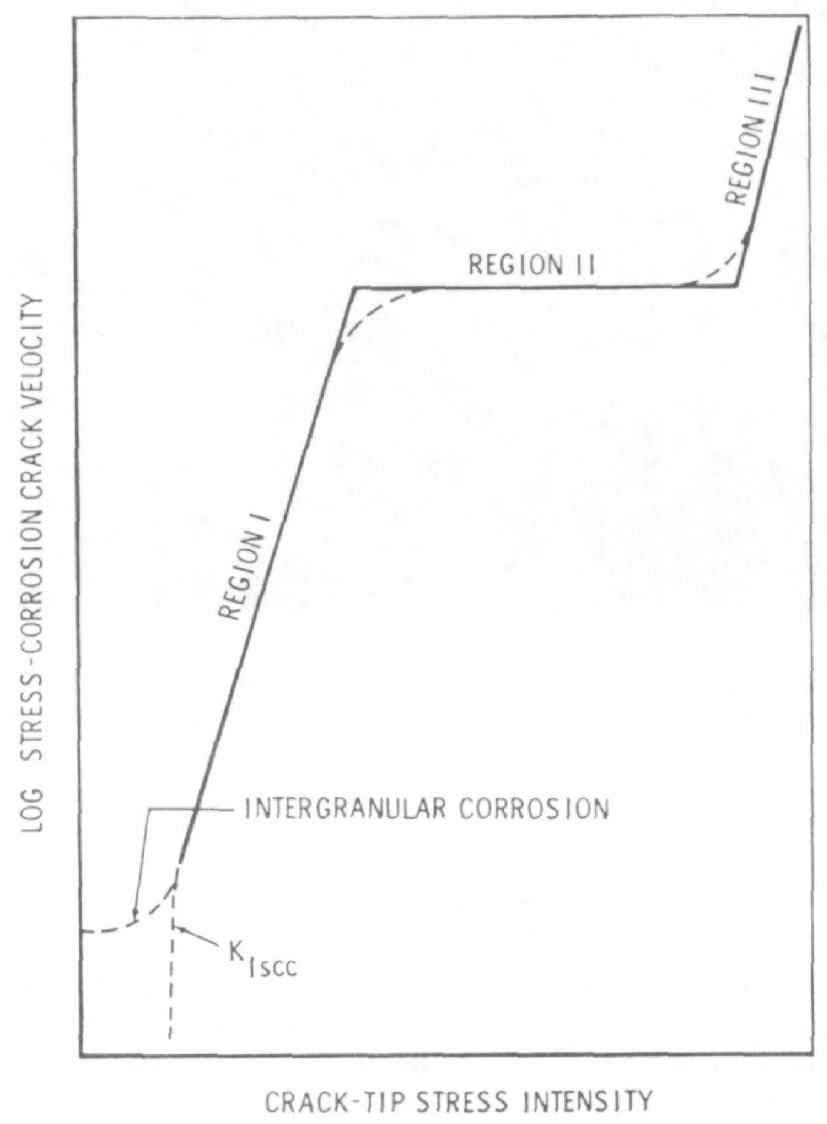

FIGURE 8. Appearance of stress corrosion cracks in titanium alloys is generally relatable to cracking kinetic behavior: Region I cracking tends to be intergranular, region II is clevage-like plus dimples which increase in size and proportion with increasing crack tip stress intensity, becoming entirely dimples in region 111 (approaching $K_{l c}$ conditions). See Reference [1] for details.

In region I the cracks are intergranular, with some cleavage which increases in proportion as the $K$ level rises toward the plateau, and there may also be incipient branching on a microscopic scale. On the plateau the fractures are cleavage plus dimples (microvoids) which increase in proportion as the $K$ level rises; macro-branching may appear in the plateau region. The foregoing is to be taken as a generalization from which there may be exceptions, but it holds for many combinations of alloys and environments, including liquid metals such as mercury. One known exception is carbon tetrachloride, for which no intergranular SCC has been reported even though clearcut region I behavior is exhibited.

Although many SCC fractures are cleavage (transgranular), some low-amplitude fatigue fractures and sustained-load fractures may be so similar in appearance that these three fracture modes may not be distinguishable by even skillful electron fractography.

There is one environment, gaseous hydrogen, which produces what appears to be a fracture topography differing enough from other fracture mode topography to be diagnostic, and that topography is terraced cleavage, as shown in figure 9. 


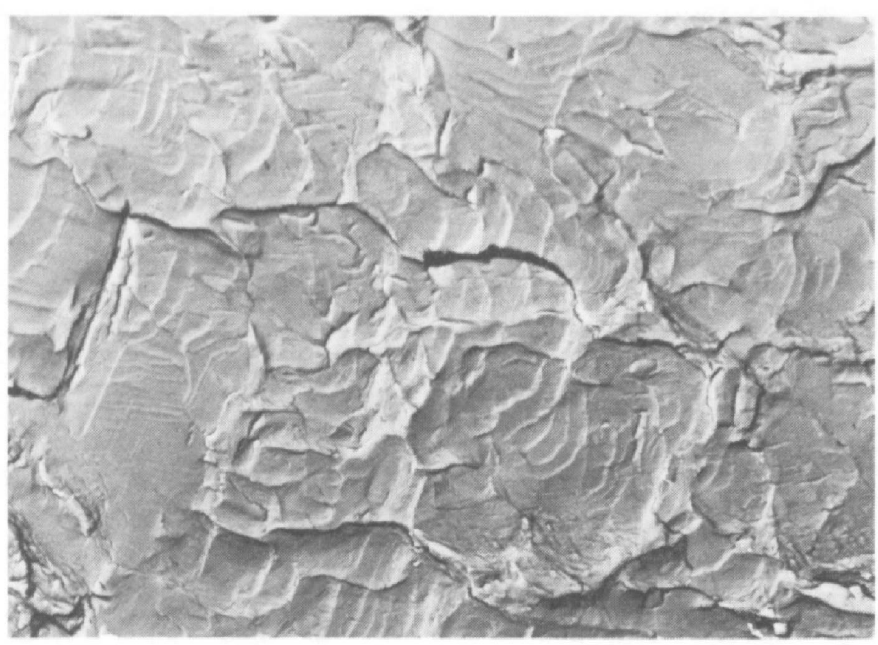

Figure 9. Terraced Cleavage in Ti-8\%Al-1\%Mo-1\%V cracked in gaseous hydrogen. Electron fractograph, magnification 3000X. Courtesy of Mr. D. A. Meyn.

\section{Theory}

One would not expect to find a single mechanism to account for SCC in titanium alloys in all the diverse environments in which it is observed. One mechanism which has been proposed for several environments, however, involves hydrogen which is envisioned as sorbing at crack growth sites and reducing the energy for separation. It is known that hydrogen in the alloy, inherited from processing, can cause sustained load cracking in titanium alloys, and it is entirely credible that during the SCC process in titanium alloys in sea water, distilled water, and methanol, hydrogen can be reduced from the environment, enter the metal, and cause cracking by the same ultimate mechanism as dissolved hydrogen or perhaps also gaseous hydrogen.

Titanium when stressed in salt water is ordinarily kept passive by reaction with the water to form a tight adherent layer of $\mathrm{TiO}_{2}$, which insulates the underlying metal from the environment and stifles further attack. But inside a crack the reaction of titanium with water to produce $\mathrm{TiO}_{2}\left(\mathrm{Ti}+2 \mathrm{H}_{2} \mathrm{O}=\right.$ $\mathrm{TiO}_{2}+4 \mathrm{H}^{+}+4 \mathrm{e}$ ) also produces excess hydrogen ions which cause local acidity. This acidity builds up to the point that $\mathrm{TiO}_{2}$ is not stable. Therefore the crack tip can not go passive but continues to react to produce hydrogen, some of which enters the metal and the rest of which is available to maintain the local acidity.

With methanol, titanium reacts to form an organic compound which is soluble in methanol and which therefore does not form a protective film; the reaction also produces hydrogen which can enter the titanium metal to participate in the cracking process. In methanol no generation of acid is therefore required to prevent titanium from passivating-the solubility of the metallic corrosion product obviates that need. Hence, in methanol the crack can initiate from a smooth surface.
Hot salt cracking appears to occur as follows: sodium choloride produces hydrochloric acid locally by reactions involving pyrohydrolysis and the acid penetrates the otherwise protective oxide film. The acid then attacks the underlying metal, producing hydrogen. The hydrogen then enters the metal and assists the sustained stress to produce a fracture which is typically intergranular near the surface and partially cleavage away from the surface. The hydrogen is viewed as reducing the energy for fracture by sorbing, as noted above.

The mechanism of cracking in $\mathrm{N}_{2} \mathrm{O}_{4}$ may require the periodic rupture of the oxide at the crack tip, followed by the oxidation of the bared metal, then repetition of the cycle, somewhat like the mechanism postulate for brass in tarnishing solutions.

\section{Summary}

The practical SCC hazards to titanium involve a wide range of environments.

For some groups of environments, such as natural waters and nearly neutral aqueous solutions, the cracking occurs only in the presence of a preexisting crack-like flaw, and fracture mechanics type tests readily characterize the SCC behavior of alloys. Unalloyed titanium and the widely used $\mathrm{Ti}-$ $6 \% \mathrm{Al}-4 \% \mathrm{~V}$ alloy are reasonably resistant to $\mathrm{SCC}$ in these environments. The alloys $\mathrm{Ti}-8 \% \mathrm{Mn}, \mathrm{Ti}-$ $4 \% \mathrm{Al}-4 \% \mathrm{Mn}, \mathrm{Ti}-8 \% \mathrm{Al}-1 \% \mathrm{Mo}-1 \% \mathrm{~V}, \mathrm{Ti}-7$ or $8 \% \mathrm{Al}-$ $2 \% \mathrm{Cb}-1 \% \mathrm{Ta}$, Ti-5\% Al-5\%Zr-5\% Sn, Ti-5\% Al- $1.4 \%$ $\mathrm{Cr}-1.5 \% \mathrm{Fe}-1.2 \% \mathrm{Mo}$, Ti-5\% Al-2.27\% Cr-1.25\% Fe, Ti-5\%Al-2 $1 / 2 \% \mathrm{Sn}, \mathrm{Ti}-13 \% \mathrm{~V}-11 \% \mathrm{Cr}-3 \% \mathrm{Al}$, Ti$100 \mathrm{~A}$ and $\mathrm{Ti}-5 \% \mathrm{Al}-4 \%(\mathrm{Fe}+\mathrm{Cr})$ should be avoided unless specific SCC tests using precracked specimens demonstrate compatibility with the service environment. Most of these alloys are no longer in production.

For two chemical oxidizers, $\mathrm{N}_{2} \mathrm{O}_{4}$ and red fuming nitric acid, practical control of the problem is available through controlling the composition of the oxidizers, for which standard specifications are available.

For the hot salt cracking problem during heat treatment, meticulous cleanliness of the titanium, backed up preferably by excluding moisture and oxygen from the heat treating atmosphere, serves to control the problem. Though untried in practice, a nickel barrier paint may be useful when contamination at elevated temperatures cannot be avoided in service; the alternative is to design for low operating stresses, but these have not been quantified.

For some environments, such as methanol, mercury, cadmium or silver, the necessary strategy is simply to exclude them from titanium surfaces.

\section{References}

[1] Blackburn, M. J., Smyrl, W. H. and Feeney, J. A., Stress corrosion cracking in high strength steels and in titanium and aluminum alloys. (B. F. Brown, ed.), Naval Research Lab., Washington, D. C., 1972, p. 245.

[2] Feige, N. G. and Covington, L. C., STP 518 (H. Lee Craig, Jr., Ed.), Am. Soc. for Testing and Mat., Philadelphia, PA, (1972), p. 119. 


\section{Trtanium Alloys}

[3] Cotton, J. B., The science, technology and application of titanium, (Robert I. Jaffee and N. E. Promisel, Eds.), (Pergamon, London, 1970), p. 156.
[4] Meyn, D. A., Effect of hydrogen on fracture and inertenvironment sustained load cracking resistance of alphabeta titanium alloys, Metallurgical Transactions, Vol. 5, No. 11, p. 2405 (1974). 



\section{CHAPTER 6}

\section{HIGH STRENGTH STEELS}

The term "high strength steel" as used in this work refers to a steel having a yield strength of 130 $\mathrm{ksi}\left(900 \mathrm{MNm}^{-2}\right)$ or greater, whether the strength is developed by heat treatment of any sort or by cold working, and whether the steel is stainless or not. Two cases involving lower strength steel are included because generically they belong to the high strength family and they illustrate important points. The factors involved in most service SCC are the following:

(a) Water, aqueous solutions, atmospheric water vapor, $\mathrm{H}_{2} \mathrm{~S}$ and $\mathrm{H}_{2}$

(b) Sustained tensile stress

(c) Degree of susceptibility

(d) Electrochemical potential

For the most part, the environments which are of major concern to the cracking of high strength steels are natural waters-rain water, sea water, and atmospheric moisture. Any of these may of course be contaminated to produce environments significantly more likely to cause SCC than the uncontaminated ones. Contamination with $\mathrm{H}_{2} \mathrm{~S}$ is especially serious, and in fact the presence of $\mathrm{H}_{2} \mathrm{~S}$ in high concentrations in salt water associated with certain deep oil wells (termed "sour crude" wells) places an upper limit (roughly $90 \mathrm{ksi}, 600 \mathrm{MNm}^{-2}$ ) on the yield strength which can be tolerated in stressed steel in such environments without causing cracking. This experience, together with experience with sour gas condensate wells, has given rise to a "sour" test solution of water plus 0.5 percent acetic acid, the whole periodically saturated with $\mathrm{H}_{2} \mathrm{~S}$; this solution may additionally contain either 3.5 or 6 percent $\mathrm{NaCl}$. Such a solution may constitute something of a worst case for high strength steels, but most present day investigators consider the sour test solution as being unrealistically agressive to give useful ranking of the various steels for service not involving $\mathrm{H}_{2} \mathrm{~S}$. Those investigators who are engaged in comparing the SCC properties of various steels usually employ water containing about 3.5 percent $\mathrm{NaCl}$, artificial sea water, the marine atmosphere, or (rarely) natural sea water.

For many small components such as bolts and springs made of high strength heat treated steels for stresses causing service SCC failures are the design stresses, but in large forgings the heat treating stresses are the most important cause of failures. In other cases, assembly stresses can be responsible, for example in certain rocket motor cases made of hard rolled AISI 301 stainless steel sheets assembled by spot welding; residual stresses associated with these spot welds have caused some service failures. Although the term "sustained" stress is almost inevit- ably used as one of the necessary conditions for SCC, note that repetitive loads between two levels in tension, or from tension to zero stress, can constitute the necessary and sufficient stress conditions for SCC, even though it may be "cyclic SCC.," and such failures have been noted in high strength steel fasteners in vibrating equipment.

By way of introduction let us briefly review the physical metallurgy and nomenclature of the various classes of high strength steels. The martensitic steels, also known as quenched and tempered or Q $\& \mathrm{~T}$ steels, have been known since antiquity, but the technology of present day low alloy martensitic steels is a 20th century development, and current premium melting technologies are space age developments. Some of the martensitic steels, typified by AISI type 410 , contain enough chromium to qualify as stainless steels. The martensitic steels are heat treated by being first heated into the range of very roughly $840-1000^{\circ} \mathrm{C}\left(1550-1830^{\circ} \mathrm{F}\right)$, at which temperature the crystal structure is face centered cubic and is designated austenitic. The carbon dissolves in this austenite, which upon being quenched or otherwise sufficiently rapidly cooled, transforms to a metastable body-centered tetragonal structure designated martensite. The maximum hardness and strength which this martensite can possess is determined largely by the amount of carbon originally dissolved in the austenite, but in commercial steels this maximum strength is usually accompanied by brittleness too severe to be tolerated, so that the strength of the as-quenched martensite is sacrificed in a tempering operation to improve the toughness to an acceptable level.

The precipitation hardening steels are also hardened by heat treatment, in this case consisting of solution treatment at high temperature followed by rapid cooling which may or may not form martensite, depending on composition. Even if martensite is formed, it is not hard like the martensite of AISI 4340 steel, for example, and the strengthening of the alloy is achieved by subsequent precipitation (or aging) reactions at elevated temperature. Underaging at lower temperatures and overaging at higher temperature produce less than the maximum strength with compensating changes in brittleness and SCC characteristics. Most of the precipitation hardening steels are stainless.

The maraging steels-the name represents an abbreviated combination of "martensitic" and "aging"-constitute the newest class of heat treated high strength steels. After being solution treated (annealed) at high temperature $\left(815^{\circ} \mathrm{C}, 1500^{\circ} \mathrm{F}\right)$ and cooled, they are martensitic, but the martensite contains extremely low carbon and is of low strength until after being aged $\left(480^{\circ} \mathrm{C}, 900^{\circ} \mathrm{F}\right)$. One of the 
interesting possibilities of the maraging steels is the ability to make very large structures which require only the low temperature aging treatment to achieve very high strength. Annealed plates are welded, and the as-welded weld areas are in the annealed condition, ready for both prime plate and weld areas to be strengthened by the low temperature aging treatment. We will see an example of a structure-a research submersible-too large to be readily heat treated if made of a martensitic steel but successfully fabricated of the 18 percent nickel grade maraging steel. Stainless grades of maraging steels have been developed.

One may distinguish three classes of steels whose high strength is due to cold work. (1) One is unalloyed carbon steel such as is used in making wire rope (cable) or piano wire. The steel used extensively for bridge cable has a yield strength typically $180 \mathrm{ksi}$ $\left(1250 \mathrm{MNm}^{-2}\right)$; this steel consists of crystals of ferrite (body centered cubic iron) plus aggregates of ferrite plus iron carbide (the aggregate termed pearlite), all highly deformed and, incidentially, ferromagnetic. (2) AISI type $301 \mathrm{EFH}$ (extra full hard) is a stainless steel having a yield strength which can exceed $230 \mathrm{ksi}\left(1600 \mathrm{MNm}^{-2}\right)$; the deformation process produces some martensite, and the alloy is weakly magnetic because of this martensite. 301 EFH is used for some rocket cases, e.g., those rockets used for the launching of communication satellites. (3) Finally there is a class of high strength cold worked steels containing a high percent of manganese (e.g., $18 \% \mathrm{Mn}$ ) but which are fully austenitic and are therefore nonmagnetic. Because of their high strength (e.g., yield strength $175 \mathrm{ksi}, 1200$ $\mathrm{MNm}^{-2}$ ) and nonmagnetic character, they are used for retainer rings for generator rotors. This class of steel can be made stainless if desired.

Table 1 below summarizes the various groups of high strength steels and gives examples of prominent types in each group.

TABLE 1. Summary of types of high strength steels

\begin{tabular}{ll}
\hline \multicolumn{1}{c}{ General group } & \multicolumn{1}{c}{ Examples of types } \\
\hline & Heat treated \\
Low alloy martensitic & AISI 4130, AISI 4330, AISI 4340, 300M \\
Stainless martensitic & AISI 403, AISI 410, AISI 416, AISI 431 \\
Precipitation hardening & $\begin{array}{l}\text { AM-350, Almar 362, 17-4PH, PH13-8- } \\
\text { Mo }\end{array}$ \\
Maraging steels & $\begin{array}{l}18 \% \text { nickel grades 200, 250, \& 300 } \\
\text { Unalloyed }\end{array}$ \\
Cold worked \\
Austenitic & $\begin{array}{c}\text { Piano wire, wire rope (cable, "improved } \\
\text { plow steel") }\end{array}$ \\
Stainless & $\begin{array}{l}18 \% \text { manganese } \\
\text { AISI 301 }\end{array}$ \\
\hline
\end{tabular}

As in other alloy families, the Unified Numbering System for steels consists of a letter followed by five numbers. The letter may be G for AISI and SAE carbon and nonstainless alloy steels, $H$ for steels of controlled response to heat treatment (hardenability), $\mathrm{K}$ for miscellaneous alloy and specialty steels (such as valve steels), $\mathrm{S}$ for stainless steels, and $\mathrm{T}$ for tool steels. The five numbers usually incorporate the numbers of the most commonly known designation. Thus S41000 is AISI type 410 stainless steel, G43400 is AISI type 4340 , and S17400 is $17-4 \mathrm{PH}$. But the tool steel designated AISI H-11 is T20811. Some of the important high strength steels such as the maraging steels have not yet been assigned a UNS designation. All the UNS designations for steels have appeared too recently to have been incorporated in the literature, and for the most part only the older designations will be used here.

\section{Degree of Susceptibility}

There seems to be little doubt that in salt water and fresh water there exists a true threshold $K_{\text {Iscc }}$ for all the high strength steels which have been tested using fracture mechanics methods, and this appears to be a useful way to characterize their SCC behavior. The best available summary of SCC characteristics of heat treated high strength steels is given in reference [1], from which figure 1 is taken. In this figure the data were taken in salt water or sea water environments in the freely corroding condition. For modern clean commercial steels the SCC characteristics show little anisotropy, but even so they are customarily tested in the most vulnerable direction, S-L. (See ch. 4, figs. 1 and 2 for the meaning of this designation.) The graphs of figure 1 show $K_{I s c c}$ plotted against yield strength, but rather than individual points, envelopes are drawn enclosing all known valid data for the various steels. The steel featured in each individual graph is represented by the envelope drawn with a heavy line which can be compared with characteristics available in other steels represented by the light envelopes. See chapter 2 for further explanation of the diagrams of figure 1 .

From data such as those from which figure 1 was derived and other studies the following generalizations have been derived. The most important single factor in determining the SCC characteristics of steels is strength level. Yet at any given strength level there are obviously other factors which can combine to make large differences in characteristics. High manganese content, (e.g., 2 percent; used in part to counter the embrittling effect of sulfur) is detrimental to the SCC characteristics of martensitic steels. High purity in high strength steels, such as one can achieve using premium melting stock vacuum-induction melted and vacuum arc remelted (VIM-VAR), is associated with superior SCC properties, possibly attributable to low sulfur and oxides. (Note for example HP 9-4-20 and the upper bound for maraging steel in fig. 1.) In martensitic steels at a given strength level there appears to be an advan- 
tage to having low carbon contents, e.g., 0.2 percent or less. There are other elements the presence of which affects SCC characteristics, but these have not been identified. One structural feature has been
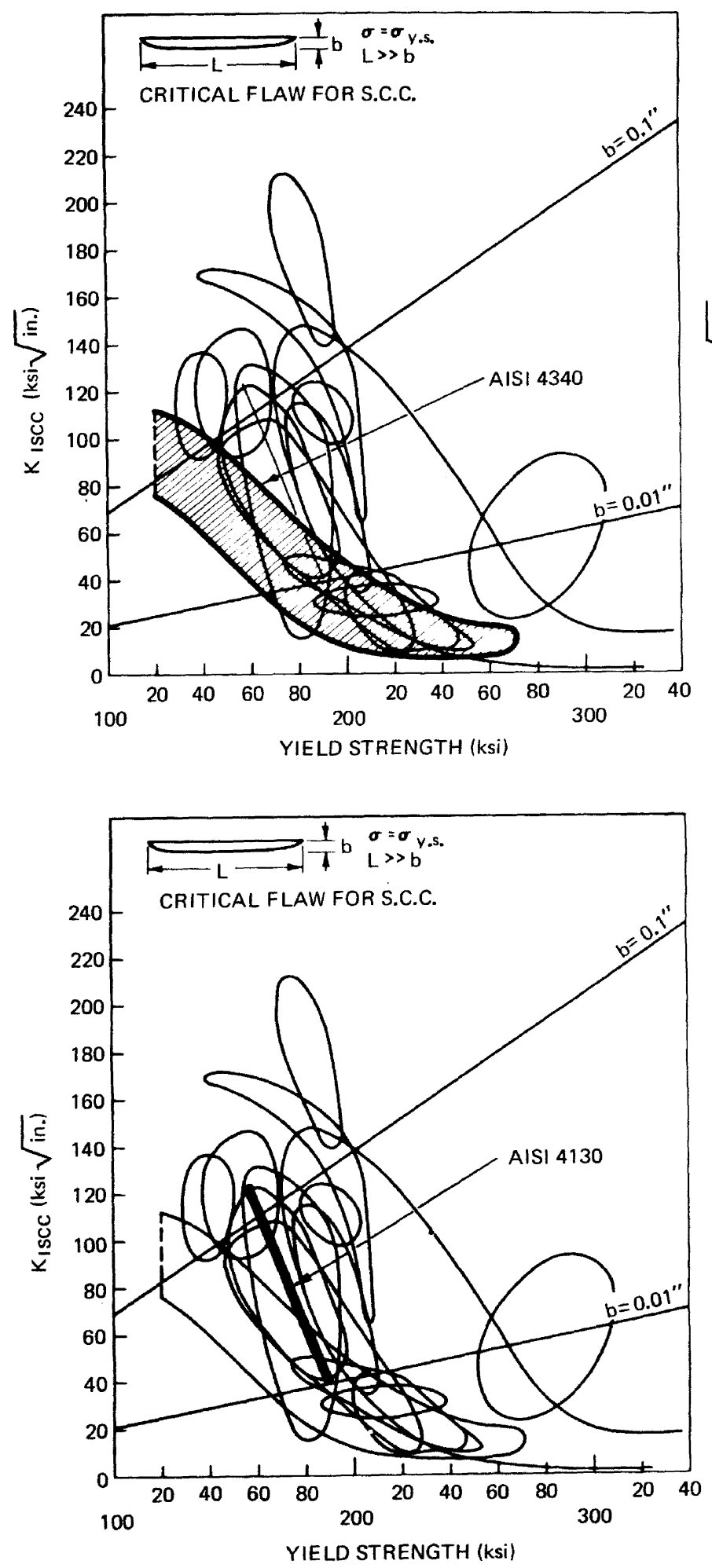

identified as being very detrimental to SCC properties of martensitic steels, and that is the structure which the metallographer terms "twinned martensite."
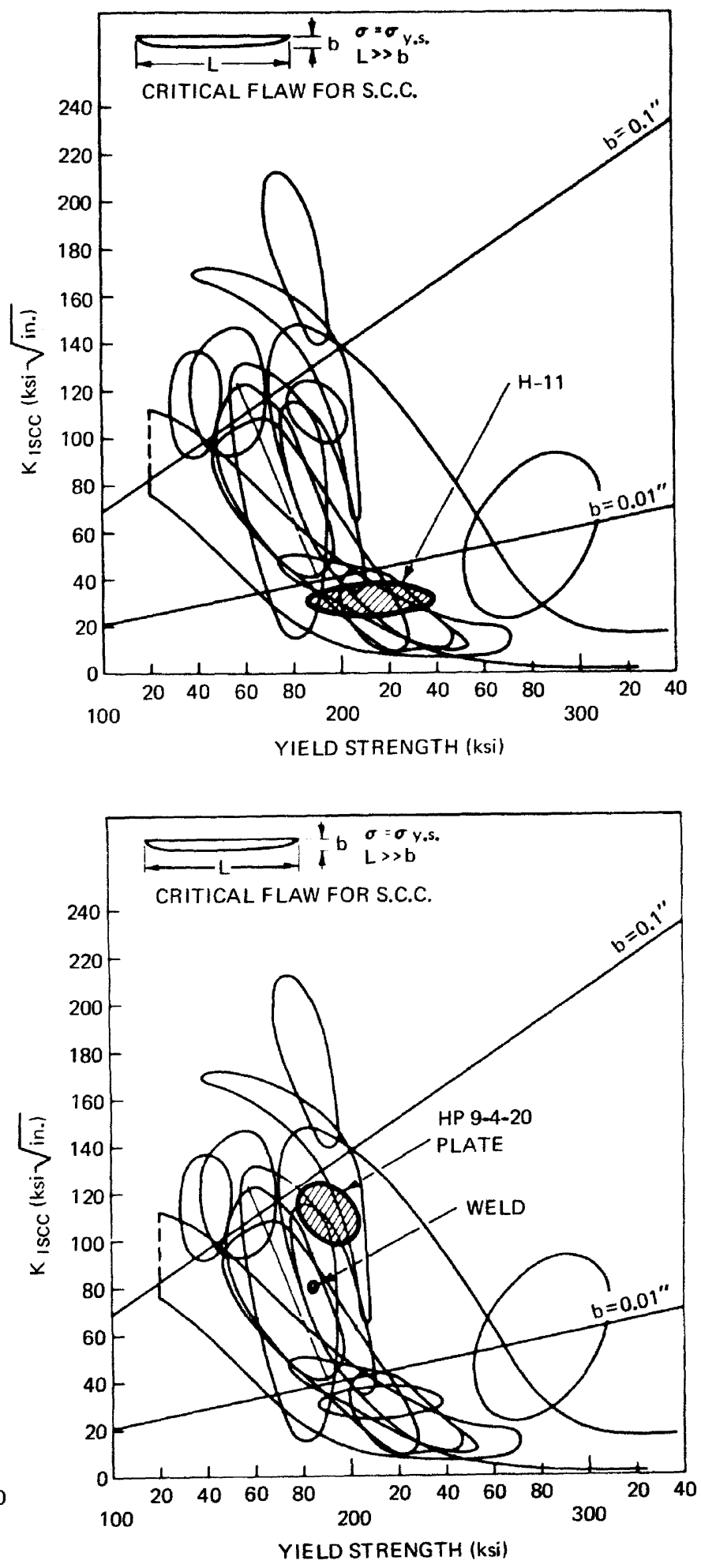

FIGURE 1. Envelopes for $\mathrm{K}_{\mathrm{lscc}}$ data for individual steels (heavy line) compared with similar envelopes for other steels (light line). Oval envelope at far right is for strain-aged experimental alloy AF-77; its interesting properties may be due to cold work. From Sandoz (ref. [1]). 
The high chromium content which confers stainlessness in the ordinary sense does not confer immunity to SCC, as the data for $17-4 \mathrm{PH}$ steel clearly show. In point of fact, the data shown for this alloy may be grossly optimistic, as may similar data taken on all other stainless high strength steels in salt water. The reason is that the saline test solution is nearly neutral, whereas in sheltered areas, such as in crevices, the salt water tends to become extremely acid, the $\mathrm{pH}$ about $\mathrm{l}$, and this acid solution
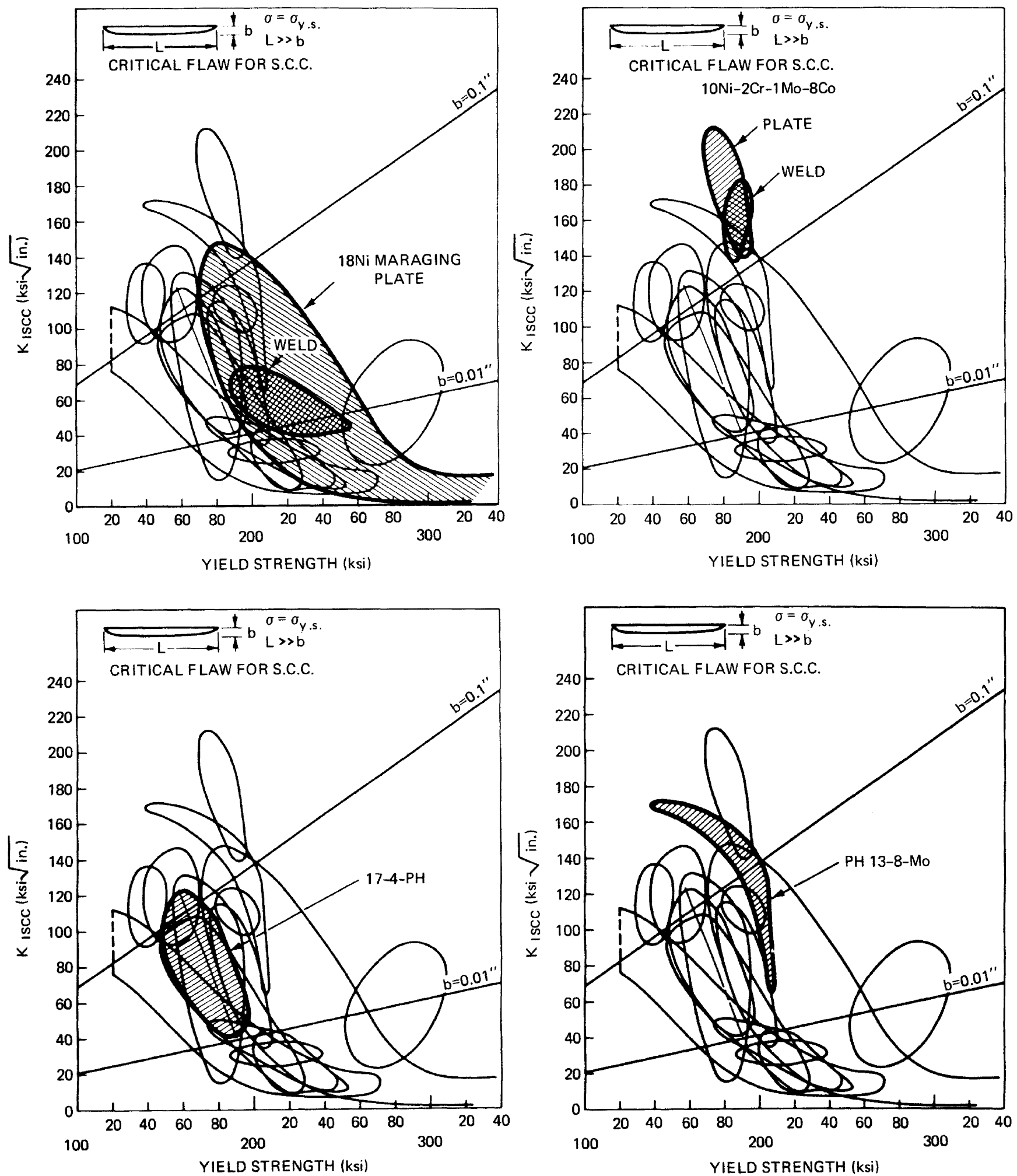

Figure 1. (continued) 
can be extremely effective in initiating SCC. The reason for this acidity is understood by the corrosion scientist as a consequence of a chemical reaction termed the hydrolysis of chromium corrosion products. This problem is discussed further under the topic of cathodic protection.

The acidity within corroding crevices in stainless
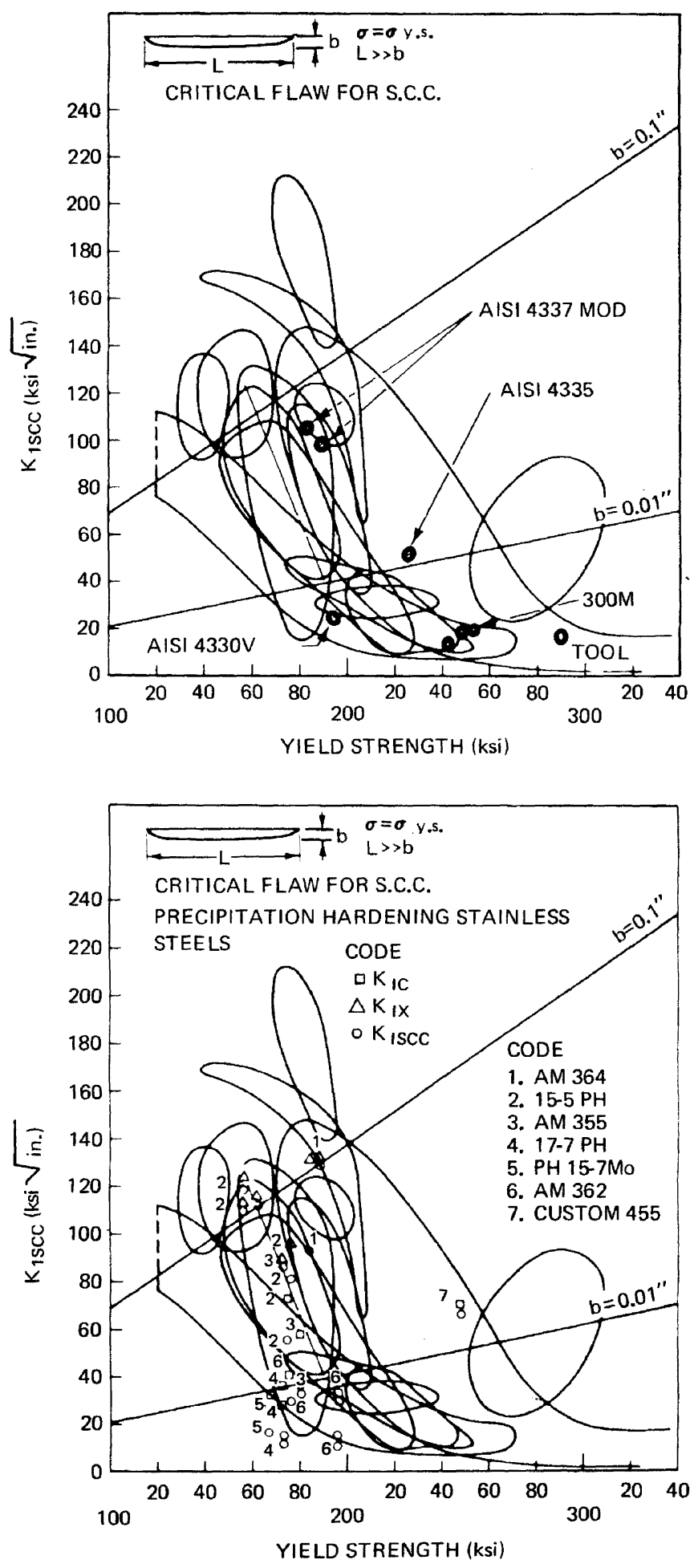

FIGURE 1. (continued) steels mentioned above represents an extreme situation. Variations in bulk $\mathrm{pH}$ from about 3 to 10 have little effect on cracking behavior. In the few comparisons which have been made, $K_{\text {Iscr }}$ values determined using 3.5 percent $\mathrm{NaCl}$ solution have not usually been found different from those determined using natural sea water.

Figure 1 includes only data on heat treated steels. The SCC characteristics of cold drawn wire such as is used for wire rope (cable) and bridges have not been well established by quantitative methods. AISI type 301 is one of the few nominally austenitic stainless steels which crack at room temperature in the atmosphere, but little can be said quantitatively about its characteristics. (In the usual cold-worked state, 301 contains much martensite). The $K_{\text {scc }}$ of the austenitic 18 percent manganese steel cold worked to produce a yield strength of $175 \mathrm{ksi}(1200$ $\mathrm{MNm}^{-2}$ ) for generator retaining rings, as determined in distilled water, was found to be about $7.5 \mathrm{ksi} \sqrt{\text { in }}(8$ $\mathrm{MNm}^{-3 \mid 2}$ ). Such a low value indicates that a scratch would suffice to set off SCC at stresses approaching yield. (ref. [2]) A related steel was used for the hull of a comatant submarine which will be mentioned further below.

Note in the graph for HP 9-4-20 steel in figure 1 that the weld metal has a somewhat lower resistance to SCC than does the prime plate. The limited experience to date suggests that this is usually the case with heat treated weldments, the weld centerline being often the most vulnerable location.

\section{Control Measures}

A primary measure to avoid SCC should be the selection of a steel with good SCC properties, in particular selecting one with no higher strength than is needed. In this regard the practice of specifying minimum strengths but not maximum strengths is a faulty one, not only with respect to SCC but with respect to brittle fracture as well.

The Marshall Space Flight Center (MSFC) guidelines (ref. [7]) permit the use of the steels in table 1 for space vehicles and associated equipment without prior approval. It should be understood that the information in tables 1,2 and 3 apply only to room temperature service in the atmosphere and do not pertain to elevated temperatures or to chemical environments, for which special information must be obtained.

The steels in table 2 may be used for aerospace equipment for MSFC only after MSFC approval. Proposed use of materials in this table for application involving high sustained tensile stress (such as springs and fasteners will not be approved.

The steels in table 3 have been found to be highly susceptible to SCC and MSFC permits their use only after it has been demonstrated conclusively that SCC is not possible for environmental reasons.

After a steel and its strength level have been selected, additional measures to mitigate SCC may be considered, as below. 
TABLE l. High strength steels with high resistance to stress corrosion cracking (after ref. [7])

\begin{tabular}{ll}
\hline \hline \multicolumn{1}{c}{ Steel } & \multicolumn{1}{c}{ Condition } \\
\hline AM350 stainless steel & SCT 1000 and above \\
AM355 stainless steel & SCT 1000 and above \\
Almar 362 stainless steel & H1000 and above \\
Custom 455 stainless steel & H1000 and above \\
PH 13-8 Mo stainless steel & H1000 and above \\
15-5 PH stainless steel & H1000 and above \\
17-4 PH stainless steel & H1000 and above \\
PH 14-8 Mo stainless steel & CH900 and SRH950 and above \\
PH 15-7 Mo stainless steel & CH900 \\
17-7 PH stainless steel & CH900 \\
Carbon steel (1000 Series) & Below 180 ksi YS (1250 MNm $\left.\mathrm{MN}^{-2}\right)$ \\
Low alloy steel (4130, 4340, & Below 180 ksi YS (1250 MNm \\
D6AC, etc.) & \\
Music wire (ASTM 228) & Cold drawn \\
\hline
\end{tabular}

TABLE 2. High strength steels with moderate resistance to stress corrosion cracking (after ref. [7])

\begin{tabular}{|c|c|}
\hline Steel & Condition \\
\hline Carbon steel (1000 series) & $\begin{array}{l}180 \text { to } 200 \mathrm{ksi} \text { Y.S. } \\
\quad\left(1250-1380 \mathrm{MNm}^{-2}\right)\end{array}$ \\
\hline $\begin{array}{l}\text { Low alloy steel }(4130,4340 \text {, } \\
\text { D6AC, etc.) }\end{array}$ & $\begin{array}{l}180 \text { to } 200 \mathrm{ksi} \text { Y.S. } \\
\left(1250-1380 \mathrm{MNm}^{-2}\right)\end{array}$ \\
\hline $\begin{array}{l}\text { PH13-8 Mo stainless steel } \\
15-5 \mathrm{PH} \text { stainless steel } \\
\text { 17-4PH stainless steel }\end{array}$ & $\begin{array}{l}\text { Below H1000 } \\
\text { Below H1000 } \\
\text { Below H1000 }\end{array}$ \\
\hline
\end{tabular}

TABLE 3. High strength steels with low resistance to stress corrosion cracking (after ref. [7])

Steel $\quad$ Condition

Carbon steel (1000 Series)

Low alloy steel $(4130,4340$, D6AC, etc.)

H-11 steel

440 stainless steel

$18 \mathrm{Ni}$ maraging steel, 200 grade $18 \mathrm{Ni}$ maraging steel, 250 grade $18 \mathrm{Ni}$ maraging steel, 300 grade $18 \mathrm{Ni}$ maraging steel, 350 grade AM 350 stainless steel

AM 355 stainless steel Custom 455 stainless steel PH 15-7 Mo stainless steel 17-7PH stainless steel
Above 200 ksi Y.S. (1380 $\mathrm{MNm}^{-2}$ )

Above $200 \mathrm{ksi}$ Y.S. (1380 $\mathrm{MNm}^{-2}$ )

Above 200 ksi Y.S. (1380 All $\mathrm{MNm}^{-2}$ )

Aged at $900^{\circ} \mathrm{F}\left(480^{\circ} \mathrm{C}\right)$ Aged at $900^{\circ} \mathrm{F}\left(480^{\circ} \mathrm{C}\right)$ Aged at $900^{\circ} \mathrm{F}\left(480^{\circ} \mathrm{C}\right)$ Aged at $900^{\circ} \mathrm{F}\left(480^{\circ} \mathrm{C}\right)$ Below SCT 1000

Below SCT 1000

Below H1000

All except CH900

All except $\mathrm{CH} 900$
Inhibitors are available which are very effective in preventing the growth of corrosion pits which are the common forerunners of SCC in steels in natural waters, and they should be considered for closed systems. Sodium chromate was at one time a common inhibitor, but its disposal now presents a problem because of environmental protection regulations. Effective as it was in preventing pitting, it has not been found to be effective in preventing the propagation of existing cracks. It is possible though by no means certain that future research may disclose inhibitors which are practical and effective against crack growth.
Cathodic protection is a measure which, where feasible, is also very effective in preventing pitting corrosion in steels. Its use on high strength steels must be done with care to prevent hydrogen damage and hydrogen cracking which can be caused by "overprotection." Protection and "overprotection" are best discussed in terms of the electrochemical potential of the steel surface compared to that of a standard reference electrode, such as the saturated calomel electrode (SCE). The potential of freely corroding low alloy steel such as AISI type 4340 in sea water is about $-0.6-0.7 \mathrm{~V}$ (SCE) and that of high alloy steel such as $17-4 \mathrm{pH}$ is about $-0.4 \mathrm{~V}$, with the potentials of the nonstainless maraging steels in between these potentials. The potential of unalloyed steel is also about $-0.6-0.7 \mathrm{~V}$, that of cadmium about $-0.75 \mathrm{~V}$, and that of zinc is $-1.03 \mathrm{~V}$. The potentials of freely corroding aluminum and its alloys in sea water are apt to vary considerably with time as the protective films break down and re-form. It is common practice to design cathodic protection systems for ship hulls to produce a potential of $-0.85 \mathrm{~V}$ (SCE), which prevents both pitting and general rusting. Cathodic protection inadequate to prevent general rusting may still be adequate to prevent pitting. As an example of this pattern, we see that unalloyed steel coupled to maraging steel in sea water does not prevent rusting of the maraging steel but does prevent its pitting. In most cases in which the effect of cathodic protection on $K_{I s c c}$ has been measured, little or no effect has been observed between the potential of the freely corroding high strength steel and $-0.85 \mathrm{~V}$ (SCE). For the case of 18 percent Ni maraging steel, however, cathodic protection increased $K_{I s c c}$. But at potentials more negative than $-0.85 \mathrm{~V}$, the $K_{I s c c}$ values for $17-4 \mathrm{pH}$ fall off rapidly because of hydrogen discharged on the high strength steel.

If one stresses high strength steel somewhat above $K_{I s c c}$, holds the $K$ level nearly constant, and varies the potential from the freely corroding potential toward more negative potentials, one observes decreasing cracking rates as one approaches the potential which is that of normal designs, but at somewhat more negative potentials (overprotection region) there is a sharp rise in cracking rates. This behavior is illustrated by the data in figure 2 . In this figure the ordinate, labeled "dial deflection rate," is a measure of cracking rate. This experiment was conducted in 3.5 percent $\mathrm{NaCl}$ solution, and the potential was measured not against a calomel electrode but against a silver-silver chloride electrode, which however in this solution has essentially the same potential as the calomel electrode. In this figure the left-most point corresponds to the freely corroding potential of a given steel, and the points to the the right of this point represent varying degrees of cathodic protection extending to overprotection. Note that despite the large differences in the several steels, not only in composition but in strengthening mechanisms as well, all show a minimum in cracking rates, and all at substantially the same potential.

Stainless high strength steels in aqueous salt environments pose the special problem of crevice corro- 
EFFECT OF ELECTROCHEMICAL POLARIZATION ON CRACKING RATES

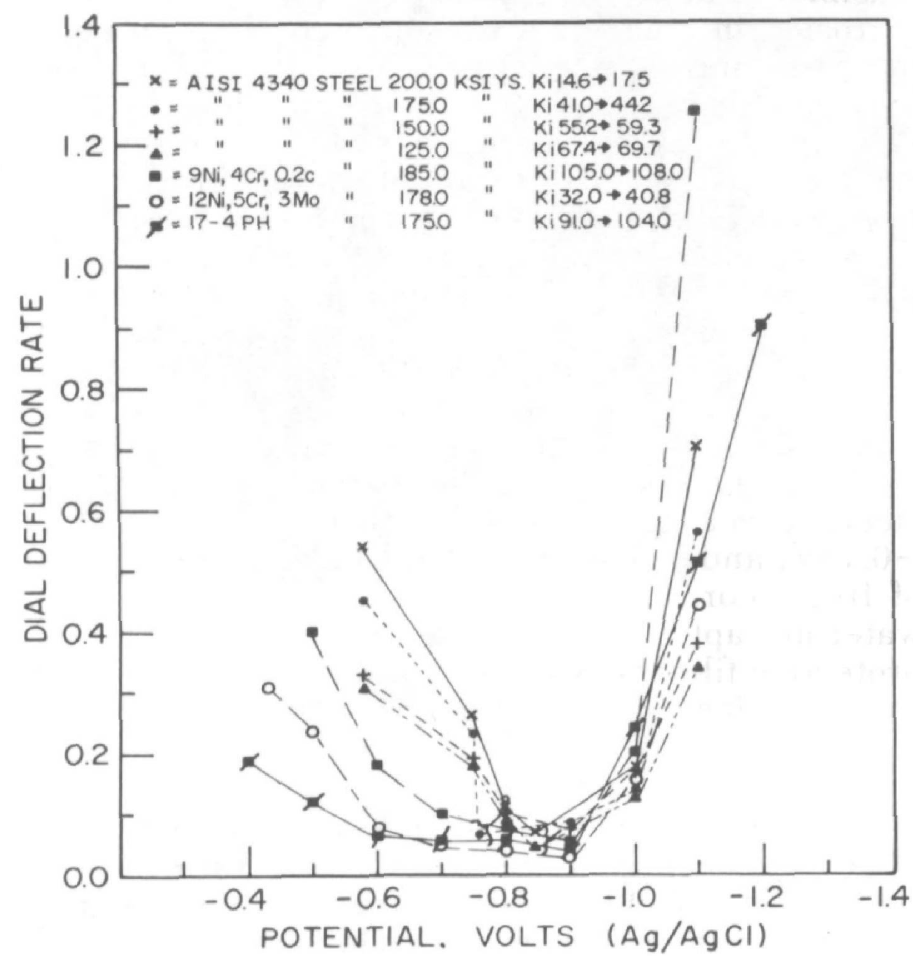

FiguRE 2. Effect of varying degrees of cathodic protection on SCC rate (DIAL DEFLECTION RATE) at nearly constant $K$. Left-most point on each curve represents freely corroding potential. Visible hydrogen evolution appears on right-hand branch.

sion and attendant acidity noted above, and cathodic protection is a very effective measure to mitigate this form of attack. Without this protection, the acid solution in crevices (or pits) can cause SCC not predictable from present fracture mechanics data.

Summarizing the effects of cathodic protection, a moderate degree is effetive in mitigating pitting in all steels and crevice corrosion in stainless steels. This same moderate degree of cathodic protection has little detrimental effect on $K_{I s c c}$ and in some steels may increase $K_{I s c c}$. Cathodic protection also decreases crack growth rate above $K_{I s c c}$. Excessive protection, which may be defined as conditions producing potentials more negative than about $-0.85 \mathrm{~V}$ (SCE), confers no additional benefit, can be seriously detrimental in decreasing $K_{I s c c}$ drastically, and in the situation of potentials more negative than about $-1 \mathrm{~V}$ may appreciably accelerate cracking rates.

Organic coatings are not reliable means for preventing SCC in high strength steels, but even poor coatings improve the ability of a cathodic protection system to perform its function. Coating with cadmium is beneficial in two ways: It acts as a barrier to corrodents, and even when the steel is bared by scratches or other damage to the cadmium coat, the adjacent cadmium tends to protect the nearby steel without danger of overprotection. (Note the potential of cadmium in the discussion of Cathodic Protection above.) Zinc coating is hazardous to heat treated high strength steel because of the possibility of over- protecting at breaks in the coating. But steels which are strengthened by cold work are much less susceptible to hydrogen enbrittlement, hence galvanized cold drawn bridge wires perform well.

\section{Examples of Practices and Failures Illustrating Principles}

The rocket motor case illustrated in figure 3 was made of a martensitic steel designated AMS 6434 and was heat treated to a yield strength slightly over $200 \mathrm{ksi}\left(1400 \mathrm{MNm}^{-2}\right)$. It was pressure tested with tap water, and before the specified 15-min hold was completed, the tank shattered. Examination of the fracture showed that most of it was purely mechanical brittle fracture, with shear lips bordering the flat fracture whose chevron markings (characteristic of brittle fracture) pointed back to a thumbnail-shaped origin (fig. 4). The electron microscope fractographic

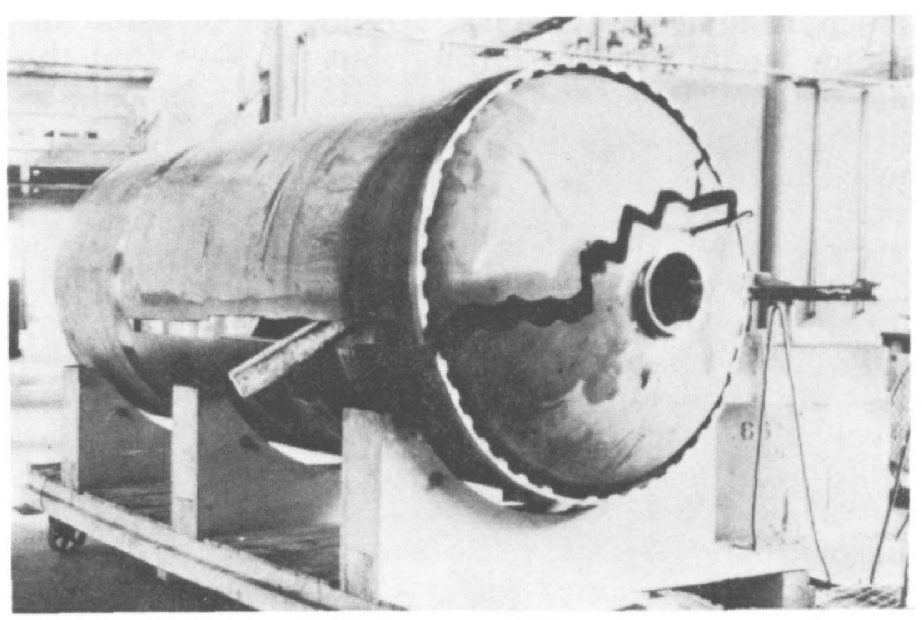

FIGURE 3. Brittle fracture of high strength steel rocket motor case triggered by stress corrosion cracking. Photo courtesy of the late Mr. J. A. Kies.

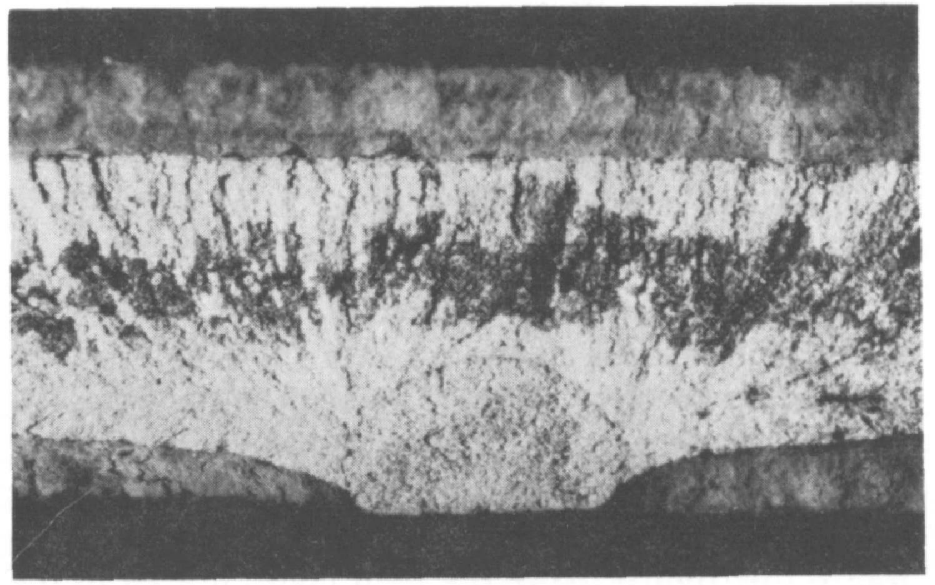

FIGURE 4. Origin of failure of figure 3, enlarged about, $15 X$. Thumbnail-shaped area at bottom is stress corrosion cracking. Brittle fracture chevrons are beginning to develop, radiating from the thumbnail area. Gray bands at top and bottom are shear lips. Dark areas on brittle fracture are rust. Photo by D. Price. 
features of this thumbnail shaped area (intergranular fracture) matched those of a stress corrosion crack generated in the same steel in the laboratory, also using tap water, and accordingly the origin was concluded to have been caused by SCC. Let us look at the problem using fracture mechanics. The $K_{\mathrm{Iscc}}$ of this steel in tap water would have been about $10 \mathrm{ksi}$ $\sqrt{\text { in }}\left(11 \mathrm{MNm}^{-32}\right)$. In the era of the manufacture of this motor case, a certain amount of out-ofroundness was inevitable, so that although the average stress during the pressure test was somewhat less than yield, some out-of-round areas would be at or above yield strength. Therefore we are justified in applying the simplified version of the Irwin equation (eq (2), ch. 2) for a surface crack, and we find that the critical flaw depth needed to initiate SCC is $0.2(10 / 200)^{2}=0.0005$ in or about $0.01 \mathrm{~mm}$ ! Such a small flaw could be provided easily by a grain boundary intrusion of oxide, a common occurrence in the heat treating atmospheres of large furnaces in use at that time, and in fact such intrusions were noted in this particular motor case. Adding a corrosion inhibitor would prevent pitting, but the fact that the failure occurred in less than $15 \mathrm{~min}$ indicated that no pitting was neeed to initiate the SCC, and as we have noted earlier, inhibitors tested to date have not been found effective in preventing growth of existing cracks, which the oxide intrusions could have provided. Cathodic protection would not be practical in an environment of high resitivity such as the tap water, and, even in a highly conducting electrolyte, cathodic protection would at best simply slow the rate of growth of the stress corrosion cracks from the oxide intrusion. Though coating the interior of the case would have been possible, it would have been impractical. Therefore the solution chosen was to replace the tap water with an inert oil as the pressurizing fluid. In addition, new specifications were written for the steel to have lower levels of impurities (sulfur and phosphorus) and slightly lower strength (190 ksi, $1300 \mathrm{MNm}^{-2}$ ), which would raise $K_{I s c c}$ somewhat and improve fracture toughness markedly, so that a much larger stress corrosion flaw would have to grow (assuming SCC could occur by contamination of the oil) before brittle fracture would occur. With these measures the problem was brought under control.

The Silver Bridge (frontispiece) was constructed of a steel of strength too low (80 ksi, $\left.550 \mathrm{MNm}^{-2}\right)$ to qualify as a high strength steel as defined above, but its SCC and fracture toughness characteristics make it very suitable for treatment with the high strength steels. The bridge collapsed on December 15, 1967, and a study of the cause pointed to an eye of one of the eye-bars of which the bridge was constructed. (ref. [3]) A portion of one of the fractures of the eye is shown in figure 5 , with the inside of the eye at the top in this figure. Note the light colored area in the upper right corner, which is obviously the origin of the brittle fracture. This area was concluded to have been caused by stress corrosion cracking. In salt water containing $\mathrm{H}_{2} \mathrm{~S}$ the $K_{I s c c}$ was found to be 15 $\mathrm{ksi} \sqrt{\text { in }}\left(16 \mathrm{MNm}^{-3 / 2}\right)$. The design allowable stress used in the shank of the eye-bar was $50 \mathrm{ksi}(350$

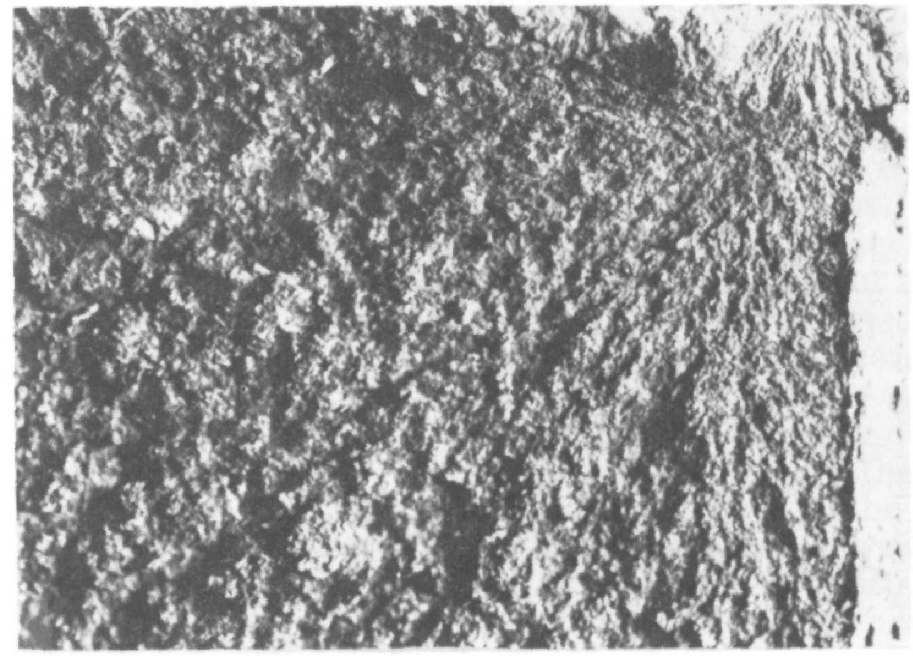

Figure 5. Portion of fracture of eye-bar of the "Silver Bridge". Eye is at top. SCC area (lighter color, upper right) extended downward about 0.12 in $(3 \mathrm{~mm})$. Brittle fracture spread down and toward left. Photo courtesy of Mr. H. C. Burnett, National Bureau of Standards.

$\mathrm{MNm}^{-2}$ ), which because of the stress raising properties of the eye placed the material in the region of the fracture at just over the yield strength, and we are therefore again justified in using the simplified form of the Irwin equation. The size flaw needed to initiate the stress corrosion crack would be $0.2(15 /$ $80)^{2}=0.007$ in (about $0.2 \mathrm{~mm}$ ), a flaw which a tiny corrosion pit probably supplied. The fracture toughness $\left(K_{I c}\right)$ of the steel was found to be $46 \mathrm{ksi} \sqrt{\text { in }}(50$ $\mathrm{MNm}^{-3 / 2}$ ). The flaw required to achieve $K_{I c}$ would be given approximately by $0.2(46 / 80)^{2}=0.066$ in $(1.67$ $\mathrm{mm})$. The actual stress corrosion crack in figure 5 is 0.12 in $(3 \mathrm{~mm})$ deep, not a really bad agreement considering that the steel varied in yield strength from 70 to $86 \mathrm{ksi}\left(480\right.$ to $\left.590 \mathrm{MNm}^{-2}\right)$, that the shape of the SCC area is not "long and thin" as the simplified equation assumes, and that the brittle fracture is propagating at an angle to the minor axis of the elliptical SCC area.

This failure will be discussed further in the section below entitled "Single-Load-Path Designs."

The General U. S. Grant bridge over the Ohio River at Portsmouth, Ohio, was constructed of cold drawn wire having a yield strength of about $180 \mathrm{ksi}$ $\left(1250 \mathrm{MNm}^{-2}\right)$. The wires were ungalvanized, and after about 12 years of service a number of breaks were found and led to the replacement of the affected cables with cables made of galvanized wire. The breaks were intergranular and could be duplicated in the laboratory by stressing the wire immersed in dilute $(0.01 \mathrm{~N})$ ammonium nitrate or sodium nitrate, and the service failures were then diagnosed as SCC (ref. [4]). Zinc coating (and perhaps the organic coating over the zinc) solved the problem. Note that this is cold drawn steel, not heat treated, and the cold drawn steel is much more resistant than heat treated steels to any hydrogen embrittlement which the zinc might threaten at a break in the coating because of the electrochemical potential of zinc (see Cathodic Protection above). 
The Mount Hope bridge in Rhode Island was constructed using quenched and tempered steel wire of about the same strength as that of the U. S. Grant bridge, and cracking failures occurred a few months after the wire was spun, well before the bridge had been completed. This wire was hot dip galvanized, but unlike the cold drawn wire the martensitic wire was highly susceptible to hydrogen cracking, which probably occurred at breaks in the zinc coating. The solution adopted was to replace the martensitic wire with galvanized cold drawn wire. (ref. [4])

The Lockheed submersible Deep Quest (fig. 6) was made of slightly modified 18 percent nickel 200 grade maraging steel, actually heat treated to only about $190 \mathrm{ksi}\left(1300 \mathrm{MNm}^{-2}\right)$ yield strength for enhanced fracture toughness. The aging treatment

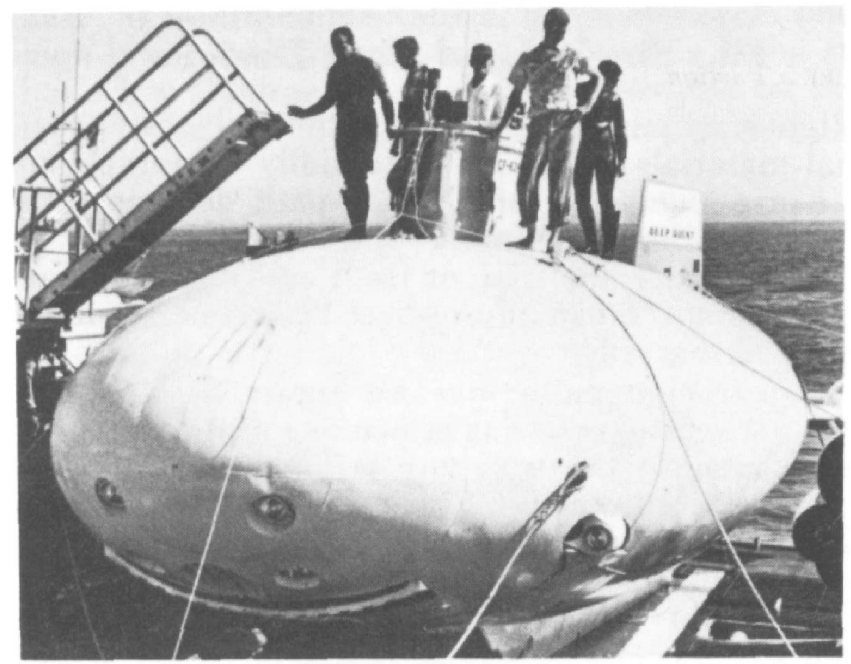

FIGURE 6. Submersible DEEP QUEST aboard support ship. Although the steel of the hull can be made to undergo SCC at high stress intensities in the laboratory, conservative material specification, design, fabrication and maintenance added up to satisfactory performance. Photo courtesy of Lockheed Missile and Space Company.

which confers high strength was given only after welding together the spun hemispheres to form the spherical hull. The $K_{I s c c}$ of the welds and hull plate after aging were in the range of 50-60 ksi $\sqrt{\text { in }}(55-65$ $\mathrm{MNm}^{-3 \mid 2}$ ), so that the critical flaw size for SCC would be about 0.01 in $(0.25 \mathrm{~mm})$ assuming yield stresses. But since the steel was welded in the weak condition, the residual stresses would not likely be as high as the yield strength of the aged material, and the critical size flaw for existing stresses was probably very much larger. It is common practice in such structures to grind the welds which both reduces the stress raising capability of the weld crowns and enhances the detectability of any cracks present. The hull was given an organic coating system (carefully maintained at approximately semiannual inspections) plus additional insurance in the form of cathodic protection. In this case the cathodic protection system chosen consisted of carbon steel sacrificial anodes, which as noted in the section above on cathodic protection would tend to prevent pitting of the maraging steel without any possible hazard from overprotection. Thus the vehicle was made of a high strength steel capable of being cracked in the laboratory using sea water, but the combination of several measures added up to a successful vehicle-simplicity of form, conservatism in strength level, selection of maraging steel having superior SCC properties (compared with alternative materials at the same strength level), a carefully maintained coating, and moderate cathodic protection. Another example of successfully pyramiding control measures.

A stainless steel component made of the stainless precipitation hardening steel designated UNS S35500 for which the heat treatment is unavailable but which probably left the steel lower in strength than that of Deep Quest was put in service in the highly corrosive marine atmosphere of Cape Canaveral. The component experienced SCC from assembly stresses (fig. 7). One solution to the problem

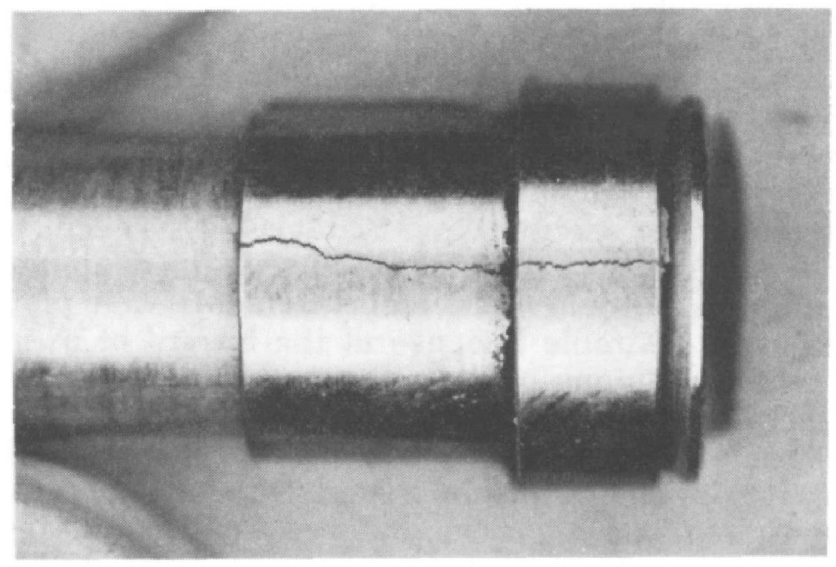

FIGURE 7. Fitting of high strength precipitation hardening stainless steel designated UNS S35500 which cracked, because of assembly stress, in the extremely corrosive marine atmosphere at Cape Kennedy, Florida. Magnification 5X. Courtesy of Mr. J. D. Morrison, NASA.

would be overaging at a higher temperature. Another solution might be to switch to a nonferrous alloy resistant to both cracking and other forms of corrosion in the marine atmosphere. MIL STANDARD 1568 (Material and Processes for Corrosion Prevention and Control in Aerospace Weapons Systems) prohibits the use of precipitation hardening stainless steels heat treated to their maximum strength (H900).

A class of European combatant submarines was designed using an 18 percent Mn 5 percent $\mathrm{Cr}$ steel related to the nonmagnetic steel used for generator rotor retaining rings described earlier and for which a $K_{\text {Isc }}$ of $7.5 \mathrm{Ksi} \sqrt{\text { in }}\left(8 \mathrm{MNm}^{-3 \mid 2}\right)$ has been measured. The SCC properties of the submarine hull steel were probably similar to those of the generator steel. We know from the popular press that there were service failures, and the corrective measure 
was to scrap the design. Note here that the submarine hull was probably of complex design compared with Deep Quest and hence probably had high residual stress from assembly as well as being made of probably a much more susceptible steel.

Aircraft bolts are made of high strength martensitic steel, and where they are under sustained tension in service, they would be subject to inevitable cracking if they should react with water, including atmospheric moisture. They are therefore coated with cadmium, commonly by electrodeposition. Such electroplating with cadmium hazards the steel with embrittlement by hydrogen co-deposited with the cadmium and concentrated in the steel immediately beneath the cadmium plate, which seals the hydrogen in the steel. But baking of the steel after plating (according to MIL-S-5002 $23 \mathrm{~h}$ at $350{ }^{\circ} \mathrm{F}, 175{ }^{\circ} \mathrm{C}$, a treatment which may not be adequate for critical items) redistributes the hydrogen sufficiently to bring the maximum concentration down to a tolerable level. If the cadmium coating should be abraded or scratched deep enough to expose bare steel, the cadmium would tend to protect the adjacent steel from pitting corrosion with a minimal hazard to hydrogen discharge and without hazard of overprotection, as discussed in the section on Cathodic Protection. Cadmium plating is not suitable for applications involving sliding or wear. Also it is not recommended for service above $230^{\circ} \mathrm{C}\left(450^{\circ} \mathrm{F}\right)$ because of the possibility of cracking because of the cadmium itself (akin to liquid metal embrittlement). Zinc plating is not desirable because of the hazard of overprotection, among other reasons. The Canadian Forces high speed prototype hydrofoil Bras d'Or has a 250 grade maraging steel main high speed foil which is hollow with the inside coated with an inorganic zinc-rich paint; a crack admitted sea water, and subsequent extension of the crack was attributed to hydrogen discharged because of the overprotection from zinc. (ref. [5])

An aircraft landing gear is typically constructed of martensitic steel which may be heat treated to as much as $240 \mathrm{ksi}\left(1650 \mathrm{MNm}^{-2}\right)$ yield strength. AISI 4340 and, more recently, $300 \mathrm{M}$ steels have been used, and at such high strength levels they are of course highly susceptible to SCC. They are, however, cadmium plated, carefully monitored for initiating cracks, and the sustained stress (when parked) is kept much lower than maximum design landing stress, perhaps under $100 \mathrm{ksi}\left(700 \mathrm{MNm}^{-2}\right)$. Once again a combination of measures, no one of which might be adequate, adds up to a largely successful technological solution.

A disk in a low-pressure turbine of the Hinkley Point " $A$ " power plant (Britain) disintegrated causing catastrophic failure of one $87 \mathrm{MW}$ turbine and damage to two identical neighboring turbines. Investigation showed that brittle fracture of the martensitic steel disk had originated from an intergranular stress corrosion crack located in a keyway. The keyway probably elevated the stress in that crack region to something approximating the yield strength of the steel. The corrodent responsible for the crack- ing was presumed to be the steam condensate, with caustic entering with carryover and possibly concentrated by alternate wetting and drying during turbine operations. The measured $K_{\mathrm{r}}$ varied from about 36 to $80 \mathrm{ksi} \sqrt{\text { in }}\left(40-90 \mathrm{MNm}^{-3 / 2}\right)$, the spread being due to inhomogeneity. It is interesting that the size of the stress corrosion crack $(1 / 16$ in. $1.6 \mathrm{~mm})$ enables us to make an independent estimate of the fracture toughness of the steel. Assuming yield point (107 ksi, $740 \mathrm{MNm}^{-2}$ ) stresses and the simplified Irwin equation, $0.0625-0.2\left(K_{\mathrm{l}} / 107\right)^{2}, K_{\mathrm{c}}=60$ $\mathrm{ksi} \sqrt{\mathrm{in}}\left(65 \mathrm{MNm}^{-3 / 2}\right)$, near the middle of the range measured directly. Corrective measures were (1) to redesign to eliminate the keyways in the highly stressed bore region, (2) to avoid construction which exposed highly stressed regions to wet steam, and (3) to use steel of higher fracture toughness. (ref. [6])

\section{Single-Load-Path Designs}

High strength steels are not the only constructional materials which are potentially vulnerable to the consequences of single-load-path designs. But they can be highly vulnerable. Two examples have appeared in the illustrations used above, and hence this appears to be an appropriate place to call attention to the hazard.

In the rocket motor case of figure 3 , once the stress corrosion crack has grown to a size critical for brittle fracture, the structure is doomed. Likewise the vast structure of the Silver Bridge (frontispiece) was doomed when one stress corrosion crack had propagated 0.12 in $(3 \mathrm{~mm})$. The rotor disk of the Hinkley Point " $A$ " steam turbine disintegrated when a stress corrosion crack grew to a depth of $1 / 16$ in (1.6 $\mathrm{mm})$. The corrodents responsible for the SCC in these three cases were respectively tap water, atmospheric moisture (probably contaminated), and steam condensate, perhaps concentrated. All were operating at high nominal stresses, and in each case the monimal stress was elevated by stress raisers: out-of-round areas in the motor case, the eye of the eye-bar, and the bore of the disk plus the keyway in the case of the turbine. Let us then summarize the elements of these generically related failures: (1) SCC (2) in relatively mild corrodents (3) in singleload-path design structures (4) fabricated of steel having low fracture toughness (5) with high design stresses (6) elevated by stress raisers.

The lesson is abundantly clear: If the consequences of a failure cannot be tolerated, the designer is denied the option of single-load-path design unless he has thorough knowledge of both the stress corrosion possibilities and the fracture toughness of the steel. Note that the SCC failures in the General U. S. Grant bridge did not lead to a catastrophe because unlike the Silver Bridge, the Grant bridge was a multiple-load-path structure, with redundancy in the multiple paths.

At the time of material selections for the Silver Bridge and the Hinkley Point turbine it was not suspected that SCC could occur in those steels in their intended environments, and as fracture 
mechanics had not yet been developed, the consequences of having a sharp crack (such as a stress corrosion crack) in a stressed steel component having what we now know as low fracture toughness were unknown.

\section{Diagnosing SCC}

SCC in the high strength steels can be intergranular (along the grain boundaries of the prior austenite grains, fig. 8), quasi-cleavage or transgranular with respect to the prior austenite grains, (fig. 9), or it can occur as microvoid coalescence, resembling figure 6 of chapter 5 , or by a combination of all three modes. The factor which determines which of these three modes is operative appears to be the $K$ level. At low levels of $K$, intergranular cracking tends to predominate, at intermediate values, quasi-cleavage, and at high levels, microvoid coalescence. If a given steel has a low toughness, it may not be possible for the $K$ level to be raised high enough to cause microvoid

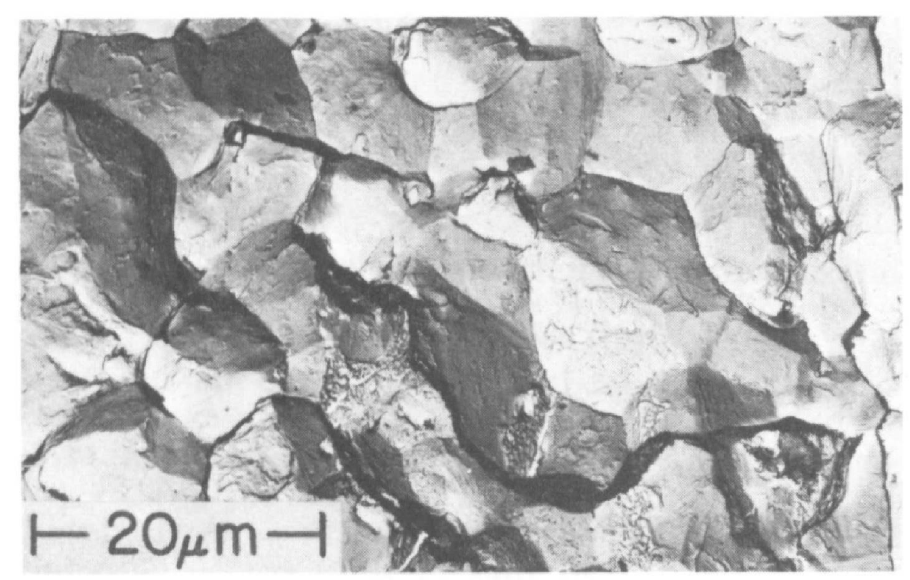

FIGURE 8. Intergranular SCC in martensitic steel. Replication electron fractograph, magnification 2250X. Courtesy of Mr. C. D. Beachem.

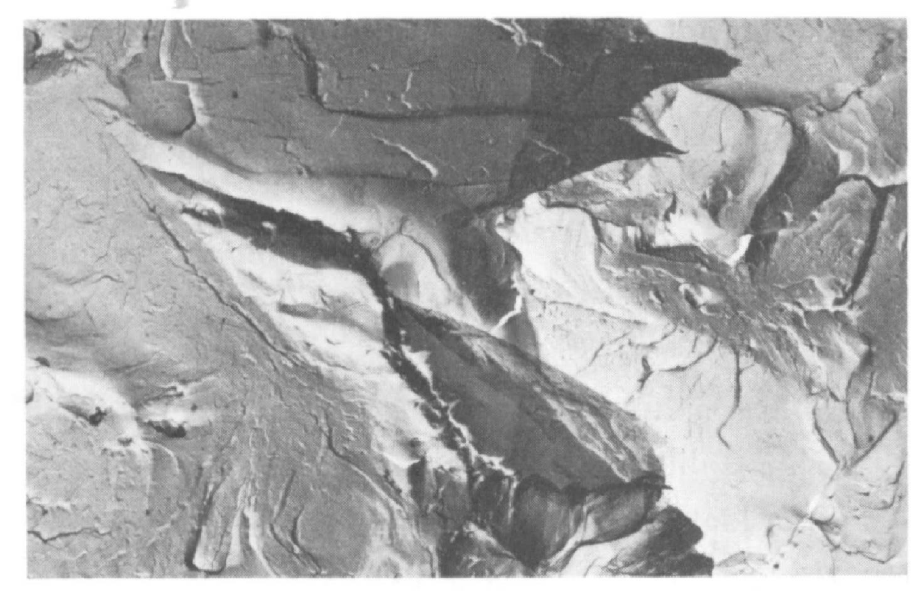

FIGURE 9. Quasi-cleavage SCC facets in precipitation hardening steel. Replication electron fractograph, magnification $2400 \mathrm{X}$. Courtesy of Mr. D. A. Meyn coalescence SCC before brittle fracture occurs. Also, if the steel has high resistance to SCC, it may not be possible to propagate a stress corrosion crack at $K$ levels low enough to permit the grain boundary mode to operate. Thus the cracking mode is not indicative of corrodent. Neither does the cracking mode permit one to distinguish between SCC and hydrogen embrittlement (see Theory below). Finally, cyclic stresses between two levels of tension have been observed capable of producing intergranular cracking indistinguishable from sustained load SCC.

\section{Theory}

It is known that all high strength steels are susceptible to cracking by hydrogen. In many circumstances it is known that hydrogen is produced deep within the growing stress corrosion crack, and in many additional circumstances it is known that the thermodynamic conditions there are favorable for hydrogen ion reduction. The general macroscopic appearance of stress corrosion cracks in high strength steels is the same as hydrogen embrittlement cracks (except that SCC may leave corrosion products on the fracture surfaces), and the details of SCC fractures and hydrogen embrittlement fractures as viewed by high resolution electron fractography are indistinguishable. It is probable that many, perhaps even most, of the service failures involving high strength steels in aqueous or other hydrogen-bearing environments are due to hydrogen.

\section{Summary}

Most SCC service failures in high strength steel structures are due to a combination of design plus assembly loads, aqueous environments (which may include contaminants important to the failures), and susceptible alloys. The most important single factor in determining the degree of susceptibility is strength level, which for SCC resistance should be as low as other considerations permit. Premium melting stock and premium melting practice to minimize sulfur, phosphorus and oxides are significantly beneficial to SCC resistance. The combination of composition and heat treatment which produces twinned martensite should be avoided. Cadmium plating is beneficial for atmospheric service, and cathodic protection (but not overprotection) is beneficial where feasible. Successful structures of non-redundant load path design place special requirements on knowledge and comprehension of SCC and brittle fracture technology.

\section{References}

[1] Sandoz, G., Stress corrosion cracking in high strength steels and in titanium and aluminum alloys (B. F. Brown, Ed.), Naval Research Lab., Washington, D. C., (1972) p. 80.

[2] Speidel, Markus O., Stress corrosion cracking in Fe-Mn-Cr alloys, Corrosion/75 Paper No. 110, Nat'l. Assn. of Corrosion Engrs., Houston, (1975). 


\section{High Strength Steels}

[3] Bennett, J. A. and Mindlin, Harold J., Testing and Evaluation, Vol. 1, No. 2 (1973), p. 152.

[4] Pollard, R. E., Symposium on stress corrosion cracking of metals, A. S. T. M., Philadelphia, 1945, p. 437.

[5] Carson, J. A. H., Barer, R. D. and Peters, B. F., Fourth inter-naval conference on marine corrosion, Extended
Abstracts of Papers, Naval Research Lab., Washington, D. C., 1972, p. 1 .

[6] Kalderon, D., Proc. institution of mechanical engineers, Vol. $18631 / 72$, (1972) p. 341.

[7] Franklin, D. B., Design criteria for controlling stress corrosion cracking, Marshall Space Flight Center Document No. 10M33107 (B), 1975. 


\section{CHAPTER 7}

\section{STAINLESS STEELS (Austenitic and Ferritic)}

\begin{abstract}
Stainless steels owe their stainlessness primarily to the presence of chromium, 12 percent or more of which in a steel is generally considered sufficient to qualify the steel to be called stainless. The stainless steels considered here are the low strength grades in which the crystal structure is either face-centered cubic (austenitic, which is nonmagnetic) or body centered cubic (ferritic, which is strongly magnetic). Some of the steels which are nominally austenitic may contain enough of either ferrite or martensite (particularly after being cold worked) to be weakly magnetic. AISI type 301 has a high proportion of austenite, but after being cold worked it contains much martensite and can be made strong enough to qualify as a high strength steel. It is discussed with those steels in chapter 6 . It is also mentioned briefly below. There are martensitic precipitation hardening, and maraging stainless steels which are discussed exclusively in the chapter on high strength steels. The physical metallurgy of all stainless steels
\end{abstract} is discussed in great detail in reference [1].

As a rule, the carbon content of the austenitic and ferritic stainless steels is kept as low as economics will allow, but there is in almost all the commercial steels enough carbon so that if these steels are held long enough in a broad elevated temperature zone, carbides rich in chromium will precipitate, impoverishing the adjacent regions in chromium and thereby altering their corrosion behavior. This precipitation occurs preferentially in the grain boundaries and is called sensitization, and it is of great importance to the corrosion technology of the stainless steels. It can be removed by "annealing", which in these alloys means extended heating at about 1065 ${ }^{\circ} \mathrm{C}\left(1950{ }^{\circ} \mathrm{F}\right)$ for austenitic steels or $790{ }^{\circ} \mathrm{C}\left(1450{ }^{\circ} \mathrm{F}\right)$ for ferritic steels, followed by quenching or rapid cooling to room temperature to keep the carbon in solution. Alternatively the sensitized steel (if austenitic) may be heated for a few hours at about 840 ${ }^{\circ} \mathrm{C}\left(1550{ }^{\circ} \mathrm{F}\right)$ to homogenize the chromium; this practice is too risky to be a preferred measure.

Even after the carbides are dissolved and held in solution by rapid cooling, the annealing treatment does not confer permanent insurance against resensitization, which may occur in the heat affected zone of a weld, made after annealing, for example. Stainless steel components are sometimes welded to a non-stainless carbon steel pressure vessel, and pursuant to the pressure vessel fabrication code, the pressure vessel (with any stainless steel attachments) is heated to $620^{\circ} \mathrm{C}\left(1150{ }^{\circ} \mathrm{F}\right)$ to relieve fabrication stresses to avoid brittle fracture of the carbon steel. During this stress relieving anneal, the stainless steel generally becomes severely sensitized, and in this situation, usually irreversibly, as it is not feasible to heat large pressure vessels to $1065^{\circ} \mathrm{C}$ and then cool them sufficiently rapidly.

It is possible to add a strong carbide former such as columbium (niobium) (in type 347 ) or titanium (in type 321) which "stabilizes" the steel by tying up most of the carbon in carbides more stable than the chromium containing carbides. Low carbon and extra low carbon grades are available in some types and are effective in minimizing sensitization at welds. Low carbon stainless steels are usually indicated by the suffix "L" after the grade number.

The stainlessness of these steels is due to the formation of a tight, adherent oxide skin on the surface which tends to isolate the steel from chemical environments. The stainlessness is thus not an intrinsic property of the metal, and when the oxide film is broken, as can be done mechanically or chemically (especially by chloride ions), the underlying metal may form a new oxide film (repassivate). Alternately, some form of corrosion, including SCC, may ensue. In some technologies it is common practice to "passivate" stainless steel components in nitric acid with or without sodium dichromate before they are placed in service. A flash "pickle" in $\mathrm{HNO}_{3}$ $+\mathrm{HF}$ is also used. Such passivation treatments are beneficial in that they tend to clean the surface, but they do not confer permanent inertness. Federal Specification QQ-P-35 is often followed to passivate stainless steel components after fabrication. The important property of the nitric acid in conferring passivity is its oxidizing power, not its acidity.

The Unified Numbering System designations for all stainless steels, including austenitic and ferritic grades, consist of the letter " $S$ " followed by five numbers which usually incorporate the numbers of the more common alternative designations. Thus S30400 is the austenitic stainless steel commonly designated AISI type 304, and S44600 is the ferritic steel AISI type 446. The UNS designations have not commenced to appear in the technical literature at this writing, therefore the commonly used designations will be used here.

The general approach for avoiding the SCC problem in (low strength) stainless steels depends upon the environments which the various technological needs impose. This chapter is accordingly organized according to environment categories.

\section{Marine Environments}

In sea water at or near room temperature the commercial austenitic and ferritic stainless steels do not experience SCC. They are, however, subject to crevice corrosion or pitting to the extent that they 
are not suitable for prolonged service in sea water unless special precautions are taken. One such precaution is cathodic protection. If the ferritic steels are overprotected (see Cathodic Protection in ch. 6), they are apt to blister or crack because of the hydrogen discharged by the cathodic protection action. Hence it is probably unwise to attempt to protect such steels to a potential more negative than about $-0.85 \mathrm{~V}$ (SCE). There are some non-U. S. austenitic stainless steels having carbon contents of 0.2 percent (higher than the U. S. grades) which, when sensitized, cracked in sea water at room temperature, and even higher carbon alloys ( 0.5 percent $\mathrm{C}$ ) cracked in sea water without being sensitized. The high strength stainless steels crack readily in sea water at room temperature, as do the low alloy high strength steels, as discussed in chapter 6 .

The tubing used to heat liquid bulk cargoes in merchant ships may be made of austenitic stainless steel, typically AISI type 316 or $316 \mathrm{~L}$. These heating coils, when cold after discharging a particular cargo, may be safely washed with sea water, but they should be rinsed immediately with fresh water to avoid crevice corrosion, and especially they must be so rinsed before steam is admitted, for in heated sea water, chloride SCC (discussed below) is a high hazard to such steels. For the same reasonavoiding hot chloride SCC-condensers using austenitic stainless steel tubes must be so designed and maintained as to prevent hot sea water from contacting the steel.

In the marine atmosphere the temperature of the surface of steel in sunlight, particularly in tropical and subtropical climates, may range from near atmospheric temperature to one substantially higher. Although SCC is seldom seen in austenitic or ferritic stainless steels in other atmospheric conditions, in the marine atmosphere SCC has been seen occasionally, particularly in the tropics, particularly (but not only) in parts heated by solar radiation, in the following AISI types: 201 (sensitized), 202 (sensitized), 301 (see also ch. 6), 302 (sensitized), 303 and sensitized 304 (plastically strained), all of which are austenitic, and $430 \mathrm{~F}$, which is ferritic. (See figs. 1 and 2). Types 302,303 and $430 \mathrm{~F}$ contain especially high levels of sulfur or selenium to make them free-machining, and the resulting sulfides or selenides are probably responsible for accelerated SCC initiation and perhaps propagation in these steels. Note the word "occasionally" above is emphasized. Large numbers of stainless steel structures serve successfully in the marine atmosphere, and the failures represent exceptions. Type 304 L might be worth the premium if one is concerned with a critical component which will be unavoidably sensitized in manufacture.

Periodic cleansing to remove accumulated salt, particularly if the situation permits a follow-up application of a water-displacing oil spray, is helpful in mitigating SCC in the marine atmosphere in structures made of the steels mentioned above. For critical items, types 304 or 316 might be preferred over the vulnerable types cited if the mechanical property requirements can be met. Type 316 has one qualitycontrol advantage: This steel contains $2-3$ percent molybdenum, the presence of which is readily detected by a simple spot test. Of the vulnerable steels

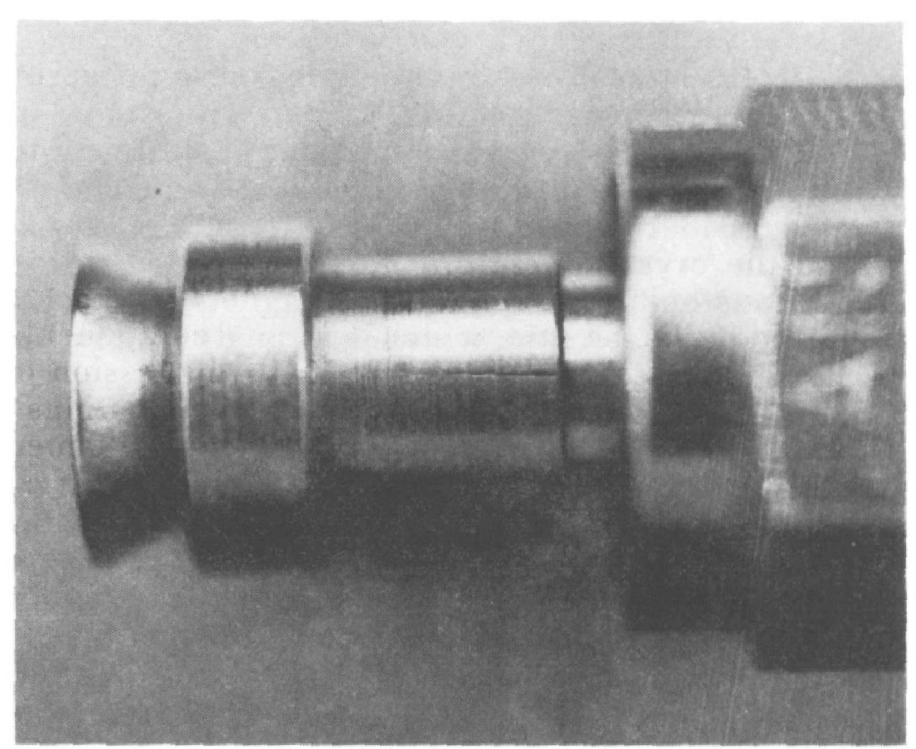

FigURE 1. SCC in AISI type 303 stainless steel sleeve in service in the marine atmosphere near windward surf at Cape Kennedy. Magnified 3X. This sort of cracking of austenitic stainless steel at room temperature is rare. A Similar steel but without the extra sulfur or selenium of 303 would probably not have cracked. Courtesy of Mr. J. D. Morrison, NASA,

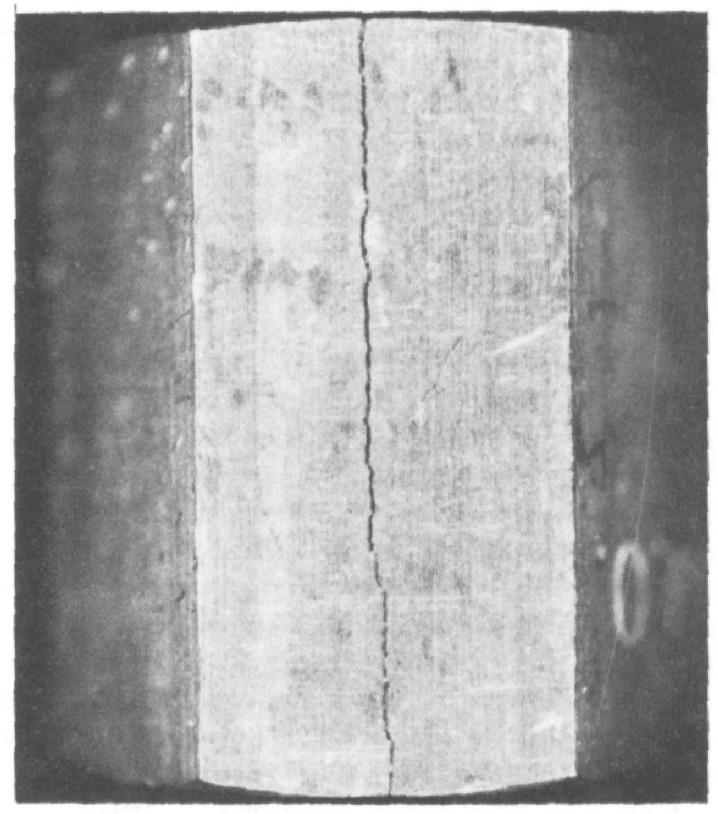

FIGURE 2. SCC in free machining ferritic stainless steel, AISI type $430 F$, in service, in the marine atmosphere near windward surf at Cape Kennedy. Magnified 3X. Cracking of this steel in the temperature at room temperature is rare. A similar steel but without the extra sulfur or selenium of $430 \mathrm{~F}$ would probably not have cracked. Courtesy of Mr. J. D. Morrison, NASA 
mentioned above, only 303 contains molybdenum, and that at a sustantially lower level $(0.6$ percent maximum).

\section{Other Low Temperature Environments}

Although the commercial U. S. austenitic stainless steels do not crack in sea water at room temperatures, there are three groups of other aqueous chemical environments which can cause SCC at room temperature, two of them of practical importance, and the third an interesting laboratory test environment: (1) Polythionic acids cause SCC of sensitized steels at room temperature. These acids may be found in petroleum refinery components under certain conditions, and further discussion of them will be deferred to the "Refinery Applications" section. (2) Dilute fluoride solution has been blamed for causing SCC in sensitized type 304 stainless steel in newly constructed nuclear power components having high residual tensile stresses. Cold worked surface areas, crevices, elevated temperatures and visible oxide films (as may appear near welds) seem to promote this type of cracking, which is invariably intergranular. Concentrations of $\mathrm{F}^{-}$as low as $1 \mathrm{ppm}$ sufficed to produce cracking in laboratory tests, but cracking is thought unlikely in more dilute solutions. The source of fluoride in practical cases is presumably weld flux. Phosphate or hydrazine additions served to prevent the cracking in laboratory tests (refs. [2] and [3]). The preferred remedial measure is probably meticulous clean-up and packaging immediately following fabrication and proof testing. It is possible that factors in addition to fluoride may be important to this form of cracking as some attempts to reproduce the failures in the laboratory have not been successful. The marine atmosphere has been blamed for cracking in heavily sensitized type 304 steel. (3) Certain strong acid solutions containing chloride, of interest primarily as laboratory test environments, have been found capable of causing SCC in austenitic stainless steels at room temperature. These have included the following: $5 \mathrm{NH}_{2} \mathrm{SO}_{4}+0.5 \mathrm{~N}$ $\mathrm{NaCl}$ (which produced both intergranular and transgranular cracking); $3 M \mathrm{HClO}_{4}+0.5 M \mathrm{NaCl}$; and $0.5 M-1.0 M \mathrm{HCl}$. Any strong acid containing a trace of chloride may cause cracking at room temperature. Perhaps the cracking in these environments is akin to that in hot chloride environments. Tap water plus 1 percent $\mathrm{HNO}_{3}$ has also been reported to cause cracking of type 304 steel at room temperature with or without added chlorides. Sulfurous acid $\left(\sim 6 \% \mathrm{H}_{2} \mathrm{SO}_{3}\right)$ also can cause $\mathrm{SCC}$ in sensitized stainless steel at or near room temperature.

Heavy slabs of type 304 are sensitized due to the slow cooling from the hot rolling temperature. After being heavily ground (to remove surface imperfections) they may crack intergranularly if stored outdoors in industrial atmospheres for several months. The solution to this problem is to regrind to remove incipient cracks in any slabs that have been so stored over three months. (ref. [4])

\section{Chloride Cracking}

The first SCC seen in stainless steels was aqueous chloride cracking, which remains by far the most prevalent form of SCC in stainless steels today. It has been observed in austenitic stainless steels of various types in steam power plants (fossil fuel and nuclear), chemical plants, petroleum refineries, the food processing industry, the pulp and paper industry, the metal processing industry, and others. An example of SCC in an AISI type 347 boiler superheater type is shown in figure 3. Table I illustrates the widespread nature of the problem in various technologies.

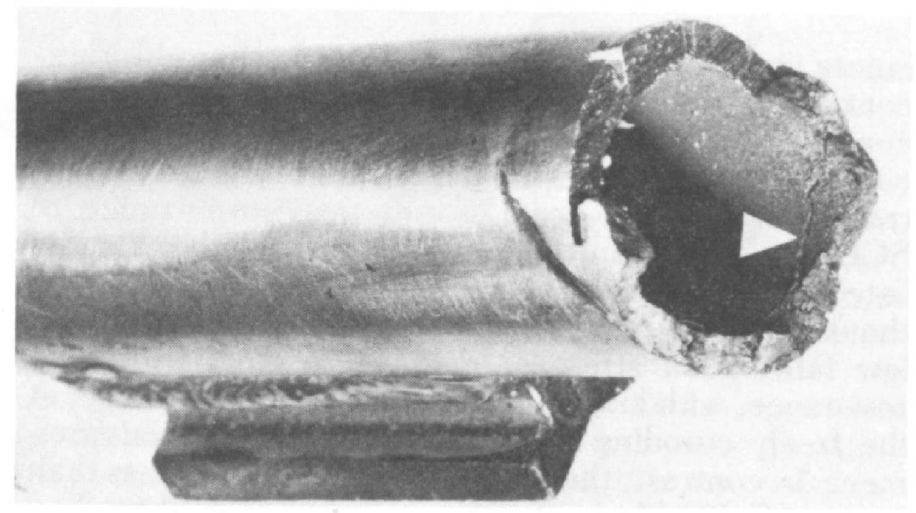

FIGURE 3. SCC in 1 in diameter superheater tube made of AISI type 347 stainless steel. The corrodent may have been chloride in "carry-over", concentrated by evaporation. The stress responsible for cracking is presumably due to a bending moment generated by thermal stresses and the support shoe (bottom) frozen in place by fly ash. Eighteen out of forty-five such superheater tubes failed thus in ninety steaming hours. Careful attention to boiler water chemistry to diminish carry-over solved the problem.

The primary causative factors in the problem are as follows:

(1) Chloride ions in aqueous solutions or in solutions containing water or perhaps other electrolyte

(2) Sustained tensile stress

(3) A susceptible steel

(4) Oxygen or other oxidizer (except note test below)

(5) Elevated temperature (except as noted earlier in this chapter)

(6) Favorable electrochemical potential

(7) Opportunity to develop local acidity

(8) Opportunity for local breakdown of passivity.

We will consider these factors in the order given.

The chloride ions can be supplied by an almost incredible diversity of sources: sea water, the marine atmosphere, river water (with a chloride concentrating mechanism operative), sweaty hands, human waste, salted foodstuffs, soluble contam- 
TABLE 1. Some illustrative service SCC failures of austenitic stainless steels. (after ref. [5])

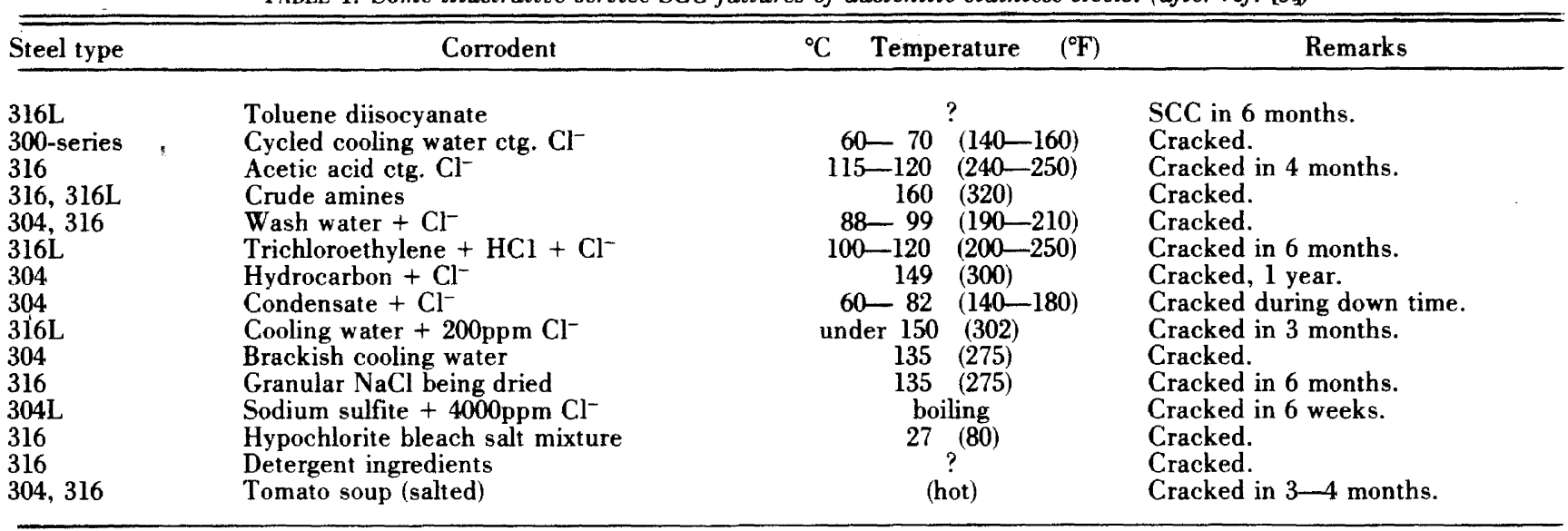

inants in thermal insulation, $\mathrm{HCl}$ and other chloridecontaining contaminants, lubricants, sealants, decomposition products of polyvinyl chloride (PVC) components in fires-the list is endless. The concentration of chloride ions of practical importance to SCC depends upon the condition of the other factors listed above. The level of concern may be a few thousand ppm (parts per million) in a component with low fabrication stresses, made of a steel with high resistance, with low oxygen, near room temperature, at the freely coroding potential, in an alkaline environment. In contrast, the level of concern may be less than $1 \mathrm{ppm}$ of chloride in structures involving cold worked components of a susceptible steel (such as type 304) with a few ppm of oxygen at high temperature (e.g., 250 ${ }^{\circ} \mathrm{C}, 480^{\circ} \mathrm{F}$ ) in the near neutral range, also at the freely corroding potential. The more concentrated the chloride, the more probable SCC becomes. Therefore one designs to avoid concentrating mechanisms, such as wetting and drying cycles.

The stresses responsible for chloride cracking in service are almost always those caused by fabrication, fit-up, welding, or differential heating rather than either design stresses or stresses due to heat treatment. The stress responsible for the cracking in figure 3 was probably caused by bending due to the support shoe which was probably immobilized by being prevented from sliding or tilting by furnace slag. Stresses even lower than $10 \mathrm{ksi}\left(70 \mathrm{MNm}^{-2}\right)$ can cause cracking in a steel having an ultimate tensile strength of $90 \mathrm{ksi}\left(630 \mathrm{MNm}^{-2}\right)$. The stresses which can cause cracking are in fact so low that reliance for control of chloride cracking is largely placed in the control of one or more of the other factors. Attempts to counteract other stresses by shot peening have not been very successful.

The relative susceptibilities of the major austenitic stainless steels have been evaluated in one study in which homogenous data (rare in this field) were developed using boiling magnesium chloride, about which more later. The findings of this investigation are shown in figure 4 , which is taken from reference [6].

At zero nickel content (and with certain other conditions discussed below met) the steels are ferritic and have high resistance to chloride cracking. With increasing nickel content, starting as low as 0.1 percent $\mathrm{Ni}$ (in hot magnesium chloride solutions) stainless steels become rapidly more susceptible to SCC, reaching a maximum vulnerability at about 8-12 percent nickel, the range which includes the most commonly used austenitic types. With still higher nickel contents the resistance to cracking in magnesium chloride increases until at about 42 percent or higher the alloys appear to be immune to cracking in this test. There is some evidence for a similar behavior in other chloride test environments. Increasing silicon is beneficial in magnesium chloride but not in sodium chloride solutions. Nitrogen is detrimental, and the high nitrogen contents used in some grades to reduce the need for nickel (needed to produce the austenitic crystal lattice) cause the steel (e.g., type 205) to be quite susceptible. Phosphorus is detrimental. Sensitization promotes pitting or grain boundary grooving, both of which establish local acidity and can act as stimuli to initiate SCC. Therefore low carbon grades (e.g., 304L) or a stabilized grade (e.g., type 347 ) is preferred if welding is to be done, as the welding process otherwise is certain to cause sensitization in the heat affected zone. In the austenitic steels molybdenum is detrimental as far as transgranular chloride cracking is concerned. If sensitization can be avoided, keeping the carbon on the high side is generally thought to be advantageous.

Summarizing the susceptibilities of the austenitic stainless steels, all are susceptible to chloride cracking and there is not a tremendous difference between the resistance of the least resistant and the most resistant, but even so, one might recognize four non-quantitative categories of relative susceptibility, as follows: 


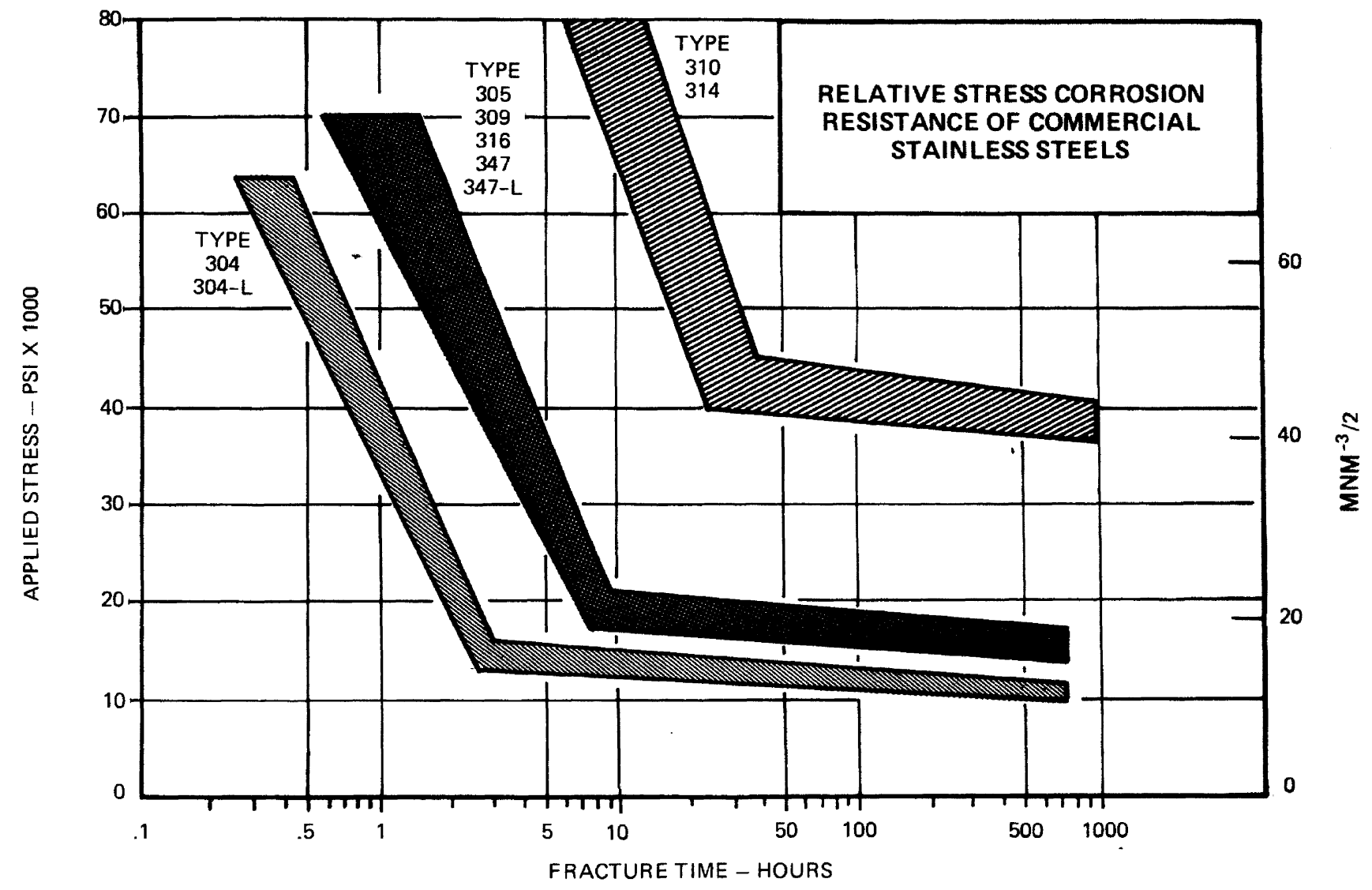

FIGURE 4. Relative SCC behavior of major types of austenitic stainless steel in boiling magnesium chloride. (E. E. Denhard, ref. [6]).

\section{Highest}

susceptibility: e.g., sulfur bearing $303 ; 301$;

Intermediate susceptibility: e.g., nonsensitized 304; 304L

Lower susceptibility: e.g., 316;316L; 347; 347L

\section{Lowest}

$$
\text { susceptibility: e.g., 310; 314; USS 18-18-2. }
$$

There are stainless alloys (e.g., Carpenter $20 \mathrm{Cb}-3$ ) which have even lower susceptibility to chloride cracking.

In recent years there have been important advances made in the technology of ferritic stainless steels which make some of them suitable or even preferred substitutes for austenitic stainless steels as far as chloride SCC is concerned. These developments have included the discovery that limiting the nickel and copper contents to easily achievable levels and keeping the nitrogen and carbon ("interstitials") to very low levels confer on these steels superior resistance to chloride cracking, though not total immunity. One such alloy containing 26 percent $\mathrm{Cr}$ and 1 percent Mo is commercially available and is designated ASTM XM-27 (ref. [7]). Another low in- terstitial ferritic stainless steel developed to be resistant to corrosion pitting as well as cracking contains 28 percent $\mathrm{Cr}$ and 4 percent Mo (ref. [8]). A third steel is high purity 18 percent $\mathrm{Cr}-2$ percent $\mathrm{Mo}$. Welding procedures are available for these alloys but care is required to exclude oxygen and nitrogen which would embrittle the weld area. There are two other embrittlement phenomena which must also be avoided. One of these phenomena is commonly known in the U. S. as "885 embrittlement" and occurs if service temperatures approach $885^{\circ} \mathrm{F}(475$ ${ }^{\circ} \mathrm{C}$ ). The other is sigma phase embrittlement at somewhat higher temperatures. Additionally, as in all ferritic steels, there is a ductile-to-brittle transition which can be an important consideration regarding structural integrity at thicknesses exceeding about $3 \mathrm{~mm}$ (1/8th in) (ref. [7]).

In addition to austenitic and ferritic stainless steels, there are stainless steels which are a mixture of austenite and ferrite. These are called "duplex" steels some of which may have interesting SCC properties. The value of having several per-cent of ferrite in otherwise austenitic weld metal to avoid SCC in austenitic steel weldments is well recognized, and is possibly related to the performance of duplex steels. 
Oxygen or an oxidizer is an important factor in chloride cracking in neutral solutions, and as a consequence it will be seen that control of oxygen level is an important measure in avoiding SCC in pressurized water reactors. It is somewhat surprising to note in table 1 that cracking occurred in a sulfite solution, which would be reducing. Oxygen is not necessary for cracking in slightly acid solutions, such as the (deaerated) boiling magnesium chloride solution extensively used in laboratory studies of SCC in stainless steel. The sulfite solution mentioned above may have been acidic, or it may have permitted local acidification in corrosion pits.

Temperature is an important factor in chloride SCC. Except for a few chemical environments cited earlier, SCC of austenitic stainless steels seldom occurs except at elevated temperatures, above about $60^{\circ} \mathrm{C}\left(140{ }^{\circ} \mathrm{F}\right)$. Nevertheless, one must be prepared for ugly and usually unexplained surprises in this regard. This is the reason for including in table $I$ the case of type 316 steel being cracked by hypochlorite bleach salt mixture essentially at room temperature.

There appears to be an electrochemical potential below which chloride cracking does not occur in austenitic stainless steels. In the research literature this potential is sometimes called the critical potential for cracking. In environments having sufficient conductivity, this phenomenon can be exploited to prevent cracking by coupling a more anodic material such as carbon steel, aluminum, or even lead, which would cause the potential of the stainless steel to become lower than the critical cracking potential in many environments. This technique is an example of cathodic protection.

The factors of local breakdown of passivity and local acidification are interrelated. In the presence of chloride ions the passive oxide film on stainless steel tends to break down, and by hydrolysis, the chloride, chromium and water cause local generation of hydrochloric acid. If this acid is sufficiently concentrated, it is difficult for the steel to re-grow a good passive film, and a corrosion pit may form, often the precursor of SCC. The liquid near the tip of a growing crack remains acid as long as the crack is growing. Cathodic protection tends to prevent the acidification from occurring in the first place, and is also capable of neutralizing the acid solution and therefore permitting repassivation. The development of local acidification tends to be promoted by a shelter such as a crevice or wet thermal insulation, the possibility of which would be best avoided in design. Local acidification is also favored by shelters such as those under sand or rust deposits, which contribute what is commonly termed a "poultice effect." Hence meticulous cleaning and passivating are useful practices. Sometimes pickling of stainless steels causes incipient grain boundary corrosion which tends to act as a crevice, and incomplete removal of acid can give chloride acidification a head start. Alkaline rinsing of pickled components is therefore helpful.

\section{Caustic Cracking}

Hot caustic solution (sodium hydroxide or potassium hydroxide) over a wide range of concentrations, from one percent to 100 percent, can cause cracking of stressed stainless steel without the requirement of oxygen and, as far as we know, without the requirement of any other chemical species.

One current reason for interest in caustic cracking of stainless steels lies in their use for sodium cooled reactors from which presumably the sodium may be drained on occasions, and if incompletely, there is the possibility of residual sodium reacting with moisture to generate the caustic. Of even more immediate interest, where heat transfer surfaces are in contact with water containing even small amounts of free caustic, there is the possibility of high rates of local boiling in stagnant areas, with resulting increase in causticity. Such caustic solutions, based either on sodium or potassium, cause cracking of austenitic stainless steels. Caustic cracking has been a problem in the chemical and paper industries, and sodium freed from ion exchange resins has been blamed for caustic cracking in steam generating equipment. By contrast with the subject of chloride cracking, caustic cracking of austenitic stainless steels has received only limited study.

Studies to date indicate that there is little difference in the susceptibilities of the various austenitic steel types studies, and that 304, 304L, 316, 316L, 347 , and USS 18-18-2 all crack rapidly in solutions of 10 to 50 percent $\mathrm{NaOH}$ and at temperatures of $150-370^{\circ} \mathrm{C}\left(300-700{ }^{\circ} \mathrm{F}\right)$. Carbon content and degree of sensitization have no effect on the relative susceptibility in this temperature range; at somewhat lower temperatures sensitization can have a somewhat adverse effect. Whatever the mechanism of caustic cracking of austenitic stainless steels, it is not the same as the caustic embrittlement of carbon steel such as in boiler desuperheater tubes, in which hydrogen generated by caustic corrosion of the steel reacts with carbides inside the steel to form methane, which in turn produces internal cracks.

See reference [9] for a recent major study of caustic cracking of austenitic stainless steels.

\section{Oxygen Cracking}

There have been a limited number of incidents of SCC in sensitized type 304 stainless steel in high temperature high purity water which at present do not appear to fit the pattern for either chloride cracking or caustic cracking. Since this cracking tends to occur in systems in which the oxygen content of the water is $0.2 \mathrm{ppm}$ or higher, it has come to be known as oxygen SCC. There is a tendency for this kind of cracking to occur preferentially in type 304 which is sensitized and in areas of high stress, perhaps exceeding yield. 
See references [10] and [11] for recent major studies on the subject, which is discussed further below.

\section{Protective Measures Illustrating Principles}

Chemical industry. One important measure is to avoid conditions by which chloride can be leached from thermal insulation and then become concentrated by drying on underlying hot stainless steel pipe. One way to achieve this is to use insulation low in chloride, ${ }^{1}$ another is to waterproof the insulation thoroughly. Still another measure is to coat piping prior to insulating. Inhibited asbestos or calcium silicate insulation is now available as a substitute for chloride-contaminated insulation and either provides another satisfactory way to avoid the SCC problem on the insulated side of stainless steel equipment.

One seeks to avoid conditions in which leaks of even low chloride water can drip on hot stainless steel and concentrate chlorides by evaporation. (Such concentration may also occur at a waterline.) A further measure is to avoid insulating the bottom several inches of a storage tank, which is the zone where leached chlorides would accumulate and where the insulation would provide a "poultice" effect, permitting the concentration of damaging species. In heat exchangers be sure the design is such that there is proper circulation of cooling water and that there are no zones of stagnation or air pockets, so that temperatures remain as low as possible and there is no opportunity for chlorides to concentrate by splashing. Another measure is to avoid designs with crevices where possible. In a vertical heat exchanger, coating the water side of the top tube section by oxyacetylene spraying of a lead alloy ( 2 percent tin, 2 percent antimony) physically protects the warmest (most vulnerable) ends of the tubes and electrochemically protects (by cathodic protection) the bare stainless steel for as long a distance as the conductivity of the cooling water affords. In caustic solutions contaminated with chloride, minor additions of lead nitrate (presumably tying up the chloride as insoluble lead chloride) have been reported to permit the safe use of caustic for cleaning stainless steel without risk of either chloride or caustic cracking. And one final use of lead: considerable cracking of flanges has been attributed to chloride leached from asbestos gaskets; an emulsion of a light oil and litharge applied to the gasket surfaces has been reported effective in preventing such cracking. ${ }^{2}$ (Largely summarized from ref. [12])

\footnotetext{
I ASTM standard "wick" test C692-71 can be used to evaluate the chlonide cracking characteristics of thermal insulation, to which silicate inhibitar is sometimes added to reduce risk of cracking.

2 Caution: Note in chapter 8 that lead in high temperature water systems can cause cracking of certain nickel-base alloys.
}

Power industry. SCC of austenitic stainless steel is not observed in completely dry steam; the design and operation of stainless steel superheating tubes in fossil fuel power plants therefore aim to avoid the carrying over of water containing either chloride or caustic from the steam drum into the main steam line and the turbine. Free caustic can cause cracking if carry-over occurs and if the boiler water is maintained alkaline by free hydroxide. By use of the conventional phosphate treatment to maintain alkalinity, the hazard of caustic cracking is minimal, according to laboratory tests.

SCC has been observed in the nuclear power industry, where stainless steel is used extensively in contact with water as well as steam. Eighty-eight such failures have been collected and analyzed in reference [13]. Residual stresses from fabrication, and sensitization during stress relief annealing of carbon steel components, are recurring themes in this account. The fluorinated and/or chlorinated hydrocarbons used for lubricants, gaskets, and leak-checking gases are rather stable at room temperature, but at the temperatures of pressurized water reactors (PWR's) and boiling water reactors (BWR's) they tend to decompose to liberate fluorides and chlorides to which are attributed a significant number of failures. Leachable chloride in asbestos gasketing has been a cause of cracking of austenitic stainless steel.

The trend to meticulous cleanliness in fabrication and maintenance, avoidance of sensitization, care to minimize fabrication stress, and care to avoid crevices and other means by which either caustic or chlorides can concentrate (as by wet-and-dry cycles, for example), have gone a long way in reducing the incidence of SCC failures in the power industry. Maintaining low chloride levels in nuclear power plants (e.g., 50 parts per billion maximum chloride, less than 0.3 parts per million oxygen in BWR's and much lower in PWR's) have been important operational measures in controlling the SCC problem. Overpressuring PWR's with hydrogen is believed important in minimizing SCC in these power plans by keeping the oxygen low.

Water chemistry in PWR's is specified by AEC RDT Standard Al-1T; the corresponding document for BWR's is RDT Al-2.

Refinery applications. In addition to the hazards from hot chloride cracking and caustic cracking, the petrochemical industry has an additional threat in the form of polythionic acid cracking, which can occur after shut down of equipment due to the formation of this complex acid by decomposition of sulfides on metal walls in the presence of oxygen and water. This form of cracking occurs only in sensitized steels, such as may be found in heat-affected zones of welds and in components which have operated in the sensitizing range-above $425^{\circ} \mathrm{C}\left(800^{\circ} \mathrm{F}\right)$. Different steels have different degrees of susceptibility to this form of cracking, which can be assessed by an ASTM recommended practice (G35-73). 
The preferred way to avoid polythionic acid cracking is to use only unsensitized steel. But even an initially unsensitized steel, such as unsensitized type 304 , may become susceptible to polythionic acid cracking after prolonged service above about $425^{\circ} \mathrm{C}$ $\left(800^{\circ} \mathrm{F}\right)$. For such service mill stabilized type 321 or 347 is preferred.

When equipment containing welded or otherwise sensitized steel and in which polythionic acid can form is shut down, there are a number of available tactics which can be used, depending upon conditions, to alkalize, deny oxygen, or avoid a liquid phase. These tactics are collected in NACE Recommended Practice RP-01-70 (Protection of Austenitic Stainless Steel in Refineries against SCC by use of Neutralizing Solutions During Shutdown.)

If equipment is not to be opened, once the equipment is depressurized but before metal surfaces have reached the dew point, it should be purged with an inert gas containing a minimum of $5000 \mathrm{ppm}$ of ammonia, after taking care that any brass be isolated. This alkalizing and exclusion of air prevents polythionic acid cracking. If the equipment is opened, the most effective way to neutralize is to wash all stainless steel surfaces with a $1.5-2$ percent solution of soda ash (sodium carbonate) in water; the addition of 0.5 percent sodium nitrate is recommended to reduce the probability of chloride cracking. The Recommended Practice may be consulted for many practical and detailed suggestions.

A review of refinery experience in SCC is given in references [14] and [15].

\section{Identifying SCC}

Chloride cracking of austenitic stainless steel is typically transgranular and extensively branched except in sensitized steel in which it can be (but is not always) intergranular. (figs. 5 and 6) Chloride cracking of ferritic stainless steel is almost always intergranular in service failures and in laboratory specimens in hot sodium chloride solutions, but transgranular cases have been seen in laboratory specimens cracked in magnesium chloride solutions.

The crack path in austenitic steels in caustic solutions may vary with the concentration of solution. One study (ref. [8]) indicated branching intergranular cracking at low concentrations and branching transgranular cracking at high concentrations. The polythionic acid cracking of (sensitized) austenitic stainless steel is invariably intergranular. The occasional cracking of highly stressed sensitized type 304 stainless steels in BWR's occurring in water extremely low in chloride but containing about $0.2 \mathrm{ppm}$ oxygen or more is invariably intergranular.

\section{Theory}

No system has received more theoretical study than the austenitic stainless steel/chloride system. Many theories have been proposed, but none has succeeded in being generally accepted. One theory

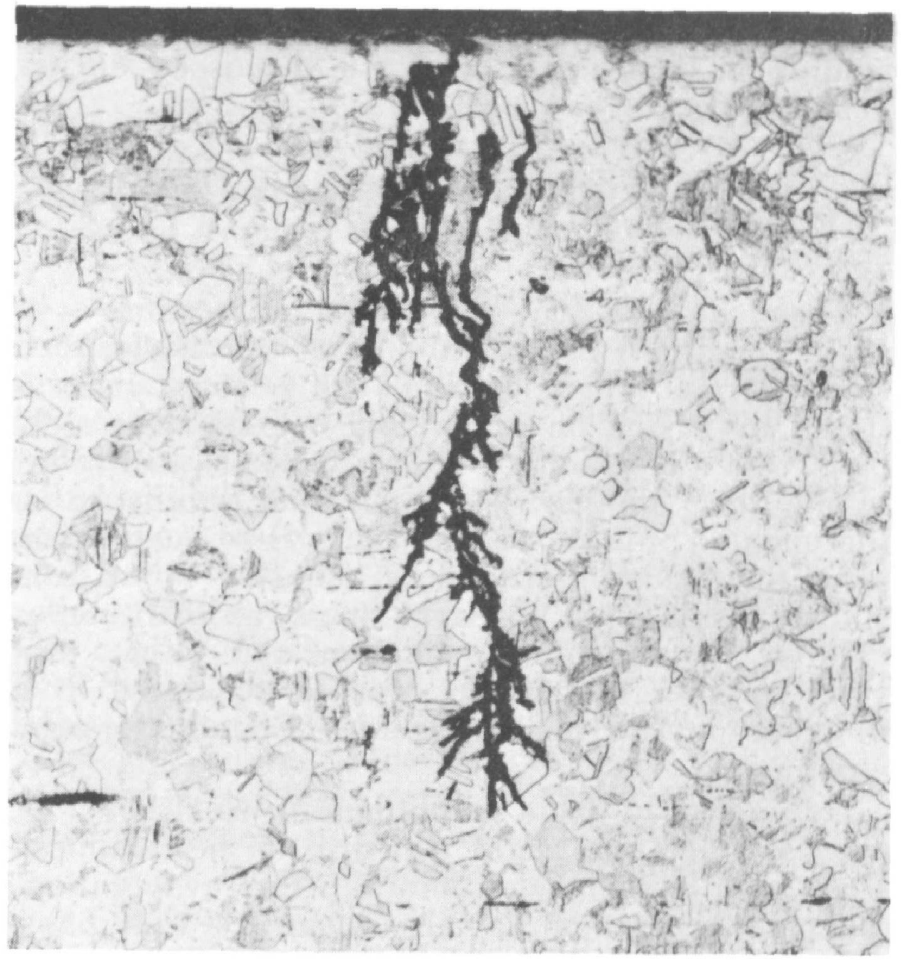

Figure 5. Chloride SCC, service failure in AISI type 304 stainless steel showing typical branching cracks. Magnification 250X. Photo courtesy of Mr. W. Gerhold, National Bureau of Standards.

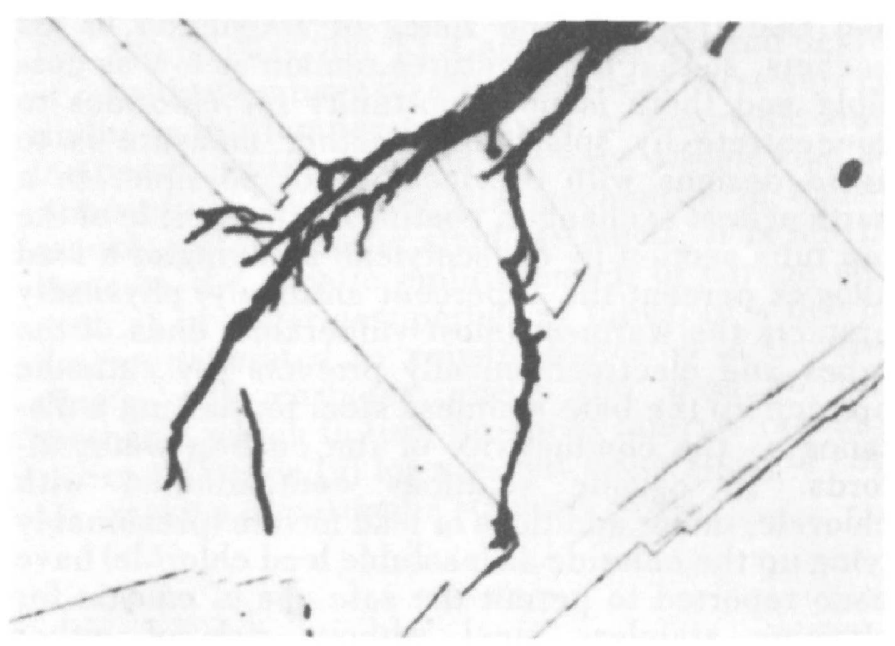

Figure 6. High magnification (900X) photomicrograph of transgranular SCC produced in the laboratory. AISI type 304 stainless steel. Courtesy of Dr. J. Kruger, National Bureau of Standards.

which accounts for many observations is termed the "slip dissolution model" and pictures the tip of the advancing crack remaining chemically active (and dissolving) due to the continual arrival of fresh metal surface by creep (plastic flow). The model is discussed in detail in reference [16]. Arguments have been put forward that hydrogen plays a causative role. These arguments are summarized in reference [17]. 
The theory of the other cracking processes in stainless steels is even more incompletely developed.

\section{Summary}

SCC at room temperature is rarely a problem with austenitic and ferritic stainless steels except in the petrochemical industry, for which detailed practical guidance is available in the form of an NACE Recommended Practice. (Warning: High strength stainless steels can be highly susceptible to cracking at room temperature. See ch. 6.)

The most serious SCC problem with austenitic stainless steel is caused by chlorides. Although it isn't feasible to totally eliminate chlorides, meticulous care to minimize their introduction is both effective and essential. Avoiding thermal insulation and gasketing material high in chlorides, avoiding elastomers, sealants, lubricants and other materials containing halogens, avoiding sensitizing, minimizing fabrication stress, in particular avoiding severe cold work, and practicing meticulous cleanliness have combined to permit extensive satisfactory use of stainless steels.

\section{References}

[1] Gordon, G. M., Stress corrosion cracking and hydrogen embrittlement of iron base alloys, (J. Hochmann and R. W. Staehle, Eds.), National Association of Corrosion Engineers, Houston, Texas, in press.

[2] Ward, C. T., Mathis, D. L. and Staehle, R. W., Corrosion, Vol. 25, No. 9, p. 394 (1969).
[3] Theus, G. J. and Cels, J. R., Corrosion problems in energy conversion and generation, (Craig S. Tedmon, Jr., Ed.), Electrochemical Society, Princeton, New Jersey, 1974, p. 384 .

[4] Heger, J. J., private communication to the author, 1975.

[5] E-BRITE 26-1, Second Performance Rept., (November 1974. Published by AIRCO Vacuum Metals. Other compilations of SCC failures in stainless steels are given in A.S.T.M. STP $264(1960)$ and in paper by A. W. Loginow et al., Materials Performance, Vol. 11, No. 5. p. 35 (May 1972).

[6] Denhard, E., Corrosion, Vol. 16, No. 7, p. 131 (1960).

[7] Dillon, C. P., Materials Performance, Vol. 14, No. 8, p. 36 (1975).

[8] Streicher, Michael A., Stress corrosion of ferritic steels, Paper No. 68, Corrosion/75, NACE, Houston, Texas.

[9] Wilson, I. L., Pement, F. W. and Aspden, R. G., Corrosion, Vol. 30, No. 4, p. 139 (1974)

[10] Clarke, W. L. and Gordon, G. M., Corrosion, Vol. 29, No. 1, p. 1 (1973).

[11] Cowan, R. L. and Gordon, G. M., Stress corrosion cracking and hydrogen embrittlement of iron base alloys (J. Hochmann and R. W. Staehle, Eds.), National Association of Corrosion Engineers, Houston, Texas, in press.

[12] van Droffelaar, H., Rapport technique 172, CEBELCOR, Brussels, (January 1970.)

[13] Bush, S. H. and Dillon, R. L., Stress corrosion cracking and hydrogen embrittlement of iron base alloys (J. Hochmann and R. W. Staehle, Eds.), National Association of Corrosion Engineers, Houston, Texas, in press.

[14] Couper, A. S. and McConomy, H. F., Proc. API Div of Refining, Vol. 46, p. 321 (1966).

[15] Manuel, R. W., Proc. API Div. of Refining, Vol. 52, p. 476, 1972.

[16] Staehle, R. W., The theory of stress corrosion cracking in alloys (J. C. Scully, Ed.), NATO, Brussels, 1971, p. 223.

[17] Theus, G. J. and Staehle, R. W., Stress corrosion cracking and hydrogen embrittlement of iron base alloys, ( $J$. Hochmann and R. W. Staehle, Eds.), National Association of Corrosion Engineers, Houston, Texas, in press. 



\section{CHAPTER 8}

\section{NICKEL ALLOYS}

Nickel and the alloys treated in this chapter have the face centered cubic crystal structure. With rare exceptions, stress corrosion cracks in these materials are intergranular, often with extensive branching.

The Unified Numbering system for this family of materials consists of the letter $\mathrm{N}$ followed by the customary five numbers, which usually include the numbers of traditional designations. Thus Alloy 400 (Monel* 400) is designated N04400, Alloy 600 is N06600, Alloy 800 is N08800, etc. The UNS designations have not yet appeared in the technical literature, therefore the traditional designations are used here.

\section{Chemical Industry}

Pure nickel is used to contain hot caustic solutions in the chemical industry, all the way up to pure fused caustic. There have been cases of grain boundary cracking when the caustic was contaminated with mercury. Above about $315{ }^{\circ} \mathrm{C}\left(600{ }^{\circ} \mathrm{F}\right)$ there have been instances of cracking along precipitated grain boundary graphite in nickel 200 , but this cracking can be avoided by using the low carbon nickel 201 . (ref. [l])

Cold drawn Alloy 400 has been found cracked by warm hydrofluosilic acid, mercury, and mercury salts. (ref. [2]). Alloy 800 has been observed to crack in polythionic acids, but only when sensitized. (ref. [3])

Sensitization causes Hastelloy* $\mathrm{C}$ to be susceptible to SCC in hot chloride solutions, including 10 percent ferric chloride at temperatures as low as 50 ${ }^{\circ} \mathrm{C}\left(120^{\circ} \mathrm{F}\right)$. Removal of the sensitization by a solution anneal removes the susceptibility. Hastelloy $\mathrm{C}-4$, having low carbon and containing the carbide stabilizer titanium, appears to be immune even when given what would otherwise be a sensitizing anneal. (ref. [4]).

\section{Power Industry}

The high nickel alloys play a critical role as materials for steam generating tubes in nuclear power plants and as materials for other components in both nuclear and fossil fuel power plants. The corrosion performance of a given steam generator depends not only on the alloy used and the water chemistry but also on design (particularly thermohydraulic characteristics and the presence or absence of crevices), fabrication (including cleanliness and magnitude of residual stresses) and operation (including especially the integrity of the condenser.)

\footnotetext{
* In no case does identification of certain materials by their trade names imply recommendation or endorsement by the National Bureau of Standards, nor does it imply that the material identified is necessarily the best available for the purpose.
}

Alloy 600, which has been in commercial use for about 40 years, has been used world-wide in nuclear steam generators. The performance record for this alloy has been impressive, but there have been some SCC service failures the recognition of which offers guidance for better future performance. Only one of these failures has been reported in initiate from the primary side. In this instance it cannot be excluded that the pickling process which was applied to the primary side during the final stages of fabrication, and the water chemistry during the early days of operation, have influenced or accelerated the corrosion (ref. [5]).

The remaining SCC service failures of alloy 600 in steam generators have initiated on the secondary side usually near the tube sheet. This is a region which may have poor circulation, crevices, sludge, and high residual stresses. There is evidence that the solution within the crevices associated with some of the cracked tubes was strongly caustic. The free caustic condition can be avoided by using a water treatment of hydrazine to control oxygen, ammonia to control $\mathrm{pH}$, and care to avoid inleakage of minerals from the condenser cooling water. This all-volatile treatment has largely replaced the phosphate treatment formerly used in many $P W R$ steam generators.

Laboratory tests of alloy 600 at high stress and temperature have demonstrated cracking in high purity water as well as in the presence of caustic or lead compounds. Lead contamination produces intergranular cracking in annealed material but (surprisingly) transgranular cracking in sensitized material.

The nature of the oxide film on the alloy, whether produced in the mill or formed by reaction with dissolved oxygen in service, may have an important effect on cracking behavior by moving the electrochemical potential into a range favorable for SCC. Over-pressurizing with hydrogen (practiced in PWR's) keeps oxygen levels low.

Extended laboratory tests $(22,000 \mathrm{~h})$ in uncontaminated deaerated water at $300^{\circ} \mathrm{C}\left(570^{\circ} \mathrm{F}\right)$ showed slight intergranular penetration but no cracking. (ref. [6]) Tests at higher temperature, $330^{\circ} \mathrm{C}\left(625^{\circ} \mathrm{F}\right)$, run to $16,000 \mathrm{~h}$ in uncontaminated water have led to the conclusion that nonpickled alloy 600 having commercially important microconstructures does not suffer intergranular SCC under those conditions, providing the material is not excessively strained. (ref. [7])

A metallurgical reaction of unknown significance has been reported in alloy 600 in steam generators. (refs. [5] and [8])

The experience with SCC of alloy 600 in the nuclear power industry has been reviewed in references [9] to [13]. 
It is to be expected that as the roles of design, fabrication, operation, alloy composition, microstructure and processing are better understood, the performance of alloy 600 in steam generators will be even more impressive than at present. Avoidance of high stress is essential.

Alloy 800 has recently been selected for use in several European steam generators.

\section{Aerospace Industry}

Marshall Space Flight Center (MSFC) has published guidelines for controlling SCC in space vehicles and associated equipment for service in space or in the atmosphere essentially at room temperature (ref. [14]). These guidelines do not pertain to special chemical environments such as may be associated with propulsion and power devices.

The following nickel alloys are deemed by MSFC to have high resistance to atmospheric SCC and may be selected by their contractors in all conditions without prior approval by MSFC: Hastelloy C-Hastelloy X-Incoloy 901-Incoloy 903Inconel 718-Inconel X-750-Ni-Span-C 902Rene' 41-Unitemp 212 and Waspaloy.

\section{References}

[1] Corrosion resistance of nickel and nickel containing alloys in caustic soda and other alkalies, Corrosion Engineering Bulletin CEB-2, International Nickel Co., New York (1973).

[2] Fraser, O. B. J., Symposium on Stress Corrosion Cracking of Metals, American Society for Testing Materials, Philadelphia, PA, (1945) p. 458.
[3] Boyd, W. K. and Berry, W. E., Stress corrosion cracking of metals-A state of the art (H. Lee Craig, Jr. Ed.) STP 518, American Society for Testing Materials, Philadelphia, PA (1972) p. 58

[4] Streicher, Michael A., The effect of composition and structure on crevice, intergranular and stress corrosion of some wrought Ni-Cr-Mo alloys, submitted to Corrosion, August 1975.

[5] Schenk, H. J., Tube defects in KWO steam generators and results of their investigation, NACE Preprint, Corrosion/ 75. See also Materials Performance, Vol. 15, No. 3, p. 25, (1976).

[6] Flint, G. N. and Weldon, B. A., Some investigations into the stress corrosion behavior of $\mathrm{Fe}-\mathrm{Ni}-\mathrm{Cr}$ alloys in high temperature water, Preprint for conference on Water Chemistry and Aqueous Corrosion in Steam Generators, Ermenonville, France, March 13-17, 1972.

[7] Pement, F. W. and Graham, N. A., Corrosion problems in energy conversion and generation (Craig S. Tedmon, Jr., Ed.), The Electrochemical Society, Princeton, NJ, (1974), p. 423.

[8] Weber, J. and Sury, P., Materials Performance, Vol. 15, No. 2, p. 34, (1976).

[9] van Rooyen, D., Corrosion, Vol. 31, No. 9. p. 237 (1975).

[10] Bush, S. H. and Dillon, R. L., Stress corrosion in nuclear systems, Proceedings of International Conference on SCC and HE of Iron-Base Alloys, R. W. Staehle et al., NACE, Houston, TX, in press.

[11] Cordovi, M. A. Corrosion considerations in light water cooled nuclear power plants, paper presented at the International Nickel Power Conference, Kyoto, Japan, 1972.

[12] Fletcher, W. D. and Malinowski, D. D., Operating experience with Westinghouse steam generators, paper presented at the International Conference on Materials for Nuclear Steam Generators, Gatlinburg, Tennessee, (Sept. 1975).

[13] Berry, Warren E., Materials Performance, Vol. 15, No. 1, p. 7 (Jan. 1976).

[14] Franklin, D. B., Design criteria for controlling stress corrosion cracking, Marshall Space Flight Center Document 10M33107, 1975. 


\section{APPENDIX}

\section{GLOSSARY OF TERMS*}

**alclad. Composite sheet produced by bonding either corrosion-resistant aluminum alloy or aluminum of high purity to base metal of structurally stronger aluminum alloy. (The cladding is usually anodic to the base alloy.)

**alloy. A substance having metallic properties and being composed of two or more chemical elements of which at least one is an elemental metal.

**anion. A negatively charged ion.

**anisotropy. The characteristic of exhibiting different values of a property in different directions with respect to a fixed reference system in the material.

* anode. The electrode of an electrolytic cell at which oxidation is the principal reaction. (Electrons flow away from the anode in the external circuit. It is usually the electrode where corrosion occurs and metal ions enter solution.)

**austenite. A solid solution of one or more elements in face-centered cubic iron. Unless otherwise designated (such as nickel austenite), the solute is generally assumed to be carbon.

** austenitic steel. An alloy steel whose structure is normally austenitic at room temperature. (In the present book austenitic steels owe their structure primarily to the addition of nickel, or in a few cases, to manganese.)

** brass. An alloy consisting mainly of copper (over $50 \%$ ) and zinc, to which smaller amounts of other elements may be added.

** Brinell hardness test. A test for determining the hardness of a material by forcing a hard steel or carbide ball of specified diameter into in under a specified load. The result is expressed as the Brinell hardness number, which is the value obtained by dividing the applied load in kilograms by the surface area of the resulting impression in square millimeters. (A Brinell impression may be used to produce sustained stresses in a metal for SCC testing.)

* cathode. The electrode of an electrolytic cell at which reduction is the principal reaction. (Electrons flow toward the cathode in the external circuit.)

* cathodic protection. A technique to reduce the corrosion rate of a metal surface by making it the cathode of an electrochemical cell.

corrosion. The chemical reaction between a metal or alloy and its environment.

** corrosion fatigue. A cracking process caused by the combination of repetitive stress and corrosion. (In some situations, corrosion fatigue can include cyclic stress corrosion cracking.)

\footnotetext{
*Definitions marked with asterisk are verbatim ASTM definitions (G15-74). Tutoria material in parentheses is by the author.

** Definitions marked with two asterisks are from Metals Handbook, Vol. 1, Amer. Soc. for Metals, Metals Park, $\mathrm{OH}, 1961$. Tutorial material in parentheses is by the author.
}

** crevice corrosion. A type of 'concentration-cell corrosion; corrosion of a metal that is caused by the concentration of dissolved salts, metal ions, oxygen or other gases, and such, in crevices or pockets remote from the principal fluid stream, with a resultant building up of differential cells that ultimately cause deep pitting.

critical cracking potential. The electrochemical potential above which SCC occurs but below which it is not observed.

* electrode potential. The potential of an electrode in an electrolyte as measured against a reference electrode. The electrode potential does not include any resistance losses in potential in either the solution or external circuit. It represents the reversible work to move a unit charge from the electrode surface through the solution to the reference electrode. (In this volume the sign of the potential follows the Pourbaix (Stockholm) convention.)

** Erichsen test. A cupping test in which a piece of sheet metal, restrained except at the center, is deformed by a cone-shaped spherical-end plunger until fracture occurs. The height of the cup in millimeters at fracture is a measure of the ductility. (Deformation in the plastic range but short of fracture is sometimes used to produce residual stresses in sheet metal for SCC testing.)

** erosion. Destruction of metals or other materials by the abrasive action of moving fluids, usually accelerated by the presence of solid particles or matter in suspension. When corrosion occurs simultaneously, the term erosion-corrosion is often used.

**fatigue. The phenomenon leading to fracture under repeated or fluctuating stresses having a maximum value less than the tensile strength of the material. Fatigue fractures are progressive, beginning as minute cracks that grow under the action of the fluctuating stress.

** ferrite. A solid solution of one or more elements in body-centered cubic iron. Unless otherwise designated (for instance, as chromium ferrite), the solute is generally assumed to be carbon. On some equilibrium diagrams there are two ferrite regions separated by an austenite area. The lower area is alpha ferrite; the upper, delta ferrite. If there is no designation, alpha ferrite is assumed.

* filiform corrosion. Corrosion that occurs under some coatings in the form of randomly distributed threadlike filaments.

Fracture mechanics. The science of the cracking behavior of a cracked body under stress. In this volume the term is restricted to the linear elastic fracture mechanics of Irwin and Kies.

** hydrogen embrittlement. A condition of low 
ductility in metals resulting from the absorption of hydrogen.

*inhibitor. A chemical substance or combination of substances that, when present in the proper concentration and forms in the environment, prevents or reduces corrosion.

* intergranular corrosion. Preferential corrosion at or adjacent to the grain boundaries of a metal or alloy.

$\mathbf{K}_{l s c c \text {. The lowest stress intensity at which }}$ stress corrosion cracking has been observed for a given alloy in a given environment. The units are stress times the square root of length, as $\mathrm{ksi} \sqrt{\text { in }}$ or $\mathrm{MNm}^{-3 / 2}$. See "stress intensity" below.

** martensite. (1) In an alloy, a metastable transitional structure intermediate between two allotrophic modifications whose abilities to dissolve a given solute differ considerably, the hightemperature phase having the greater solubility. The amount of the high-temperature phase transformed to martensite depends to a large extent upon the temperature attained in cooling, there being a rather distinct beginning temperature. (2) A metastable phase of steel, formed by a transformation of austenite below the $M_{s}$ (or "Ar") temperature. It is an interstitial supersaturated solid solution of carbon in iron having a body-centered tetragonal lattice. Its microstructure is characterized by an acicular, or needle-like, pattern. (Martensite is the structure responsible for the hardness and strength of the traditional quenched and tempered steels.)

* paseive. The state of the metal surface characterized by low corrosion rates in a potential region that is strongly oxidizing for the metal. Passivity is generally due to the formation of thin, tight oxide film, usually invisible to the naked eye.
* pitting. Corrosion of a metal surface, confined to a point or small area, that takes the form of cavities.

poultice effect. The concentration of corrosive chemical species under debris or other sheltering material.

${ }^{* *}$ precipitation hardening. Hardening caused by the precipitation of a constituent from a supersaturated solid solution.

sensitizing. A heat treatment, whether accidental, intentional, or incidental (as during welding) which causes carbide precipitation at grain boundaries, often causing the alloy to be susceptible to SCC.

SCE. Saturated calomel electrode, a standard reference electrode for measurements of electrochemical potentials.

Shear lip. The border of a brittle fracture, sloping nominally 45 degrees to the plane of the brittle fracture.

* stress-corrosion cracking. A cracking process that requires the simultaneous action of a corrodent and sustained tensile stress. This excludes corrosion-reduced sections which fail by fast fracture. It also excludes intercrystalline or transcrystalline corrosion which can disintegrate an alloy without either applied or residual stress. (The term as used in this volume is not restricted to any mechanism.)

Stress intensity (or stress intensity parameter). A quantitative continuum mechanics descriptor of the stress field around the tip of a crack in a stressed body. It is designated $K$ but is not to be confused with the Neuber K. The units are length times the square root of stress. Note that "stress intensity" as used throughout this volume is the fracture mechanics parameter. It is unrelated to "stress intensity" as used in the ASME code to designate the stress difference or two times the shear stress. 


\section{INDEX*}

\section{$\mathbf{A}$}

\section{Aerospace industry}

aluminum components $\ldots \ldots \ldots \ldots \ldots \ldots \ldots 25(\mathrm{~F}), 26,30,31,32$

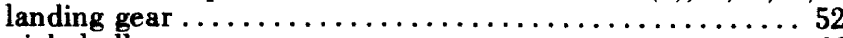

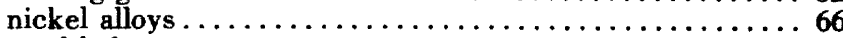

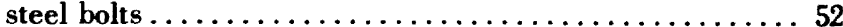

titanium components $\ldots \ldots \ldots \ldots \ldots \ldots \ldots \ldots 36,37,37(\mathrm{~F}), 38$

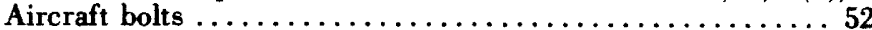

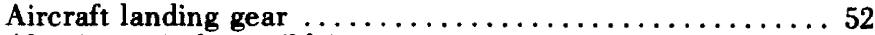

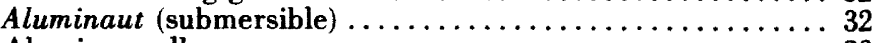

Aluminum alloys $\ldots \ldots \ldots \ldots \ldots \ldots \ldots \ldots \ldots \ldots \ldots \ldots \ldots, \ldots \ldots \ldots$

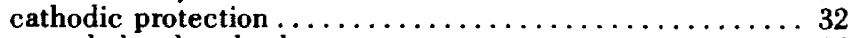

extruded rod and tube $\ldots \ldots \ldots \ldots \ldots \ldots \ldots \ldots \ldots, \ldots \ldots \ldots$

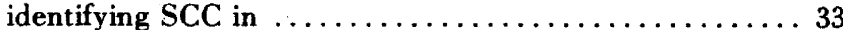

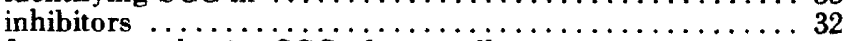

fracture mechanics SCC of some alloys ........... 28

$K$ vs. cracking rates, various alloys $\ldots \ldots \ldots \ldots \ldots \ldots \ldots 28(\mathrm{~F})$

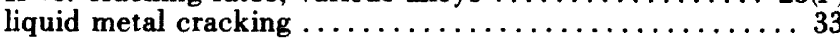

machining effects $\ldots \ldots \ldots \ldots \ldots \ldots \ldots \ldots \ldots \ldots 28,31$

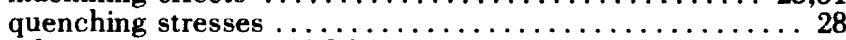

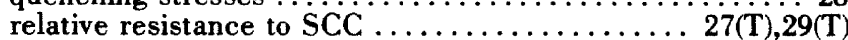

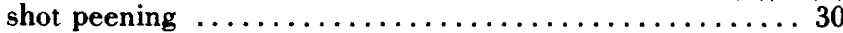

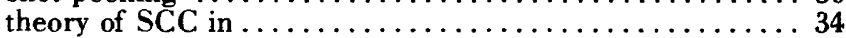

Aluminum alloys (specific alloys)

cast alloys (characteristics of 19 alloys) . . . . . . . 29(T) wrought alloys (characteristics of 49 alloys

and tempers) . . . . . . . . . . . . 29 2 (T). See 31-32

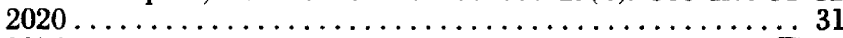

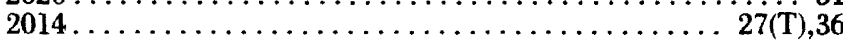

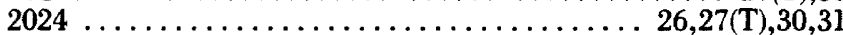

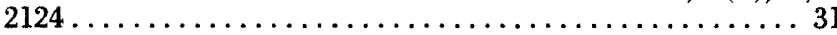

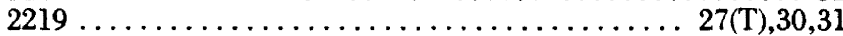

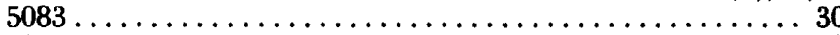

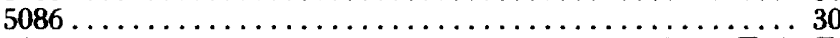

$5456 \ldots \ldots \ldots \ldots \ldots \ldots \ldots \ldots \ldots \ldots \ldots, 33(\mathrm{~F}), 34(\mathrm{~F})$

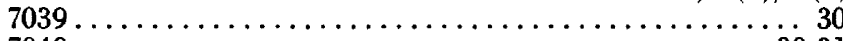

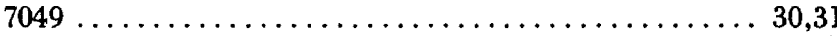

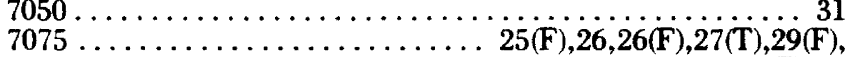

$30,30(\mathrm{~F}), 31$

$7079 \ldots \ldots \ldots \ldots \ldots \ldots \ldots \ldots \ldots \ldots \ldots \ldots \ldots \ldots$ 11(F),27(T),30,31

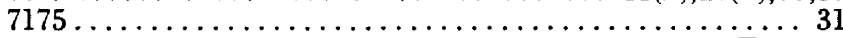

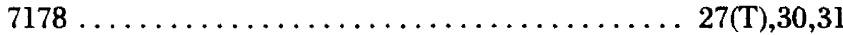

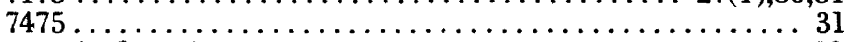

Ammonia (brass) ............................. 13

anhydrous $\ldots \ldots \ldots \ldots \ldots \ldots \ldots \ldots \ldots \ldots \ldots \ldots \ldots \ldots \ldots \ldots$

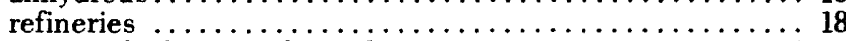

Austenitic high strength steel $\ldots \ldots \ldots \ldots \ldots \ldots \ldots \ldots 47,51$

Austenitic stainless steel (see Stainless Steels)

B

Bolts (aircraft) ........................... 52

Bridges

General U.S. Grant $\ldots \ldots \ldots \ldots \ldots \ldots \ldots \ldots \ldots \ldots \ldots . \ldots$

Mount Hope ........................... 51

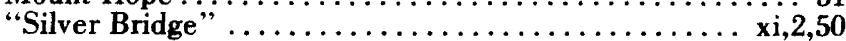

$\mathbf{C}$

Cadmium (titanium alloys) $\ldots \ldots \ldots \ldots \ldots \ldots \ldots \ldots \ldots . \ldots \ldots$

Carbon tetrachloride

aluminum alloys $\ldots \ldots \ldots \ldots \ldots \ldots \ldots \ldots \ldots \ldots \ldots \ldots$

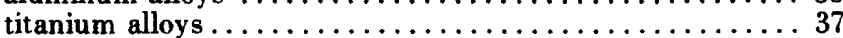

Cathodic protection

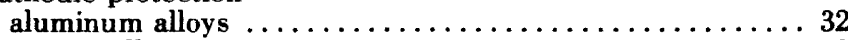

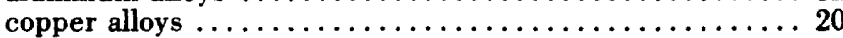

high strength steels $\ldots \ldots \ldots \ldots \ldots \ldots \ldots \ldots \ldots \ldots$

stainless steels ......................... 60,61

Caustic cracking (stainless steel) $\ldots \ldots \ldots \ldots \ldots \ldots \ldots \ldots \ldots, 60$

* $F$ following a page number indicates a figure on that page, $T$ indicates one or more tables.
Chemical industry

nickel alloys $\ldots \ldots \ldots \ldots \ldots \ldots \ldots \ldots \ldots \ldots \ldots, 65$

stainless steels $\ldots \ldots \ldots \ldots \ldots \ldots \ldots \ldots \ldots \ldots \ldots \ldots \ldots, 61$

Chloride

stainless steel $\ldots \ldots \ldots \ldots \ldots \ldots \ldots \ldots \ldots \ldots \ldots \ldots \ldots$

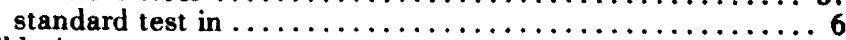

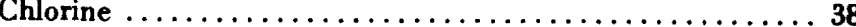

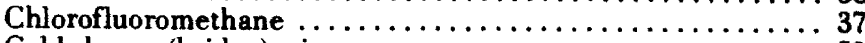

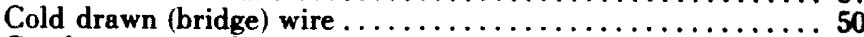

Condensers (see heat exchangers)

Constant strain rate test $\ldots \ldots \ldots \ldots \ldots \ldots \ldots \ldots \ldots \ldots 10$

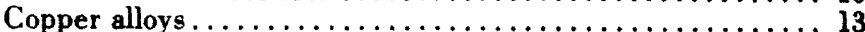

agricultural and anhydrous ammonia $\ldots \ldots \ldots \ldots \ldots \ldots \ldots 13$

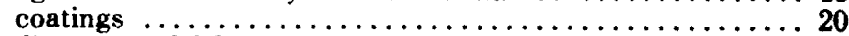

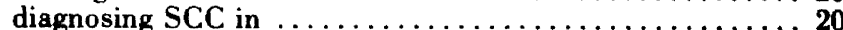

heat exchangers $\ldots \ldots \ldots \ldots \ldots \ldots \ldots \ldots \ldots \ldots \ldots \ldots$

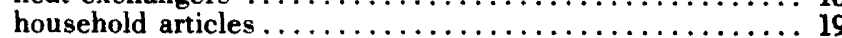

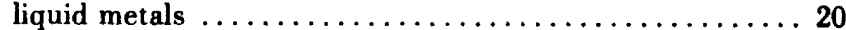

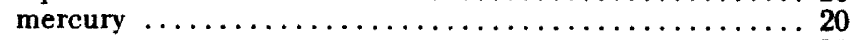

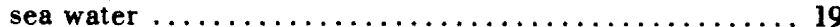

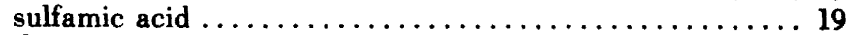

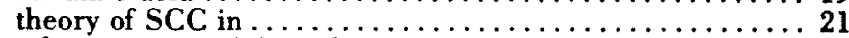

relative susceptibility of in ammonia .......... 16 $(\mathrm{T})$

Copper alloys (specific alloys)

admiralty brass $\ldots \ldots \ldots \ldots \ldots \ldots \ldots \ldots \ldots \ldots$ 14(T),16(T),18

aluminum brass . . . . . . . . . . . . . . . . 15, 16 (T), 18,21

aluminum bronze $\ldots \ldots \ldots \ldots \ldots \ldots \ldots \ldots \ldots \ldots$ 14(T),15,19

antimonial admiralty . . . . . . . . .

beryllium copper $(\mathrm{Cu}-\mathrm{Be}) \ldots \ldots \ldots \ldots \ldots \ldots \ldots \ldots \ldots$

commercial bronze ................ 14(T),16(T)

cupronickel $(10 \%) \ldots \ldots \ldots \ldots \ldots \ldots \ldots \ldots \ldots$ 16(T),17,20

cupronickel $(30 \%) \ldots \ldots \ldots \ldots \ldots \ldots \ldots \ldots \ldots$ 14(T), 16(T)

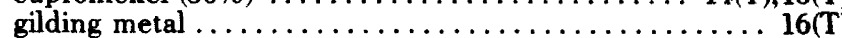

leaded brass $\ldots \ldots \ldots \ldots \ldots \ldots \ldots \ldots \ldots \ldots \ldots \ldots$ 16(T)

low brass $\ldots \ldots \ldots \ldots \ldots \ldots \ldots \ldots \ldots \ldots \ldots \ldots \ldots$ 16(T)

manganese bronze . . . . . . . . . . . . . . . 16(T),19

Muntz metal . . . . . . . . . . . . . .

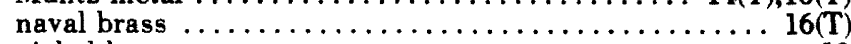

nickel bronzes ............................ 19

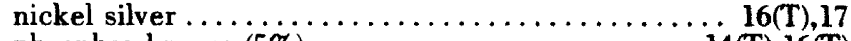

phosphor bronze $(5 \%) \ldots \ldots \ldots \ldots \ldots \ldots \ldots \ldots$ 14(T),16(T)

phosphor bronze $(10 \%) \ldots \ldots \ldots \ldots \ldots \ldots \ldots \ldots \ldots$ 14(T)

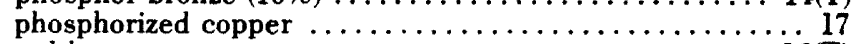

red brass ...................... 16

silicon bronze (low) $\ldots \ldots \ldots \ldots \ldots \ldots \ldots \ldots \ldots \ldots$ 16(T)

silicon bronze $(3 \%) \ldots \ldots \ldots \ldots \ldots \ldots \ldots \ldots$ i4(T), 16(T),19

silnic bronze ......................... 16(T)

tough pitch copper................... 16(T)

D

Deliquescence.$\ldots \ldots \ldots \ldots \ldots \ldots \ldots \ldots \ldots \ldots \ldots \ldots \ldots \ldots$

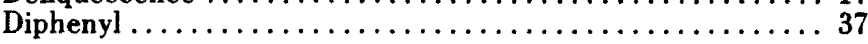

$\mathbf{F}$

Fracture plane (ASTM designations) $\ldots \ldots \ldots \ldots \ldots \ldots \ldots 24$

Fracture mechanics $\ldots \ldots \ldots \ldots \ldots \ldots \ldots \ldots \ldots \ldots, 7,67$

\section{$\mathbf{G}$}

Gallium ........................... $33, \mathbf{3 8}$

General U.S. Grant Bridge .................. 50

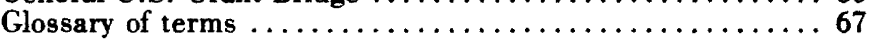

H

Heat exchangers

$18,19,20,56,61$

High strength steels $\ldots \ldots \ldots \ldots \ldots \ldots \ldots \ldots \ldots \ldots \ldots \ldots, 43$

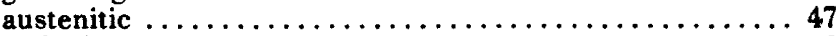

cathodic protection $\ldots \ldots \ldots \ldots \ldots \ldots \ldots \ldots \ldots \ldots, \ldots, \ldots \ldots$

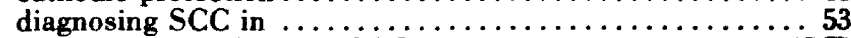

relative susceptibility to $\mathrm{SCC} \ldots \ldots \ldots \ldots \ldots \ldots 43,45-47(\mathrm{~F})$ 
stainless grades are susceptible to SCC $\ldots \ldots \ldots \ldots \ldots \ldots 46$ theory of SCC in ....................... 53

High strength steels (specific alloys)

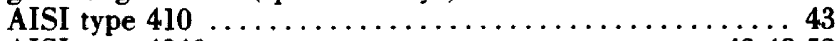

AISI type $4340 \ldots \ldots \ldots \ldots \ldots \ldots \ldots \ldots \ldots \ldots \ldots \mathbf{4 3 , 4 8 , 5 2}$

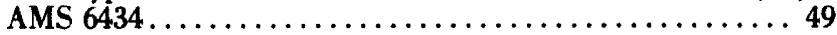

cold drawn bridge wire $\ldots \ldots \ldots \ldots \ldots \ldots \ldots \ldots \ldots$

HP 9-4-20 ..................... 44,47

maraging-200 ............................... 51

various steels (characteristics in salt water) $45-47(\mathrm{~F})$. See also

48(T)

$17-4$ PH $\ldots \ldots \ldots \ldots \ldots \ldots \ldots \ldots \ldots \ldots \ldots \ldots \ldots .46,48,51$

$18 \%$ manganese $\ldots \ldots \ldots \ldots \ldots \ldots \ldots \ldots \ldots \ldots \ldots, 47,51$

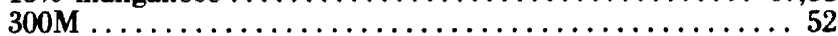

Hinkley Point turbine $\ldots \ldots \ldots \ldots \ldots \ldots \ldots \ldots \ldots \ldots \ldots$

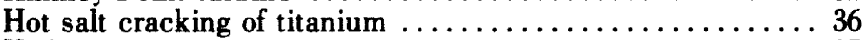

Hydrazine . ............................. 37

Hydrogen chloride $\ldots \ldots \ldots \ldots \ldots \ldots \ldots \ldots \ldots \ldots \ldots \ldots \ldots \ldots$

Hydrogen embrittlement $\ldots \ldots \ldots \ldots \ldots \ldots \ldots \ldots \ldots \ldots, 1,38$

I

Inhibitors

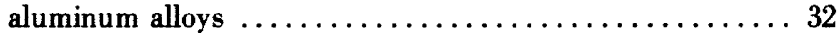

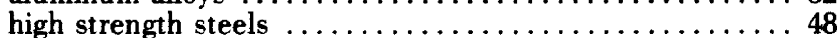

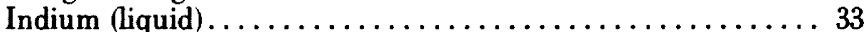

Industrial environments

copper alloys ........................... 19

stainless steel $\ldots \ldots \ldots \ldots \ldots \ldots \ldots \ldots \ldots \ldots \ldots \ldots \ldots .57$

Insulation (thermal, and stainless steel) $\ldots \ldots \ldots \ldots \ldots \ldots \ldots \ldots$

\section{$\mathbf{K}$}

$\mathbf{K}_{\text {Iscc }}$

defined $\ldots \ldots \ldots \ldots \ldots \ldots \ldots \ldots \ldots \ldots \ldots \ldots \ldots \ldots, 68$

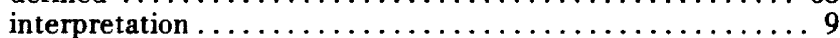

$\mathbf{L}$

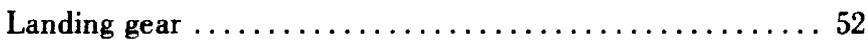

Liquid metal embrittlement

in aluminum alloys $\ldots \ldots \ldots \ldots \ldots \ldots \ldots \ldots \ldots, \ldots \ldots$

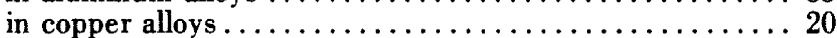

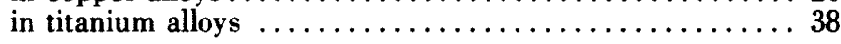

$\mathbf{M}$

Marine atmosphere

Magnesium chloride

stainless steels $\ldots \ldots \ldots \ldots \ldots \ldots \ldots \ldots \ldots \ldots \ldots .58,59(\mathrm{~T})$

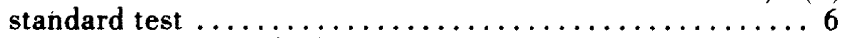

Manganese austenitic high strength steel $\ldots \ldots \ldots \ldots \ldots \ldots 47$

Maraging steels ........................... 43 relative susceptibilities $\ldots \ldots \ldots \ldots \ldots \ldots \ldots \ldots 45-47(F)$

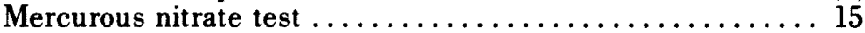

Mercury

aluminum alloys $\ldots \ldots \ldots \ldots \ldots \ldots \ldots \ldots \ldots \ldots \ldots \ldots$

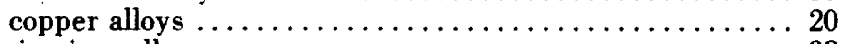

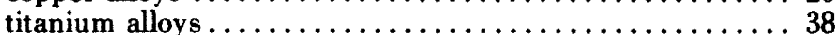

Methanol

aluminum alloys $\ldots \ldots \ldots \ldots \ldots \ldots \ldots \ldots \ldots \ldots \ldots \ldots \ldots$

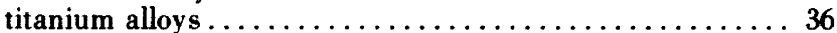

Mount Hope Bridge $\ldots \ldots \ldots \ldots \ldots \ldots \ldots \ldots \ldots \ldots \ldots \ldots$ I

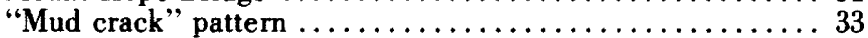

\section{$\mathbf{N}$}

Nickel and nickel alloys $\ldots \ldots \ldots \ldots \ldots \ldots \ldots \ldots \ldots \ldots 6$

aerospace industry $\ldots \ldots \ldots \ldots \ldots \ldots \ldots \ldots \ldots, 66$

chemical industry $\ldots \ldots \ldots \ldots \ldots \ldots \ldots \ldots \ldots \ldots \ldots \ldots$

lead ..............................65

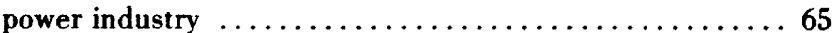

Nitric acid

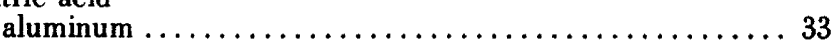

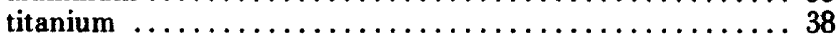

Nitrogen tetroxide $\left(\mathrm{N}_{2} \mathrm{O}_{4}\right)$

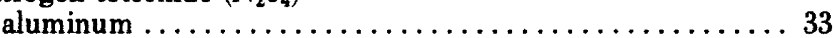

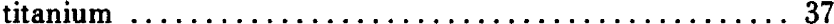

Non-redundant load path designs $\ldots \ldots \ldots \ldots \ldots \ldots \ldots \ldots 52$

$\mathbf{P}$

Polythionic acids

refineries $\ldots \ldots \ldots \ldots \ldots \ldots \ldots \ldots \ldots \ldots \ldots \ldots \ldots, 62$

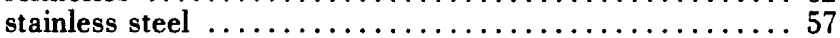

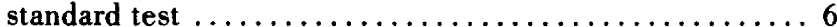

Polyvinyl chloride ........................ 58

Precipitation hardening steels .................43

relative susceptibilities $\ldots \ldots \ldots \ldots \ldots \ldots \ldots \ldots \ldots 45-47(\mathrm{~F})$

Propellers (marine) . . . . . . . . . . . . . . . . . . . 19

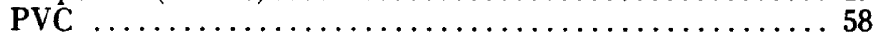

$\mathbf{R}$

Refinery applications $\ldots \ldots \ldots \ldots \ldots \ldots \ldots \ldots \ldots$ 18,61

Rocket motor case

high strength steel $\ldots \ldots \ldots \ldots \ldots \ldots \ldots \ldots \ldots \ldots . \ldots 49$

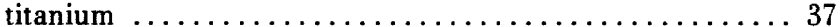

\section{$\mathbf{S}$}

SCC features $\ldots \ldots \ldots \ldots \ldots \ldots \ldots \ldots \ldots \ldots \ldots \ldots \ldots$

SCC standard test solutions

alternate immersion $(\mathrm{NaCl}) \ldots \ldots \ldots \ldots \ldots \ldots \ldots \ldots$

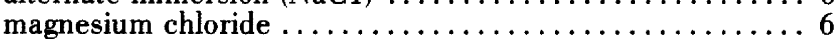

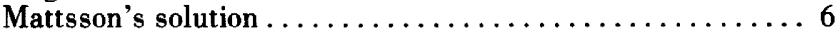

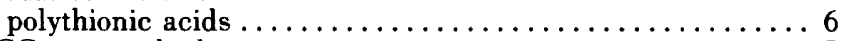

SCC test methods ......................... 5

constant strain rate $\ldots \ldots \ldots \ldots \ldots \ldots \ldots \ldots \ldots \ldots \ldots$

fracture mechanics ..................... 7

precracked specimens $\ldots \ldots \ldots \ldots \ldots \ldots \ldots \ldots \ldots \ldots \ldots$

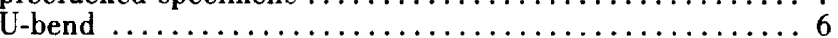

SCC theory

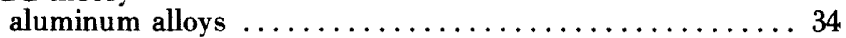

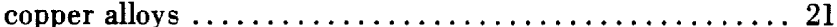

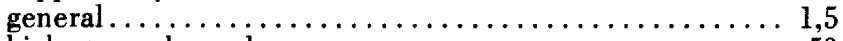

high strength steels $\ldots \ldots \ldots \ldots \ldots \ldots \ldots \ldots \ldots \ldots \ldots \ldots, 53$

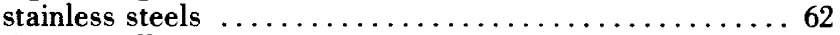

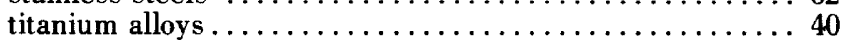

Sea water/salt water

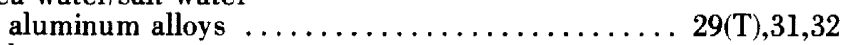

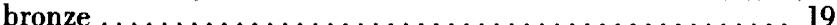

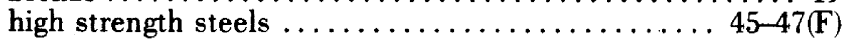

stainless steels $\ldots \ldots \ldots \ldots \ldots \ldots \ldots \ldots \ldots \ldots \ldots \ldots$

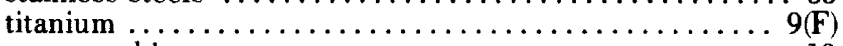

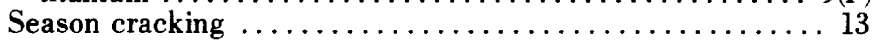

Sensitization (stainless steels) $\ldots \ldots \ldots \ldots \ldots \ldots \ldots \ldots 5,58,61$

Sensitized stainless steels $\ldots \ldots \ldots \ldots \ldots \ldots \ldots \ldots \ldots, 56,59,59,60,61,62$

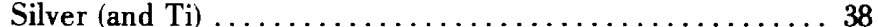

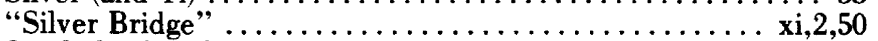

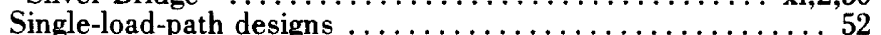

Sodium (liquid) $\ldots \ldots \ldots \ldots \ldots \ldots \ldots \ldots \ldots \ldots \ldots \ldots \ldots \ldots \ldots \ldots \ldots \ldots \ldots \ldots, 33$

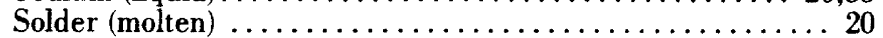

Stainless steels (austenitic and ferritic; see "High

Strength Steels" for high strength stainless steels) $\ldots \ldots \ldots 55$

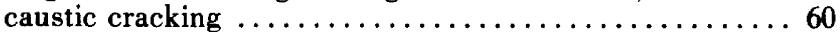

chemical industry $\ldots \ldots \ldots \ldots \ldots \ldots \ldots \ldots \ldots \ldots, \ldots \ldots \ldots$

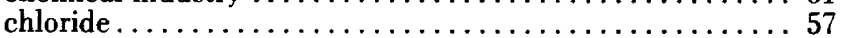

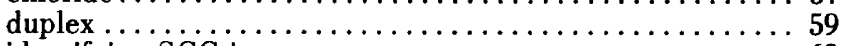

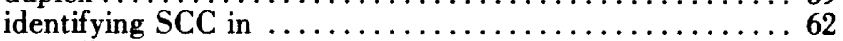

miscellaneous service environments $\ldots \ldots \ldots \ldots \ldots \ldots$ 58(T)

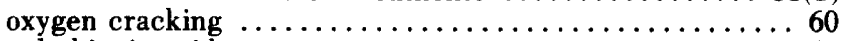

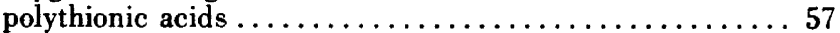

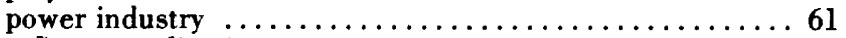

refinery applications....................61

relative susceptibilities of austenitic steels

to chloride SCC $\ldots \ldots \ldots \ldots \ldots \ldots \ldots \ldots \ldots \ldots \ldots$ (T)

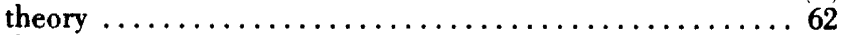

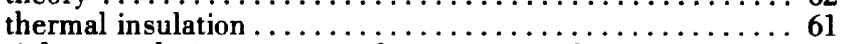

Stainless steels (austenitic or ferritic), (specific

alloys)

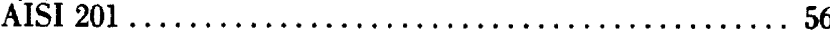

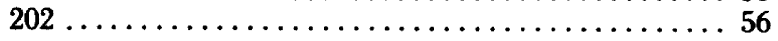




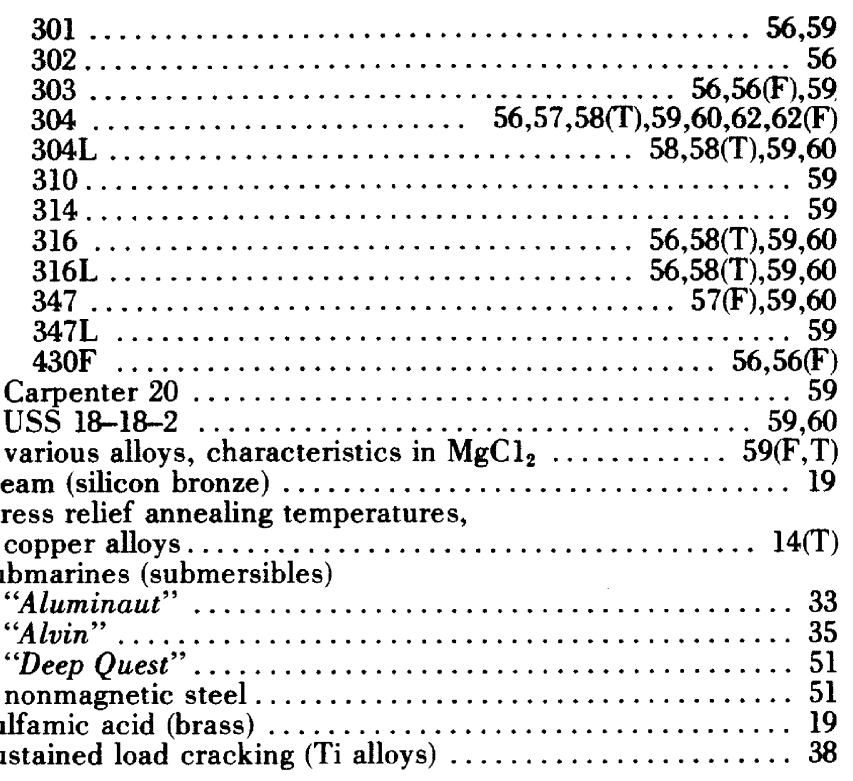

$\mathbf{T}$

Theory of SCC

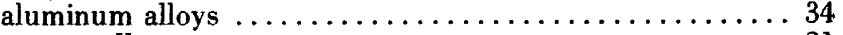

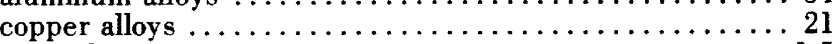

general ................................ 1,5

high strength steels $\ldots \ldots \ldots \ldots \ldots \ldots \ldots \ldots \ldots \ldots \ldots \ldots 53$

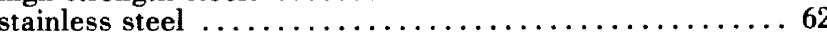

titanium alloys $\ldots \ldots \ldots \ldots \ldots \ldots \ldots \ldots \ldots \ldots \ldots \ldots, 40$

Tin (liquid) $\ldots \ldots \ldots \ldots \ldots \ldots \ldots \ldots \ldots \ldots \ldots \ldots \ldots \ldots \ldots \ldots \ldots \ldots \ldots \ldots, 33$

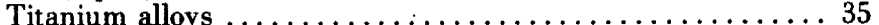

chlorinated diphenyl $\ldots \ldots \ldots \ldots \ldots \ldots \ldots \ldots \ldots \ldots \ldots \ldots$

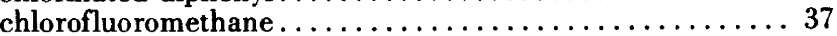

diagnosing SCC in $\ldots \ldots \ldots \ldots \ldots \ldots \ldots \ldots \ldots \ldots \ldots \ldots \ldots \ldots$

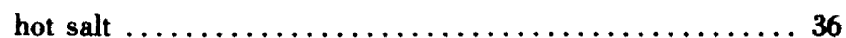

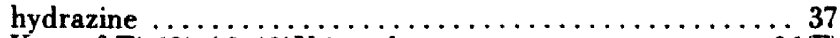

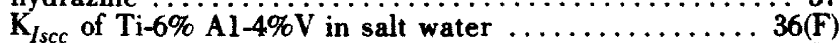

$\mathrm{K}_{\text {Isce }}$ of various alloys in salt water $\ldots \ldots \ldots \ldots \ldots \ldots, \mathbf{9 ( F )}$

liquid and solid metals ...................... 38

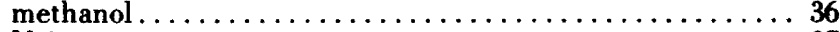

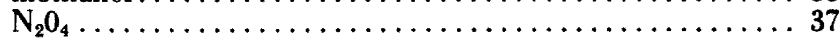

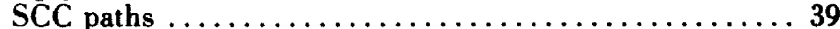

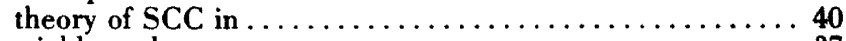

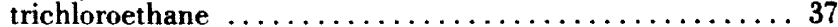

trichlorotrifluoroethane $\ldots \ldots \ldots \ldots \ldots \ldots \ldots \ldots \ldots \ldots$

Titanium alloys (specific alloys)

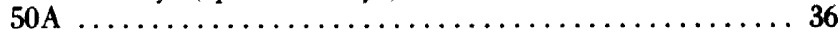

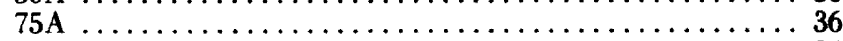

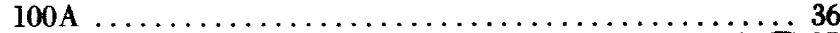

$6-4 \ldots \ldots \ldots \ldots \ldots \ldots \ldots \ldots \ldots \ldots \ldots \ldots \ldots \ldots \ldots \ldots \ldots, 36$ (F),37

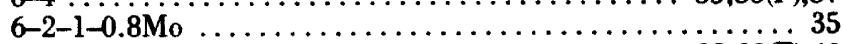

8-1-1 .......................

various alloys characteristics in sea water ........ $9(\mathrm{~F})$

various alloys, mostly obsolete $\ldots \ldots \ldots \ldots \ldots \ldots \ldots \ldots \ldots, 40$

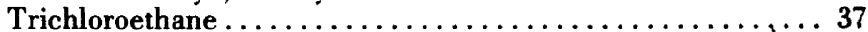

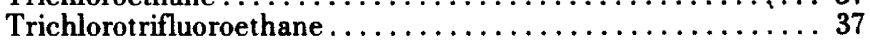

Turbine (Hinkley Point) . . . . . . . . . . . . . . . . . . 52

$\mathbf{U}$

U.S. Grant Bridge

50

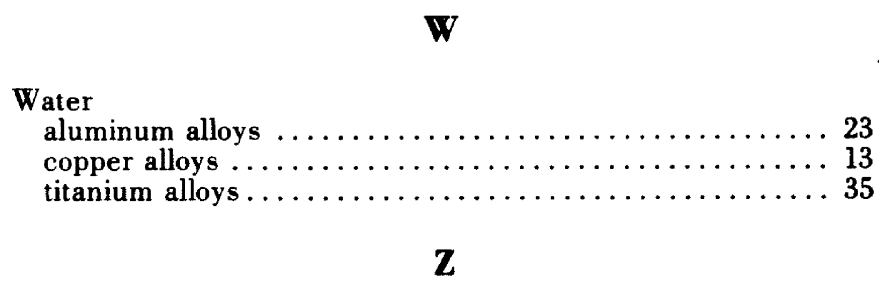

Zinc (liquid) $\ldots \ldots \ldots \ldots \ldots \ldots \ldots \ldots \ldots \ldots \ldots \ldots \ldots \ldots \ldots$ 


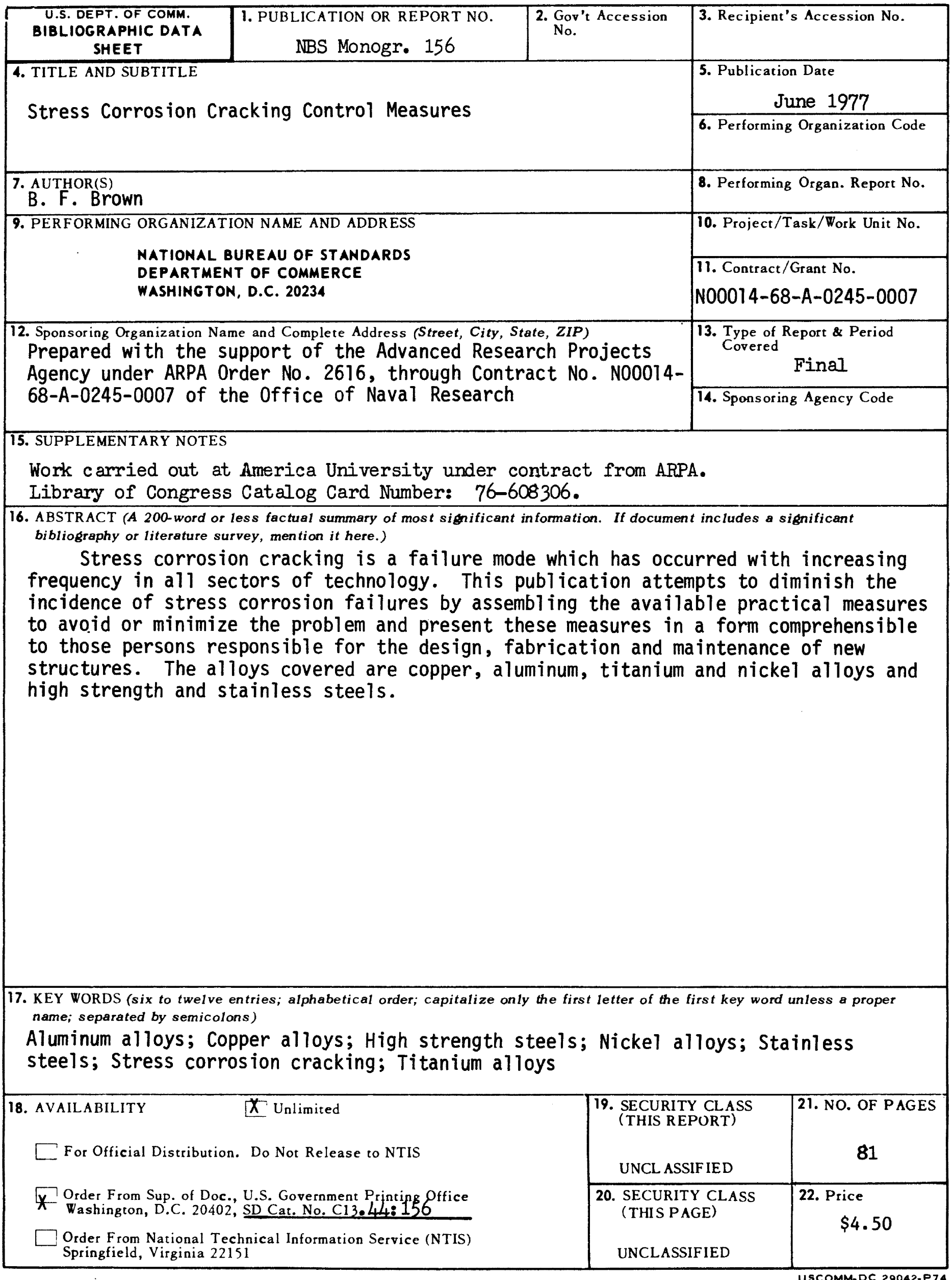

